\title{
Tailored pain management for subgroups of patients with chronic musculoskeletal pain : an evaluation of treatment effectiveness
}

Citation for published version (APA):

Verra, M. L. (2013). Tailored pain management for subgroups of patients with chronic musculoskeletal pain : an evaluation of treatment effectiveness. [Doctoral Thesis, Maastricht University]. Datawyse / Universitaire Pers Maastricht. https://doi.org/10.26481/dis.20131220mv

Document status and date:

Published: 01/01/2013

DOI:

10.26481/dis.20131220mv

Document Version:

Publisher's PDF, also known as Version of record

Please check the document version of this publication:

- A submitted manuscript is the version of the article upon submission and before peer-review. There can be important differences between the submitted version and the official published version of record.

People interested in the research are advised to contact the author for the final version of the publication, or visit the DOI to the publisher's website.

- The final author version and the galley proof are versions of the publication after peer review.

- The final published version features the final layout of the paper including the volume, issue and page numbers.

Link to publication

\footnotetext{
General rights rights.

- You may freely distribute the URL identifying the publication in the public portal. please follow below link for the End User Agreement:

www.umlib.nl/taverne-license

Take down policy

If you believe that this document breaches copyright please contact us at:

repository@maastrichtuniversity.nl

providing details and we will investigate your claim.
}

Copyright and moral rights for the publications made accessible in the public portal are retained by the authors and/or other copyright owners and it is a condition of accessing publications that users recognise and abide by the legal requirements associated with these

- Users may download and print one copy of any publication from the public portal for the purpose of private study or research.

- You may not further distribute the material or use it for any profit-making activity or commercial gain

If the publication is distributed under the terms of Article $25 \mathrm{fa}$ of the Dutch Copyright Act, indicated by the "Taverne" license above, 


\section{Tailored pain management for subgroups of patients with chronic musculoskeletal pain}

An evaluation of treatment effectiveness 
(C) copyright Martin L Verra, Maastricht 2013 All rights reserved

Published by Datawyse | Universitaire Pers Maastricht ISBN 9789461592811 


\title{
Tailored pain management for subgroups of patients with chronic musculoskeletal pain
}

\section{An evaluation of treatment effectiveness}

\author{
DISSERTATION
}

To obtain the degree of Doctor at Maastricht University, on the authority of the Rector Magnificus, Prof. dr. L.L.G. Soete in accordance with the decision of the Board of Deans,

to be defended in public on

Friday $20^{\text {th }}$ of December 2013, at $16: 00$ hours

by

Martinus Lodewijk Verra

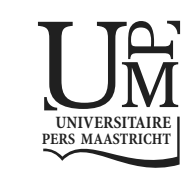




\section{Supervisor}

Prof. dr. R.A. de Bie

\section{Co-supervisor}

Dr. J.B. Staal

\section{Assessment Committee}

Prof. dr. L.W. van Rhijn, chairman

Dr. A. Apeldoorn, MC Alkmaar

Prof. dr. P.J.M. Helders, UMC Utrecht

Prof. dr. M.H. Prins

Prof. dr. R.J.E.M. Smeets

The research presented in this thesis was conducted at the School for Public Health and Primary Care: CAPHRI, Department of Epidemiology, of Maastricht University. CAPHRI participates in the Netherlands School for Primary Care research CaRe. CAPHRI was classified as "excellent" by the external evaluation committee of leading international experts that reviewed CAPHRI in December 2010. 


\section{CONTENTS}

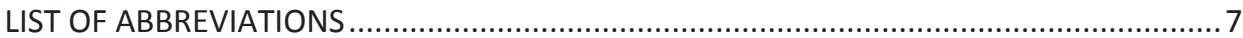

\section{CHAPTER 1}

General introduction

PART I

Clinimetric studies

\section{CHAPTER 2}

Translation, cross-cultural adaptation, reliability, and validity of the German version of the Coping Strategies Questionnaire (CSQ-D)

\section{CHAPTER 3}

Reliability of the Multidimensional Pain Inventory and stability of the MPI

Classification System in chronic back pain

\section{CHAPTER 4}

Refined insights into the pain-depression association in chronic pain patients

\section{PART II}

Evaluation studies

\section{CHAPTER 5}

Does classification of persons with fibromyalgia into Multidimensional Pain Inventory subgroups detect differences in outcome after a standard chronic pain management program?

\section{CHAPTER 6}

Differences in pain, function and coping in Multidimensional Pain Inventory subgroups of chronic back pain: A one-group pretest-posttest study

\section{CHAPTER 7}

Effectiveness of a subgroup-specific pain management program based on the MPI Classification System: A pragmatic randomized controlled trial in patients with chronic back pain 


\section{CHAPTER 8}

General discussion.....

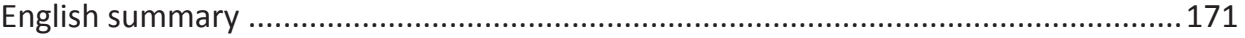

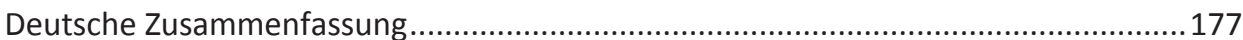

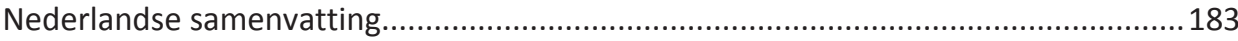

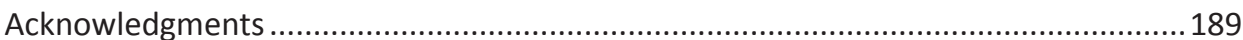

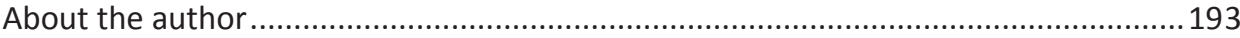

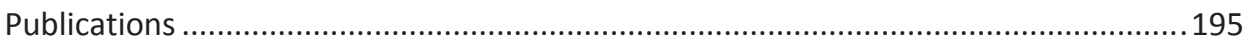




\section{LIST OF ABBREVIATIONS}

$A C$ Multidimensional Pain Inventory cluster Adaptive Coper

BPS Back Performance Scale

CA Cronbach's Alpha coefficient

CBT Cognitive Behavioral Therapy

CES-D Centre of Epidemiological Studies Depression Scale

CEQ Credibility and Expectancy Questionnaire

COST European Cooperation in Science and Technology

CSQ Coping Strategies Questionnaire

CSQ-D German (Deutsch) version of the Coping Strategies Questionnaire

DYS Multidimensional Pain Inventory cluster Dysfunctional

EK AG Ethic Commission of Canton Aargau

et al. et alia (and others)

ES Effect Size

FABQ Fear Avoidance and Beliefs Questionnaire

FESV-BW Fragebogen zur Erfassung der Schmerzverarbeitung

FSK Fragebogen zur Erfassung Schmerzbezogener Kontrollüberzeugungen

FSS Fragebogen zur Erfassung Schmerzbezogener Selbstinstruktionen

HADS Hospital Anxiety and Depression Scale

HADS-D German (Deutsch) version of the Hospital Anxiety and Depression Scale

HRQL Health-Related Quality of Life

HSCL-25 25-item Hopkins Symptoms Checklist

ICC Intraclass Correlation Coefficient

ICF International Classificational of Functioning, disability and health

ID Multidimensional Pain Inventory cluster Interpersonally Distressed

IMMPACT Initiative on Methods, Measurement, and Pain Assessment

K Kappa coefficient

KSI Kieler Schmerz-Inventar

m Mean score

MCID Minimal Clinically Important Difference 


$\begin{array}{ll}\text { MCS } & \text { Mental Component Summary } \\ \text { MOS SF-36 } & \text { Medical Outcome Studies Short Form } 36 \\ \text { MPI } & \text { Multidimensional Pain Inventory } \\ \text { MPI-D } & \text { German (Deutsch) version of the Multidimensional Pain Inventory } \\ \text { 5-MWD } & \text { 5-Minute Walk Distance Test } \\ \text { n } & \text { Number of patients } \\ \text { NRS } & \text { Numeric Rating Scale } \\ \text { nS } & \text { Not significant } \\ \text { NSARD } & \text { Non-Steroidal Anti-Rheumatic Drugs } \\ \text { OCS } & \text { O'Sullivan Classification System } \\ \text { ODI } & \text { Oswestry Disability Index } \\ \text { OR } & \text { Odds Ratio } \\ \text { P } & \text { Significance level } \\ \text { PCS } & \text { Physical Component Summary } \\ \text { RCT } & \text { Randomized Controlled Trial } \\ r_{p} & \text { Pearson's product-moment correlation coefficient } \\ \text { ROM } & \text { Range Of Motion } \\ r_{s} & \text { Spearman's rank correlation coefficient } \\ \text { S } & \text { Standard deviation } \\ \text { SF-36 } & \text { Short Form 36 } \\ \text { SMD } & \text { Cohen's Standard Mean Difference d } \\ \text { SPSS } & \text { Statistical Package for the Social Sciences } \\ \text { TBC } & \text { Delitto's Treatment-Based Classification system } \\ \text { ZISP } & \text { Zurzach Interdisciplinary Pain (German: Schmerz) Program) } \\ & \end{array}$


CHAPTER 1

General introduction 
CHAPTER 1 


\section{Background}

\section{Epidemiology of chronic musculoskeletal pain in Switzerland}

In a large survey with 46,394 respondents from fifteen European countries, including Switzerland and Israel, Breivik et al. reported that chronic pain of moderate to severe intensity occurred in 19\% of adult Europeans (Numeric Rating Scale $=5-10$ ), seriously affecting the quality of their social and working lives. In-depth interviews showed that $59 \%$ had suffered from pain for two to fifteen years, $21 \%$ had been diagnosed with depression because of their pain, $61 \%$ were less able or unable to work outside their home, $19 \%$ had lost their job, and $13 \%$ had changed jobs because of their pain. The daily activities that chronic pain sufferers were no longer or less able to do consisted of exercising, 73\%; household chores, 54\%; attending social activities, 48\%; maintaining an independent lifestyle, $30 \%$; and maintaining relationships with family and friends, $27 \%$. Very few were managed by pain specialists and nearly half of the chronic pain sufferers reported inadequate pain management (e.g. Switzerland, 54\%; the Netherlands, 56\%) [1]. The results of this survey were largely replicated by another survey in a sample of the populations from the United Kingdom, France, Spain, Germany and Italy [2]. Altogether, the prevalence and consequences of chronic pain represented a substantial burden to individuals and their family and friends, employers, health care systems and society in general.

The economic burden of musculoskeletal pain is huge because of medical treatment cost, it complicates treatment of other ailments, and it lowers worker productivity. In 2010 in the United States the total costs ranged from $\$ 560$ to $\$ 635$ billion. The annual cost of pain was greater than the annual cost of heart disease ( $\$ 309$ billion), cancer (\$243 billion), and diabetes (\$188 billion) [3]. After the United States Switzerland has the most expensive health care system worldwide. Therefore, the costs of total musculoskeletal pain in the United States may be translated to the situation in Switzerland. The Breivik survey showed that the most common body location of chronic pain was the spine with $44 \%$ (18\% lower back, 24\% back, unspecified) [1]. A survey in 2005 with a sample of 2,507 German-speaking respondents showed that the total economic burden of back pain to Swiss society varied between 1.6 and $2.3 \%$ of gross domestic product (€4.8 to $€ 6.6$ billion) with indirect productivity losses of $€ 4.6$ billion mainly through absenteeism [4].

Moreover, musculoskeletal pain disorders do not solely affect function, activities, and health-related quality of life, but are also associated with risk of mortality. In a cohort study with 4,515 adults in North West England, McBeth et al. described a longterm increase of 20 to $30 \%$ in the risk of cancer and cardiovascular-related mortality [5]. In a former study with subjects with widespread and regional pain syndromes similar associations with both cancer onset (incidence) and subsequent reduced survival were reported [6]. The strongest relationship was with breast and prostate cancer, with 
smaller effects for gastrointestinal and lung cancer. These relationships persisted after adjustment for age, gender, social class and smoking.

\section{Current evidence-based practice}

Exercise therapy appears to be slightly effective at decreasing pain and improving function in adults with chronic low back pain [7]. There is little or no difference between behavioral therapy and group exercises for chronic back pain or depressive symptoms [8]. In trials with patients with chronic, nonspecific back pain, comparing exercise therapy, behavioral therapy or multidisciplinary treatment with no-treatment, modest effects were measured $[9,10]$. In trials comparing two interventions, often no differences were found [9]. Relative to a host of widely used conventional medical treatment, comprehensive interdisciplinary pain management programs offer the most efficacious and cost-effective, evidence-based treatment for patients with chronic back pain [11, 12]. Accordingly, several international clinical guidelines recommend multidisciplinary (biopsychosocial) treatment (e.g. [13]. When looking at inpatient rehabilitation in Germany, summarized in a systematic review of thirty studies, both controlled and uncontrolled, a multitude of positive somatic and psychological changes were reported. However, methodological quality was often poor [14]. To the knowledge of the author, only one randomized controlled trial with chronic back pain patients in a rehabilitation setting has been conducted in Switzerland [15]. This study evaluated the effect of functioncentred compared with pain-centred inpatient rehabilitation in chronic nonspecific low back pain. Function-centred rehabilitation increased the number of work days, selfefficacy, and lifting capacity.

However, back pain is nonspecific in about $90 \%$ of cases, which means that no relevant physical cause of the pain can be identified, and its origins remain unclear [12, 16]. Chronic back pain is a heterogeneous condition, and this affects the way it is diagnosed, classified, treated, and studied [17]. The search for homogeneous subgroups of patients with nonspecific low back pain who respond best to subgroup-specific pain management interventions - repeatedly described as the Holy Grail of low back pain research - has been on the international research agenda for many years $[12,13,18$ 20]. Lack of prospective specification, inadequate sample size, inability to maintain power, and the cumulative effect of sampling error in trials designed to detect overall treatment effects complicate the interpretation of a posteriori subgroup analyses [21, 22]. Among other recommendations, studies investigating treatment effect modifiers should limit their analyses to a small number of plausible predictors (subgroups) that are nominated prior to the conduct of the trial $[23,24]$. Several, mainly physiotherapy movement based classification systems to subgroup low back pain patients with the intent to guide treatment, have been developed (for overview: reference [25]). Some are descriptive, some prognostic, and some, as in this thesis, attempt to direct treatment. So far, the effects of a few classification-based interventions have been tested in 
different settings [26-31]. These trials showed large variations in categorization method, therapeutic interventions and outcome.

\section{Why this research?}

According to the recommendations by the COST B13 Working Group on Guidelines for Chronic Low Back Pain more research is needed to develop tools to improve the classification and identification of specific clinical subgroups of chronic back pain patients [13]. Subsequent good quality randomized controlled trials are needed to determine the effectiveness of specific interventions aimed at those specific target groups. More emphasis should be placed on identifying the right treatment for the right patient. The Multidimensional Pain Inventory (MPI) Classification System, which classifies back pain patients into three predominantly psychosocial subgroups, has been used by several research groups to show a posteriori significant differences in score changes for pain, mental health, disability and coping $[32,33]$. The three unique MPI profiles or subgroups have a high recognition value for both chronic pain patients and health professionals. However, no randomized controlled trial has been conducted to evaluate the effects of tailored pain interventions to a priori classified MPI subgroups of patients with chronic back pain in a rehabilitation setting.

\section{Rehabilitation}

\section{Admission criteria to inpatient musculoskeletal rehabilitation in Switzerland}

Biopsychosocial multidisciplinary rehabilitation in Switzerland is available in rehabilitation centres and to a lesser extent as outpatient rehabilitation, or in pain clinics. Patients in Switzerland are mainly referred by general practitioners, rheumatologists, psychiatrists, and hospitals (mainly departments of rheumatology and anaesthesiology) to the multimodal, interdisciplinary pain programs and are screened for possible participation. The condition for recruitment to inpatient treatment programs is a history of failed or insufficient efficacy of outpatient treatment, as a rule, after at least three series of nine ambulatory physiotherapy sessions (each lasting 30 minutes to one hour). This criterion has been established by the Swiss Association of Rheumatologists in consensus with the association of health insurance companies [34]. Basically, this means that pain patients can start inpatient rehabilitation within three months after the onset of symptoms. Early identification of patients at risk of developing a chronic pain condition and early admission to inpatient pain programs is very much supported by the Swiss rehabilitation clinics. Compared to most Western countries, this difference in referral policy in Switzerland possibly reflects differences in cultural background, local traditions in managing chronic pain, and the willingness-to-pay of the Swiss premium 
payer. There have been several instances of Swiss health politicians trying to reduce the total number of hospitals and rehabilitation clinics and direct self-referral to medical specialists. However, in most cases, Swiss voters made use of referendums (direct democracy in a federalist system), and reversed the decisions of the politicians. A relatively flourishing Swiss economy might have facilitated these final judgements. Meanwhile, as an example, pain patients are burdened with an average duration of symptoms of six to eleven years before being admitted to the Zurzach Interdisciplinary Pain Program [34-36].

Each rehabilitation clinic in Switzerland has its own specific screening criteria for patients. The screening process for patients participating in the Zurzach Interdisciplinary Pain Program consists of three steps. First, diagnostic screening is performed by the head of the program on the basis of the admission report. The diagnosis of nonspecific back pain or general widespread pain syndromes including fibromyalgia must be confirmed (see also the inclusion criteria below). Second, the head of program contacts potential candidates by telephone to evaluate the inclusion and exclusion criteria listed below. Third, approximately $10 \%$ of the candidates interviewed by phone visit the clinic for a one-hour consultation to clarify any uncertainties concerning the first or second screening steps. Inclusion criteria are: 1) chronic back pain (i.e. lumbar, thoracic, cervical, or panvertebral pain syndrome) [13] or fibromyalgia according to the definition of the American College of Rheumatology [37], both of at least three months' duration; 2) willingness to learn behavioral patterns and motivation to participate in exercise therapy programs; 3) ability to formulate realistic functional goals (e.g. increasing walking distance, ability to carry a shopping bag without apprehension); 4) sufficient cognitive abilities and German language skills to understand the content of the interventions; and 5) agreement to participate in all the therapies of the program (that means, no selection by the patient of preferred therapies). Exclusion criteria to participation in the Zurzach Interdisciplinary Pain Program are: 1) severe somatic illness requiring specific treatment such as cancer, inflammatory rheumatic disease, neurologic disease, pain after a recent operation; and 2) manifest psychiatric disorder such as dementia, psychosis, suicidality.

\section{Content of the Zurzach Interdisciplinary Pain Program}

All studies in this thesis were performed with patients participating in the Zurzach Interdisciplinary Pain Program (ZISP). The Zurzach Interdisciplinary Pain Program was founded in March 1996. It emerged as a further development of "The meaning of social, interpersonal, and psychological factors for coping with chronic diseases and the development of disability", being part of the National Research Program 26B supported by the Swiss National Science Foundation. Roberto Brioschi, clinical psychologist and research associate, developed a program for patients with musculoskeletal pain, mainly chronic back pain or fibromyalgia. He is still head of the program. In contrast to a psy- 
chosomatic clinic or a pain clinic, the Zurzach Interdisciplinary Pain Program limits itself to a small segment of pain patients. The program starts every month, lasts for four weeks, and is organized in the rehabilitation clinic RehaClinic, locations Bad Zurzach and Braunwald, Switzerland [38]. The program language is German. Since May 2000 additional groups for Italian-speaking patients have been organized. Two weekend holidays are permitted during their stay at the clinic.

The program is based on the biopsychosocial model [39], the concept of salutogenesis [40], and the integration of various psychotherapeutic methods. It addresses the medical, personal, and social complexity of patients with chronic pain disorders. The interdisciplinary pain program aims to stop the process of pain chronification, to increase resilience, and to improve quality of life [41, 42]. If a withdrawal reaction can be prevented by increasing the physical and mental activity level of the patient and by improving self-efficacy and competence to control pain (locus of control), i.e. active adaptive pain coping strategies, this will help to reduce perceived pain [34]. The program is intensive (in total over one hundred hours of therapy). At the start of the program the patients have to hand over their medication to the nursing staff. Over the course of treatment patients receive on average six daily sessions of the following treatments: physiotherapy, aerobic endurance training, qigong / tai chi exercises, individual psychotherapy including cognitive behavioral therapy, participation in a pain coping group, relaxation therapy, humor therapy, horticultural therapy, information and education about the pathophysiology of pain mechanisms and management of chronic disabling pain, nursing care, and regular medical consultations including drug therapy.

Individual treatment strategies are identified and discussed during the interdisciplinary meetings of the pain management team (two per week for six patients). Results of baseline assessment and follow-up are discussed with the patients. In the first and in the last week of the pain management program the patient participates in the planning and review of his or her individual treatment strategies. Standard self-report follow-up is done after three and six months. Outpatient rehabilitation after completing the inpatient Zurzach Interdisciplinary Pain Program at RehaClinic is organized for selected patients and is performed by the therapists of the pain management team. Otherwise, further outpatient care by external therapists is discussed and organized with the patients.

The health care providers involved - all educated pain specialists - are: rheumatologists, clinical psychologists, physiotherapists, occupational therapists, nurses, a movement analyst and clown Pello, a humor therapist. All health care providers of the pain management team have completed a standardized educational training in theoretical, conceptual, and therapeutic basics of interdisciplinary pain management. The head of the program, an experienced psychologist, provides clinical supervision, supervision of the health professionals in the pain management team, and additional case-specific instructions during the course of treatment. Several studies, published in peer- 
reviewed journals over the past few years, have reported the outcomes of different aspects of this pain management program [34-36].

\section{Aim of the thesis}

The primary objective of this thesis is to examine the effectiveness of tailored pain management in patients with chronic musculoskeletal pain classified according the Multidimensional Pain Inventory Classification System in order to improve patient care. The secondary objective encompasses the exploration of differences in effects between individual Multidimensional Pain Inventory subgroups. Finally, the third objective, as a prerequisite to achieve the first two objectives, is testing clinimetric features of the measurement tools Coping Strategies Questionnaire and the Multidimensional Pain Inventory Classification System.

\section{Outline of the thesis}

Because many relevant systematic reviews, partly with meta-analyses, in the field of rehabilitation of chronic musculoskeletal pain conditions already exist (e.g. $[10,11,14$, 41, 43-56] ), this thesis did not start with a review, but focussed on clinimetric and evaluation studies in patients participating in the Zurzach Interdisciplinary Pain Program (Figure 1). 


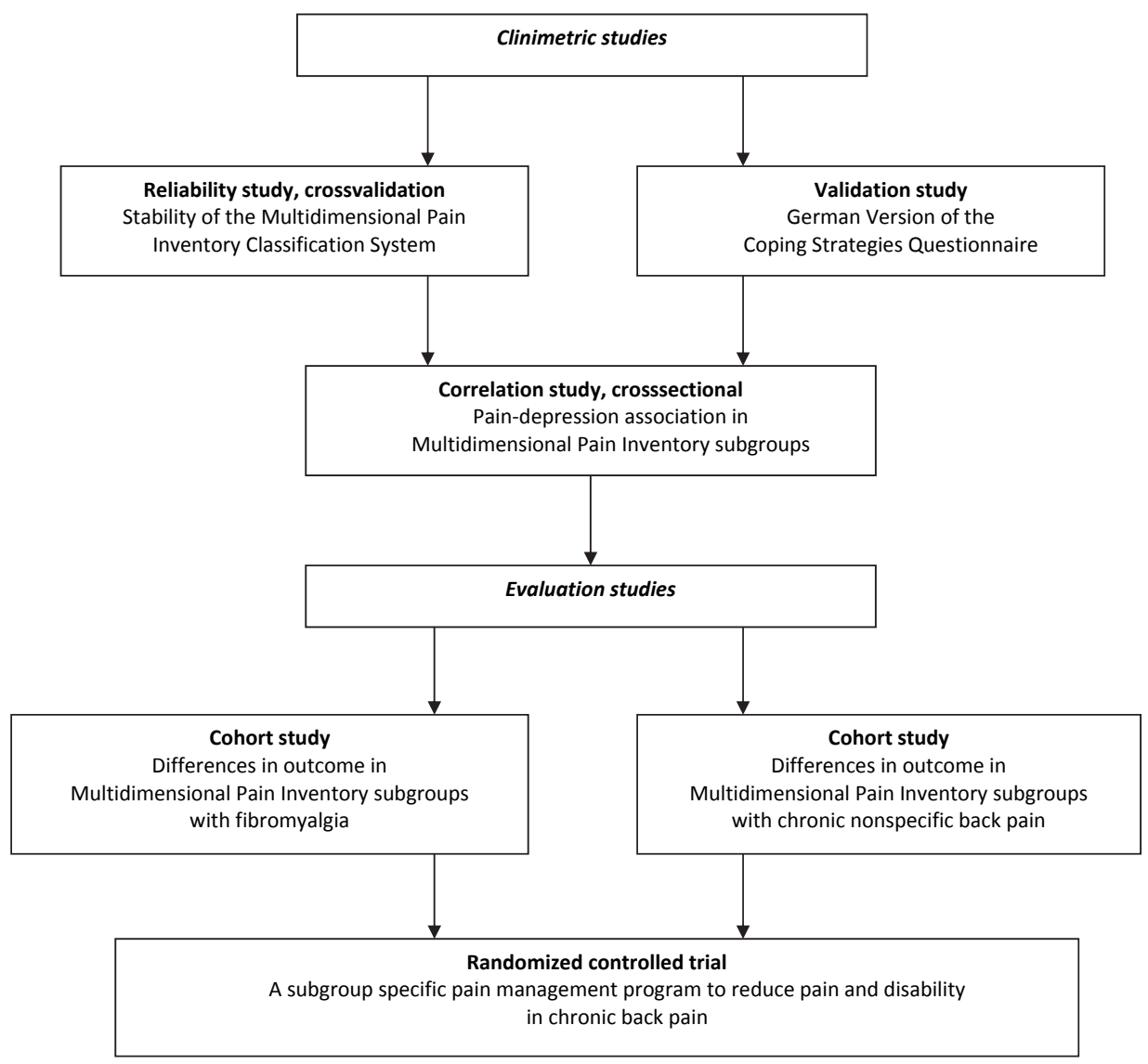

Figure 1. Flow chart of the outline of the thesis

\section{Part 1: Clinimetric studies}

The research project started with a translation, cross-cultural adaptation, and validation of the internationally most widely used measure of pain coping strategies, the Coping Strategies Questionnaire (Chapter 2: Translation, cross-cultural adaptation, reliability, and validity of the German version of the Coping Strategies Questionnaire (CSQ-D)). As in the Zurzach Interdisciplinary Pain Program, one of the main goals of pain management is to support the patient in learning how to cope with his chronic, recurrent pain condition. Despite eventual failure to completely alleviate pain, patients should learn to set realistic, functional goals and "go on with their lives". The success of these active, adapted pain coping strategies had to be evaluated with clinimetrically sound measurement tools. So far, like several other important questionnaires that have been developed in English-speaking countries, the CSQ was not available in German. 
The Multidimensional Pain Inventory Classification System distinguishes three unique profiles or subgroups for patients on how they cope with chronic pain. Previous international studies mainly involving fibromyalgia patients showed poor test-retest reliability scores for this classification tool. Previous international studies mainly involving fibromyalgia patients showed that retest resulted in 33-38\% of patients being assigned to a different Multidimensional Pain Inventory subgroup classification. Therefore, the second study in this thesis was a cross validation study, examining the stability of the MPI Classification System mainly in chronic back pain patients (Chapter 3: Reliability of the Multidimensional Pain Inventory and stability of the MPI Classification System in chronic back pain).

In patients with chronic musculoskeletal pain, depression is the comorbidity with the highest prevalence. Depression and chronic pain have a high impact on healthrelated quality of life and individual health care. Management of both disorders is often unsuccessful and the question arises as to whether pain and depression are not just highly associated, but causally related. If so, one disorder could be influenced by treatment of the other. Several previous studies showed controversial results. In one of our studies we aimed to derive refined (i.e. by stratification into MPI subgroups, different methods, continuous scales, etc.) correlation and regression data from a patient sample to contribute to the debate of whether depression and pain are strongly enough related to support the hypothesis of causality (Chapter 4: Refined insights into the paindepression association in chronic pain patients).

\section{Part 2: Evaluation studies}

MPI subgroups have been described in several studies with different patient groups and different settings. A subsequent study aimed to replicate and validate the empirically derived subgroup classification based on the Multidimensional Pain Inventory (MPI) in a sample of highly disabled fibromyalgia patients (Chapter 5: Does classification of persons with fibromyalgia into Multidimensional Pain Inventory subgroups detect differences in outcome after a standard chronic pain management program?). Second, it examined how the identified subgroups differed in their response to our standard, interdisciplinary inpatient pain management program. If so, this retrospective MPI subgroup classification could provide information that might help to improve the effects of standard pain management programs: matching patients with the treatment strategies and therapeutic methods that they are most likely to respond to and where they show the greatest need of treatment and/or where they show the largest deficits.

The main aim of the next study was to examine a sample of highly disabled patients with chronic back pain to find out how the three subgroups based on the Multidimensional Pain Inventory differed in their response to the standardized interventions of the Zurzach Interdisciplinary Pain Program (Chapter 6: Differences in pain, function and coping in Multidimensional Pain Inventory subgroups of chronic back pain: a onegroup pretest-posttest study). If this were the case, information would be provided 
that might help to improve the clinical outcomes of standard pain management programs by a priori implementation of classification methods for matching interventions (i.e., tailored pain management) to subgroups of patients.

Finally, based on the information of the previous studies, subgroup-specific interventions in the fields of physiotherapy and psychotherapy were developed and subsequently tested by means of a randomized clinical trial (Chapter 7: Effectiveness of a subgroup-specific pain management program based on the MPI Classification System: A pragmatic randomized controlled trial in patients with chronic back pain). This study examined the effectiveness of tailored pain management on pain and disability in patients with chronic nonspecific back pain a priori classified according to the Multidimensional Pain Inventory (MPI) Classification System, compared to general pain management. The secondary objective focussed on the exploration of differences in effects between individual MPI subgroups and the control group.

The last chapter (Chapter 8: General discussion) provides an overall discussion, including implications for clinical practice and recommendations for further research relevant to this $\mathrm{PhD}$ thesis project. 


\section{References}

1. Breivik H, Collett B, Ventafridda V, Cohen R, Gallacher D: Survey of chronic pain in Europe: prevalence, impact on daily life, and treatment. European journal of pain 2006, 10(4):287-333.

2. Langley PC: The prevalence, correlates and treatment of pain in the European Union. Current medical research and opinion 2011, 27(2):463-480.

3. Gaskin DJ, Richard P: The economic costs of pain in the United States. The journal of pain : official journal of the American Pain Society 2012, 13(8):715-724.

4. Wieser S, Horisberger B, Schmidhauser S, Eisenring C, Brugger U, Ruckstuhl A, Dietrich J, Mannion AF, Elfering A, Tamcan O et al: Cost of low back pain in Switzerland in 2005. The European journal of health economics : HEPAC : health economics in prevention and care 2011, 12(5):455-467.

5. McBeth J, Symmons DP, Silman AJ, Allison T, Webb R, Brammah T, Macfarlane GJ: Musculoskeletal pain is associated with a long-term increased risk of cancer and cardiovascular-related mortality. Rheumatology 2009, 48(1):74-77.

6. Macfarlane GJ, McBeth J, Silman AJ: Widespread body pain and mortality: prospective population based study. Bmj 2001, 323(7314):662-665.

7. Hayden JA, van Tulder MW, Malmivaara A, Koes BW: Exercise therapy for treatment of non-specific low back pain. Cochrane database of systematic reviews 2005(3):CD000335.

8. Henschke N, Ostelo RW, van Tulder MW, Vlaeyen JW, Morley S, Assendelft WJ, Main CJ: Behavioural treatment for chronic low-back pain. Cochrane database of systematic reviews 2010(7):CD002014.

9. Keller A, Hayden J, Bombardier C, van Tulder M: Effect sizes of non-surgical treatments of non-specific low-back pain. European spine journal : official publication of the European Spine Society, the European Spinal Deformity Society, and the European Section of the Cervical Spine Research Society 2007, 16(11):1776-1788.

10. van Middelkoop M, Rubinstein SM, Kuijpers T, Verhagen AP, Ostelo R, Koes BW, van Tulder MW: A systematic review on the effectiveness of physical and rehabilitation interventions for chronic nonspecific low back pain. European spine journal : official publication of the European Spine Society, the European Spinal Deformity Society, and the European Section of the Cervical Spine Research Society 2011, 20(1):19-39.

11. Gatchel RJ, Okifuji A: Evidence-based scientific data documenting the treatment and cost-effectiveness of comprehensive pain programs for chronic nonmalignant pain. The journal of pain : official journal of the American Pain Society 2006, 7(11):779-793.

12. Koes BW, van Tulder MW, Thomas S: Diagnosis and treatment of low back pain. Bmj 2006, 332(7555):1430-1434.

13. Airaksinen O, Brox JI, Cedraschi C, Hildebrandt J, Klaber-Moffett J, Kovacs F, Mannion AF, Reis S, Staal JB, Ursin $\mathrm{H}$ et al: Chapter 4. European guidelines for the management of chronic nonspecific low back pain. European spine journal : official publication of the European Spine Society, the European Spinal Deformity Society, and the European Section of the Cervical Spine Research Society 2006, 15 Suppl 2:S192-300.

14. Huppe A, Raspe H: [Efficacy of inpatient rehabilitation for chronic back pain in Germany: a systematic review 1980-2001]. Die Rehabilitation 2003, 42(3):143-154.

15. Kool JP, Oesch PR, Bachmann S, Knuesel O, Dierkes JG, Russo M, de Bie RA, van den Brandt PA: Increasing days at work using function-centered rehabilitation in nonacute nonspecific low back pain: a randomized controlled trial. Archives of physical medicine and rehabilitation 2005, 86(5):857-864.

16. Waddell G: Diagnostic triage. In: The back pain revolution. 1 edn. Edinburgh: Churchill Livingstone; 1998: 9-25.

17. Fourney DR, Andersson G, Arnold PM, Dettori J, Cahana A, Fehlings MG, Norvell D, Samartzis D, Chapman JR: Chronic low back pain: a heterogeneous condition with challenges for an evidence-based approach. Spine 2011, 36(21 Suppl):S1-9.

18. Borkan JM, Cherkin DC: An agenda for primary care research on low back pain. Spine 1996, 21(24):28802884. 
19. Henschke N, Maher CG, Refshauge KM, Das A, McAuley JH: Low back pain research priorities: a survey of primary care practitioners. BMC family practice 2007, 8:40.

20. Costa Lda C, Koes BW, Pransky G, Borkan J, Maher CG, Smeets RJ: Primary care research priorities in low back pain: an update. Spine 2013, 38(2):148-156.

21. Brookes ST, Whitely E, Egger M, Smith GD, Mulheran PA, Peters TJ: Subgroup analyses in randomized trials: risks of subgroup-specific analyses; power and sample size for the interaction test. Journal of clinical epidemiology 2004, 57(3):229-236.

22. Moye LA, Deswal A: Trials within trials: confirmatory subgroup analyses in controlled clinical experiments. Controlled clinical trials 2001, 22(6):605-619.

23. Kamper SJ, Maher CG, Hancock MJ, Koes BW, Croft PR, Hay E: Treatment-based subgroups of low back pain: a guide to appraisal of research studies and a summary of current evidence. Best practice \& research Clinical rheumatology 2010, 24(2):181-191.

24. Hancock M, Herbert RD, Maher CG: A guide to interpretation of studies investigating subgroups of responders to physical therapy interventions. Physical therapy 2009, 89(7):698-704.

25. Karayannis NV, Jull GA, Hodges PW: Physiotherapy movement based classification approaches to low back pain: comparison of subgroups through review and developer/expert survey. $B M C$ musculoskeletal disorders 2012, 13:24.

26. Vibe Fersum K, O'Sullivan P, Skouen JS, Smith A, Kvale A: Efficacy of classification-based cognitive functional therapy in patients with non-specific chronic low back pain: A randomized controlled trial. European journal of pain 2012.

27. Apeldoorn AT, Ostelo RW, van Helvoirt H, Fritz JM, Knol DL, van Tulder MW, de Vet HC: A randomized controlled trial on the effectiveness of a classification-based system for subacute and chronic low back pain. Spine 2012, 37(16):1347-1356.

28. Hill JC, Whitehurst DG, Lewis M, Bryan S, Dunn KM, Foster NE, Konstantinou K, Main CJ, Mason E, Somerville $S$ et al: Comparison of stratified primary care management for low back pain with current best practice (STarT Back): a randomised controlled trial. Lancet 2011, 378(9802):1560-1571.

29. Fritz JM, Delitto A, Erhard RE: Comparison of classification-based physical therapy with therapy based on clinical practice guidelines for patients with acute low back pain: a randomized clinical trial. Spine 2003, 28(13):1363-1371; discussion 1372.

30. Brennan GP, Fritz JM, Hunter SJ, Thackeray A, Delitto A, Erhard RE: Identifying subgroups of patients with acute/subacute "nonspecific" low back pain: results of a randomized clinical trial. Spine 2006, 31(6):623-631.

31. Browder DA, Childs JD, Cleland JA, Fritz JM: Effectiveness of an extension-oriented treatment approach in a subgroup of subjects with low back pain: a randomized clinical trial. Physical therapy 2007, 87(12):1608-1618; discussion 1577-1609.

32. Bergstrom G, Bergstrom C, Hagberg J, Bodin L, Jensen I: A 7-year follow-up of multidisciplinary rehabilitation among chronic neck and back pain patients. Is sick leave outcome dependent on psychologically derived patient groups? European journal of pain 2010, 14(4):426-433.

33. Vollenbroek-Hutten MM, Hermens HJ, Wever D, Gorter M, Rinket J, ljzerman MJ: Differences in outcome of a multidisciplinary treatment between subgroups of chronic low back pain patients defined using two multiaxial assessment instruments: the multidimensional pain inventory and lumbar dynamometry. Clinical rehabilitation 2004, 18(5):566-579.

34. Angst F, Brioschi R, Main CJ, Lehmann S, Aeschlimann A: Interdisciplinary rehabilitation in fibromyalgia and chronic back pain: a prospective outcome study. The journal of pain : official journal of the American Pain Society 2006, 7(11):807-815.

35. Angst F, Verra ML, Lehmann S, Brioschi R, Aeschlimann A: Clinical effectiveness of an interdisciplinary pain management programme compared with standard inpatient rehabilitation in chronic pain: a naturalistic, prospective controlled cohort study. Journal of rehabilitation medicine : official journal of the UEMS European Board of Physical and Rehabilitation Medicine 2009, 41(7):569-575. 
36. Verra ML, Angst F, Beck T, Lehmann S, Brioschi R, Schneiter R, Aeschlimann A: Horticultural therapy for patients with chronic musculoskeletal pain: results of a pilot study. Alternative therapies in health and medicine 2012, 18(2):44-50.

37. Wolfe F, Clauw DJ, Fitzcharles MA, Goldenberg DL, Hauser W, Katz RS, Mease P, Russell AS, Russell IJ, Winfield JB: Fibromyalgia criteria and severity scales for clinical and epidemiological studies: a modification of the ACR Preliminary Diagnostic Criteria for Fibromyalgia. The Journal of rheumatology 2011, 38(6):1113-1122.

38. Matter C: Outcome italienischer Schmerzpatientinnen und -patienten im Vergleich mit schweizerischen Schmerzpatientinnen und -patienten nach Teilnahme an einer stationären interdisziplinären Rehabilitation: eine prospektive Kohortenstudie. Baden: Zurich University of Applied Sciences; 2011.

39. Engel GL: The need for a new medical model: a challenge for biomedicine. Science 1977, 196(4286):129136.

40. Lindstrom B, Eriksson M: Salutogenesis. Journal of epidemiology and community health 2005, 59(6):440442.

41. Goldenberg DL, Burckhardt C, Crofford L: Management of fibromyalgia syndrome. JAMA : the journal of the American Medical Association 2004, 292(19):2388-2395.

42. Main CJ, Sullivan MJ, Watson PJ: Pain management: practical applications of the biospychosocial perspective in clinical and occupational settings, second edn. Edinburgh: Churchill Livingstone Elsevier; 2008.

43. Burckhardt CS: Multidisciplinary approaches for management of fibromyalgia. Current pharmaceutical design 2006, 12(1):59-66.

44. Hayden JA, van Tulder MW, Tomlinson G: Systematic review: strategies for using exercise therapy to improve outcomes in chronic low back pain. Annals of internal medicine 2005, 142(9):776-785.

45. Hayden JA, van Tulder MW, Malmivaara AV, Koes BW: Meta-analysis: exercise therapy for nonspecific low back pain. Annals of internal medicine 2005, 142(9):765-775.

46. Morley S, Eccleston C, Williams A: Systematic review and meta-analysis of randomized controlled trials of cognitive behaviour therapy and behaviour therapy for chronic pain in adults, excluding headache. Pain 1999, 80(1-2):1-13.

47. Scharrer M, Ebenbichler G, Pieber K, Crevenna R, Gruther W, Zorn C, Grimm-Stieger M, Herceg M, Keilani $M$, Ammer K: A systematic review on the effectiveness of medical training therapy for subacute and chronic low back pain. European journal of physical and rehabilitation medicine 2012, 48(3):361-370.

48. Smidt N, de Vet HC, Bouter LM, Dekker J, Arendzen JH, de Bie RA, Bierma-Zeinstra SM, Helders PJ, Keus $\mathrm{SH}$, Kwakkel $\mathrm{G}$ et al: Effectiveness of exercise therapy: a best-evidence summary of systematic reviews. The Australian journal of physiotherapy 2005, 51(2):71-85.

49. van der Giessen RN, Speksnijder CM, Helders PJ: The effectiveness of graded activity in patients with non-specific low-back pain: a systematic review. Disability and rehabilitation 2012, 34(13):1070-1076.

50. Oesch P, Kool J, Hagen KB, Bachmann S: Effectiveness of exercise on work disability in patients with non-acute non-specific low back pain: Systematic review and meta-analysis of randomised controlled trials. Journal of rehabilitation medicine : official journal of the UEMS European Board of Physical and Rehabilitation Medicine 2010, 42(3):193-205.

51. Reese C, Mittag O: Psychological interventions in the rehabilitation of patients with chronic low back pain: evidence and recommendations from systematic reviews and guidelines. International journal of rehabilitation research Internationale Zeitschrift fur Rehabilitationsforschung Revue internationale de recherches de readaptation 2013, 36(1):6-12.

52. Karjalainen K, Malmivaara A, van Tulder M, Roine $R$, Jauhiainen $M$, Hurri $H$, Koes B: Multidisciplinary biopsychosocial rehabilitation for subacute low back pain among working age adults. Cochrane database of systematic reviews 2003(2):CD002193.

53. Rainville J, Hartigan C, Martinez E, Limke J, Jouve C, Finno M: Exercise as a treatment for chronic low back pain. The spine journal : official journal of the North American Spine Society 2004, 4(1):106-115.

54. Guzman J, Esmail R, Karjalainen K, Malmivaara A, Irvin E, Bombardier C: Multidisciplinary rehabilitation for chronic low back pain: systematic review. Bmj 2001, 322(7301):1511-1516. 
55. Liddle SD, Baxter GD, Gracey JH: Exercise and chronic low back pain: what works? Pain 2004, 107(12):176-190.

56. Kool J, de Bie R, Oesch P, Knusel O, van den Brandt P, Bachmann S: Exercise reduces sick leave in patients with non-acute non-specific low back pain: a meta-analysis. Journal of rehabilitation medicine : official journal of the UEMS European Board of Physical and Rehabilitation Medicine 2004, 36(2):49-62. 

PART I

Clinimetric studies 



\section{CHAPTER 2}

\section{Translation, cross-cultural adaptation, reliability, and validity of the German version of the Coping Strategies Questionnaire (CSQ-D)}

Verra ML, Angst F, Lehmann S, Aeschlimann A.

Translation, Cross-Cultural Adaptation, Reliability and Validity of the German Version of the Coping Strategies Questionnaire (CSQ-D).

Journal of Pain 2006;7(5):327-336. 


\section{Abstract}

Objectives. The aim of this study was to translate and cross-culturally adapt the American version of the Coping Strategies Questionnaire (CSQ) and to test the reliability and validity of the German version (CSQ-D).

Methods. The CSQ was translated and cross-culturally adapted following international guidelines. Reliability and validity were tested in 62 individuals with chronic musculoskeletal pain syndromes. For the concurrent criterion-related validity, the CSQ-D scales were compared with the German Pain Coping Questionnaire (FESV-BW) and for the construct validity with the German Short Form 36 (SF-36).

Results. The translation process proceeded without major difficulties. In testing for reliability, the CSQ-D as a whole had a Cronbach's alpha of 0.94 and an intraclass correlation coefficient of 0.89 ( $95 \% \mathrm{Cl}$ : 0.86-0.98). The total CSQ-D score was correlated to the FESV-BW scales with scores of $r=0.32-0.55$ and with the SF-36 Mental Component Summary with scores of $r=0.32-0.53$. The CSQ-D is a precisely translated and highly reliable instrument in the assessment of chronic pain coping strategies. Its concurrent criterion-related validity and construct validity are low. The main reason for the low level of agreement between the CSQ-D and the FESV-BW was revealed by factor analysis.

Conclusions. This paper presents the German Version of the CSQ, together with the results of clinimetric testing. The CSQ-D is a feasible and reliable outcome measure to be used in trials with German-speaking patients or large multicenter multinational trials to assess pain coping strategies in patients with chronic musculoskeletal pain. 


\section{Introduction}

Coping strategies in the context of chronic pain refer to the way individuals who experience pain develop ways to tolerate, minimize or reduce their pain. Interest in the concept of coping has been reinforced by a review of the literature on pain coping strategies and by meta-analytical research that supports interdisciplinary intervention in the form of cognitive-behavioral therapy as one of the few effective treatments for patients with chronic musculoskeletal pain [1-3].

In the new European guidelines for the management of chronic nonspecific low back pain, the most promising approaches seem to be cognitive-behavioral interventions encouraging activity and exercise [4]. The evaluation and training of cognitive and behavioral coping strategies is an interdisciplinary enterprise, in which patients, physiotherapists, occupational therapists, psychologists, nurses and medical doctors are involved. The Coping Strategies Questionnaire (CSQ) is internationally the most widely used measure of pain coping strategies [5]. The value of the CSQ is its ability to assess various cognitive and behavioral coping factors derived from a rationally constructed pool of strategies reported by patients experiencing pain and cross-validated by pain clinicians and pain psychologists [5-8]. It identifies both active and passive coping strategies [7]. For example, the use of passive, maladaptive coping strategies such as "Praying or Hoping" and "Catastrophizing" is suggested as predictive of a poor 1-year response to treatment [9-14]. The CSQ has received considerable research attention aimed at improving interpretability via factor-analytic studies of dimensions of coping, clinical studies comparing patient subgroups, and the evaluation of treatment outcomes [5, 15-19].

In the German-speaking countries, several pain coping strategy questionnaires exist in the German language (e.g. Fragebogen zur Erfassung Schmerzbezogener Selbstinstruktionen (FSS)/Fragebogen zur Erfassung Schmerzbezogener Kontrollüberzeugungen (FSK), Kieler Schmerzinventar (KSI), and Fragebogen zur Erfassung der Schmerzverarbeitung (FESV) [20-23]. According to the recommendations of the Initiative on Methods, Measurement, and Pain Assessment (IMMPACT), the use of a standard set of validated outcome measures for chronic pain clinical trials would facilitate the process of developing research protocols, encourage development of multi-centre projects in which all participating institutions agree to include these measures, provide a basis for determining the treatment outcomes that constitute clinically important differences, permit pooling of data from different studies, and provide a basis for meaningful comparisons of treatments and the clinical importance of their outcomes, particularly through systematic reviews [24]. To be able to participate in large multicentre multinational trials, the adapted version of the CSQ must undergo the process of validation [25]. Several German translations of the CSQ exist, but none of them were done according to the 
international guidelines (Luka-Krausgrill, personal communication). The validation process of a certain German version of the CSQ has been sustained in 1995 [26, 27]. Therefore, the aims of the study were: 1 ) to translate and develop a cross-cultural adaption of the original CSQ, and 2) to investigate the clinimetric properties (reliability and validity) of the German version of the CSQ in a Swiss-German population of patients with chronic musculoskeletal pain syndromes. The final version for use in clinical trials in German-speaking populations is presented.

\section{Methods}

The study was conducted at RehaClinic, a Swiss rehabilitation clinic in Bad Zurzach, which is attended by patients from all the German-speaking countries in Europe. All patients were participants in the in-house pain management programs with a cognitivebehavioral approach, including physical exercise, and had no other diagnosis that could interfere with these rehabilitation activities. Twenty-two inpatients with chronic pain due to whiplash injury $(n=15)$, other back pain $(n=2)$, fibromyalgia $(n=4)$, or generalized widespread pain $(n=1)$ were assessed over a weekend for reliability data with an interval of $48 \mathrm{~h}$ between test and retest, i.e. without having undergone any therapy or intervention. Out of 208 names and addresses of former in-house chronic musculoskeletal pain patients who had consented to be addressed for studies of chronic musculoskeletal pain and who were registered in a database of the Research Department of RehaClinic, the 58 most recently treated patients were additionally enrolled for the validation study. After patient information by telephone, 4 patients refused participation. After written patient information was handed out, written informed consent was obtained from an additional 40 chronic pain patients $(9$ patients did not return the questionnaire, 1 had died, and 3 patients returned the questionnaire after the deadline), resulting in a sample of 62 patients for the validity testing [28].

The average age of the participants was 44 years (range $16-68$ years), and $77 \%$ were female. Twenty-one had suffered a whiplash injury, 11 other chronic back pain, 17 fibromyalgia, and 13 generalized widespread pain syndrome.

\section{Translation and cross-cultural adaptation}

Translation and cross-cultural adaptation was performed following the international guidelines for self-report measures published by the American Association of Orthopedic Surgeons Outcomes Committee [29]. This process consists of 6 steps, called stages, of which each is documented by a written report. 


\section{Stage I: Initial translation}

The primary translation of the CSQ was done independently by 1 bilingual researcher (FA) aware of the objective of the questionnaire and 1 other bilingual person (AK) without any knowledge of the instrument or the construct of coping with chronic pain.

\section{Stage II: Synthesis of the translations}

The 2 translators and the recording observer (MLV) synthesized the results of the translations by consensus.

\section{Stage III: Back-translation}

The synthesis of the 2 translations was then independently translated back into English again by 2 different bilingual persons: 1 person with native-language American English $(\mathrm{RH})$ and 1 professional translator with native-language British English (JB) who had no prior knowledge of the instrument.

\section{Stage IV: Expert committee review}

The expert committee, consisting of all translators, 1 neurologist (RM), 1 general practitioner (FA), 2 psychologists (FG and MS), 2 physiotherapists (HS and MLV) and 1 research assistant (SL), compared the original version with the various translations and back-translations and developed the prefinal version by consensus. The other role of the expert committee was to achieve semantic, idiomatic, experiential, and conceptual equivalence between the original CSQ and the CSQ-D.

\section{Stage V: Test of the prefinal version}

The pre-final version was tested for face and content validity purposes by physiotherapists and occupational therapists from Switzerland, Germany and Austria (with nativelanguage German). The questionnaire was also tested on 12-13-year-old children and evaluated to establish that this version could be understood by a person with limited educational status [30].

Stage VI: Submission of documentation to the developers

All the reports and forms were submitted for appraisal of the adaptation process to Francis J. Keefe, co-developer of the original CSQ.

\section{Outcome measures}

\section{Coping}

The CSQ is a widely used instrument to assess coping strategies used by individuals with chronic pain. It was developed in 1983 in the USA by Rosenstiel and Keefe [5]. It is a 48item self-report questionnaire that assesses 6 cognitive (Diverting Attention, Reinterpreting Pain Sensations, Coping Self-Statements, Ignoring Pain Sensations, Praying or 
Hoping, Catastrophizing) and 2 behavioral (Increasing Activity Level, Increasing Pain Behaviors) coping techniques. Each domain is comprised of 6 items, and participants rate the frequency of their use of specific coping strategies on a 7-point Likert scale from 0 ("Never do that") to 6 ("Always do that"). The CSQ also includes 2 1-item scales that assess participants' subjective ability to control or decrease their pain. These 2 scales are not thought to measure coping strategies but rather their effectiveness. Using a similar 7-point Likert scale, participants rate from 0 to 6, with 0 signifying "No control/No ability to decrease pain", and 6 signifying "Complete control/Complete ability to decrease pain".

The CSQ has demonstrated satisfactory internal consistency and test-retest reliability $[5,6]$. Factor-analytic studies examining the relationships between the subscales have failed to find a reliable factor structure underscoring the difficulties in conceptualizing important dimensions of coping [5, 15-19]. Therefore, given the extensive use of the CSQ, as well as the concerns and apparent variability of its factor structure in different populations and lack of longitudinal data for measuring responsiveness, we decided to translate, cross-culturally adapt, and test the reliability and validity of the original "full-version" (48+2 items) CSQ.

Pain-related coping strategies were also assessed by the German Pain Coping Questionnaire "Fragebogen zur Erfassung der Schmerzverarbeitung-Schmerzbewältigung" (FESV-BW), comprising 6 subscales [22]. It is divided into 3 subscales with cognitive coping strategies Action-Oriented Coping (German: Handlungsplanungskompetenzen), Cognitive Restructuring (German: Kognitive Umstrukturierung) and Self-Efficacy (German: Kompetenzerleben), and 3 subscales with behavioral coping strategies Mental Distraction (German: Mentale Ablenkung), Counter-Activities (German: Gegensteuerende Aktivitäten), and Relaxation (German: Ruhe- und Entspannungstechniken). Each scale consists of 4 items. Scale values range from 4 to 24. Cronbach's alpha coefficients of the scales vary between $\alpha=0.68$ and $\alpha=0.78$, and the test-retest reliability scores of the scales vary between $r=0.71$ and $r=0.89$ [31]. This German instrument showed low and moderate correlations with stress coping questionnaires $(r=0.35$ 0.60 ) but has not been validated against other German pain coping strategies questionnaires.

\section{Health Related Quality of Life (HRQL)}

The Medical Outcomes Study Short Form 36 (SF-36) is a widely accepted selfadministered generic instrument that assesses biopsychosocial health related to quality of life [32]. The 36 questions of the SF-36 comprise 8 scales, each containing between 2 and 10 items, plus a single item to assess health transition. The scales cover the dimensions of Physical Functioning (unweighted mean of 10 items), Role Physical (4 items), Bodily Pain (2 items), General Health (5 items), Vitality (4 items), Social Functioning (2 items), Role Emotional (3 items), and Mental Health (5 items). It yields a total score ranging from 0 (maximal symptoms/maximal limitations/poor health) to 100 (no symp- 
toms/no limitations/excellent health). The SF-36 allows the construction of 2 summary scales, the Physical Component Summary (PCS) and the Mental Component Summary (MCS). We used the validated German version of the SF-36 [33].

\section{Statistical analysis}

All instruments' scales were transformed into a scale from 0 (maximal symptoms/maximal limitations/poor health/no control or coping ability) to 100 (no symptoms/no limitations/excellent health/maximal control or coping ability) according to the original scaling of the widespread SF-36. For the CSQ-D, 0 means "never do that" and 100 means "always do that", except for Praying and Hoping and Catastrophizing, for which 0 means "always do that" and 100 means "never do that", because these 2 scales reflect the maladaptive passive coping strategies [7]. The purpose was to ease comparison of the scores across different instruments in the listing of the descriptive data.

The test-retest reliability of the CSQ-D was determined by intraclass correlation coefficients (ICCS). The ICC measures the agreement of the 2 (test and retest) responses pairwise for each item and each patient for the whole sample and ranges from 0 (no agreement) to 1 (perfect agreement). It is calculated using variance estimates obtained through the analysis of variance. Therefore, it reflects both degree of correspondence and agreement among ratings [34]. Although the ICC is primarily designed for use with interval/ratio data, the ICC can be applied without distortion to data on the ordinal scale when intervals between such measurements are assumed to be equivalent [35].

The internal consistency for the CSQ-D was assessed with Cronbach's alpha, a statistic used to calculate the strength of the association between the individual questions within the scale (carried out separately for the total score and for the cognitive coping strategies and behavioral coping strategies subscales) [36]. The alpha coefficient examines inter-item correlations within a subscale and therefore relates to its homogeneity. The concurrent criterion-related validity of the CSQ-D, assessed with non-parametric

Spearman rank correlation coefficients, was determined by analyzing the relationship between its scores and the scores from the subscales of the FESV-BW. As both questionnaires consist of both cognitive and behavioral scales for pain coping strategies, we decided to use the FESV-BW as the "gold standard" in testing the validity of the CSQ-D. The 2 other existing German pain coping strategy questionnaires, the FSS/FSK and the KSI, were rejected because the FSS/FSK showed lower reliability scores and the $\mathrm{KSI}$ was too extensive (120 items) $[6,23]$. There is no universally accepted measure for pain coping (a so-called "gold standard") but there is a broad consensus of using instruments with the same construct to assess validity.

Confirmatory factor analysis of the subscales of the CSQ-D and the FESV-BW was used to determine whether the FESV-BW could actually be regarded as the "gold standard" for measuring cognitive and behavioral pain coping strategies [37]. This 
strategy of including subscales into the factor analysis was also applied to the original CSQ [6]. A priori, we hypothesized that the cognitive CSQ scales would load together with the cognitive FEVS-BW scales on one factor, and the behavioral CSQ scales together with the behavioral FESV-BW scales on another factor. This would be a precondition for the use of the FESV-BW as a so-called "gold standard" measuring the same construct.

The construct validity of the CSQ-D, also assessed with nonparametric Spearman rank correlation coefficients, was investigated by examining the relationship between the CSQ-D scores and those from the MCS and PCS scales of the SF-36.

A priori, a high correlation was expected between the CSQ-D and the FESV-BW, a moderate correlation between the CSQ-D and the MCS subscale of the SF-36 (convergent validity), and a low correlation between the CSQ-D and the PCS subscale of the SF36 (discriminant validity).

As a further construct validity analysis, the overall rating of item 49, "Based on all the things you do to cope, on an average day, how much control do you feel you have over it?", was Spearman rank correlated to the eight CSQ scales. This procedure corresponds to the "known groups method", expecting that the patients with high scores in item 49 would also show high scores in the other 8 scales [34].

Data were analyzed with SPSS 11.5 for Windows (SPSS, Chicago, IL).

\section{Ethical approval}

The study was approved by the local research ethics committee (Health Department in Aarau, Switzerland) and was carried out at the Research Department of RehaClinic in Zurzach, Switzerland. All participants gave written informed consent.

\section{Results}

\section{Development of the CSQ-D}

The translation and back-translation of the CSQ proceeded without major difficulties. The expert committee discussed seven items (nos. 10, 18, 30, 36, 47, 49, and 50), but consensus for the prefinal version was easily obtained (e.g. in item 47, "projects" was translated into "andere Alltagstätigkeiten" because the word-by-word translation into "Projekte" would represent a more technical term used in science or technology). The German translation of the 1-item scales about control (item 49) and the ability to decrease pain (item 50) were differently formulated to improve ease of understanding without losing their original meaning.

After testing the prefinal version on 3 12-13-year-old children, 29 physiotherapists and 9 occupational therapists from Switzerland, Germany, and Austria (with native 
language German), and appraisal of the adaptation process by Francis J. Keefe, no revisions had to be made for the final version. The final German version of the CSQ is enclosed in Appendix A.

\section{Descriptive data}

Table 1 shows the descriptive data of the validation setting $(n=62)$. All CSQ-D scores were well distributed over almost the full range of the scaling, showing means around the middle of the scales from 0 to 100 . For the CSQ-D, only in the subscale Reinterpreting Pain Sensations was a floor effect over $20 \%$ measured. All other CSQ-D subscales and the total scales showed very low or no floor and ceiling effects.

Table 1. Descriptive data of the validation setting $(n=62)$

\begin{tabular}{|c|c|c|c|c|c|c|c|}
\hline Instr. & Scale & Minimum & Floor & Maximum & Ceiling & Mean & s \\
\hline \multirow[t]{10}{*}{ SF-36 } & Physical Functioning & 0 & - & 95.0 & - & 51.7 & 21.6 \\
\hline & Role Physical & 0.0 & $74 \%$ & 100.0 & $5 \%$ & 14.1 & 28.1 \\
\hline & Bodily Pain & 0.0 & $15 \%$ & 51.0 & - & 21.3 & 13.7 \\
\hline & General Health & 20.0 & - & 92.0 & - & 46.0 & 17.3 \\
\hline & Vitality & 0.0 & $5 \%$ & 75.0 & - & 24.9 & 17.0 \\
\hline & Social Functioning & 0.0 & $7 \%$ & 100.0 & $5 \%$ & 43.4 & 25.8 \\
\hline & Role Emotional & 0.0 & $52 \%$ & 100.0 & $26 \%$ & 38.2 & 43.5 \\
\hline & Mental Health & 4.0 & - & 96.0 & - & 47.7 & 19.9 \\
\hline & Physical Component Summary & 17.6 & - & 50.6 & - & 31.9 & 7.1 \\
\hline & Mental Component Summary & 15.2 & - & 61.8 & - & 36.3 & 11.3 \\
\hline \multirow[t]{11}{*}{ CSQ-D } & Diverting Attention & 13.9 & - & 80.6 & - & 47.5 & 16.0 \\
\hline & Reinterpreting Pain Sensations & 0.0 & $21 \%$ & 75.0 & - & 24.7 & 21.9 \\
\hline & Coping Self-Statements & 19.4 & - & 97.2 & - & 55.3 & 13.8 \\
\hline & Ignoring Pain Sensations & 6.7 & - & 94.4 & - & 46.7 & 16.2 \\
\hline & Praying or Hoping & 8.3 & - & 94.4 & - & 58.4 & 20.6 \\
\hline & Catastrophizing & 5.6 & - & 100.0 & $2 \%$ & 54.6 & 20.8 \\
\hline & Increasing Activity Level & 22.2 & - & 86.1 & - & 53.9 & 15.0 \\
\hline & Increasing Pain Behaviors & 27.8 & - & 83.3 & - & 56.2 & 12.0 \\
\hline & Control over Pain & 0.0 & $2 \%$ & 66.7 & - & 45.2 & 16.1 \\
\hline & Ability to Decrease Pain & 16.7 & - & 83.3 & - & 40.3 & 13.7 \\
\hline & CSQ-D total & 30.3 & - & 68.7 & - & 49.4 & 8.4 \\
\hline \multirow[t]{6}{*}{ FESV-BW } & Action-Oriented Coping & 10.0 & - & 95.0 & - & 53.9 & 20.4 \\
\hline & Cognitive Restructuring & 0.0 & $2 \%$ & 90.0 & - & 48.4 & 21.3 \\
\hline & Self-Efficacy & 0.0 & $2 \%$ & 95.0 & - & 49.4 & 22.1 \\
\hline & Mental Distraction & 0.0 & $2 \%$ & 90.0 & - & 48.4 & 22.1 \\
\hline & Counter-Activities & 0.0 & $2 \%$ & 85.0 & - & 41.9 & 20.4 \\
\hline & Relaxation & 0.0 & $3 \%$ & 100.0 & $2 \%$ & 43.7 & 22.7 \\
\hline
\end{tabular}

Abbreviations: Instr., instrument; SF-36, Short Form 36, German version; CSQ-D, Coping Strategies Questionnaire, German version; FESV-BW, Fragebogen zur Erfassung der Schmerzverarbeitung-Bewältigung (German 
Pain Coping Questionnaire); s, standard deviation.

NOTE. Scaling: $0=$ worst; $100=$ best.

\section{Reliability}

The single ICCS $(n=22)$ for the individual CSQ-D scales are listed in Table 2 together with the corresponding Cronbach's alpha. Instead of listing all the single item ICCs, their ranges are indicated per scale to reduce the size of the table. All scale ICCs ranged from 0.82 to 0.93 except the Ability to Decrease Pain scale (ICC=0.55). At the item level, the lowest ICC's (ICC $=0.55$ ) could be measured for item 33 ("When I feel pain, I take a shower or a bath") and item 26 ("No matter how bad it gets, I know I can handle it"). The highest ICCs at item level were measured for items 34, 7, 19, 41, 48 (ICC = 0.89) and item 39 ("When I feel pain, I try to be around other people") (ICC =0.90).

Table 2. Results of the reliability testing of the CSQ-D scales with a 48-hour interval $(n=22)$

\begin{tabular}{llllll}
\hline Scale & CA & ICC & $95 \%-C l$ & Range of item ICC's & No. of items \\
\hline Diverting Attention & 0.93 & 0.88 & $0.72-0.95$ & $0.72-0.87$ & 6 \\
Reinterpreting Pain Sensations & 0.95 & 0.90 & $0.78-0.96$ & $0.71-0.89$ & 6 \\
Coping Self-Statements & 0.93 & 0.87 & $0.71-0.94$ & $0.61-0.82$ & 6 \\
Ignoring Pain Sensations & 0.96 & 0.93 & $0.83-0.97$ & $0.73-0.87$ & 6 \\
Praying or Hoping & 0.96 & 0.92 & $0.82-0.97$ & $0.78-0.89$ & 6 \\
Catastrophizing & 0.97 & 0.93 & $0.85-0.97$ & $0.63-0.88$ & 6 \\
Increasing Activity Level & 0.95 & 0.91 & $0.80-0.96$ & $0.78-0.90$ & 6 \\
Increasing Pain Behaviors & 0.92 & 0.85 & $0.67-0.94$ & $0.55-0.89$ & 6 \\
Ability to Decrease Pain & - & 0.55 & $0.18-0.78$ & - & 1 \\
Control over Pain & - & 0.82 & $0.62-0.92$ & - & 1 \\
CSQ-D total & 0.94 & 0.89 & $0.76-0.95$ & $0.55-0.90$ & 50 \\
\hline
\end{tabular}

Abbreviations: CA, Cronbach's alpha coefficient; ICC, intraclass correlation coefficient; $95 \% \mathrm{Cl}, 95 \%$ confidence interval.

\section{Concurrent criterion-related validity}

Concurrent validity was measured by comparing the total CSQ-D score with the scores of the scales of the FESV-BW (Table 3). The total CSQ-D score was correlated to the FESV-BW scales with scores between $r=0.32$ (Self-Efficacy) and $r=0.55$ (CounterActivities). At the scale level of the CSQ-D, moderate correlations were found between Ignoring Pain and Cognitive Restructuring $(r=0.60)$, Catastrophizing and Mental Distraction ( $r=0.52)$, Activity Level and Relaxation $(r=0.51)$ and Activity Level and Cognitive Restructuring $(r=0.57)$. All other scales showed very low correlations to each other, with scores between -0.22 and 0.46 . 
GERMAN VERSION OF COPING STRATEGIES QUESTIONNAIRE

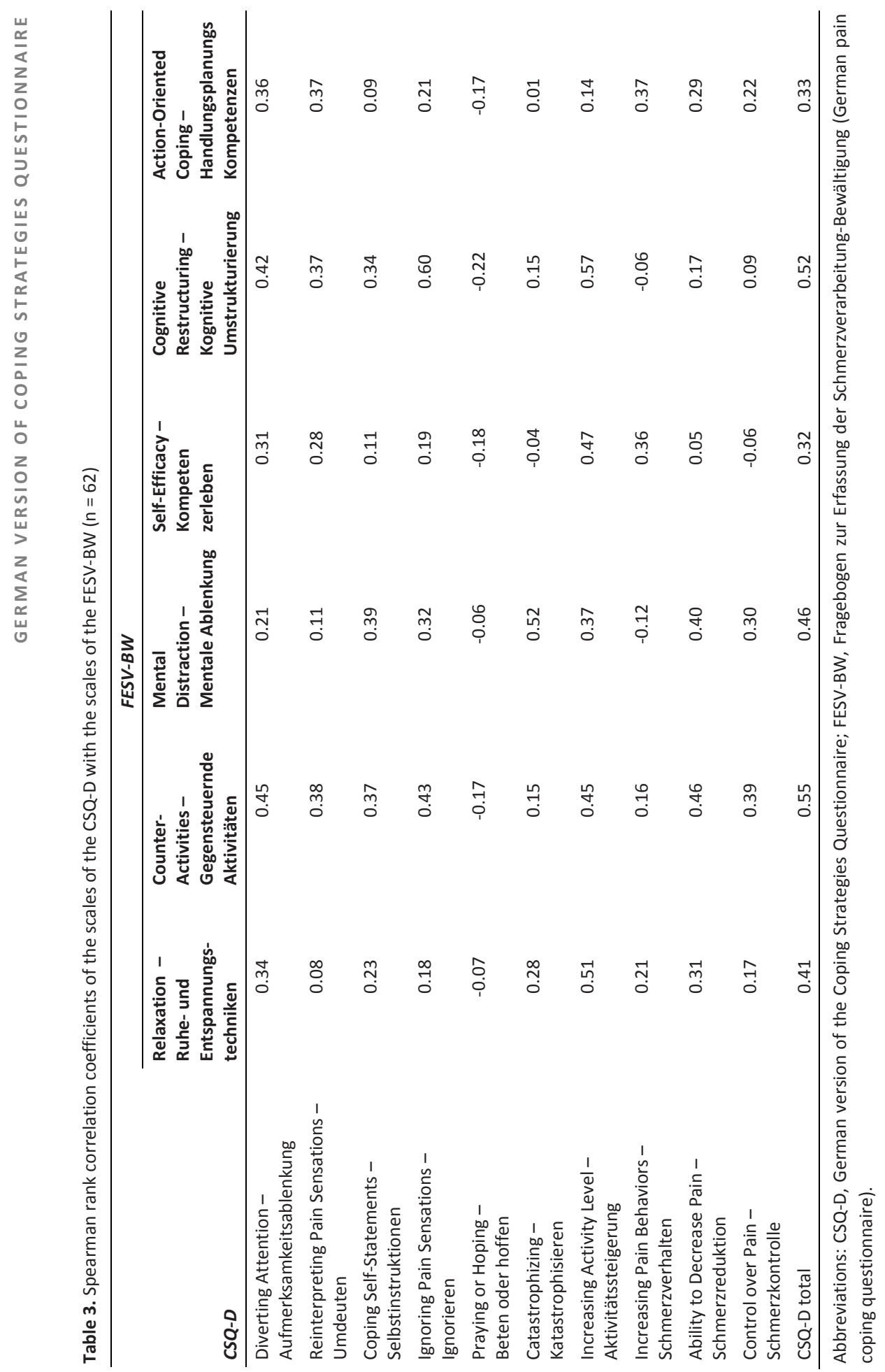




\section{Construct validity}

Construct validity was measured by comparing the responses of the scales of the CSQ-D with the responses of the scales of the SF-36 (Table 4). The total CSQ-D correlated to the MCS subscale of the SF-36 with a score of $r=0.53$ and to the SF-36 mental health scales with scores between $r=0.32$ and $r=0.53$. The total CSQ-D correlated to the PCS subscale of the SF-36 with a score of $r=0.15$ and correlated to the SF-36 physical health scales with scores between $r=0.22$ and $r=0.35$.

Table 4. Spearman rank correlation coefficients of the scales of the CSQ-D with the scales of the SF-36 ( $n=$ 62)

\begin{tabular}{lcccccccccc}
\hline SF-36 & $\begin{array}{l}\text { Physical } \\
\text { CSQ-D }\end{array}$ & $\begin{array}{c}\text { Role } \\
\text { Functioning }\end{array}$ & $\begin{array}{l}\text { Physical } \\
\text { Pain }\end{array}$ & $\begin{array}{l}\text { General } \\
\text { Health }\end{array}$ & $\begin{array}{l}\text { Sitality } \\
\text { Punctioning }\end{array}$ & $\begin{array}{l}\text { Role } \\
\text { Emotional }\end{array}$ & $\begin{array}{l}\text { Mental } \\
\text { Health }\end{array}$ & $\begin{array}{l}\text { PCS } \\
\text { PCS }\end{array}$ \\
\hline Diverting Attention & 0.12 & 0.17 & 0.05 & 0.11 & 0.22 & 0.27 & 0.11 & 0.31 & 0.05 & 0.27 \\
Reinterpreting Pain & 0.02 & 0.15 & 0.08 & -0.10 & 0.12 & 0.01 & 0.10 & 0.09 & 0.01 & 0.09 \\
Self-Statements & 0.19 & 0.16 & 0.30 & 0.13 & 0.34 & 0.40 & -0.02 & 0.29 & 0.20 & 0.23 \\
Ignoring Pain & 0.07 & 0.19 & 0.06 & 0.06 & 0.36 & 0.26 & 0.14 & 0.31 & 0.00 & 0.32 \\
Praying or Hoping & 0.15 & 0.22 & 0.25 & 0.06 & 0.19 & 0.07 & 0.26 & 0.12 & 0.13 & 0.17 \\
Catastrophizing & 0.28 & 0.31 & 0.21 & 0.49 & 0.46 & 0.45 & 0.30 & 0.58 & 0.19 & 0.53 \\
Activity Level & 0.31 & 0.28 & 0.24 & 0.20 & 0.50 & 0.38 & 0.21 & 0.38 & 0.22 & 0.38 \\
Pain Behaviors & -0.17 & -0.20 & -0.21 & -0.18 & -0.17 & -0.06 & 0.05 & -0.02 & -0.31 & 0.04 \\
Decrease Pain & 0.31 & 0.15 & 0.18 & 0.17 & 0.29 & 0.26 & 0.23 & 0.30 & 0.16 & 0.29 \\
Control over Pain & 0.06 & 0.01 & -0.05 & 0.17 & 0.21 & 0.12 & 0.10 & 0.18 & -0.02 & 0.19 \\
CSQ-D total & 0.27 & 0.35 & 0.27 & 0.22 & 0.53 & 0.44 & 0.32 & 0.53 & 0.15 & 0.53 \\
\hline
\end{tabular}

Abbreviations: CSQ-D, German version of the Coping Strategies Questionnaire; SF-36, Short Form 36, German version.

The CSQ-D scales' correlations to the global effectiveness rating item 49 (Control over Pain) was poor to moderate (reflecting the known groups method): $r=-0.13$ (Praying and Hoping); $r=0.13$ (Increasing Pain Behaviors); $r=0.28$ (Reinterpreting Pain Sensations); $r=0.32$ (Ignoring Pain Sensations); $r=0.34$ (Increasing Activity Level); $r=0.39$ (Catastrophizing); $r=0.40$ (Coping Self-Statements); and $r=0.43$ (Diverting Attention).

\section{Confirmatory factor analysis}

Factor analysis revealed that 5 out of 10 CSQ-D scales, together with the CSQ-D total score, loaded on 1 factor (together with Counter-Activities of the FESV-BW) which was the strongest and explained most of the variance (31\%). The other 5 scales loaded on further factors, independent of the FESV-BW and the SF-36 (Table 5). 
Table 5. Results of the varimax-rotated confirmatory factor analysis of the scales of the CSQ-D, SF-36 and the FESV-BW $(n=62)$

\begin{tabular}{|c|c|c|c|c|c|c|c|}
\hline \multirow[b]{3}{*}{ Instr. } & \multirow[b]{3}{*}{ Scale } & Factor 1 & Factor 2 & Factor 3 & Factor 4 & Factor 5 & Factor 6 \\
\hline & & \multicolumn{6}{|c|}{ Explained variance } \\
\hline & & $31.0 \%$ & $15.0 \%$ & $8.2 \%$ & $6.2 \%$ & $5.9 \%$ & $5.1 \%$ \\
\hline CSQ-D & Ignoring Pain Sensations & 0.86 & -0.05 & 0.19 & 0.02 & 0.06 & 0.08 \\
\hline CSQ-D & Total & 0.83 & 0.13 & 0.25 & 0.21 & 0.15 & 0.18 \\
\hline CSQ-D & Reinterpreting Pain Sensations & 0.76 & 0.05 & -0.16 & 0.03 & 0.15 & -0.05 \\
\hline CSQ-D & Diverting Attention & 0.68 & 0.02 & 0.20 & 0.21 & -0.01 & 0.24 \\
\hline CSQ-D & Increasing Activity Level & 0.66 & 0.14 & 0.18 & 0.51 & 0.08 & 0.07 \\
\hline CSQ-D & Coping Self-Statements & 0.64 & 0.24 & 0.26 & -0.04 & -0.16 & 0.04 \\
\hline FESV-BW & Counter-Activities & 0.61 & 0.06 & -0.08 & 0.29 & -0.03 & 0.00 \\
\hline SF-36 & Physical Component Summary & 0.02 & 0.90 & -0.01 & 0.10 & -0.12 & 0.01 \\
\hline SF-36 & Bodily Pain & 0.12 & 0.83 & 0.24 & 0.03 & -0.06 & -0.07 \\
\hline SF-36 & Physical Functioning & -0.01 & 0.81 & 0.19 & 0.15 & 0.36 & 0.10 \\
\hline SF-36 & Social Functioning & 0.16 & 0.32 & 0.84 & 0.09 & 0.01 & 0.06 \\
\hline SF-36 & Mental Health & 0.16 & 0.12 & 0.74 & 0.08 & 0.42 & 0.06 \\
\hline SF-36 & Mental Component Summary & 0.18 & 0.00 & 0.72 & 0.08 & 0.60 & 0.08 \\
\hline SF-36 & Vitality & 0.27 & 0.41 & 0.50 & 0.21 & 0.20 & 0.16 \\
\hline FESV-BW & Mental Distraction & 0.20 & 0.06 & -0.02 & 0.85 & 0.02 & -0.12 \\
\hline FESV-BW & Action-Oriented Coping & 0.07 & 0.19 & 0.23 & 0.76 & 0.03 & 0.16 \\
\hline SF-36 & Role Emotional & 0.08 & 0.06 & 0.25 & 0.03 & 0.89 & 0.05 \\
\hline CSQ-D & Ability to Decrease Pain & 0.08 & -0.08 & 0.11 & 0.00 & -0.01 & 0.94 \\
\hline CSQ-D & Control over Pain & 0.26 & 0.25 & 0.00 & 0.03 & 0.20 & 0.69 \\
\hline
\end{tabular}

Abbreviations: Instr., instrument; CSQ-D, German version of the Coping Strategies Questionnaire; SF-36, Short Form 36, German version; FESV-BW, Fragebogen zur Erfassung der Schmerzverarbeitung-Bewältigung (German Pain Coping Questionnaire).

\section{Discussion}

In this study, we were able to develop a precise translation and cross-cultural adaptation of the original CSQ. Testing it on 62 patients with chronic musculoskeletal pain demonstrated that the German version of the CSQ is highly reliable in a set of patient data which were well distributed over the possible scale range. It can be recommended for use in trials with German-speaking patients or large multicenter multinational trials to assess chronic pain coping strategies. Its concurrent criterion-related validity and construct validity are acceptable in some scales, but factor analysis showed that the German Pain Coping Questionnaire (FESV-BW) was inappropriate to serve as the socalled "gold standard" for the validation analysis. For that reason, the CSQ-D may not automatically replace other measures of chronic pain coping strategies, such as the FESV-BW, which only exists in German. Rigorously interpreted, this is the main reason why the validation of the CSQ-D failed. The Catastrophizing subscale was one of the few 
subscales for which there was moderate evidence of construct validity. Catastrophizing, however, shows a much stronger correlation with pain-related anxiety and more closely reflects appraisal processes than a coping strategy per se [38]. In addition, the global effectiveness rating by item 49 (Control over Pain) showed low to only moderate correlations to all 8 scales.

Most of the CSQ-D scales showed almost equal agreement between the test and retest ratings compared to the original CSQ and slightly higher agreement in comparison to the Swedish CSQ (Table 6) [5, 6, 39]. The ICCS and Pearson product-moment correlation coefficients for the Control over Pain were better in all 3 versions (original American: $r=0.81$; Swedish version, 5-week interval: ICC $=0.63$; CSQ-D: ICC $=0.82$ ) than those for the Ability to Decrease Pain (original American: $r=0.75$; Swedish version, 5-week interval: ICC $=0.29$; CSQ-D: ICC $=0.55$ ). Within pain management settings, emphasis is placed on maintaining function and coping with pain rather than on reducing pain, which, in many cases, may be unrealistic [15]. For this reason, because patients may not be able to decrease their pain but may increase their functional level and cope better, the better reliability score for the Control over Pain has more clinical relevance than the Ability to Decrease Pain.

Table 6. Comparison of reliability data

\begin{tabular}{lll}
\hline & $\begin{array}{l}\text { CA coefficients } \\
\text { of the subscales }\end{array}$ & $\begin{array}{l}\text { ICCs** or Pearson product-moment } \\
\text { correlation coefficients* of test-retest } \\
\text { data of the subscales }\end{array}$ \\
\hline Original CSQ [5] & $0.71-0.85(n=61)$ & $0.68-0.93(n=120)^{*}$ \\
Swedish Version of CSQ [39] & $0.69-0.84(n=282)$ & $0.42-0.82(n=22)^{* *}$ \\
German Version of CSQ & $0.71-0.97(n=62)$ & $0.55-0.93(n=22)^{* *}$ \\
\hline
\end{tabular}

Abbreviations: CSQ, Coping Strategies Questionnaire; CA, Cronbach's alpha coefficient; ICC, intraclass correlation coefficient.

This means that the CSQ-D is at least as appropriate as the original and the Swedish version in these measurement properties. This is a precondition to pooling results from different rehabilitation clinics (e.g. for reviews) and different patient samples (e.g. fibromyalgia and chronic low back pain) across different cultures and languages. This increases knowledge of the outcomes or rehabilitation programmes and of "who benefits from what" [40].

To our knowledge, there are no validity studies that compare the original CSQ with the SF-36. Snow-Turek et al. found correlation coefficients (unspecified) of $r=0.56-0.71$ for the CSQ and the Vanderbilt Pain Management Inventory, differentiating active and passive coping domains [7]. In a report by Tan et al. [8], only Catastrophizing showed a moderate correlation with depression $(r=0.58)$. All other correlations between the scales of the CSQ and pain, disability and depression were equal to or lower than $r=$ 0.32. An attempt to validate a questionnaire on pain sensations and coping (Pain Beliefs 
and Perceptions Inventory) with the CSQ failed, probably owing to different constructs [41].

All these validation studies demonstrate the difficulties in conceptualizing important dimensions of coping $[7,8,31,41]$. This supports the difficulties we experienced in finding the optimal German pain coping instrument to validate the CSQ-D.

A limitation of the study was that the patient sample was somewhat heterogeneous, consisting of various diagnoses leading to chronic pain syndromes. This is a possible source of variance that may complicate the analysis, but the reliability and the validity analyses compared scores for the same patient, which is not affected by the heterogeneity of the sample.

The CSQ-D proved to be qualified for further clinimetric testing, especially for validity. For any longitudinal use of the CSQ-D, it will be necessary to determine the sensitivity to change (responsiveness) and the smallest detectable difference, a further important quality aspect of an instrument in the clinical and research assessment [34]. Furthermore, decisions on possible item and/or scale reduction to obtain a shorter version should be taken on the basis of longitudinal validation studies and further factor analysis. However, testing of the original CSQ revealed that factor solutions are highly dependent of the patient setting under investigation.

\section{Authors' contributions}

MLV and FA developed the protocol. MLV implemented and directed the study. FA did 1 translation and carried out the main statistical analysis. MLV collected and entered the data. In several steps and in cooperation with FA, MLV revised and completed the first drafts of the paper. MLV wrote the main part of the final draft. SL helped with the setup of databases and the layout of the questionnaire. AA helped with the interpretation of the data and the final draft.

\section{Acknowledgements}

We wish to thank Professor Ursula Luka-Krausgrill, PhD (Mainz University, Germany), for helpful suggestions during the translation process of the German version. We are also grateful to the members of the expert committee (the translators Joy Buchanan, Ruth Henderson and Annemarie Koller and Dr. Renato Meier, Dr. Francoise Gysi, Dr. Miriam Schirmer, and Hugo Stam, MAppSc, PT, of RehaClinic Zurzach, Switzerland). We also wish to thank Professor Francis J. Keefe, PhD (Duke University Medical Center, Durham, NC), for his appraisal of the adaptation process. 


\section{Conclusions}

This paper presents the German Version of the CSQ, together with the results of clinimetric testing. The CSQ-D is a feasible and reliable outcome measure to be used in trials with German-speaking patients or large multicenter multinational trials to assess pain coping strategies in patients with chronic musculoskeletal pain. 


\section{Appendix A. German version of the CSQ}

\section{Fragebogen zur Schmerzbewältigung: CSQ-D}

Anweisung:

Personen mit Schmerzen haben eine Vielzahl von Methoden entwickelt, mit ihren Schmerzen fertig zu werden oder mit ihnen umzugehen. Es folgt eine Liste mit Beispielen der Schmerzbewältigung von befragten Patienten. Bitte beurteilen Sie. was Sie machen wenn Sie Schmerzen haben. Bei jedem Beispiel umkreisen Sie die für Sie zutreffende Zahl. Dazu benutzen Sie bitte die Skala 0-6.

Eine 0 bedeutet: ich mache das nie. wenn ich Schmerzen empfinde.

Eine 3 bedeutet: ich mache das manchmal, wenn ich Schmerzen empfinde.

Eine 6 bedeutet: ich mache das immer, wenn ich Schmerzen empfinde.

Beachten Sie. dass Sie irgendeine für Sie zutreffende Zahl in der Skala umkreisen können.

\section{Wenn ich Schmerzen habe:}

1. Ich versuche, Abstand von den Schmerzen zu gewinnen, fast so, als ob die Schmerzen im Körper einer anderen Person wären.

2. Ich gehe aus dem Haus und unternehme etwas, wie z.B. ins Kino oder einkaufen gehen.

3. Ich versuche, an etwas Angenehmes zu denken.

4. Ich stelle inn mir nicht als Schmerz vor, sondern eher als dumpfes oder warmes Gefühl.

5. Es ist schrecklich und ich habe das Gefühl, es wird nie besser.

6. Ich sage mir, dass ich tapfer sein muss, obwohl ich Schmerzen habe.

7. Ich lese.

8. Ich sage mir, dass ich den Schmerz bezwingen kann.

9. Ich nehme meine Medikamente ein.

10. Ich zähle in Gedanken oder denke an ein Lied.

11. Ich stelle mir den Schmerz als anderes Gefühl vor, z.B. als Taubheit.

12. Es ist schrecklich und ich habe das Gefühl, dass der Schmerz mich überwältigt.

13. Ich mache Gedankenspiele, damit ich nicht an den Schmerz denke.

14. Ich habe das Gefühl, dass mein Leben nicht mehr lebenswert ist.

15. Ich weiss, eines Tages wird mir jemand helfen, und der Schmerz wird für eine Weile weggehen.

16. Ich spaziere viel.

17. Ich bete zu Gott, dass der Schmerz nicht lange anhält. 
18. Ich versuche mir vorzustellen, dass der Schmerz nicht zu meinem Körper gehört, sondern eher ausserhalb von mir ist.

19. Ich entspanne mich.

20. Ich denke nicht an den Schmerz.

21. Ich versuche, an die kommenden Jahre zu denken und wie alles sein wird, wenn ich den Schmerz losgeworden bin.

22. Ich sage mir, dass es nicht weh tut.

23. Ich sage mir, ich darf nicht zulassen, dass mir der Schmerz, bei dem, was ich zu tun habe, im Wege steht.

24. Ich beachte den Schmerz nicht.

25. Ich habe Vertrauen in die Ärzte, dass meine Schmerzen eines Tages geheilt werden.

26. Egal wie schlimm die Schmerzen werden, ich weiss, wie ich damit umgehe.

27. Ich tue so, als ob der Schmerz nicht da wäre.

28. Ich mache mir Sorgen, ob der Schmerz jemals aufhören wird.

29. Ich lege mich hin.

30. Ich denke an schöne Erlebnisse zurück.

31. Ich denke an Leute, mit denen ich gerne etwas unternehme.

32. Ich bete, damit der Schmerz aufhört.

33. Ich dusche oder nehme ein Bad.

34. Ich stelle mir vor, dass der Schmerz ausserhalb meines Körpers ist.

35. Ich mache weiter, als ob nichts geschehen wäre.

36. Ich sehe den Schmerz als Herausforderung und lasse nicht zu, dass er mich stört.

37. Obwohl es weh tut, mache ich einfach weiter.

38. Ich habe das Gefühl, dass ich den Schmerz nicht mehr aushalten kann.

39. Ich versuche unter die Leute zu gehen.

40. Ich ignoriere den Schmerz.

41. Ich verlasse mich auf meinen Glauben an Gott.

42. Ich habe das Gefühl, dass ich kann nicht mehr kann.

43. Ich denke an Dinge, die ich gerne mache.

44. Ich mache alles, um mich vom Schmerz abzulenken.

45. Ich mache etwas Erfreuliches, wie z.B. fernsehen oder Musik hören.

46. Ich stelle mir vor, dass der Schmerz kein Teil von mir ist.

47. Ich mache etwas Aktives, wie z.B. Haushaltarbeiten oder andere Alltagstätigkeiten.

48. Ich benutze ein Heizkissen.

\section{Aufgrund all Ihrer Methoden, mit dem Schmerz umzugehen oder damit fertig zu werden:}

49. Wie viel Kontrolle haben Sie an einem durchschnittlichen Tag über Ihre Schmerzen? Keine Kontrolle 
Durchschnittliche Kontrolle

Vollständige Kontrolle

50. Wie stark können Sie den Schmerz an einem durchschnittlichen Tag reduzieren?

Gar nicht

Mittel

Vollständig

Zuordnung der Items zu den Subskalen:

\begin{tabular}{ll}
\hline Aufmerksamkeitsablenkung & $3,10,13,30,31,43$ \\
Umdeuten & $1,4,11,18,34,46$ \\
Selbstinstruktionen & $6,8,23,26,36,37$ \\
Ignorieren & $20,22,24,27,35,40$ \\
Beten oder hoffen & $15,17,21,25,32,41$ \\
Katastrophisieren & $5,12,14,28,38,42$ \\
Aktivitätssteigerung & $2,7,39,44,45,47$ \\
Schmerzverhalten & $9,16,19,29,33,48$ \\
Schmerzkontrolle & 49 \\
Schmerzreduktion & 50
\end{tabular}




\section{References}

1. Jensen MP, Turner JA, Romano JM, Karoly P: Coping with chronic pain: a critical review of the literature. Pain 1991, 47(3):249-283.

2. Morley S, Eccleston C, Williams A: Systematic review and meta-analysis of randomized controlled trials of cognitive behavior therapy and behavior therapy for chronic pain in adults, excluding headache. Pain 1999, 80(1-2):1-13.

3. van Tulder MW, Ostelo RW, Vlaeyen JW, Linton SJ, Morley S, Assendelft WJ: Behavioral treatment for chronic low-back pain. Cochrane database of systematic reviews 2004(1):CD002004.

4. Airaksinen O, Brox JI, Cedraschi C, Hildebrandt J, Klaber-Moffett J, Kovacs F, Mannion AF, Reis S, Staal JB, Ursin $\mathrm{H}$ et al: Chapter 4. European guidelines for the management of chronic nonspecific low back pain. European spine journal : official publication of the European Spine Society, the European Spinal Deformity Society, and the European Section of the Cervical Spine Research Society 2006, 15 Suppl 2:S192-300.

5. Rosenstiel AK, Keefe FJ: The use of coping strategies in chronic low back pain patients: relationship to patient characteristics and current adjustment. Pain 1983, 17(1):33-44.

6. Main CJ, Waddell G: A comparison of cognitive measures in low back pain: statistical structure and clinical validity at initial assessment. Pain 1991, 46(3):287-298.

7. Snow-Turek AL, Norris MP, Tan G: Active and passive coping strategies in chronic pain patients. Pain 1996, 64(3):455-462.

8. Tan G, Jensen MP, Robinson-Whelen S, Thornby JI, Monga TN: Coping with chronic pain: a comparison of two measures. Pain 2001, 90(1-2):127-133.

9. Burton $A K$, McClune TD, Clarke RD, Main CJ: Long-term follow-up of patients with low back pain attending for manipulative care: outcomes and predictors. Manual therapy 2004, 9(1):30-35.

10. Burton AK, Tillotson KM, Main CJ, Hollis S: Psychosocial predictors of outcome in acute and subchronic low back trouble. Spine 1995, 20(6):722-728.

11. Soderlund A, Lindberg P: Whiplash-associated disorders--predicting disability from a process-oriented perspective of coping. Clinical rehabilitation 2003, 17(1):101-107.

12. Spinhoven P, Ter Kuile M, Kole-Snijders AM, Hutten Mansfeld M, Den Ouden DJ, Vlaeyen JW: Catastrophizing and internal pain control as mediators of outcome in the multidisciplinary treatment of chronic low back pain. European journal of pain 2004, 8(3):211-219.

13. Vlaeyen JW, Linton SJ: Fear-avoidance and its consequences in chronic musculoskeletal pain: a state of the art. Pain 2000, 85(3):317-332.

14. Woby SR, Watson PJ, Roach NK, Urmston M: Are changes in fear-avoidance beliefs, catastrophizing, and appraisals of control, predictive of changes in chronic low back pain and disability? European journal of pain 2004, 8(3):201-210.

15. Harland NJ, Georgieff K: Development of the Coping Strategies Questionnaire 24, a clinically utilitarian version of the Coping Strategies Questionnaire. Rehabil Psychol 2003, 48(4):296-300.

16. Riley JL, 3rd, Robinson ME, Geisser ME: Empirical subgroups of the Coping Strategies QuestionnaireRevised: a multisample study. The Clinical journal of pain 1999, 15(2):111-116.

17. Riley JL, 3rd, Robinson ME: CSQ: five factors or fiction? The Clinical journal of pain 1997, 13(2):156-162.

18. Robinson ME, Riley JL, 3rd, Myers CD, Sadler IJ, Kvaal SA, Geisser ME, Keefe FJ: The Coping Strategies Questionnaire: a large sample, item level factor analysis. The Clinical journal of pain 1997, 13(1):43-49.

19. Swartzman LC, Gwadry FG, Shapiro AP, Teasell RW: The factor structure of the Coping Strategies Questionnaire. Pain 1994, 57(3):311-316.

20. Flor H, Behle DJ, Birbaumer N: Assessment of pain-related cognitions in chronic pain patients. Behavior research and therapy 1993, 31(1):63-73.

21. Flor H: Anhang: Fragebögen. In: Psychobiologie des Schmerzes. first edn. Bern, Göttingen, Toronto: Verlag Hans Huber 1991: 274-275. 
22. Geissner E: FESV: Fragebogen zur Erfassung der Schmerzverarbeitung (Manual). Göttingen: Hogrefe; 2001.

23. Hasenbring M: Kieler Schmerz-Inventar (KSI): Handanweisung (manual). Bern: Verlag Hans Huber; 1994.

24. Dworkin RH, Turk DC, Farrar JT, Haythornthwaite JA, Jensen MP, Katz NP, Kerns RD, Stucki G, Allen RR, Bellamy $\mathrm{N}$ et al: Core outcome measures for chronic pain clinical trials: IMMPACT recommendations. Pain 2005, 113(1-2):9-19.

25. de Vet HC, Terwee CB, Bouter LM: Current challenges in clinimetrics. Journal of clinical epidemiology 2003, 56(12):1137-1141.

26. Luka-Krausgrill U, Wurmthaler C, Becker T: Die Beziehung zwischen Schmerzbewältigung, Beeinträchtigung und Depression bei chronischem Schmerz. In: Psychotherapeutische Medizin bei chronischem Schmerz: psychologische Behandlungsverfahren zur Schmerzkontrolle. Edited by Wahl R, Hautzinger M. Köln: Deutscher Ärzte-Verlag; 1994: 175-189.

27. Luka-Krausgrill U: Chronischer Schmerz und Depression: Untersuchungen zur Auftretenshäufigkeit und Bedeutung biopsychologischer Faktoren. postdoctural. Mainz: Johannes Gutenberg University 1995.

28. Donner A, Eliasziw M: Sample size requirements for reliability studies. Statistics in medicine 1987, 6(4):441-448.

29. Beaton DE, Bombardier C, Guillemin F, Ferraz MB: Guidelines for the process of cross-cultural adaptation of self-report measures. Spine 2000, 25(24):3186-3191.

30. Collins D: Pretesting survey instruments: an overview of cognitive methods. Quality of life research : an international journal of quality of life aspects of treatment, care and rehabilitation 2003, 12(3):229-238.

31. Geissner E: Verarbeitung chronischer Schmerzen - Skalen zur Erfassung der Schmerzbewältigung und der schmerzbedingten psychischen Beeinträchtigung. Zeitschrift für Klinische Psychologie und Psychotherapie 1999, 28(4):280-290.

32. Ware JE, Jr., Sherbourne CD: The MOS 36-item short-form health survey (SF-36). I. Conceptual framework and item selection. Medical care 1992, 30(6):473-483.

33. Bullinger M, Kirchberger I: SF-36 Fragebogen zum Gesundheitszustand - Handanweisung, 1998 edn. Göttingen: Hogrefe; 1998.

34. Portney LG, Watkins MP: Statistical measures of reliability. In: Foundations of clinical research: applications to practice. Second edn. Upper Saddle River, NJ: Prentice Hall Health; 2000: 557-586.

35. Tinsley HEA, Weiss DJ: Interrater reliability and agreement of subjective judgements. J Counsel Psychol 1975, 22:358-376.

36. Cronbach LJ: Coefficient alpha and the internal structure of tests. Psychometrika 1951, 16(3):297-334.

37. Streiner DL, Norman GR: Reliability. In., Second edn. New York: Oxford University Press Inc; 1995: 144162.

38. McCracken LM, Gross RT: Does anxiety affect coping with chronic pain? The Clinical journal of pain 1993, 9(4):253-259.

39. Jensen IB, Linton SJ: Coping Strategies Questionnaire: reliability of the Swedish version of the CSQ. Scand J Behav Ther 1994, 22(8):129-137.

40. Ljungquist T, Nygren A, Jensen I, Harms-Ringdahl K: Physical performance tests for people with spinal pain-sensitivity to change. Disability and rehabilitation 2003, 25(15):856-866.

41. Morley S, Wilkinson L: The Pain Beliefs and Perceptions Inventory: a British replication. Pain 1995, 61(3):427-433. 



\section{CHAPTER 3}

\section{Reliability of the Multidimensional Pain Inventory and stability of the MPI Classification System in chronic back pain}

Verra ML, Angst F, Staal JB, Brioschi R, Lehmann S, Aeschlimann A, de Bie RA.

Reliability of the Multidimensional Pain Inventory and stability of the MPI classification system in chronic back pain.

BMC Musculoskeletal Disorders 2012;13:155. 


\section{Abstract}

Objectives. This cross validation study examined the reliability of the Multidimensional Pain Inventory (MPI) and the stability of the Multidimensional Pain Inventory Classification System of the empirically derived subgroup classification obtained by cluster analysis in chronic musculoskeletal pain. Reliability of the German Multidimensional Pain Inventory was only examined once in the past in a small sample. Previous international studies mainly involving fibromyalgia patients showed that retest resulted in $33-38 \%$ of patients being assigned to a different Multidimensional Pain Inventory subgroup classification.

Methods. Participants were 204 persons with chronic musculoskeletal pain (82\% chronic non-specific back pain). Subgroup classification was conducted by cluster analysis at 4 weeks before entry (= test) and at entry into the pain management program (= retest) using Multidimensional Pain Inventory scale scores. No therapeutic interventions in this period were conducted. Reliability was quantified by intraclass correlation coefficients (ICC) and stability by kappa coefficients ( $\mathrm{k}$ ).

Results. Reliability of the Multidimensional Pain Inventory scales was least with ICC $=0.57$ for the scale life control and further ranged from ICC $=0.72$ (negative mood) to 0.87 (solicitous responses) in the other scales. At retest, $82 \%$ of the patients in the Multidimensional Pain Inventory cluster interpersonally distressed ( $\mathrm{k}=0.69$ ), $80 \%$ of the adaptive copers $(\kappa=0.58)$, and $75 \%$ of the dysfunctional patients $(\kappa=0.70)$ did not change classification. In total, $22 \%$ of the patients changed Multidimensional Pain Inventory cluster group, mainly into the adaptive copers subgroup.

Conclusions. Test-retest reliability of the German Multidimensional Pain Inventory was moderate to good and comparable to other language versions. Multidimensional Pain Inventory subgroup classification is substantially stable in chronic back pain patients when compared to other diagnostic groups and other examiner-based subgroup classification systems. The MPI Classification System can be recommended for reliable and stable specification of subgroups in observational and interventional studies in patients with chronic musculoskeletal pain. 


\section{Background}

The search for homogeneous subgroups of patients with nonspecific low back pain who respond best to subgroup-specific pain management interventions has been on the international research agenda for over 15 years [1]. The process of developing treatment-based subgroups can be divided into 3 stages: 1) hypothesis generation; proposal of potential effect modifiers; 2 ) hypothesis testing; testing of the potential effect modifiers; 3) replication; assessing generalizability [2]. Several physiotherapy-based classification systems for low back pain have been developed [3, 4]. So far, most subgrouping approaches have been based on unproven theories, are poorly validated or remain, as yet, unreplicated in other studies [5]. Besides biological factors of low back pain and spinal movement or mechanical loading strategies, especially in chronic pain syndromes psychosocial factors are also likely to modify treatment response. As such, investigation of effect modifiers from the full biopsychosocial spectrum seems the most likely way to identify clinically important subgroups [6].

The Multidimensional Pain Inventory is a self-report instrument assessing not only pain intensity and pain interference, but also the way people cope with pain, it measures support as well as potential reinforcement of pain behaviors by the patient's significant other, and peoples' general activity level. The Multidimensional Pain Inventory has been translated into several languages and validated in various settings for several diagnostic pain groups [7, 8]. The reliability of the German version of the Multidimensional Pain Inventory has been tested in a relatively small sample by only one research group for over 20 years [9]. An approach based on cluster analysis of the mean scores of the scales of the Multidimensional Pain Inventory yielded three unique profiles or subgroups for patients with chronic pain [10]. So far, two research groups assessed test-retest stability of the MPI Classification System [11-13]. In their samples of patients with low back pain and fibromyalgia up to one third of the patients changed Multidimensional Pain Inventory classification at retest. The authors concluded that for a sizeable number of chronic pain patients, Multidimensional Pain Inventory subgroup classifications may not be stable and need to be reconsidered $[11,13]$.

The main aim of the present study was to re-examine the test-retest stability of the MPI Taxonomy Classification in patients with persistent musculoskeletal pain. The secondary objective focussed on the elaboration of additional evidence concerning internal consistency of items within scales and test-retest reliability at scale level of the German version of the Multidimensional Pain Inventory. 


\section{Methods}

\section{Setting and participants}

The study was conducted at the rehabilitation clinic "RehaClinic" (locations Bad Zurzach and Braunwald, Switzerland), which is attended by severely disabled patients suffering from persistent musculoskeletal pain. The patients were assessed prior to participating in the "Zurzach Interdisciplinary Pain Program" - ZISP. The program is a 4-week inhouse, standardized, interdisciplinary pain management program. All subjects were consecutively admitted and included in the study and 1) suffered either from chronic non-specific back pain (i.e. lumbar, thoracic, or pan-vertebral pain syndrome without serious spinal pathology or nerve root pain) or suffered from fibromyalgia according to the original American College of Rheumatology criteria, 2) had pain for at least 6 months and 3) were disabled by their pain enough to warrant admission to an intensive inpatient pain management program [14, 15]. Further inclusion criteria were 4) ability to complete self-assessment questionnaires, 5) understand the German language, 6) no psycho-intellectual inabilities, and 7) provision of written, signed informed consent. Exclusion criteria were 1) severe somatic illness requiring specific treatment such as cancer, inflammatory rheumatic disease, neurological disease, and pain after a recent operation, 2) manifest psychiatric disorder such as dementia, psychosis, suicidality, and 3) failed inclusion criteria.

The study design is a cohort study with 4 weeks follow-up. The study protocol was approved by the Local Ethic Commission (Health Department in Aarau, Switzerland, no. EK AG 2008/026). All participants gave written informed consent according to the Declaration of Helsinki.

\section{Outcome measures}

The West Haven-Yale Multidimensional Pain Inventory (MPI) measures multiple aspects of the individual pain experience and comprises three sections with a total of 13 factors analytically derived from scales based on items ranging from 0 to 6 (seven points) [16]. The factor structure has been replicated in several international samples. Kerns and colleagues reported excellent validity, internal consistency, and reliability of this instrument [16]. Results of a study by Junghaenel and Broderick revealed that Multidimensional Pain Inventory ratings obtained from the partner or health care provider corresponded with the self-report patient profiles [12]. The Initiative on Methods, Measurement, and Pain Assessment in Clinical Trials (IMMPACT) recommended the Multidimensional Pain Inventory as a valuable component of a comprehensive assessment tool [17]. The German version of the Multidimensional Pain Inventory is a selfreport 51-item inventory with the same eleven scales as the original US version: pain severity, interference due to pain, life control, affective distress (synonymously de- 
scribed as negative mood), support, punishing responses, solicitous responses, distracting responses, social and recreational activities, household chores, and activities away from home [18]. The last three subscales can be summarized into one subscale of general activities. Cronbach's alpha reliability coefficients vary between $\alpha=0.63-0.93$, and test-retest reliability scores ranged from $r_{p}=0.46-0.93$ [9]. Comparing 5 assessment instruments for chronic pain, the Multidimensional Pain Inventory was most responsive in all comparable domains [19].

An approach based on cluster analysis of the mean scores of the scales of the Multidimensional Pain Inventory yielded three unique profiles or subgroups for patients with chronic pain. The Multidimensional Pain Inventory differentiates between three subgroups labelled as adaptive copers, dysfunctional, and interpersonally distressed [10]. The interpersonally distressed cluster is mainly characterized by lower levels of perceived solicitous and distraction responses from the patients' partners or spouses and higher levels of punishing responses compared to the adaptive copers and dysfunctional clusters. The adaptive copers cluster, compared with the other two subgroups, is characterized by less pain severity, less interference with everyday life due to pain and less affective distress, more perception of life control and higher activity level. The persons of the dysfunctional cluster report high pain severity, high interference and activity distress, low life control, and low activity level.

\section{Statistical analysis}

The Multidimensional Pain Inventory was assessed 4 weeks before entry to the clinic and at entry to the clinic (pre-treatment). No therapeutic interventions took place in this period. This time interval is 1 ) sufficiently short that we can assume that the underlying process of chronic musculoskeletal pain is unlikely to have changed, and 2) sufficiently long that we can assume that the patients did not memorize their item responses of the first occasion.

The internal consistency of the Multidimensional Pain Inventory was assessed by using Cronbach's alpha, a statistic used to calculate the strength of the association between the individual items within the scale. The alpha coefficient examines interitem correlations and therefore relates to its homogeneity. Because a Cronbach's alpha $\geq 0.90$ might suggest a high level of item redundancy, ideally Cronbach's alpha should be above 0.70 , but probably not higher than 0.90 [20].

Test-retest reliability of the Multidimensional Pain Inventory scales was determined by intraclass correlation coefficients (ICC). The intraclass correlation coefficient measures the consistency and degree of correspondence of the test and retest responses pairwise for each item and each patient for the whole sample and ranges from 0.00 (no consistency) to 1.00 (perfect consistency). Although the intraclass correlation coefficient is primarily designed for use with interval or ratio data, the intraclass correlation coefficient can be applied without distortion of the data on the ordinal scale of 
the Multidimensional Pain Inventory when intervals between such measurements are assumed to be equivalent [21]. For comparability with other studies test-retest reliability of the Multidimensional Pain Inventory scales was also determined by Pearson correlation coefficients: 0.00 means no correlation and 1.00 means perfect correlation.

According to Turk and colleagues, the empirically derived subgroups were defined by confirmatory cluster analysis using a predefined three cluster solution [10]. The Multidimensional Pain Inventory score patterns of this study were depicted as graphs of the mean Multidimensional Pain Inventory baseline scale scores and compared to the patterns described by Turk and colleagues and our previous studies on this topic using the rank orders of the three subgroups within one Multidimensional Pain Inventory subscale $[22,23]$.

The test-retest stability of the Multidimensional Pain Inventory clusters was determined by percent of agreement and kappa coefficients. The kappa statistic is a chancecorrected measure of percent agreement for ordinal or nominal scales [24]. It is a useful method for summarizing observer consistency (intra- or intertester reliability) and provides valuable information on the stability of classification procedures used in musculoskeletal practice, for example. The following standards for strength of agreement for the Kappa coefficient have been proposed: $<0=$ poor, 0.00-0.20 = slight, $0.21-0.40=$ fair, $0.41-0.60=$ moderate, $0.61-0.80=$ substantial and 0.81-1.00 = almost perfect [25].

All analyses were performed using the statistical software package SPSS 20.0 for Windows ${ }^{\circledR}$ (SPSS Inc., Chicago, IL, USA).

\section{Results}

\section{Participants at baseline}

Table 1 describes the demographic and medical data of the total sample of patients with mainly chronic non-specific back pain on entry into the pain management program ( $n=204$ ). The subjects were characterized by relatively young age (on average 46.8 years), high level of incapacity for work (50.5\%), and a long history of pain (on average 10.4 years). High scores for pain intensity, interference with pain, and negative mood, and low scores for life control and general activity level complete the profile of these patients in this sample (Table 2). 
Table 1. Demographic characteristics of the sample $(n=204)$

\begin{tabular}{lc}
\hline Dimension & 82 \\
\hline Diagnosis chronic back pain (\%) & 15 \\
Diagnosis fibromyalgia (\%) & 3 \\
Diagnosis, other (\%) & $46.8 \quad(16.7-72.8)$ \\
Average age, min-max (years) & $10.4 \quad(0.25-64.5)$ \\
Average beginning of symptoms, min-max (years) & 71 \\
Sex: female (\%) & 1 \\
Education: none (\%) & 31 \\
Education: Grade 10-12 (\%) & 55 \\
Education: High school graduate (\%) & 9 \\
Education: College graduate (\%) & 4 \\
Education: University graduate (\%) & 50 \\
Employment status: inability for work (\%) & 29 \\
Employment status: full-time (\%) & 43 \\
Smoking: yes (\%) & 23 \\
Marital status: single (\%) & 66 \\
Marital status: married (\%) & 11 \\
Marital status: other (\%) &
\end{tabular}

Table 2. Test-retest reliability of mean MPI scale scores and internal consistency of the items at scale level for all subjects $(n=204)$

\begin{tabular}{|c|c|c|c|c|}
\hline MPI subscales & TO $(m \pm s)$ & $\mathrm{T} 1(\mathrm{~m} \pm \mathrm{s})$ & ICC (95\% CI) & CA $(95 \% \mathrm{CI})$ \\
\hline Pain severity (100 = most) & $76.1 \pm 16.5$ & $73.9 \pm 16.0$ & 0.77 (0.70 to 0.82 ) & 0.81 (0.77 to 0.86$)$ \\
\hline Interference (100 = worst) & $74.7 \pm 15.9$ & $72.5 \pm 16.1$ & 0.82 (0.77 to 0.86$)$ & $0.83(0.76$ to 0.86$)$ \\
\hline Life control (100 = best) & $49.4 \pm 22.1$ & $50.2 \pm 21.4$ & $0.57(0.47$ to 0.66$)$ & $0.76(0.69$ to 0.81$)$ \\
\hline Negative mood (100 = worst) & $61.0 \pm 19.6$ & $58.4 \pm 22.1$ & 0.72 (0.65 to 0.78$)$ & 0.60 (0.49 to 0.69$)$ \\
\hline Support (100 = most) & $69.4 \pm 24.8$ & $69.0 \pm 26.2$ & 0.85 (0.80 to 0.88$)$ & $0.82(0.77$ to 0.86$)$ \\
\hline Negative responses (100 = most) & $25.6 \pm 26.1$ & $24.3 \pm 24.4$ & $0.75(0.69$ to 0.81$)$ & 0.86 (0.82 to 0.89$)$ \\
\hline Solicitous responses (100 = best) & $58.3 \pm 25.0$ & $58.6 \pm 25.0$ & 0.87 (0.83 to 0.90$)$ & 0.81 (0.76 to 0.85$)$ \\
\hline Distracting responses (100 = best) & $53.6 \pm 25.3$ & $55.3 \pm 24.8$ & $0.77(0.71$ to 0.82$)$ & 0.69 (0.61 to 0.76$)$ \\
\hline General activity $(100=$ most $)$ & $34.5 \pm 13.7$ & $35.1 \pm 13.4$ & $0.86(0.82$ to 0.90$)$ & $0.82(0.78$ to 0.86$)$ \\
\hline
\end{tabular}

Abbreviations: MPI, Multidimensional Pain Inventory; CA, Cronbach's alpha; 95\% Cl, 95\% confidence interval; T0, 4 weeks before entry to pain management program; $\mathrm{T} 1$, at entry to pain management program; $\mathrm{m}$, mean; s, standard deviation; ICC, intraclass correlation coefficient.

\section{Internal consistency and test-retest reliability of the MPI scales}

Cronbach's alpha was measured for 7 out of 9 Multidimensional Pain Inventory scales with scores between 0.76 and 0.86 and so reflects a good association between the individual items within their scales. The internal consistency of the items within the scales negative mood and distracting responses was smaller $(0.60$, and 0.69 , respectively). Test-retest reliability, measured at an average 4-week time interval, for the mean 
Multidimensional Pain Inventory scale scores was very good with scores between ICC = 0.72 and 0.87 . Only the score for the MPI scale life control (ICC $=0.57$ ) was less favourable (Table 2).

\section{Classification and test-retest stability of patients in the MPI subgroups}

All 204 patients could be allocated by cluster analysis into one of the three predefined chronic pain subgroups at both time points. The Multidimensional Pain Inventory scores differed significantly between the three clusters: the patients in the dysfunctional cluster showed highest scores for pain severity, interference due to pain, and negative mood and lowest scores for general activities. In accordance with the predefined profile of the empirically derived MPI Classification System, the cluster interpersonally distressed showed lowest scores for support, solicitous and distracting responses by their partner or spouses, and the highest score for negative/ punishing responses by their partner or spouses. Compared to the other two subgroups, the adaptive copers showed best scores for life control, negative mood, and general activities (Table 3).

At retest after 4 weeks, $82 \%$ of the patients in the Multidimensional Pain Inventory cluster interpersonally distressed $(\kappa=0.69), 80 \%$ of the adaptive copers $(\kappa=0.58)$, and $75 \%$ of the dysfunctional patients $(\kappa=0.70)$ did not change classification profile (Figure 1). Over the whole sample, 159 patients (78\%) had a stable MPI subgroup classification. But, $22 \%$ of the patients $(n=45)$ did change Multidimensional Pain Inventory cluster group at retest. Most of the retest classification changes occurred in the subgroup adaptive copers: 18 dysfunctional patients (17\%) and 7 interpersonally distressed patients $(14 \%)$ were classified as adaptive copers at retest. Least retest classification changes took place in the dysfunctional subgroup (4\% of interpersonally distressed patients and $6 \%$ of the adaptive copers). 
Table 3. Mean scores and standard deviations of the scales of the MPI clusters at 4 weeks before and at entry to a pain program

\begin{tabular}{|c|c|c|c|c|c|c|}
\hline \multirow[b]{2}{*}{ MPI scales } & \multicolumn{3}{|c|}{ MPI clusters at T0 $(\mathrm{m} \pm \mathrm{s})$} & \multicolumn{3}{|c|}{ MPI clusters at T1 $(m \pm s)$} \\
\hline & ID $n=49$ & $A C n=51$ & DYS $n=104$ & ID $n=55$ & $A C n=66$ & DYS $n=83$ \\
\hline Pain severity (100 = most $)$ & $75.9 \pm 15.1$ & $63.0 \pm 17.0$ & $82.6 \pm 12.7$ & $76.4 \pm 12.1$ & $59.5 \pm 15.2$ & $83.6 \pm 9.4$ \\
\hline Interference (100 = worst) & $77.2 \pm 13.0$ & $58.9 \pm 16.4$ & $81.3 \pm 10.9$ & $76.6 \pm 11.7$ & $57.5 \pm 15.2$ & $81.7 \pm 9.7$ \\
\hline Life control (100 = best $)$ & $42.2 \pm 17.6$ & $65.2 \pm 18.2$ & $45.1 \pm 22.2$ & $42.7 \pm 19.2$ & $63.7 \pm 17.0$ & $44.4 \pm 20.9$ \\
\hline Negative mood (100 = worst $)$ & $66.3 \pm 13.6$ & $39.8 \pm 17.3$ & $68.9 \pm 15.0$ & $67.3 \pm 14.9$ & $38.0 \pm 17.3$ & $68.8 \pm 18.0$ \\
\hline Support (100 = most) & $44.0 \pm 23.5$ & $61.9 \pm 19.7$ & $85.0 \pm 13.7$ & $41.6 \pm 24.0$ & $66.9 \pm 18.5$ & $88.7 \pm 12.0$ \\
\hline Negative, punishing responses (100 = most) & $34.4 \pm 29.1$ & $11.0 \pm 13.8$ & $28.6 \pm 26.5$ & $33.0 \pm 29.2$ & $13.9 \pm 15.3$ & $26.9 \pm 24.1$ \\
\hline Solicitous responses (100 = best) & $33.3 \pm 17.1$ & $47.5 \pm 20.0$ & $75.5 \pm 15.2$ & $34.5 \pm 16.7$ & $53.0 \pm 19.0$ & $79.0 \pm 15.5$ \\
\hline Distracting responses (100 = best) & $30.5 \pm 18.7$ & $43.0 \pm 21.2$ & $69.7 \pm 17.6$ & $33.7 \pm 20.5$ & $50.5 \pm 19.4$ & $73.5 \pm 16.9$ \\
\hline General activity $(100=$ most $)$ & $34.1 \pm 12.0$ & $38.1 \pm 12.1$ & $33.0 \pm 14.9$ & $37.5 \pm 11.6$ & $38.2 \pm 12.5$ & $30.9 \pm 14.3$ \\
\hline
\end{tabular}

Abbreviations: MPI, Multidimensional Pain Inventory; ID, MPI cluster interpersonally distressed; AC, MPI cluster adaptive copers; DYS, MPI cluster dysfunctional; T0, 4 weeks before entry to pain management program; 1 1, at entry to pain management program; m, mean; s, standard deviation.

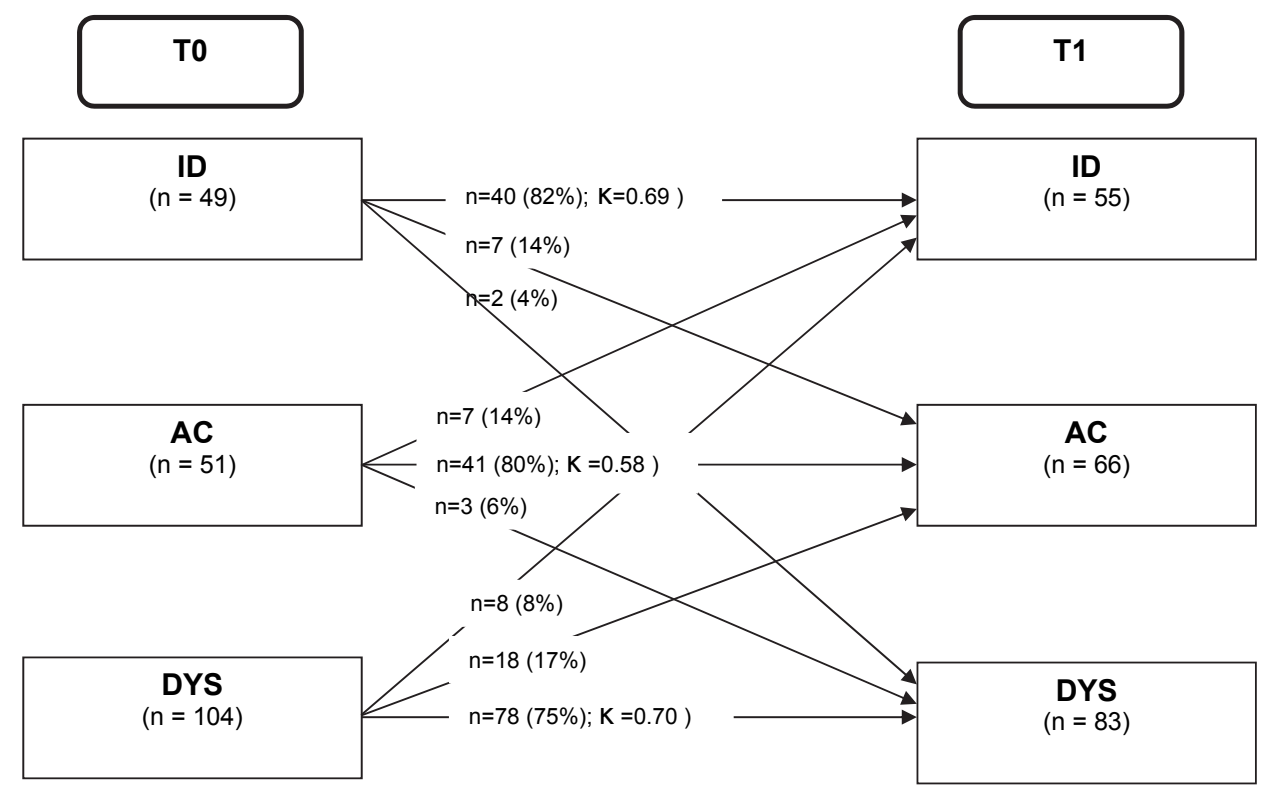

Figure 1. MPI subgroup classification changes

Abbreviations: T0, 4 weeks before entry to pain management program; T1, at entry to pain management program; MPI, Multidimensional Pain Inventory; ID, MPI cluster interpersonally distressed; AC, MPI cluster adaptive copers; DYS, MPI cluster dysfunctional; к, Cohen's Kappa coefficient. 


\section{Discussion}

In this study, we were able to provide additional evidence about the clinimetrical properties of the Multidimensional Pain Inventory. Testing it in 204 patients with chronic musculoskeletal pain - mainly chronic nonspecific back pain - demonstrated that testretest reliability at scale level of the German version of the Multidimensional Pain Inventory was moderate to good and comparable to other language versions. The Multidimensional Pain Inventory Classification System - classifying patients into predefined subgroups labelled as adaptive copers, dysfunctional, and interpersonally distressed - is substantially stable.

\section{Reliability of scales compared to other versions}

In a sample of 185 patients (60\% chronic low back pain) Flor and colleagues measured an internal consistency score for the scale general activities of $\alpha=0.63$ [9]. In our sample we found for the same scale the superior score of $\alpha=0.82$. Test-retest reliability at an average 4-week time interval of the mean Multidimensional Pain Inventory scores at scale level yielded correlation coefficients between $r_{p}=0.73$ and 0.87 , making it on average better than the original German version and comparable with the original US version and several other language versions (Table 4). For this benchmark, the testretest correlation coefficient for life control in our sample $\left(r_{p}=0.57\right)$ was lower.

Table 4. Comparison of different versions of the MPI concerning test-retest reliability of scales

\begin{tabular}{|c|c|c|c|c|c|c|}
\hline \multicolumn{7}{|c|}{ Pearson correlation coefficients $\left(r_{p}\right)$} \\
\hline MPI subscales & $\begin{array}{l}\text { Original German } \\
\text { version } \\
{[9]} \\
(n=25)\end{array}$ & $\begin{array}{l}\text { Current } \\
\text { study } \\
(n=204)\end{array}$ & $\begin{array}{l}\text { Original US } \\
\text { version } \\
16] \\
(n=60)\end{array}$ & $\begin{array}{l}\text { US cross- } \\
\text { validation } \\
{[11]} \\
(n=199)\end{array}$ & $\begin{array}{l}\text { Swedish } \\
\text { version } \\
{[28]} \\
(n=54)\end{array}$ & $\begin{array}{l}\text { Dutch } \\
\text { version } \\
{[29]} \\
(n=59)\end{array}$ \\
\hline Pain severity & 0.59 & 0.77 & 0.82 & 0.74 & 0.75 & 0.74 \\
\hline Interference & 0.78 & 0.82 & 0.86 & 0.87 & 0.85 & 0.89 \\
\hline Life control & 0.72 & 0.57 & 0.68 & 0.62 & 0.81 & 0.74 \\
\hline Negative mood & 0.68 & 0.73 & 0.69 & 0.53 & 0.74 & 0.73 \\
\hline Support & 0.46 & 0.85 & 0.80 & 0.84 & 0.88 & 0.88 \\
\hline Negative responses & 0.70 & 0.75 & 0.84 & 0.79 & 0.75 & 0.81 \\
\hline Solicitous responses & 0.72 & 0.87 & 0.89 & 0.83 & 0.73 & 0.78 \\
\hline Distracting responses & 0.89 & 0.77 & 0.62 & 0.80 & 0.76 & 0.65 \\
\hline General activity & 0.73 & 0.86 & 0.89 & 0.85 & 0.80 & 0.78 \\
\hline
\end{tabular}

Abbreviations: MPI, Multidimensional Pain Inventory; US, United States of America. 


\section{Interpretation of MPI classification changes}

Most of the retest classification changes occurred in the subgroup adaptive copers: $17 \%$ of the dysfunctional patients and $14 \%$ of the interpersonally distressed patients were at retest classified in the less disabled subgroup of adaptive copers (Figure 1). This change in the subjective pain experience of the patients in this sample occurred within a 4-week period, although no therapeutic interventions took place. We hypothesize that anticipation of participation in a pain management program might have a positive effect on the mental health of the patients (improvement of locus of control, reduction of anxiety and depression), and so explains why a substantial number of dysfunctional and interpersonally distressed patients change at retest into the more favorable adaptive copers cluster.

\section{Stability of MPI Classification System compared to other research samples}

This study partly challenges the results of three other research groups assessing the test-retest stability of the MPI Classification System [11-13]. In the two samples of fibromyalgia up to one third of the patients changed Multidimensional Pain Inventory classification at retest (Table 5). These authors concluded that for a sizeable number of chronic pain patients, Multidimensional Pain Inventory classifications may not be stable and need to be reconsidered [11-13]. Our data on test-retest stability in patients with predominantly chronic back pain suggest that the MPI Classification System is according the definition of the kappa values of $0.58-0.70$ substantially stable: only $22 \%$ of patients with predominantly chronic back pain who completed the Multidimensional Pain Inventory and who had been classified into one of the empirically derived subgroups altered their responses sufficiently to be classified into a different pain coping style after a four week time interval without therapeutic interventions. Our results are in line with the score changes of $28 \%$ of the predominantly low back pain patients in the study by Junghaenel \& Broderick [12]. Further studies are needed to replicate these results in other musculoskeletal pain disorders. So far, the German version of the Multidimensional Pain Inventory can be recommended for reliable and stable classification of subgroups of patients with chronic back pain in observational studies and randomized controlled trials.

Table 5. Comparison of this sample with prior research samples investigating MPI subgroup stability

\begin{tabular}{|c|c|c|c|c|}
\hline Authors & $\begin{array}{l}\text { Number } \\
\text { patients }\end{array}$ & f Main diagnosis & $\begin{array}{l}\text { Average time } \\
\text { between test-retest }\end{array}$ & $\begin{array}{l}\text { Percentage of unstable } \\
\text { patients at retest }\end{array}$ \\
\hline Current study & $\mathrm{n}=204$ & Chronic back pain (82\%) & 28 days & $22 \%$ \\
\hline Junghaenel \& Broderick [12] & $n=99$ & Low back pain $(84 \%)$ & 14 days & $28 \%$ \\
\hline McKillop \& Nielsen [13] & $n=376$ & Fibromyalgia (100\%) & 56 days & $33 \%$ \\
\hline Broderick et al.[11] & $\mathrm{n}=199$ & Fibromyalgia (100\%) & 27 days & $35 \%$ \\
\hline
\end{tabular}

Abbreviation: MPI, Multidimensional Pain Inventory. 


\section{Comparison of MPI Classification System with other back pain classification systems}

The Treatment Based Classification developed by Delitto and colleagues and the O'Sullivan Classification System are validated physiotherapy movement-based classification approaches to low back pain $[26,27]$. In these classifications, analysis of mainly mechanical spinal loading strategies and modified spinal movement strategies determines subgrouping. In accordance with the MPI Classification System, both classifications also assess certain psychosocial aspects (fear-avoidance behavior, and/ or maladaptive pain behavior). Comparison of percent agreement scores (75-82\%) and kappa coefficients $(0.58-0.70)$ for test-retest stability of the MPI Classification System reveals scores that are at least as good as the corresponding scores of the widely accepted Treatment Based Classification and the O'Sullivan Classification System (31-97\% agreement, $\mathrm{k}=0.11-0.80$ ) (Table 6).

Table 6. Chance-corrected measures of agreement of different back pain classification systems comprising psychosocial aspects

\begin{tabular}{llll}
\hline Classification system & No. of clusters & Percent agreement & Kappa coefficient (к) \\
\hline MPI Classification System & 3 & $75-82 \%$ & $0.58-0.70$ (current study) \\
Treatment Based Classification & 3 & $65 \%$ & $0.49-0.56[30]$ \\
& & $76 \%$ & $0.60[31]$ \\
& & $31-55 \%$ & $0.14-0.45[32]$ \\
O'Sullivan Classification System & 5 & $79-81 \%$ & $0.14[33]$ \\
& & $58-90 \%$ & $0.11-0.77[34]$ \\
& & $70-97 \%$ & $0.61(0.47-0.80)[35]$ \\
\hline
\end{tabular}

Abbreviation: MPI, Multidimensional Pain Inventory.

\section{Strengths and limitations of this study}

The present study has several strengths: a large sample size, no missing data, and the use of a valid assessment tool implemented worldwide. On the other hand, a limitation of the study was that the patient sample was somewhat heterogeneous with $82 \%$ chronic nonspecific back pain, $15 \%$ fibromyalgia and $3 \%$ other medical diagnoses. This is a possible source of variance that may complicate the analysis, but the reliability and stability analyses compared scores for the same patient, a procedure which is not affected by the heterogeneity of the sample. 


\section{Authors' contributions}

$M L V, F A, J B S, A A$ and $R A B$ were responsible for the design of the study. AA procured funding. SL, RB and MLV collected the data. Statistical analysis was performed by FA and MLV. MLV and FA interpreted the data and made a first draft of the manuscript. All authors have read and approved the final manuscript.

\section{Acknowledgements}

We gratefully thank all patients for their participation in the study and Joy Buchanan for her English editing. We appreciate Jeff McKillop for his statistical advice and data control. This study was supported by the Zurzach Rehabilitation Foundation SPA, Bad Zurzach, Switzerland.

\section{Conclusions}

The reliability of the German Multidimensional Pain Inventory was moderate to good and comparable to other language versions. Multidimensional Pain Inventory subgroup classification is substantially stable in chronic back pain patients when compared to other diagnostic groups and other examiner-based subgroup classification systems. The MPI Classification System can be recommended for reliable and stable specification of subgroups in observational and interventional studies. 


\section{References}

1. Borkan JM, Cherkin DC: An agenda for primary care research on low back pain. Spine 1996, 21(24):28802884.

2. Kamper SJ, Maher CG, Hancock MJ, Koes BW, Croft PR, Hay E: Treatment-based subgroups of low back pain: a guide to appraisal of research studies and a summary of current evidence. Best practice \& research Clinical rheumatology 2010, 24(2):181-191.

3. Karayannis NV, Jull GA, Hodges PW: Physiotherapy movement based classification approaches to low back pain: comparison of subgroups through review and developer/expert survey. $B M C$ musculoskeletal disorders 2012, 13:24.

4. Hill JC, Dunn KM, Lewis M, Mullis R, Main CJ, Foster NE, Hay EM: A primary care back pain screening tool: identifying patient subgroups for initial treatment. Arthritis and rheumatism 2008, 59(5):632-641.

5. Foster NE, Hill JC, Hay EM: Subgrouping patients with low back pain in primary care: are we getting any better at it? Manual therapy 2011, 16(1):3-8.

6. Hancock MJ, Maher CG, Laslett M, Hay E, Koes B: Discussion paper: what happened to the 'bio' in the bio-psycho-social model of low back pain? European spine journal : official publication of the European Spine Society, the European Spinal Deformity Society, and the European Section of the Cervical Spine Research Society 2011, 20(12):2105-2110.

7. Turk DC: The potential of treatment matching for subgroups of patients with chronic pain: lumping versus splitting. The Clinical journal of pain 2005, 21(1):44-55; discussion 69-72.

8. Flor H, Turk DC: Identifying patient subgroups and matching patients with treatment. In: Chronic pain: an integrated biobehavioral approach. edn. Seattle: IASP press; 2011: 289-317.

9. Flor H, Rudy TE, Birbaumer N, Streit B, Schugens MM: [The applicability of the West Haven-Yale multidimensional pain inventory in German-speaking countries. Data on the reliability and validity of the MPI-D.]. Schmerz 1990, 4(2):82-87.

10. Turk DC, Rudy TE: Toward an empirically derived taxonomy of chronic pain patients: integration of psychological assessment data. Journal of consulting and clinical psychology 1988, 56(2):233-238.

11. Broderick JE, Junghaenel DU, Turk DC: Stability of patient adaptation classifications on the multidimensional pain inventory. Pain 2004, 109(1-2):94-102.

12. Junghaenel DU, Broderick JE: Validation of the MPI patient profiles by partners and healthcare providers. Pain 2009, 144(1-2):130-138.

13. McKillop JM, Nielson WR: Improving the usefulness of the Multidimensional Pain Inventory. Pain research \& management : the journal of the Canadian Pain Society = journal de la societe canadienne pour le traitement de la douleur 2011, 16(4):239-244.

14. Airaksinen O, Brox JI, Cedraschi C, Hildebrandt J, Klaber-Moffett J, Kovacs F, Mannion AF, Reis S, Staal JB, Ursin $\mathrm{H}$ et al: Chapter 4. European guidelines for the management of chronic nonspecific low back pain. European spine journal : official publication of the European Spine Society, the European Spinal Deformity Society, and the European Section of the Cervical Spine Research Society 2006, 15 Suppl 2:S192-300.

15. Wolfe F, Smythe HA, Yunus MB, Bennett RM, Bombardier C, Goldenberg DL, Tugwell P, Campbell SM, Abeles M, Clark P et al: The American College of Rheumatology 1990 Criteria for the Classification of Fibromyalgia. Report of the Multicenter Criteria Committee. Arthritis and rheumatism 1990, 33(2):160172.

16. Kerns RD, Turk DC, Rudy TE: The West Haven-Yale Multidimensional Pain Inventory (WHYMPI). Pain 1985, 23(4):345-356.

17. Dworkin RH, Turk DC, Farrar JT, Haythornthwaite JA, Jensen MP, Katz NP, Kerns RD, Stucki G, Allen RR, Bellamy $\mathrm{N}$ et al: Core outcome measures for chronic pain clinical trials: IMMPACT recommendations. Pain 2005, 113(1-2):9-19. 
18. Flor H: Fragebögen: West Haven-Yale Multidimensionaler Schmerzfragebogen (MPI-D). In: Psychobiologie des Schmerzes. edn. Bern, Göttingen, Toronto: Verlag Hans Huber; 1991: 267-273.

19. Angst F, Verra ML, Lehmann S, Aeschlimann A: Responsiveness of five condition-specific and generic outcome assessment instruments for chronic pain. BMC medical research methodology 2008, 8:26.

20. Streiner DL, Norman GR: Selecting the items: homogeniety of the items. In: Health measurement scales a practical guide to their development and use. 4 edn. Oxford, New York: Oxford University Press; 2008: 91-96.

21. Tinsley HEA, Weiss DJ: Interrater reliability and agreement of subjective judgements. J Counsel Psychol 1975, 22:358-376.

22. Verra ML, Angst F, Brioschi R, Lehmann S, Keefe FJ, Staal JB, de Bie RA, Aeschlimann A: Does classification of persons with fibromyalgia into Multidimensional Pain Inventory subgroups detect differences in outcome after a standard chronic pain management program? Pain research \& management : the journal of the Canadian Pain Society = journal de la societe canadienne pour le traitement de la douleur 2009, 14(6):445-453.

23. Verra ML, Angst F, Staal JB, Brioschi R, Lehmann S, Aeschlimann A, de Bie RA: Differences in pain, function and coping in Multidimensional Pain Inventory subgroups of chronic back pain: a one-group pretest-posttest study. BMC musculoskeletal disorders 2011, 12:145.

24. Cohen J: A coefficient of agreement for nominal scales. Educ Psychol Meas 1960, 20:37-46.

25. Landis JR, Koch GG: The measurement of observer agreement for categorical data. Biometrics 1977, 33(1):159-174.

26. Delitto A, Erhard RE, Bowling RW: A treatment-based classification approach to low back syndrome: identifying and staging patients for conservative treatment. Physical therapy 1995, 75(6):470-485; discussion 485-479.

27. O'Sullivan P: Diagnosis and classification of chronic low back pain disorders: maladaptive movement and motor control impairments as underlying mechanism. Manual therapy 2005, 10(4):242-255.

28. Bergstrom G, Bodin L, Jensen IB, Linton SJ, Nygren AL: Long-term, non-specific spinal pain: reliable and valid subgroups of patients. Behavior research and therapy 2001, 39(1):75-87.

29. Lousberg R, Van Breukelen GJ, Groenman NH, Schmidt AJ, Arntz A, Winter FA: Psychometric properties of the Multidimensional Pain Inventory, Dutch language version (MPI-DLV). Behavior research and therapy 1999, 37(2):167-182.

30. Fritz JM, George S: The use of a classification approach to identify subgroups of patients with acute low back pain. Interrater reliability and short-term treatment outcomes. Spine 2000, 25(1):106-114.

31. Fritz JM, Brennan GP, Clifford SN, Hunter SJ, Thackeray A: An examination of the reliability of a classification algorithm for subgrouping patients with low back pain. Spine 2006, 31(1):77-82.

32. Heiss DG, Fitch DS, Fritz JM, Sanchez WJ, Roberts KE, Buford JA: The interrater reliability among physical therapists newly trained in a classification system for acute low back pain. The Journal of orthopaedic and sports physical therapy 2004, 34(8):430-439.

33. Henry SM, Fritz JM, Trombley AR, Bunn JY: Reliability of a treatment-based classification system for subgrouping people with low back pain. The Journal of orthopaedic and sports physical therapy 2012, 42(9):797-805.

34. Widerstrom B, Olofsson N, Arvidsson I, Harms-Ringdahl K, Larsson UE: Inter-examiner reliability of a proposed decision-making treatment based classification system for low back pain patients. Manual therapy 2012, 17(2):164-171.

35. Dankaerts W, O'Sullivan PB, Straker LM, Burnett AF, Skouen JS: The inter-examiner reliability of a classification method for non-specific chronic low back pain patients with motor control impairment. Manual therapy 2006, 11(1):28-39.

36. Vibe Fersum K, O'Sullivan PB, Kvale A, Skouen JS: Inter-examiner reliability of a classification system for patients with non-specific low back pain. Manual therapy 2009, 14(5):555-561. 



\section{CHAPTER 4}

\section{Refined insights into the pain-depression association in chronic pain patients}

Angst F, Verra ML, Lehmann S, Aeschlimann A, Angst J.

Refined insights into the pain-depression association in chronic pain patients.

Clinical Journal of Pain 2008;24(9):808-816. 


\section{Abstract}

Objectives. The relationship between chronic pain and depression is controversial and the data on association show strong variation. This study aimed to provide refined correlation and regression data on the basis of categorical and continuous measures.

Methods. Cross-sectional assessment was based on standardized instruments that measure on a quasi-continuous scale, the Short From-36 (SF-36), the Hospital Anxiety and Depression Scale (HADS) and the Multidimensional Pain Inventory (MPI). Correlations between depression and pain were determined by the instruments' scales, with and without correction for confounders, and within chronic pain subgroups using multivariate regression analysis.

Results. In 273 chronic pain patients participating in an inpatient pain rehabilitation program, the Multidimensional Pain Inventory pain severity scale and the Hospital Anxiety and Depression Scale depression scale showed maximum overall correlations of 0.27 to 0.29 (bivariate) and 0.30 (partial). The odds ratios for depression varied between 1.72 and 2.10 for different pain levels. Distinguishing three subtypes of pain patients, the pain-depression correlation was moderate in the "interpersonally distressed" subgroup (up to 0.57) (characterized by relatively low support, high punishing, low solicitous, and low distracting responses), weak in the "dysfunctional" subgroup (up to 0.26 ), and absent in the "adaptive copers / minimizers" subgroup (up to -0.09).

Conclusions. The strengths of the pain-depression association and the "doseresponse" relationship were both weak - weaker than to be expected if the hypothesis of a causal relationship were true. In the "interpersonally distressed" subgroup, the moderate association may have an impact on pain management, that is, pain could be treated by treatment of depression and vice versa. 


\section{Introduction}

Depression and (chronic) pain are highly prevalent disorders that make an enormous impact and high demands on individual health care and public health management and lead to high rates of chronic courses [1-3]. Management of both disorders is often unsuccessful and the question arises as to whether 1 disorder could be influenced by treatment of the other $[4,5]$. On the basis of our intuition, our clinical experience, and the findings and hypotheses of many study reports, depression and chronic pain are likely to be causally related and vice versa. This means that reduction of pain would imply reduction of depression and reduction of depression would lead to less pain. Comprehensive literature overviews on these issues and on the impact of antidepressants on pain can be found in several reviews [6-9]. Some studies favored the pathway of pain leading to depression - through the loss of functional and psychosocial activities and learned helplessness - rather than depression leading to pain [6, 10-12]. Other reports showed that pain decreased when depression was successfully treated (reviewed in Ref. [12]).

On the one hand, there are several plausible explanatory hypotheses for the paindepression association that are outlined, for example, in Ref. [13], serotonin and noradrenalin play a role in both depression and pain sensations and may influence each other. This is supported by the observation that tricyclic antidepressants and dual (serotonin and noradrenalin) reuptake inhibitors relieve pain. Additionally, exercise, psychological, and behavioral treatments both address pain and depression simultaneously [14]. In contrast, it was not possible to prove the other pathway that analgesics can reduce depression; in contrary, there are findings which indicate that the (common) use of non-steroidal antirheumatic drugs may increase the risk of depression [13].

On the other hand, the majority of experimental studies failed to prove a positive correlation between pain and depression: experimentally induced pain revealed increased pain thresholds, that is, diminished perception of pain in depressed subjects [15]. Moreover, there are many other explanatory models that hypothesized different pathophysiologic, genetic, psychosocial, psychological, therapeutic, cognitive, and role behavioral pathways [16-18]. Some of them, however, contradicted each other [15-18].

A literature search in MedLine (1966 till the end of September 2007) with the keywords depression, pain, and association or correlation yielded over 1200 articles. Reports of a large number of studies state a positive association of depression with chronic pain in population surveys (e.g. Refs. [3, 14, 19-28], in primary care (e.g. Ref. [29]), and in elderly people with a high prevalence of musculoskeletal disorders (e.g. Refs. [1, $21,30-32])$. Most of these studies were cross-sectional surveys with huge sample sizes up to 42,697 [23] and some were longitudinal [25, 26, 28, 31]. The variation of the association in these studies has a wide range showing odds ratios (ORs) from 1.14 to 7.31 $[1,3,13,14,19-27,29-32]$. 
However, there are also studies which resulted in weak or no associations between depression and chronic pain, especially when calculating correlation data in primary care (e.g. Ref. [28]: correlation 0.27, corrected for the confounders age, sex, social class, employment status, and disability: -0.04) and in clinic patient samples (e.g. Ref [33]: correlation 0.22 , [34]: correlation 0.01 for young and 0.51 for elderly patients); see also Ref. [11]. Without adjustment for confounders, chronic pain predicted future depression, but with adjustment (by age, sex, anxiety, and various general health scores) it did not [35]. Lifetime depression diagnosis was elevated in fibromyalgia when selfassessed, but was not confirmed when the patients were clinically interviewed and received DSM-IV diagnoses [20]. In summary, the strength of the pain-depression association is, therefore, not clear.

Most of the reviewed studies only used (percentage) prevalences and ORs to quantify the pain-depression association. This implies thresholds of the symptoms/syndromes to define presence or absence of the disorder. Depending on these thresholds and the disease definitions, prevalences of subjects with the diagnosis of pain and depression show a large variability resulting in widely varying association results when comparing different studies (e.g. see Refs $[8,20])$.

In contrast to a dichotomous diagnostic decision, (quasi-)continuous quantification capturing the degree, the severity, and the burden of the depression and pain syndromes on a finely graded scale, for example, from $0=$ no pain/depression to $100=$ maximal pain/depression with all possible values in between, will produce a much more refined assessment as it corresponds to clinical reality. With this approach, the association could be examined by correlation and regression analysis in a much more sophisticated way taking into account the whole range of symptoms. Although pain is usually interval (e.g. on a numeric rating scale: $0=$ no pain to $10=$ worst pain) and depression ordinal scaled (presence of symptoms: always, ..., sometimes, ..., never), the 2 scales can be correlated to each other assuming that the interval scale also represents a ordinal grading (rather than vice versa).

This study aims to derive refined (i.e. by different methods, continuous scales, stratification into subgroups, etc.) correlation and regression data from a patient sample to contribute to the debate of whether depression and pain are strongly enough related to support the hypothesis of causality. The influence of confounders on the association and the hypothesis as to whether correlations are different within partial samples/subgroups was examined. 


\section{Methods}

\section{Setting and participants}

The "Zurzach chronic pain study" was conducted to examine health and quality of life in a specific and comprehensive way before and after a specifically structured in-patient interdisciplinary pain management program [36]. Patients with chronic pain, that is, pain of at least 6 months duration, subsequently admitted to the rehabilitation clinic "RehaClinic", Bad Zurzach, Switzerland, were included. To qualify for inclusion, they had to have back pain, fibromyalgia, or chronic widespread pain, that is, soft-tissue pain syndromes in at least 3 body quadrants without meeting the diagnostic criteria for fibromyalgia (for the definition of fibromyalgia see Ref. [37]). The study's protocol was approved by the local ethics committee and written informed consent was obtained from all participants.

\section{Outcome measures}

Data were obtained by a set of self-assessment instruments, including the Short Form 36 (SF-36), the Multidimensional Pain Inventory (MPI), and the Hospital Anxiety and Depression Scale (HADS), and by reviewing the medical records. The SF-36 is the most frequently applied generic, holistic health status and quality of life instrument worldwide. It comprehensively measures self-rated biopsychosocial health and abilities on the basis of 36 items resulting in the following 8 scales: physical functioning, role physical, bodily pain, general health, vitality, social function, role emotional, and mental health [38]. It has been cross-culturally adapted into German and extensively tested in numerous settings [39]. The MPI was specially developed for the research of chronic pain and assesses pain and its biopsychosocial consequences on the basis of 51 items resulting in the following 12 scales: pain severity, interference with pain, negative mood, support, life control, self-efficacy/locus of control (control item), negative responses, solicitous responses, distracting responses (by the partner or spouse for each response scale), social and away from home activities, household chores, and outdoor work (the latter 3 activity scales are often summarized into 1 activity scale) [40]. As the German version has been tested and validated, it has been extensively used in various studies [41]. The HADS was originally developed for the specific and continuous assessment of affective health of hospital medical (nonpsychiatric) outpatients and consists of 14 items that make up the 2 scales, anxiety and depression [42]. After standardized cross-cultural adaptation, the German version was extensively tested and validated in various settings [43].

The MPI pain severity, the HADS depression, and HADS anxiety scales were transformed into a scale from $0=$ no pain/depression/anxiety to $100=$ maximal pain/depression/anxiety to ease comparison. The SF-36 bodily pain scale was scored 
from $0=$ maximal pain to $100=$ no pain and the SF-36 physical functioning from $0=$ worst/no function to $100=$ best/full function as originally described. All other scores were scaled from 0 to 100 according to the instructions in the manuals (see legend of Table 1).

In addition, pain was assessed by the numerical rating scale scaling pain into integer numbers from $0=$ no pain to $10=$ maximal pain (11 levels) [44].

Table 1. Descriptive data of the sample and the subgroups

\begin{tabular}{lllll}
\hline Mean \pm s & Whole sample & Dysfunctional & $\begin{array}{l}\text { Interpersonally } \\
\text { distressed }\end{array}$ & $\begin{array}{l}\text { Adaptive copers/ } \\
\text { minimizers }\end{array}$ \\
\hline $\mathrm{n}(\%$ female) & $273(79.9 \%)$ & $107(77.6 \%)$ & $61(85.2 \%)$ & $100(79.0 \%)$ \\
Age & $46.3 \pm 10.5$ & $44.4 \pm 10.2$ & $48.0 \pm 11.3$ & $47.2 \pm 10.3$ \\
MPI pain severity & $77.0 \pm 15.0$ & $83.3 \pm 12.4$ & $71.5 \pm 16.5$ & $73.8 \pm 14.2$ \\
MPI interference with pain & $71.7 \pm 16.7$ & $82.8 \pm 9.6$ & $66.4 \pm 18.3$ & $63.0 \pm 15.0$ \\
MPI negative mood & $57.6 \pm 22.1$ & $70.6 \pm 15.5$ & $61.1 \pm 22.1$ & $41.4 \pm 17.7$ \\
MPI support & $68.3 \pm 29.6$ & $86.3 \pm 15.7$ & $25.0 \pm 20.3$ & $75.4 \pm 17.2$ \\
MPI life control & $47.8 \pm 20.2$ & $39.2 \pm 17.5$ & $41.3 \pm 17.8$ & $61.0 \pm 16.7$ \\
MPI punishing responses & $22.5 \pm 23.6$ & $24.4 \pm 23.2$ & $30.8 \pm 29.5$ & $16.6 \pm 17.9$ \\
MPI solicitous responses & $55.8 \pm 28.6$ & $74.8 \pm 17.0$ & $20.5 \pm 17.2$ & $59.9 \pm 20.5$ \\
MPI distracting responses & $52.1 \pm 28.1$ & $69.7 \pm 19.0$ & $21.9 \pm 21.1$ & $54.4 \pm 21.9$ \\
MPI general activity & $39.9 \pm 13.4$ & $36.2 \pm 13.5$ & $40.2 \pm 14.5$ & $43.7 \pm 11.7$ \\
HADS depression & $44.5 \pm 20.8$ & $52.7 \pm 17.8$ & $50.0 \pm 21.5$ & $32.0 \pm 17.1$ \\
HADS anxiety & $50.1 \pm 20.9$ & $59.7 \pm 17.7$ & $53.1 \pm 20.4$ & $38.2 \pm 18.6$ \\
SF-36 physical functioning & $39.5 \pm 21.0$ & $32.4 \pm 18.8$ & $44.1 \pm 21.5$ & $44.3 \pm 21.1$ \\
SF-36 mental health & $45.7 \pm 19.6$ & $36.9 \pm 15.0$ & $41.2 \pm 18.8$ & $57.8 \pm 18.6$ \\
\hline
\end{tabular}

Abbreviations: s, standard deviation; MPI, Multidimensional Pain Inventory; HADS, Hospital Anxiety and Depression Scale; SF-36, Short Form 36.

NOTE. Scaling: $0=$ best, $100=$ worst for MPI pain severity, MPI interference with pain, MPI negative mood, HADS depression, HADS anxiety; 0=no response, 100= most responses for MPI responses; 0=worst, 100=best for MPI activity, SF-36 physical functioning, SF-36 mental health.

\section{Statistical analysis}

The baseline data before treatment in the rehabilitation program were analyzed for this study. The instruments' scores for pain and depression are shown descriptively and were tested for normal distribution using the Komolgorov-Smirnov test, and transformations were performed by various arithmetic functions to improve "normality" and correlation. The following transformations were tested: $1 / x, x^{2}, x^{3}, \sqrt{x},{ }^{1.5} \sqrt{x}, \sqrt[3]{ } x, \ln (x)$, $\exp (x), \sin (x), \tan (x), \arctan (x)$, where $x=$ pain or depression. A scatter plot for depression and pain was compiled and the bivariate linear regression function was determined.

Bivariate parametric Pearson and non-parametric (i.e. distribution independent) Spearman rank-correlation coefficients were then calculated for pain and depression 
and these were compared to each other [45]. Dichotomized data analysis was performed to compare our data with values obtained from published reports. The ORs were determined using the MPI pain severity scale with thresholds of $\geq 25, \geq 50, \geq 75$ (to stratify arbitrarily chosen thresholds), and 100 score points (100 = maximal pain) and the HADS depression scale with the (empirically determined) threshold score of 42.9 (100 = maximal depression) corresponding to a cut-off score of 9 ( $21=$ maximal depression), which showed the highest sensitivity and specificity in differentiating between depression or no depression [43].

Stepwise linear regression modelling was used to predict pain levels (dependent variable) on the basis of depression and possible confounders (independent variables) and to determine the partial Pearson correlation coefficients for depression and pain after controlling for the confounders [46]. According to previous studies, confounders were sex, age, living with a partner, education level, working capacity, overweight/obesity as assessed by the body mass index, no sports, smoking, number of comorbidities, history of arthritis, neurologic, and gastrointestinal diseases [19, 25].

Some previously conducted studies have dealt with the confounding role of anxiety and physical function $[12,24]$. Obviously, anxiety is part of the depressive syndrome and depressed persons - with or without pain - are physically less active. Thus, in a separate regression model, anxiety and physical functioning were included as confounders resulting in a predictive model for depression controlling for anxiety (assessed by the HADS anxiety) and physical function (assessed by the SF-36 physical functioning), that is, depression dominated by reduced mood, fatigue, and reduced concentration ability.

As primary outcomes, pain was analyzed by the MPI pain severity and depression by the HADS. The MPI pain severity scale is often used in comparable literature and has shown the best construct validity properties for the sensation of pain in comparison to the other scales of the MPI as these are confounded by psychosocial symptoms and problems [47]. The HADS depression scale revealed to be highly sensitive and specific in many settings and showed high concurrent validity when compared to other wellestablished instruments, as for example the Beck Depression Scale and the Symptom Checklist 90 Scale [48].

To keep our results comparable with literature, sensation of pain (MPI pain severity) was chosen as main outcome and not physical or psychosocial consequences of pain (i.e. by MPI interference). In a second step, all instrument scales for depression and pain were tested by the model and compared to each other. "Depression" is used to abbreviate depressive syndrome in the following.

As a last step, we tried to characterize persons with a high correlation between depression and pain. First, patients with a high pain-depression correlation were identified by the regression function using the (arbitrarily determined) +/-10 point intercept range and were then compared to those with a low correlation by analysis of variance and logistic regression [49]. Second, comparison was made between the subgroups of 
correlations empirically determined by cluster analysis of the MPI scales according to the subgroup definition of Turk et al.[50,51], a concept which was originally developed for back pain and fibromyalgia and which has been applied in several trials (e.g. Refs. [52-55]).

All analyses were performed using the statistical software package SPSS 15.0 for Windows ${ }^{\circledR}$ (SPSS Inc., Chicago, IL).

\section{Results}

\section{Patients and descriptive data}

Among all 323 patients admitted to the clinic for the first time, 273 were included, corresponding to a refusal rate of $15.5 \%$. The reasons for the 50 refusal were, that is, inability to fill out the questionnaires $(n=43,86 \%)$, dementia $(n=1)$, psychosis $(n=2)$, noncompliance $(n=1)$, and other reasons $(n=3)$. Descriptive data are shown in Tables 1 and 2. There were only a few missing data in the assessed parameters: $12(4.4 \%)$ in education, $10(3.7 \%)$ in smoking, and $13(4.8 \%)$ in sports leading to a total number of 258 patients with complete data for the regression analysis (5.5\% drop-outs). Age was normally distributed (Komolgorov-Smirnov test: $p>0.20$ ).

Table 2. Descriptive data of the confounding variables (whole sample only, $n=273$ )

\begin{tabular}{llll}
\hline Variable & & $\mathbf{n}$ & $\%$ \\
\hline Diagnosis & Back pain & 116 & 42.5 \\
& Wibromyalgia & 118 & 43.2 \\
Education & Basic school (8-9 years) & 39 & 14.3 \\
& Vocational training & 79 & 28.9 \\
Working capacity & College/High school/University & 133 & 48.7 \\
Living & No & 49 & 17.9 \\
Smoking & With partner/spouse & 135 & 49.5 \\
Sport & Yes & 210 & 76.9 \\
Comorbidities (n) & No & 108 & 39.6 \\
Arthritis & One or more & 127 & 46.5 \\
Neurological disease & Present & 216 & 81.1 \\
Gastrointestinal disease & Present & 38 & 13.9 \\
Body mass index & Present & 24 & 8.8 \\
\hline Comorbiditi: & Mean (standard deviation) & 16 & 5.9
\end{tabular}

Comorbidities: heart and circulatory, obesity, diabetes mellitus, pulmonary, gastrointestinal, cancer, endocrinologic, neurologic, psychiatric (excluded are anxiety and depression), substance abuse, and arthritis. 
The MPI pain severity and HADS depression scales ranged widely, leading to well-fitted data for the regression analysis. However, these scales were not normally distributed (Komolgorov-Smirnov test: $\mathrm{p} \leq 0.01$ ), although not far from normal distribution, showing relatively low skewness and kurtosis values (data not shown in further detail, see Table 2 and also the scatter plot in Fig. 1). The best transformations were pain $^{2}$ and $1.5 \sqrt{ }$ depression in the sense that they led to distributions which were closest to normal distribution. There were very low floor and ceiling effects on the HADS depression scale ( 1 patient scored $0=$ no depression, 2 patients scored $100=$ maximal depression) and no floor but some ceiling effects on the MPI pain severity scale ( $n=27,9.9 \%$ scored 100 = maximal pain). The other parameters measuring pain or depression, the SF-36 bodily pain (floor: $23.4 \%$ scored $0=$ maximal pain), the pain numeric rating scale (ceiling: $10.6 \%$ scored $10=$ maximal pain), the MPI negative mood (ceiling: $1.8 \%$ scored $100=$ maximal depression), and the SF-36 mental health (floor: $0.4 \%$ scored $0=$ worst mental health) (Table 2) also showed distributions not far from the normal distribution (data not shown in detail).

\section{Correlation and regression data, dichotomized data}

The bivariate relationship between depression (HADS depression) and pain (MPI pain severity) is shown in the scatter plot of Figure 1. The linear equation was pain $=0.21 \mathrm{x}$ depression +67.63 , with a bivariate Spearman correlation of 0.27 , a bivariate Pearson of 0.28 , and a multivariate, partial Pearson correlation of 0.30 (all $p<0.001$ when tested to correlation 0.00 ).

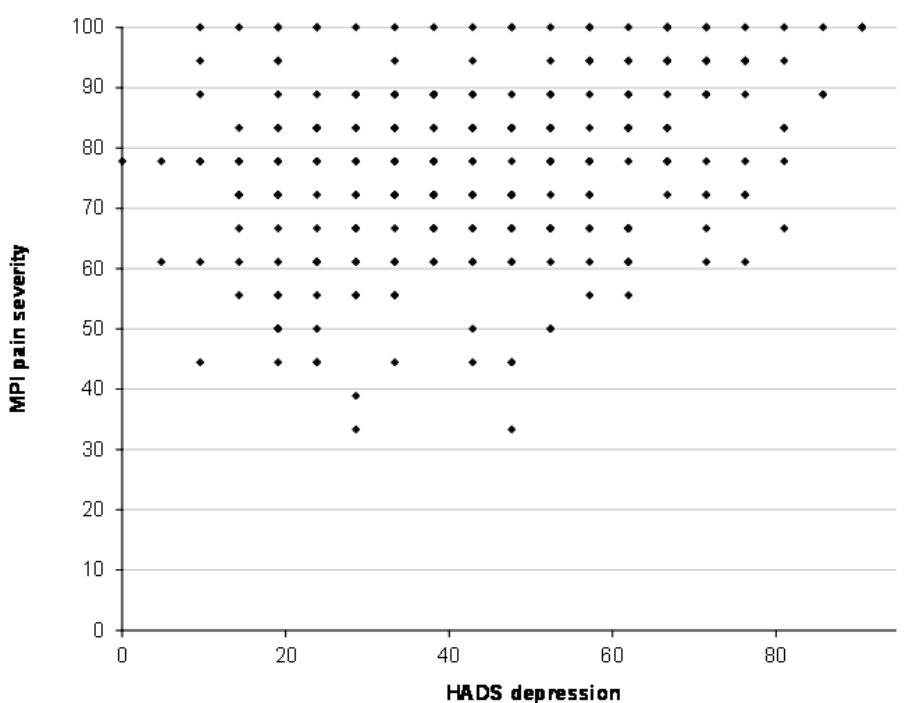

Figure 1. Scatterplot of HADS depression against MPI pain severity $(n=273)$ 
All these correlation results for the 9 possible combinations of pain and depression assessments and the goodness to fit of the regression models (explained variance $r^{2}$ ) are depicted in Table 3. Although all models resulted in a highly significant better estimate of pain than the constant model (pain = constant) $\left(p<0.001, F_{13,245}\right.$-Test), the potential to explain the variance of the pain scales was limited in all models and ranged from $13.7 \%$ to $20.6 \%$. Further consideration of duration of pain showed that this potential confounder had almost no predictive power (increase of explained variance of $+0.01 \%$ and partial correlation of -0.04 to the MPI pain severity), and was therefore excluded from regression in the following considerations.

Table 3. Correlation and regression results of the different instrument scales of all subjects ( $n=258$ )

\begin{tabular}{llllll}
\hline \multirow{2}{*}{ Pain } & Depression & Correlations & & & Regression \\
\cline { 3 - 6 } & & $\begin{array}{l}\text { Bivariate } \\
\text { Spearman }\end{array}$ & $\begin{array}{l}\text { Bivariate } \\
\text { Pearson }\end{array}$ & $\begin{array}{l}\text { Partial } \\
\text { Pearson }\end{array}$ & $\begin{array}{l}\text { Explained } \\
\text { variance }\left(\mathbf{r}^{2}\right)(\%)\end{array}$ \\
\hline MPI pain severity & HADS depression & 0.27 & 0.28 & 0.30 & 20.6 \\
MPI pain severity & MPI negative mood & 0.25 & 0.24 & 0.24 & 17.6 \\
MPI pain severity & SF-36 mental health & 0.25 & 0.26 & 0.24 & 17.5 \\
SF-36 bodily pain & HADS depression & 0.23 & 0.26 & 0.22 & 16.7 \\
SF-36 bodily pain & MPI negative mood & 0.16 & 0.19 & 0.19 & 13.7 \\
SF-36 bodily pain & SF-36 mental health & 0.22 & 0.21 & 0.17 & 15.0 \\
Pain NRS & HADS depression & 0.22 & 0.24 & 0.26 & 18.8 \\
Pain NRS & MPI negative mood & 0.13 & 0.11 & 0.11 & 14.3 \\
Pain NRS & SF-36 mental health & 0.13 & 0.13 & 0.12 & 14.4 \\
\hline
\end{tabular}

Abbreviations: MPI, Multidimensional Pain Inventory; HADS, Hospital Anxiety and Depression Scale; SF-36, Short Form 36; NRS, Numeric Rating Scale (0-10).

The best model was that of MPI pain severity and HADS depression with $20.6 \%$ explained variance as expected a priori by the appropriateness of the content validity of these 2 scales. The model with the closest to normal distribution of variables, that is, with MPI pain severity ${ }^{2}$ as dependent and ${ }^{1.5} \sqrt{\text { HADS }}$ depression as independent variables, attained an explained variance of $20.0 \%$, a bivariate Pearson correlation of 0.27 , and a partial correlation of 0.29 , and thus, did not fit better than the model with the untransformed, linear variables.

Dichotomized data analysis revealed an indeterminable OR for the MPI pain severity threshold score $\geq 25$ as there were no patients with scores $<25$. For pain $\geq 50$ (moderate pain) the OR for presence/absence of depression was 2.10 [95\% confidence interval $(\mathrm{Cl}): 0.60,7.36]$, for pain $\geq 75$ (severe pain), the OR was 1.72 (95\% Cl: 1.06, 2.79), and for maximal pain of 100 , the OR was $1.81(95 \% \mathrm{Cl}: 0.78,4.19)$. 


\section{Correlations and properties within subsamples}

First, the total patient sample $(n=273$, complete data for $n=258$ ) was split into 2 groups: those with a high correlation, defined by the linear regression equation, whose scores were in the intercept interval of \pm 10 score points: MPI pain $=0.21 \times$ HADS depression +57.63 and: MPI pain $=0.21 \times$ HADS depression +77.63 , and all others with low correlations. The group of "high correlators" consisted of 117 subjects and showed the following correlations: bivariate Spearman 0.58, bivariate Pearson 0.62, and partial Pearson 0.60. The group of "low correlators" consisted of 141 subjects and showed the following correlations: bivariate Spearman 0.27, bivariate Pearson 0.23, and partial Pearson 0.24 . The 2 groups did not differ in any of the confounding variables, the HADS depression, nor in any of the MPI scales (results of 1-way analysis of variance and logistic regression, not shown in detail), that is, did not show specific characteristics.

Second, all patients were allocated to one of the three characterizing chronic pain subgroups obtained by cluster analysis of all MPI scales according to the concept of Turk et al.[50, 51]. To assess whether a 3-cluster solution was appropriate according to mathematical criteria, hierarchical cluster analysis according to the Ward method was performed [49]. The resulting diagram with the number of clusters and the course of the sum of residual squares did not favour a 3-cluster solution (data not shown in detail). However, factor analysis revealed that a 3-factor solution fitted best with $69.6 \%$ explained variance. This was consistently true within all 3 diagnostic groups, that is, back pain, fibromyalgia, and widespread pain. Thus, the proposed "best feasible", that is, clinically characterized, empirically determined solution according to the subgroups defined by Turk et al. was chosen [49-51].

The properties of the groups according to the concept of Turk and Rudy [50] and the correlation results within these groups are shown in Table 4. Pain and depression were best, that is, moderately, correlated (up to 0.57) in the interpersonally distressed subgroup, weakly correlated (up to 0.26 ) in the dysfunctional subgroup, and absent in the adaptive copers/minimizers subgroup. 
Table 4. Correlation and regression results of the MPI pain severity and the HADS depression within the MPI cluster groups according to the concept of Turk et al. ( $n=251$ classified)

\begin{tabular}{|c|c|c|c|c|c|c|}
\hline \multirow[t]{2}{*}{ Group } & \multirow{2}{*}{$\begin{array}{l}\text { Properties } \\
\text { MPI scales }\end{array}$} & \multirow[t]{2}{*}{$\mathrm{n}$} & \multicolumn{3}{|c|}{ Correlations } & \multirow{2}{*}{$\begin{array}{l}\text { Regression } \\
\text { Explained } \\
\text { variance }\left(r^{2}\right)(\%)\end{array}$} \\
\hline & & & $\begin{array}{l}\text { Bivariate } \\
\text { Spearman }\end{array}$ & $\begin{array}{l}\text { Bivariate } \\
\text { Pearson }\end{array}$ & $\begin{array}{l}\text { Partial } \\
\text { Pearson }\end{array}$ & \\
\hline Dysfunctional & $\begin{array}{l}\uparrow \text { Pain severity } \\
\uparrow \text { Interference with pain } \\
\uparrow \text { Negative mood } \\
\downarrow \text { Life control } \\
\downarrow \text { Activity }\end{array}$ & 100 & 0.26 & 0.24 & 0.21 & 27.4 \\
\hline $\begin{array}{l}\text { Interpersonally } \\
\text { distressed }\end{array}$ & $\begin{array}{l}\downarrow \text { Support (social) } \\
\uparrow \text { Punishing responses } \\
\downarrow \text { Solicitous responses } \\
\downarrow \text { Distracting responses }\end{array}$ & 56 & 0.53 & 0.52 & 0.57 & 46.3 \\
\hline $\begin{array}{l}\text { Adaptive } \\
\text { copers/minimizers }\end{array}$ & $\begin{array}{l}\downarrow \text { Pain severity } \\
\downarrow \text { Interference with pain } \\
\downarrow \text { Negative mood } \\
\uparrow \text { Life control } \\
\uparrow \text { Activity }\end{array}$ & 95 & -0.08 & -0.05 & 0.01 & 21.9 \\
\hline
\end{tabular}

Abbreviations: $\uparrow$ indicates higher level compared with the other 2 clusters; $\downarrow$, lower level compared with the other 2 clusters; n, number of patients with complete data for all co-factors; HADS, Hospital Anxiety and Depression Scale; MPI, Multidimensional Pain Inventory.

\section{Alternative models including anxiety and function as additional confounders}

The results of the model predicting MPI pain severity based on all previously included confounders (see legend of Table 3), the HADS depression, the HADS anxiety, and the SF-36 physical functioning are listed in Table 5 for the whole sample and within the MPI subgroups. Function attained the highest correlations (up to -0.61 bivariate and -0.53 partial) and improved the predictive power of the regression models to $30.8 \%$ to $61.3 \%$ (explained variance, as compared to the models without anxiety and function). The inclusion of anxiety and function reduced the correlations of depression to pain to 0.12 overall (before: 0.30 , Table 3) and to 0.42 (before: 0.57 , Table 4) in the interpersonally distressed subgroup. The pattern of the correlations between the MPI subgroups remained consistent. After controlling for confounders, depression, and function, anxiety no longer showed any association with pain (correlations -0.06 to 0.01 ). 
Table 5. Alternative model to predict pain by depression, anxiety, and physical function

\begin{tabular}{|c|c|c|c|c|c|}
\hline & \multirow[b]{2}{*}{ MPI pain severity by } & \multicolumn{3}{|c|}{ Correlations } & \multirow{2}{*}{$\begin{array}{l}\text { Regression } \\
\text { Explained variance } \\
\left(r^{2}\right)(\%)\end{array}$} \\
\hline & & $\begin{array}{l}\text { Bivariate } \\
\text { Spearman }\end{array}$ & $\begin{array}{l}\text { Bivariate } \\
\text { Pearson }\end{array}$ & $\begin{array}{l}\text { Partial } \\
\text { Pearson }\end{array}$ & \\
\hline \multirow{3}{*}{$\begin{array}{l}\text { Overall } \\
(n=258)\end{array}$} & HADS depression & 0.27 & 0.28 & 0.12 & \multirow[t]{3}{*}{34.8} \\
\hline & HADS anxiety & 0.20 & 0.19 & 0.01 & \\
\hline & SF-36 physical functioning & -0.50 & -0.53 & -0.42 & \\
\hline \multirow{3}{*}{$\begin{array}{l}\text { Dysfunctional } \\
(n=100)\end{array}$} & HADS depression & 0.26 & 0.26 & 0.11 & \multirow[t]{3}{*}{35.2} \\
\hline & HADS anxiety & 0.13 & 0.12 & -0.04 & \\
\hline & SF-36 physical functioning & -0.41 & -0.46 & -0.32 & \\
\hline Interpersonally & HADS depression & 0.53 & 0.49 & 0.42 & \multirow[t]{3}{*}{61.3} \\
\hline \multirow{2}{*}{$\begin{array}{l}\text { distressed } \\
(n=95)\end{array}$} & HADS anxiety & 0.28 & 0.24 & -0.02 & \\
\hline & SF-36 physical functioning & -0.59 & -0.61 & -0.53 & \\
\hline $\begin{array}{l}\text { Adaptive } \\
\text { copers/ }\end{array}$ & HADS depression & -0.08 & -0.09 & -0.02 & \multirow[t]{3}{*}{30.8} \\
\hline \multirow{2}{*}{$\begin{array}{l}\text { minimizers } \\
(n=56)\end{array}$} & HADS anxiety & -0.08 & -0.14 & -0.06 & \\
\hline & SF-36 physical functioning & -0.37 & -0.42 & -0.30 & \\
\hline
\end{tabular}

Abbreviations: MPI, Multidimensional Pain Inventory; HADS, Hospital Anxiety and Depression Scale; SF-36, Short Form 36; n, number of patients with complete data for all co-factors.

\section{Discussion}

The overall cross-sectional association between chronic pain and depression with maximum correlations of 0.30 was weak - a correlation of 1.00 represents perfect association, 0.00 implies no association. A value of 0.30 means that only $9.0 \%\left(=0.30^{2}\right)$ of the variance of pain can be explained by depression [56]. In addition, the model including all possible a priori confounders explained a maximum of only $20.6 \%$ of the variance of pain, which shows that all these variables were poor predictors of the level of chronic pain. Inclusion of anxiety and function as co-factors improved the predictive power of the models, but reduced the correlations between pain and depression. Only the members of the interpersonally distressed subgroup subjectively perceiving low (social) support and high negative responses by their partners or spouses were characterized by moderate pain-depression association in our data which means that subjects with relatively low depression showed relatively low levels of pain and vice versa. A total of $32.5 \%$ (= correlation $0.57^{2}$ ) of the variance of pain in this subgroup was explained by depression.

The low correlations observed are in accordance with those of several other studies that show weak correlations ranging from 0.22 to 0.27 [28, 33]. In the United States general population survey to validate the SF-36, the correlations between the SF-36 bodily pain items with the SF-36 mental health scale, and the correlation of SF-36 men- 
tal health items with the SF-36 bodily pain scale ranged from 0.27 to 0.33 ( $n=3445$ ) [38]. In 404 elderly primary care patients, the SF-36 bodily pain association with the Hamilton depression score attained a standardized regression coefficient of $\beta=0.23$ and was almost identical to our data showing a $\beta=0.29$ (regression data not shown in detail) [57]. Our ORs of around 2.0 showed that depression in patients with higher levels of pain was twice as frequent as in patients with no or lower pain (on different pain thresholds) and were thus consistent with the data from the published literature (see Introduction). However, dichotomized data analysis is dependent on thresholds for the classification of the cases and can even lead to statistically significant OR data (OR = 1.72 for MPI pain $\geq 75$ ) although continuous data do not show strong associations.

Therefore, the pain-depression association was present, but its strength was weak. A strong association (correlation) is more likely to have a causal component than a moderate association [58]. However, a weak association does not rule out causality but is likely to be explained by undetected biases [51]. Second, the biological gradient between depression and pain was also weak: the outcome should increase monotonically with increasing dose of exposure $[58,59]$. On the one hand, the slope of the linear paindepression curve was very low (1 unit depression leads to 0.21 unit pain, Fig. 1), on the other hand, the ORs determined for different pain thresholds did not show a gradient at all because depression was not more frequent in patients with increasingly severe pain. The strength of the association and the biological gradient are the 2 most important of 9 necessary conditions for causality as expressed by the well-known Bradford Hill epidemiological criteria, however, their value to predict causality has been the subject of an ongoing philosophical debate for decades [58, 59]. In other words, if there was a (strong) causal relationship between pain and depression, a high correlation and a high biological gradient would have to be empirically observed, even in crosssectional examinations. It may prove extremely difficult to resolve the issue of the paindepression interaction by (currently known) epidemiological methods alone because there may be other, currently unknown, confounders [59].

Coping with pain and especially catastrophizing may play an important confounding role as was also shown by the MPI subgroup analysis in this and in other studies [16, 34, $60]$. Patients with high correlations of pain and depression could not be specifically characterized a priori, that is, by strata of pain level, but there were large correlation differences between the groups characterized psychobehaviorally according to the concept of Turk et al. [50,51]. According to the MPI subgroup results, it can be hypothesized that treatment of depression in the interpersonally distressed subgroup may have an impact on pain reduction (and vice versa) but little in the dysfunctional and no impact in the adaptive copers/minimizers subgroup.

Pain management programs may have a certain number of treatment modalities that are the same for all patients, but they should also include (additional) subgroupspecific interventions [55]. In the treatment study of Turk et al, the dysfunctional patients improved in pain, disability, and depression, but the interpersonally distressed 
subjects did not improve in any of these 3 health dimensions [53]. They should probably receive treatment that addresses their pain problem and also their specific psychosocial needs, for example, family therapy, focussing on interpersonal and marital problems as stated previously and to be examined in future $[60,61]$. In our study, the dysfunctional subgroup with the highest scores for pain and depression did not show the highest correlation between pain and depression possibly owing to a relatively high ceiling effect in pain (15.9\% rated maximal pain in the MPI pain severity in contrast to $6.6 \%$ of the interpersonally distressed and $6.0 \%$ in the adaptive copers/minimizers data not shown in the results).

The alternative regression model including anxiety (HADS) and function (SF-36) showed that decrease of function was moderately correlated to increase of depression, and anxiety was not correlated with pain when controlling for depression and function. This means that depressive syndrome characterized mainly by reduced mood level and reduced concentration ability (and not by anxiety and function) had a much lower correlation with pain than depressive syndrome additionally characterized by anxiety and reduced activity. The inclusion of function increased the predictive value of the models by an approximate factor of 1.5 , that is, by $50 \%$.

the use of valid and reliable assessment tools, and controlling for possible confounders. However, the following limitations have to be stated: the sample consisted of severely affected chronic pain patients, which may limit the generalizability of the results. The cross-sectional assessment principally did not capture time-dependent effects on course, for example, when pain increased by increased depression (only) after a certain time (and vice versa). However, this quantification would be difficult by 2 reasons: to determine the integral of the symptoms over time would require multiple assessment time points with narrow intervals, and latency and symptom threshold to induce pain (or depression) may have wide inter-individual variation.

\section{Acknowledgements}

The authors thank Ms Joy Buchanan and Assistant Professor Haiko Sprott, MD for helping to prepare the manuscript.

\section{Conclusions}

The strengths of the pain-depression association and the "dose-response" relationship were both weak - weaker than to be expected if the hypothesis of a causal relationship were true. In the interpersonally distressed subgroup, the moderate association may have an impact on pain management, that is, pain could be treated by treatment of depression and vice versa. 


\section{References}

1. Carroll L, Cassidy JD, Cote P: The Saskatchewan Health and Back Pain Survey: the prevalence and factors associated with depressive symptomatology in Saskatchewan adults. Canadian journal of public health Revue canadienne de sante publique 2000, 91(6):459-464.

2. Neumann L, Buskila D: Epidemiology of fibromyalgia. Current pain and headache reports 2003, 7(5):362368.

3. Ohayon $\mathrm{MM}$, Schatzberg $\mathrm{AF}$ : Using chronic pain to predict depressive morbidity in the general population. Archives of general psychiatry 2003, 60(1):39-47.

4. Goldenberg DL, Burckhardt C, Crofford L: Management of fibromyalgia syndrome. JAMA : the journal of the American Medical Association 2004, 292(19):2388-2395.

5. Airaksinen O, Brox JI, Cedraschi C, Hildebrandt J, Klaber-Moffett J, Kovacs F, Mannion AF, Reis S, Staal JB, Ursin $\mathrm{H}$ et al: Chapter 4. European guidelines for the management of chronic nonspecific low back pain. European spine journal : official publication of the European Spine Society, the European Spinal Deformity Society, and the European Section of the Cervical Spine Research Society 2006, 15 Suppl 2:S192-300.

6. Fishbain DA, Cutler R, Rosomoff HL, Rosomoff RS: Chronic pain-associated depression: antecedent or consequence of chronic pain? A review. The Clinical journal of pain 1997, 13(2):116-137.

7. O'Malley PG, Balden E, Tomkins G, Santoro J, Kroenke K, Jackson JL: Treatment of fibromyalgia with antidepressants: a meta-analysis. Journal of general internal medicine 2000, 15(9):659-666.

8. Bair MJ, Robinson RL, Katon W, Kroenke K: Depression and pain comorbidity: a literature review. Archives of internal medicine 2003, 163(20):2433-2445.

9. Staiger TO, Gaster B, Sullivan MD, Deyo RA: Systematic review of antidepressants in the treatment of chronic low back pain. Spine 2003, 28(22):2540-2545.

10. Brown GK: A causal analysis of chronic pain and depression. Journal of abnormal psychology 1990, 99(2):127-137.

11. Kuch K: Psychological factors and the development of chronic pain. The Clinical journal of pain 2001, 17(4 Suppl):S33-38.

12. Von Korff M, Simon G: The relationship between pain and depression. The British journal of psychiatry Supplement 1996(30):101-108.

13. Onder G, Landi F, Gambassi G, Liperoti R, Soldato M, Catananti C, Finne-Soveri H, Katona C, Carpenter I, Bernabei R: Association between pain and depression among older adults in Europe: results from the Aged in Home Care (AdHOC) project: a cross-sectional study. The Journal of clinical psychiatry 2005, 66(8):982-988.

14. McWilliams LA, Goodwin RD, Cox BJ: Depression and anxiety associated with three pain conditions: results from a nationally representative sample. Pain 2004, 111(1-2):77-83.

15. Lautenbacher S, Krieg JC: Pain perception in psychiatric disorders: a review of the literature. Journal of psychiatric research 1994, 28(2):109-122.

16. Dersh J, Polatin PB, Gatchel RJ: Chronic pain and psychopathology: research findings and theoretical considerations. Psychosomatic medicine 2002, 64(5):773-786.

17. Krueger RF, Tackett JL, Markon KE: Structural models of comorbidity among common mental disorders: connections to chronic pain. Advances in psychosomatic medicine 2004, 25:63-77.

18. Klossika I, Flor H, Kamping S, Bleichhardt G, Trautmann N, Treede RD, Bohus M, Schmahl C: Emotional modulation of pain: a clinical perspective. Pain 2006, 124(3):264-268.

19. Neuhauser H, Ellert U, Ziese T: [Chronic back pain in the general population in Germany 2002/2003: prevalence and highly affected population groups]. Gesundheitswesen 2005, 67(10):685-693.

20. Raphael KG, Janal MN, Nayak S, Schwartz JE, Gallagher RM: Psychiatric comorbidities in a community sample of women with fibromyalgia. Pain 2006, 124(1-2):117-125.

21. Patten SB, Williams JV, Wang J: Mental disorders in a population sample with musculoskeletal disorders. BMC musculoskeletal disorders 2006, 7:37. 
22. Garcia-Cebrian A, Gandhi P, Demyttenaere K, Peveler R: The association of depression and painful physical symptoms--a review of the European literature. European psychiatry : the journal of the Association of European Psychiatrists 2006, 21(6):379-388.

23. Demyttenaere K, Bruffaerts R, Lee S, Posada-Villa J, Kovess V, Angermeyer MC, Levinson D, de Girolamo $\mathrm{G}$, Nakane H, Mneimneh $\mathrm{Z}$ et al: Mental disorders among persons with chronic back or neck pain: results from the World Mental Health Surveys. Pain 2007, 129(3):332-342.

24. Scott KM, Bruffaerts R, Tsang A, Ormel J, Alonso J, Angermeyer MC, Benjet C, Bromet E, de Girolamo G, de Graaf $\mathrm{R}$ et al: Depression-anxiety relationships with chronic physical conditions: results from the World Mental Health Surveys. Journal of affective disorders 2007, 103(1-3):113-120.

25. Carroll L, Cassidy JD, Cote P: Factors associated with the onset of an episode of depressive symptoms in the general population. Journal of clinical epidemiology 2003, 56(7):651-658.

26. Ohayon MM: Specific characteristics of the pain/depression association in the general population. The Journal of clinical psychiatry 2004, 65 Suppl 12:5-9.

27. Frohlich C, Jacobi F, Wittchen HU: DSM-IV pain disorder in the general population. An exploration of the structure and threshold of medically unexplained pain symptoms. European archives of psychiatry and clinical neuroscience 2006, 256(3):187-196.

28. Badcock L, Lewis M, Hay EM, McCarney R, Croft PR: Chronic shoulder pain in the community: a syndrome of disability or distress? Annals of the rheumatic diseases 2002, 61(2):128-131.

29. Arnow BA, Hunkeler EM, Blasey CM, Lee J, Constantino MJ, Fireman B, Kraemer HC, Dea R, Robinson R, Hayward C: Comorbid depression, chronic pain, and disability in primary care. Psychosomatic medicine 2006, 68(2):262-268.

30. Landi F, Onder G, Cesari M, Russo A, Barillaro C, Bernabei R, Group S-HS: Pain and its relation to depressive symptoms in frail older people living in the community: an observational study. Journal of pain and symptom management 2005, 29(3):255-262.

31. Geerlings SW, Twisk JW, Beekman AT, Deeg DJ, van Tilburg W: Longitudinal relationship between pain and depression in older adults: sex, age and physical disability. Social psychiatry and psychiatric epidemiology 2002, 37(1):23-30.

32. Arnold LM, Hudson JI, Keck PE, Auchenbach MB, Javaras KN, Hess EV: Comorbidity of fibromyalgia and psychiatric disorders. The Journal of clinical psychiatry 2006, 67(8):1219-1225.

33. Genet F, Lapeyre E, Schnitzler A, Hausseguy A, D'Apolito AC, Lafaye de Michaux R, Regrain E, Revel M, Poiraudeau S: [Psychobehavioral assessment for chronic low back pain]. Annales de readaptation et de medecine physique : revue scientifique de la Societe francaise de reeducation fonctionnelle de readaptation et de medecine physique 2006, 49(5):226-233.

34. Turk DC, Okifuji A, Scharff L: Chronic pain and depression: role of perceived impact and perceived control in different age cohorts. Pain 1995, 61(1):93-101.

35. McBeth J, Macfarlane GJ, Silman AJ: Does chronic pain predict future psychological distress? Pain 2002, 96(3):239-245.

36. Angst F, Brioschi R, Main CJ, Lehmann S, Aeschlimann A: Interdisciplinary rehabilitation in fibromyalgia and chronic back pain: a prospective outcome study. The journal of pain : official journal of the American Pain Society 2006, 7(11):807-815.

37. Wolfe F, Smythe HA, Yunus MB, Bennett RM, Bombardier C, Goldenberg DL, Tugwell P, Campbell SM, Abeles M, Clark P et al: The American College of Rheumatology 1990 Criteria for the Classification of Fibromyalgia. Report of the Multicenter Criteria Committee. Arthritis and rheumatism 1990, 33(2):160172.

38. Ware JE, Kosinski M, Gandek B: SF-36 health survey: manual and interpretation guide, vol. 5, 3 edn. Lincoln, RI: QualityMetric Incorporated; 2004.

39. Bullinger M, Kirchberger I: SF-36 Fragebogen zum Gesundheitszustand - Handanweisung, 1998 edn. Göttingen: Hogrefe; 1998.

40. Kerns RD, Turk DC, Rudy TE: The West Haven-Yale Multidimensional Pain Inventory (WHYMPI). Pain 1985, 23(4):345-356. 
41. Flor H, Rudy TE, Birbaumer N, Streit B, Schugens MM: [The applicability of the West Haven-Yale multidimensional pain inventory in German-speaking countries. Data on the reliability and validity of the MPI-D.]. Schmerz 1990, 4(2):82-87.

42. Zigmond AS, Snaith RP: The hospital anxiety and depression scale. Acta psychiatrica Scandinavica 1983, 67(6):361-370.

43. Herrmann C, Buss U, Snaith RP: HADS-D: Hospital Anxiety and Depression Scale-Deutsche Version. Ein Fragebogenzur Erfassung von Angst und Depressivität in der somatischen Medizin. Berne, Switzerland: Verlag Hans Huber; 1995.

44. Farrar JT, Young JP, Jr., LaMoreaux L, Werth JL, Poole RM: Clinical importance of changes in chronic pain intensity measured on an 11-point numerical pain rating scale. Pain 2001, 94(2):149-158.

45. Rosner B: Rank correlation. In: Fundamentals of biostatistics. 5 edn. Edited by Rosner B. Boston: PWSKent; 2000: 496-502.

46. Portney LG, Watkins MP: Multivariate analysis. In: Foundations of clinical research: applications to practice. 2 edn. Upper Saddle River, NJ: Prentice Hall Health; 2000: 587-597.

47. Beck JG, Chase TJ, Berisford MA, Taegtmeyer H: Pain profiles of patients with nonorganic chest pain: a preliminary report of the Multidimensional Pain Inventory. Journal of pain and symptom management 1992, 7(8):470-477.

48. Bjelland I, Dahl AA, Haug TT, Neckelmann D: The validity of the Hospital Anxiety and Depression Scale. An updated literature review. Journal of psychosomatic research 2002, 52(2):69-77.

49. Backhaus K: Faktorenanalyse, logistische Regression, Clusteranalyse. In: Multivariate Analysemethoden. 10 edn. Edited by Backhaus K, Erichson B, Plinke W. Berlin: Springer; 2003: 259-542.

50. Turk DC, Rudy TE: Toward an empirically derived taxonomy of chronic pain patients: integration of psychological assessment data. Journal of consulting and clinical psychology 1988, 56(2):233-238.

51. Turk DC, Okifuji A, Sinclair JD, Starz TW: Pain, disability, and physical functioning in subgroups of patients with fibromyalgia. The Journal of rheumatology 1996, 23(7):1255-1262.

52. Jamison RN, Rudy TE, Penzien DB, Mosley TH, Jr.: Cognitive-behavioral classifications of chronic pain: replication and extension of empirically derived patient profiles. Pain 1994, 57(3):277-292.

53. Turk DC, Okifuji A, Sinclair JD, Starz TW: Differential responses by psychosocial subgroups of fibromyalgia syndrome patients to an interdisciplinary treatment. Arthritis care and research : the official journal of the Arthritis Health Professions Association 1998, 11(5):397-404.

54. Johansson $E$, Lindberg $P$ : Low back pain patients in primary care: subgroups based on the Multidimensional Pain Inventory. Int J Behavioral Med 2000, 7(4):340-352.

55. Thieme K, Spies C, Sinha P, Turk DC, Flor H: Predictors of pain behaviors in fibromyalgia syndrome. Arthritis and rheumatism 2005, 53(3):343-350.

56. Abrahamson JH, Abrahamson ZH: Measures of strength. In: Making sense of data: a selfinstruction manual on the interpretation of epidemiologic data. 3 edn. Edited by Abrahamson JH, Abrahamson ZH. Oxford: Oxford University Press; 2001: 200-201.

57. Calabrese SK, Lyness JM, Sorensen S, Duberstein PR: Personality and the association of pain and depression. The American journal of geriatric psychiatry : official journal of the American Association for Geriatric Psychiatry 2006, 14(6):546-549.

58. Hofler M: The Bradford Hill considerations on causality: a counterfactual perspective. Emerging themes in epidemiology 2005, 2:11.

59. Rothman KJ, Greenland S: Causation and causal inference in epidemiology. American journal of public health 2005, 95 Suppl 1:S144-150.

60. Bergstrom G, Bodin L, Jensen IB, Linton SJ, Nygren AL: Long-term, non-specific spinal pain: reliable and valid subgroups of patients. Behavior research and therapy 2001, 39(1):75-87.

61. King SJ, Wessel J, Bhambhani Y, Sholter D, Maksymowych W: Predictors of success of intervention programs for persons with fibromyalgia. The Journal of rheumatology 2002, 29(5):1034-1040. 
PART II

Evaluation studies 



\section{CHAPTER 5}

\section{Does classification of persons with}

fibromyalgia into Multidimensional Pain Inventory subgroups detect differences in outcome after a standard chronic pain management program?

Verra ML, Angst F, Brioschi R, Lehmann S, Keefe FJ, Staal JB, de Bie RA, Aeschlimann A. Does classification of persons with fibromyalgia into Multidimensional Pain Inventory subgroups detect differences in outcome after a standard pain management program? Pain Research and Management 2009;14(6):445-453. 


\section{Abstract}

Objectives. The present study aimed to replicate and validate the empirically derived subgroup classification based on the Multidimensional Pain Inventory (MPI) in a sample of highly disabled fibromyalgia patients. Second, it examined how the identified subgroups differed in their response to an intensive, interdisciplinary inpatient pain management program.

Methods. Participants were 118 persons with fibromyalgia who experienced persistent pain and were disabled. Subgroup classification was conducted by cluster analysis using MPI subscale scores at entry to the program. At program entry and discharge, participants completed the MPI, Medical Outcomes Study Short Form-36, Hospital Anxiety and Depression Scale, and the Coping Strategies Questionnaire.

Results. Cluster analysis identified three subgroups in this highly disabled sample that were similar to those described by other studies using less disabled samples of fibromyalgia. The dysfunctional subgroup (DYS; $36 \%$ of the sample) showed the highest level of depression, the interpersonally distressed subgroup (ID; $24 \%$ ) showed a modest level of depression and the adaptive copers subgroup (AC; 38\%) showed the lowest depression scores in the MPI (negative mood), Medical Outcomes Study Short Form-36 (mental health), Hospital Anxiety and Depression Scale (depression), and Coping Strategies Questionnaire (catastrophizing). Significant differences in treatment outcome were observed among the three subgroups in terms of reduction of pain severity (as assessed using the MPI). The effect sizes were 1.42 for DYS, 1.32 for AC, and 0.62 for ID ( $p$ $=0.004$ for pair wise comparison of ID-AC and $p=0.018$ for ID-DYS).

Conclusions. These findings underscore the importance of assessing individuals' differences in how they adjust to fibromyalgia. 


\section{Introduction}

People with fibromyalgia, classified according the American College of Rheumatology 1990 criteria [1], are viewed as a homogeneous group. However, both health care professionals and researchers often state that fibromyalgia patients with widespread pain for at least six months in combination with tenderness at 11 or more of the 18 specific tender point sites are extremely heterogeneous with regard to their biopsychosocial impairments and responsiveness to interventions. Classification of people with fibromyalgia into homogeneous subgroups may be an important objective in order to tailor interventions and to control for subgroup differences when evaluating treatment outcome. The process of subclassification is a clinical reality, but is often undertaken on an individual level and in an unstructured way [2]. Recent research shows that persons with fibromyalgia have profiles showing difficulties in both the physical, and functional and psycho-social realms [3, 4]. Several research groups identified subgroups of people with fibromyalgia on the basis of fear of pain, readiness to adopt a self-management approach to chronic pain, or psychosocial and behavioral responses to pain [5-7].

The Multidimensional Pain Inventory (MPI), which measures a number of psychosocial and behavioral variables, has been used to identify subgroups of people with chronic musculoskeletal pain in different settings and with different biomedical diagnosis [8, 9]. Persons with temporomandibular disorders [7], whiplash-associated disorders [10], and back pain $[6,11-13]$ have been classified into empirically derived subgroups based on analyses of the scales of the MPI. In the studies cited above, the MPI differentiated between three distinct subgroups labelled as adaptive copers (AC), dysfunctional (DYS), and interpersonally distressed (ID) $[9,14]$. The ID cluster is mainly characterized by lower levels of perceived solicitous and distraction responses from the patients' partners or spouses and higher levels of punishing responses compared with the AC and DYS clusters. The AC cluster, compared with the other two subgroups, is characterized by less pain severity, less interference with everyday life due to pain and less affective distress, as well as more perception of life control and higher activity level. The persons of the DYS cluster report high pain severity, high interference and activity distress, low life control and low activity level.

Several studies have attempted to identify MPI subgroups in persons with fibromyalgia $[7,15,16]$. These studies have found the same three subgroups identified in other populations. At least one study has found that subgroup membership is related to the outcome of an outpatient multidisciplinary pain management program. Although the results of these studies are interesting, they were obtained from samples of fibromyalgia patients who were outpatients and much less disabled than those typically seen in inpatient pain management programs.

The aims of the present study were to investigate whether it was possible to replicate and describe the three MPI cluster solution and profiles found in less disabled American sample of outpatients with fibromyalgia in a more disabled German-speaking 
sample of patients with fibromyalgia treated in an intensive inpatient pain management program; validate the three-cluster solution by comparing the three clusters with measures of pain, psycho-social function, physical and mental health, anxiety and depression, and chronic pain coping strategies; and examine the effects of cluster membership on the outcome of a standardized four-week interdisciplinary in-patient pain management program.

The first hypothesis was that moderate validity would be found between the MPI subgroups and the corresponding subscales of the Medical Outcome Study Short Form36 (SF-36) - especially worst physical functioning and mental health in the DYS subgroup; the Hospital Anxiety and Depression Scale (HADS) - especially most anxiety and depression in the DYS subgroup; and the Coping Strategies Questionnaire (CSQ) - especially most catastrophizing in the DYS subgroup. Second, we hypothesized that, with pair wise comparisons between subgroups, the most significant differences in effect sizes after the standard pain management program would be seen between the AC and DYS subgroups (with highest effect sizes for DYS).

\section{Methods}

\section{Setting and participants}

The present study was conducted at the rehabilitation clinic "RehaClinic" (Bad Zurzach, Switzerland), which is attended by disabled patients having persistent pain and come from all German-speaking countries in Europe. This report is an extension of the recently published cohort study [17].

All subjects included in the study suffered from fibromyalgia according to the American College of Rheumatology criteria [1], had pain for at least six months and were disabled by their pain enough to warrant admission to an intensive inpatient pain management program. Further inclusion criteria included the ability to complete selfassessment questionnaires, which especially requires sufficient German language skills, and psycho-intellectual abilities; and written, signed informed consent. The patients with fibromyalgia were participants in the "Zurzach Interdisciplinary Pain (German: Schmerz) Program". The program is a four-week, in-house, standardized, interdisciplinary pain management program. This program has three main components: medical care (including adapted drug therapy), exercise therapy and psychotherapy (mainly cognitive and operant behavioral therapy) - a total over $100 \mathrm{~h}$ of therapy. The program is intensive. Over the course of treatment patients received, on average, six daily sessions of the following treatments: physiotherapy, aerobic endurance training, qigong and tai chi exercises, individual psychotherapy including cognitive behavioral therapy, participation in a pain coping group, relaxation therapy, humor therapy, information and education about pathophysiology of pain mechanisms and management of chronic 
disabling pain, nursery care, and regular medical consultations including drug therapy. Individual treatment strategies were identified and discussed during the interdisciplinary meetings of the pain management team ( $2 \mathrm{~h}$ per week for six patients). Detailed information on inclusion and exclusion criteria, as well as interdisciplinary treatment goals, are published elsewhere [17].

The present study's protocol was approved by the Independent Local Ethic Commission (Health Department in Aarau, Switzerland, no. EK AG 2008/026).

\section{Outcome measures}

\section{Sociodemographic data and comorbidities}

Sociodemographic data were collected using a standardized questionnaire from a previous study [18]. Additional information about physical and mental comorbidities and medication were obtained from the medical records.

\section{Psycho-social and behavioral aspects of chronic pain}

The West Haven-Yale Multidimensional Pain Inventory (MPI) assesses pain and its consequences in terms of symptoms, disability, activity, behavior, mood and social relationships [8]. The German version of the Multidimensional Pain Inventory (MPI-D) is a self-reported 51-item inventory with 11 subscales: "pain severity", "interference with pain", "life control", "affective distress" (synonymously described as "negative mood"), "support", "punishing responses", "solicitous responses", "distracting responses", "social and recreational activities", "household chores", and "activities away from home" [19]. The last three subscales can be summarized into one subscale - "general activities". The range of each subscale is 0 to 6 (seven points). The internal consistency coefficient of MPI-D subscales has been reported to range from 0.63 to 0.94 , and the testretest intra-class correlation coefficient ranges from 0.46 to 0.93 [20].

For external validation of the cluster solution and calculation of effect sizes (entry = baseline in pain program - discharge after 4 weeks), the instruments listed below were used.

\section{Health related quality of life}

The Medical Outcome Study Short Form-36 (SF-36) is a self-administered generic instrument that assesses health-related quality of life [21]. It consists of four physical scales ("physical functioning", "role physical", "bodily pain" and "'general health") and four mental scales ("vitality", "social functioning", "role emotional" and "mental health"). "The SF-36 has been implemented in numerous studies in over 40 languages worldwide and its clinimetric quality has been proven in various settings. The reliability of SF-36 scale scores, estimated using internal consistency methods for 3455 patients, vary with a range of coefficients from 0.65 to 0.94 . Test-retest reliability scale scores, measured over a two-week interval, vary from 0.60 to 0.81 [22]. The validated German 
version of the SF-36 was used to enquire about symptoms and functioning during the preceding four weeks [23].

\section{Anxiety and depression}

The Hospital Anxiety and Depression Scale (HADS) is a short, self-rating measure of anxiety and depression (seven items each), these being two of the most important affective health dimensions for people with chronic musculoskeletal pain [24]. The questionnaire was developed for the evaluation of persons in a nonpsychiatric setting, has a long history of application in chronic pain management and has been well tested in large populations and patient surveys [25]. The validated German version (HADS-D) was used. The internal consistency coefficients of the HADS-D subscales are 0.80 (anxiety subscale) and 0.81 (depression subscale). The split-half coefficient is 0.81 for both scales [26].

\section{Coping}

The Coping Strategies Questionnaire (CSQ) is an internationally used self-report instrument to assess active and passive coping strategies: it is used by individuals with chronic pain $[27,28]$. This widely used measure is a 48 -item questionnaire that assesses six cognitive ("diverting attention", "reinterpreting pain sensations", "coping selfstatements", "ignoring pain sensations", "praying or hoping", and "catastrophizing") and two behavioral coping strategies ("increasing activity level" and "increasing pain behaviors"). Each domain comprises six items, and participants rate the frequency of their use of specific coping strategies on a seven-point Likert scale from 0 (i.e. "never do that") to 6 (i.e. "always do that"). The CSQ also includes two one-item scales that assess participants' subjective ability to control or decrease their pain. These two scales measure the perceived effectiveness of participants' coping strategies. Using a similar seven-point Likert scale, participants rate their ability from 0 to 6 , with 0 signifying "no control/no ability to decrease pain", and 6 signifying "complete control/complete ability to decrease pain". The validated German version of the CSQ (CSQ-D) was used, which is a translation and cross-cultural adaptation of the original questionnaire. The internal consistency coefficient of the CSQ-D subscales has been reported to range from 0.71 to 0.97 , and the test-retest intraclass correlation coefficient ranges from 0.55 to 0.93 [29].

\section{Statistical analysis}

The outcome measures were administered on entry to the clinic (baseline, pretreatment) and at discharge from the rehabilitation clinic after four weeks (posttreatment). Other than as an outcome measure, the baseline scores of the scales of the MPI were used for subgroup classification. 
The scores of the SF-36, HADS, CSQ, MPI "life control", MPI "support", MPI "solicitous responses", MPI "distracting responses" and MPI "general activities" were scaled from 0 (maximal pain/maximal disability/maximal symptoms/worst coping) to 100 (no pain/full function/no symptoms/best coping) based on a procedure originally described in the SF-36 manual. This scaling was performed to ease comparison of the clusters on these external validation measures. According to the subgroup classification of Turk and Rudy, the MPI "pain severity", MPI "interference with pain", MPI "affective distress" and MPI "punishing responses" were scaled from 0 (best) to 100 (worst). Descriptive statistics were determined according to the "missing rules" of the instruments' scores; i.e. at least $50 \%$ valid items per scale for the SF-36, two of three valid items for the MPI and the CSQ, and at least six of seven valid items for the HADS.

According to Turk and Rudy [9], the empirically derived subgroups were defined by confirmatory cluster analysis using a predefined three-cluster solution. Cluster analysis is an exploratory method by which multiple sources of information are analyzed simultaneously to group individuals into clusters. Individuals within a cluster are similar to each other on the variables included in the statistical analysis and differ significantly from those in the other cluster groups. The MPI score patterns were depicted as graphs of the mean MPI baseline scores and compared to the patterns described by Turk et al. using the rank orders of the three subgroups within one MPI scale. To assess whether a three-cluster solution was appropriate according to mathematical criteria, hierarchical cluster analysis according to the Ward method was performed [30]. The resulting diagram with the number of clusters and the course of the sum of residual squares did not favour a three-cluster solution (data not shown in detail). However, factor analysis revealed that a factor solution fitted best with three factors explaining $67.4 \%$ of the variance. Thus, the proposed "best feasible" (i.e. clinically characterized) empirically determined solution according to the subgroups defined by Turk et al. was chosen.

To test validity, the SF-36, HADS and CSQ scores had to show the same or similar patterns (across the three subgroups) within the sub scores with a similar construct; e.g. the pattern of the MPI "pain severity" was compared with the SF-36 "bodily pain", and the MPI "negative mood" was compared with SF-36 "mental health", HADS "depression", and CSQ "catastrophizing" [31]. Pairwise analyses between the three MPI subgroups were tested using the Mann-Whitney-U-test for significance (type-one error 0.05).

Effect sizes (ES) were determined by the score difference between entry (baseline) and discharge, divided by the group standard deviation at entry for the whole sample and the three subgroups [32]. Positive ES indicate improvement of the pain condition, while negative ES indicate worsening after completion of the pain management program. An ES of 0.80 or greater is considered as large, 0.50 to 0.79 as moderate, 0.20 to 0.49 as small and 0.00 to 0.19 as very small [32]. Pairwise analyses between the three MPI subgroups were tested using the Mann-Whitney-U-test for significance (type one error 0.05 ). The minimal clinically important difference (MCID), which is principally a 
method to assess the smallest effect that patients perceive to be beneficial, was added to get an impression of the clinical relevance of the effects at discharge[33]. If the MCID is less than the lower limit of the $95 \%$ confidence interval $(95 \% \mathrm{CI})$, results are likely to be statistically significant and clinically important [34]. If the MCID is greater than the upper limit of the $95 \% \mathrm{Cl}$, results are likely to be clinically unimportant. If the MCID lies within the limits of the $95 \% \mathrm{Cl}$, it is unclear whether the effect is clinically important. All analyses were performed using the statistical software package SPSS 16.0 for Windows (SPSS Inc, USA).

\section{Results}

\section{Participants at baseline}

Table 1 describes the demographic and medical data of the total sample of patients with fibromyalgia on entry into the pain management program $(n=118)$. The present sample is an extension of the recently published cohort study of 65 persons with fibromyalgia [17]. The subjects were characterized by a relatively young age, a long history of pain, high levels of pain, high physical disability, high prevalence and high levels of depression and anxiety, and low psychosocial functioning, as characterized by far lower scores than expected by general population norms for SF-36 and HADS. 
Table 1. Demographic and medical data for the total sample of persons with fibromyalgia at entry to the pain program $(n=118)$

\begin{tabular}{|c|c|}
\hline Age, mean $\pm s$ (range), years & $45.5 \pm 9.84(19.7-67.2)$ \\
\hline Female sex & 95.8 \\
\hline \multicolumn{2}{|l|}{ Marital status } \\
\hline Single & 16.7 \\
\hline Married & 68.4 \\
\hline Other & 14.9 \\
\hline \multicolumn{2}{|l|}{ Education } \\
\hline Grade $10-12$ & 31.6 \\
\hline High school graduate & 50.0 \\
\hline College graduate & 12.3 \\
\hline University & 6.1 \\
\hline \multicolumn{2}{|l|}{ Employment status } \\
\hline Full time & 12.3 \\
\hline Part time & 43.0 \\
\hline Unemployed & 42.1 \\
\hline Retired & 0.6 \\
\hline \multicolumn{2}{|l|}{ Use of medication } \\
\hline No medication & 3.4 \\
\hline NSAR or acetaminophen & 49.3 \\
\hline Opioids or opiates & 17.0 \\
\hline Antidepressants & 20.4 \\
\hline \multicolumn{2}{|l|}{ Depression } \\
\hline No depression & 28.0 \\
\hline Depression & 72.0 \\
\hline \multicolumn{2}{|l|}{ Pain duration } \\
\hline 7-12 months & 3.5 \\
\hline 13 - 24 months & 9.6 \\
\hline $25-36$ months & 7.0 \\
\hline $37-48$ months & 7.0 \\
\hline $49-60$ months & 27.8 \\
\hline$>5$ years & 44.1 \\
\hline
\end{tabular}

Abbreviations: s, standard deviation; NSAR, nonsteroidal antirheumatic NOTE. Data presented as percentages unless otherwise indicated.

\section{Classification of persons with fibromyalgia by the MPI into subgroups}

Table 2 and Figure 1 show the mean baseline scores of the MPI. A total of 116 of 118 patients with fibromyalgia could be allocated to one of the three chronic pain subgroups obtained by cluster analysis of all MPI scales, according to the concept of Turk et al.[7, 9]. Twenty-four percent $(n=28)$ were classified as "interpersonally Distressed" (ID), 38\% ( $n=45)$ were classified as "Adaptive Copers" (AC) and 36\% $(n=43)$ were classified as "Dysfunctional" (DYS). The two remaining persons with fibromyalgia were classified as "anomalous" (did not fit into any of the 3 profiles). With the exception of pain duration - persons with fibromyalgia in the DYS cluster had shorter pain duration than people in the AC and ID clusters - no significant differences in demographic and 
medical baseline data were found between the three clusters (data not shown in detail).

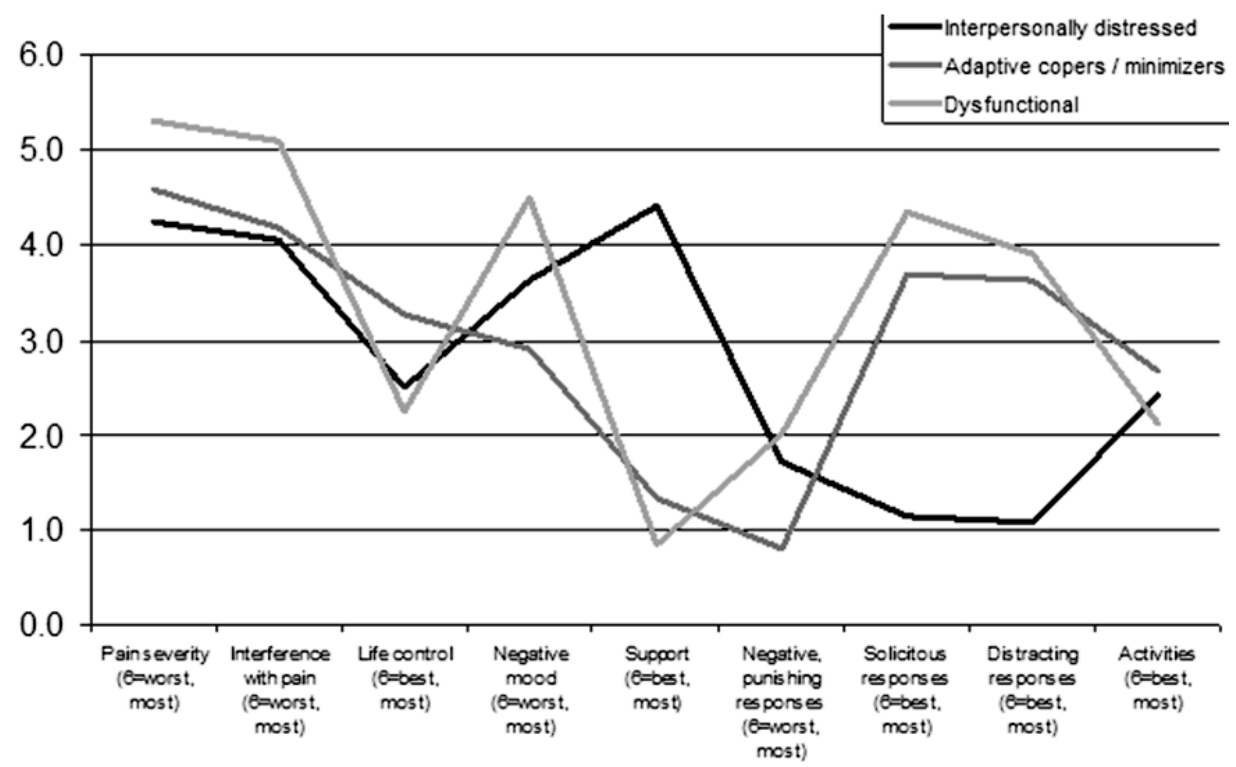

Figure 1. Mean baseline scores for patient profiles on the German version of the Multidimensional Pain Inventory

Table 2. Mean Multidimensional Pain Inventory subscale baseline scores and pairwise analyses for significance of the three cluster groups

\begin{tabular}{|c|c|c|c|c|c|c|}
\hline MPI subscales & ID $(n=28)$ & $A C(n=45)$ & DYS $(n=43)$ & ID-AC & ID-DYS & AC-DYS \\
\hline Pain severity (6=worst, most) & $4.3 \pm 1.0$ & $4.6 \pm 0.8$ & $5.3 \pm 0.6$ & 0.090 & $<0.001^{*}$ & $<0.001^{*}$ \\
\hline Interference with pain ( $6=$ worst, most) & $4.0 \pm 1.6$ & $4.2 \pm 0.9$ & $5.1 \pm 0.5$ & ns & $<0.001^{*}$ & $<0.001^{*}$ \\
\hline Life control (6=best, most) & $2.5 \pm 1.1$ & $3.3 \pm 1.2$ & $2.3 \pm 1.1$ & $0.010^{*}$ & 0.193 & $<0.001^{*}$ \\
\hline Affective distress ( $6=$ worst, most) & $3.6 \pm 1.2$ & $2.9 \pm 1.0$ & $4.5 \pm 0.8$ & $0.011^{*}$ & $0.001^{*}$ & $<0.001^{*}$ \\
\hline Support (6=best, most) & $1.6 \pm 1.2$ & $4.7 \pm 1.1$ & $5.2 \pm 1.0$ & $<0.001 *$ & $<0.001 *$ & $0.026^{*}$ \\
\hline Punishing responses ( $6=$ worst, most) & $1.7 \pm 1.8$ & $0.8 \pm 0.9$ & $2.0 \pm 1.5$ & 0.086 & ns & $<0.001^{*}$ \\
\hline Solicitous responses ( $6=$ best, most) & $1.1 \pm 1.0$ & $3.7 \pm 1.2$ & $4.3 \pm 1.1$ & $<0.001 *$ & $<0.001^{*}$ & $0.018^{*}$ \\
\hline Distracting responses ( $6=$ best, most) & $1.1 \pm 1.2$ & $3.6 \pm 1.4$ & $3.9 \pm 1.2$ & $<0.001 *$ & $<0.001^{*}$ & ns \\
\hline General activities ( $6=$ best, most) & $2.4 \pm 0.9$ & $2.7 \pm 0.7$ & $2.1 \pm 0.8$ & ns & ns & $0.001^{*}$ \\
\hline
\end{tabular}

Abbreviations: MPI, Multidimensional Pain Inventory; ID, MPI cluster interpersonally distressed; AC, MPI cluster adaptive copers; DYS, MPI cluster dysfunctional; *Significance level $p \leq 0.0050$; ns, not significant $(p>0.050)$

NOTE. Data presented as mean \pm standard deviation unless other indicated. 


\section{Validation of the subgroup classification}

Table 3 shows the mean baseline scores and standard deviations of the scales of the SF36, HADS, and CSQ for the three MPI cluster groups. Comparing the results of Table 2 and Table 3, the scores of the subgroups of the SF-36, HADS and CSQ showed almost the same pattern as the MPI. On the MPI "pain severity", the rank order of the three cluster subgroups in terms of reported pain was DYS (most pain), AC, and ID (least pain). This same order was found on the SF-36 "bodily pain"; DYS showed most pain (bodily pain 10.7; $p=0.005$, comparing ID with DYS; $p=0.014$ comparing AC with DYS). The MPI "general activities" was compared to SF-36 "physical functioning"; DYS showed the lowest activity level ("physical functioning" 26.1; $p=0.001$, comparing ID with DYS and AC with DYS). The same was consistently true when comparing MPI "interference with pain" with SF-36 "physical functioning". The mean baseline score of MPI "life control" was compared to the score of CSQ "ability to control pain"; AC had best control (48.2; $p=0.016$ comparing ID with AC). The MPI "affective distress" was compared to the SF-36 "mental health", HADS "Depression" and "Anxiety", and CSQ "Catastrophizing"; DYS showed most and AC the least affective symptoms in all scales (significant differences in various pairwise subgroup comparisons). It was not possible to replicate the specific MPI characteristics of the ID subgroup (punishing responses and lack of support by partner or spouse) because the scores of the subscales of the SF-36, HADS and CSQ are not able to measure social support. Overall, the differences of scores between the three clusters were in agreement with theoretical expectations and implied support for moderate validity.

\section{Differential treatment responses within the MPI subgroups}

Table 4 shows significant differences between the scores of the ES of pairwise comparisons between the three MPI subgroups that were found for four MPI scales (pain severity, interference with pain, affective distress and support), two SF-36 scales (physical functioning and social functioning) and three CSQ scales (increasing activity level, ability to control pain and ability to decrease pain). For example, significant differences in treatment outcome were observed among the three subgroups in terms of pain severity, as assessed using the MPI. The ES were 1.42 for DYS, 1.32 for AC, and 0.62 for ID ( $p=$ 0.004 for pair wise comparison of ID-AC and $p=0.018$ for ID-DYS). Also, significant differences in treatment outcome could be measured in terms of physical functioning, as assessed using the SF-36. The ES were 0.82 for DYS, 0.69 for AC, and 0.22 for ID ( $p=$ 0.028 for pair wise comparison of ID-AC and $p=0.090$ for ID-DYS). 
Table 3. Mean baseline scores and pair wise analyses for significance of the scales of the SF-36, HADS, and CSQ for the three MPI cluster groups

\begin{tabular}{|c|c|c|c|c|c|c|}
\hline \multirow[b]{2}{*}{ Subscales } & \multirow[b]{2}{*}{ ID $(n=28)$} & \multirow[b]{2}{*}{$A C(n=45)$} & \multirow[b]{2}{*}{ DYS $(n=43)$} & \multicolumn{3}{|l|}{$\underline{p}$} \\
\hline & & & & ID-AC & ID-DYS & AC-DYS \\
\hline \multicolumn{7}{|l|}{ SF-36 (100 = best $)$} \\
\hline Physical functioning & $43.6 \pm 22.2$ & $40.1 \pm 13.4$ & $26.1 \pm 15.8$ & ns & 0.001 & 0.001 \\
\hline Bodily pain & $19.9 \pm 14.0$ & $18.0 \pm 14.5$ & $10.7 \pm 10.7$ & ns & 0.005 & 0.01 \\
\hline General health & $37.3 \pm 13.0$ & $42.2 \pm 14.3$ & $34.5 \pm 12.1$ & ns & ns & 0.015 \\
\hline Vitality & $19.8 \pm 16.4$ & $26.7 \pm 15.6$ & $16.1 \pm 14.3$ & 0.092 & ns & $<0.001$ \\
\hline Social functioning & $36.4 \pm 19.9$ & $44.4 \pm 24.1$ & $35.7 \pm 26.1$ & ns & ns & 0.086 \\
\hline Role emotional & $17.8 \pm 26.4$ & $38.5 \pm 43.8$ & $16.3 \pm 32.0$ & 0.083 & ns & 0.009 \\
\hline Mental health & $42.3 \pm 17.5$ & $52.1 \pm 16.3$ & $32.3 \pm 15.2$ & 0.074 & 0.006 & $<0.001$ \\
\hline \multicolumn{7}{|c|}{ HADS (100 = no anxiety or depression) } \\
\hline Anxiety & $47.6 \pm 20.2$ & $55.0 \pm 20.1$ & $37.9 \pm 18.6$ & ns & 0.053 & $<0.001$ \\
\hline Depression & $51.4 \pm 20.5$ & $63.5 \pm 17.1$ & $45.9 \pm 18.4$ & 0.009 & ns & $<0.001$ \\
\hline \multicolumn{7}{|l|}{$\operatorname{CSQ}(100=$ best $)$} \\
\hline Diverting attention & $42.4 \pm 18.0$ & $54.4 \pm 18.7$ & $54.5 \pm 16.7$ & 0.007 & 0.005 & ns \\
\hline Praying or hoping & $58.8 \pm 22.9$ & $50.7 \pm 25.2$ & $41.5 \pm 21.6$ & ns & 0.002 & ns \\
\hline Catastrophizing & $44.6 \pm 15.5$ & $52.2 \pm 19.1$ & $33.9 \pm 16.3$ & ns & 0.003 & $<0.001$ \\
\hline Increasing activity level & $52.5 \pm 15.3$ & $58.4 \pm 15.4$ & $58.0 \pm 15.8$ & 0.090 & ns & ns \\
\hline Pain behaviors & $56.6 \pm 12.4$ & $60.2 \pm 14.1$ & $66.0 \pm 13.3$ & ns & 0.007 & 0.070 \\
\hline Ability to control pain & $34.5 \pm 23.1$ & $48.2 \pm 22.5$ & $41.7 \pm 23.4$ & 0.016 & ns & ns \\
\hline Ability to decrease pain & $25.6 \pm 17.9$ & $45.2 \pm 20.6$ & $36.5 \pm 19.9$ & 0.001 & 0.030 & 0.051 \\
\hline
\end{tabular}

Abbreviations: MPI, Multidimensional Pain Inventory; SF-36, Medical Outcome Studies - Short Form 36; HADS, Hospital Anxiety and Depression Scale; CSQ, Coping Strategies Questionnaire; ID, MPI cluster interpersonally distressed; AC, MPI cluster adaptive copers; DYS, MPI cluster dysfunctional; $p$, significance level $p \leq$ 0.0050 ; ns, not significant $(p>0.050)$

NOTE. Data presented as mean \pm standard deviation. 
Comparing the three MPI subgroups, the DYS cluster showed the highest effects in MPI "pain severity" (ES = 1.42) and "interference with pain" (ES = 1.55), SF-36 "physical functioning" (ES = 0.82), but also the least improvement in SF-36 "social functioning" (ES = 0.40), worsening in CSQ "increasing activity level" (ES = -0.17), and the least improvement in CSQ "ability to control pain" (ES $=0.19$ ) and "ability to decrease pain" (ES $=0.41$ ). The AC cluster showed most improvement in MPI "support" (ES $=0.39$ ) and CSQ "increasing activity level" (ES = 0.27).

\section{Discussion}

\section{Summary of main findings}

The findings of the present study showed that the MPI subgroups previously identified in less disabled samples of fibromyalgia patients are also evident in a highly disabled fibromyalgia sample. The three subgroups identified (DYS, ID and AC) showed significant differences in pain severity outcomes following a standard inpatient pain management program. The results of the present study suggest that, by attending to fibromyalgia patients' subgroup status, one may be able to individualize some of the patient management efforts.

\section{Comparison with other studies}

Our results after completing the four-week pain management program challenge the conclusions of the study of Turk et al. An analysis of 48 American patients with fibromyalgia, who completed a six-half day outpatient pain management program consisting of medical, physical, occupational, and psychological therapies spaced over a period of four weeks, revealed that persons in the DYS subgroup seemed to benefit most from the pain program. After completing this less intensive pain program, these persons showed significant improvement in pain severity, self-reported disability and psychological distress. In contrast, the persons in the AC subgroup showed significant improvement in pain severity but their self-reported psychological distress and disability did not change (Table 5). Therefore, Turk et al.[15] raised the question of whether these persons with fibromyalgia actually require all the components of the outpatient pain management program. In another study by King et al. $[35,36]$, the subjects were randomly assigned into one of three interventions (exercise only, education only, or a combination of exercise and education, one to three times per week) or a control group. This study $(n=128)$ stated that no MPI subgroup responded more than another subgroup on any of the instruments involved. With the exceptions of pain severity and depression in the DYS subgroup, our patients showed larger ES in all subgroups when 
compared to the study of Turk et al. mentioned previously (Table 5). Especially in the ID subgroup (physical functioning) and the AC subgroup (physical functioning and depression), in which Turk et al. found no effect (ES $=-0.03$ to 0.01 ), our patients showed at least small ( $E S=0.22$ ) to moderate ( $E S=0.50$ and 0.69 ) ES. One explanation may be the different interventions and differences in treatment intensity. Our standard four-week inpatient pain management program involved a broad array of chronic pain management strategies (active individual physiotherapy, aerobic endurance training, individual psychology, participation in a pain coping group, relaxation therapy, humor therapy, occupational therapy, qigong and tai chi, information about neurophysiology of pain and the possible contribution of psycho-social aspects in chronic pain, nursery care, and medical consultations including drug therapy) and was more intense; therapies were administered up to six h per day and six days per week [17]. Another explanation may be that, although the patients in the AC subgroup at entry to the pain program scored better than the other two subgroups, their burden of disease was nevertheless substantial compared with available normative data collected from healthier outpatient samples.

Table 5. Comparison of differences in effect sizes (entry-discharge) between the American four-week outpatient pain management program ([15] ; six half-days) and the present Swiss four-week inpatient pain management program (Verra et al; 29 days, up to $6 \mathrm{~h}$ of therapy per day)

\begin{tabular}{lllllll}
\hline & \multicolumn{2}{l}{ Dysfunctional ES } & \multicolumn{3}{l}{ Interpersonally distressed ES } & \multicolumn{2}{l}{ Adaptive copers ES } \\
\cline { 2 - 7 } & $\begin{array}{l}\text { Turk et al. } \\
(\mathbf{n}=\mathbf{1 6})\end{array}$ & $\begin{array}{l}\text { Verra et al. } \\
(\mathbf{n}=\mathbf{4 3})\end{array}$ & $\begin{array}{l}\text { Turk et al. } \\
(\mathbf{n}=\mathbf{1 7})\end{array}$ & $\begin{array}{l}\text { Verra et al. } \\
(\mathbf{n}=\mathbf{2 8})\end{array}$ & $\begin{array}{l}\text { Turk et al. } \\
(\mathbf{n}=\mathbf{1 5})\end{array}$ & $\begin{array}{l}\text { Verra et al. } \\
(\mathbf{n}=\mathbf{4 5})\end{array}$ \\
\hline MPI Pain severity & 1.85 & 1.42 & 0.21 & 0.62 & 1.00 & 1.32 \\
MPI Interference with pain & 1.00 & 1.55 & 0.20 & 0.47 & 0.54 & 0.87 \\
Physical functioning & 0.63 (ODI) & 0.82 (SF-36) & 0.01 (ODI) & 0.22 (SF-36) & 0.01 (ODI) & 0.69 (SF-36) \\
Depression & 0.80 (CES-D) & 0.54 (HADS) & 0.44 (CES-D) & 0.50 (HADS) & -0.03 (CES-D) & 0.50 (HADS) \\
\hline
\end{tabular}

Abbreviations: CES-D, Center for Epidemiological Studies Depression Scale; HADS, Hospital Anxiety and depression Scale; MPI, Multidimensional Pain Inventory; ODI, Oswestry Disability Index; SF-36, Medical Outcomes Studies Short Form-36, physical functioning scale. NOTE. Data from reference 15 and the present study.

\section{Validation of the subgroup pattern}

In support of the first hypothesis, the score differences at entry between the subgroups, as described by the MPI, were consistent with comparable constructs measured using the SF-36, HADS, and CSQ. The persons in the AC cluster showed better general and mental health, less fear and depression, less catastrophizing, and better self-efficacy (ability to control and decrease their pain) than persons in the DYS cluster. The persons in the DYS cluster reported higher levels of pain, anxiety, depression, and use of maladaptive coping strategies (praying and hoping, and catastrophizing), and the lowest levels of physical function, social function, and mental health compared with the 
AC cluster (Table 3). The ID pattern of the MPI could not be replicated by the other instruments due to lack of scales with comparable construct.

\section{Differences in effect between MPI subgroups}

Our second hypothesis was that, with pairwise comparisons between subgroups at discharge, we expected to find the highest ES for DYS and most significant differences in effects between the AC and DYS subgroups. This hypothesis could be partly confirmed by our results - the hypothesis was true for pain (MPI and SF-36), interference with pain (MPI), activities and function (MPI and SF-36), and affective health (MPI, SF36, HADS, and CSQ "catastrophizing"). However, some of these effect differences were small and did not reach significance. No other scales showed significant differences.

\section{Clinical implications for pain management program}

This study showed, for most scales, positive small ( $E S=0.20$ to 0.49 ) to large ( $E S>0.80$ ) ES for the total population of 116 persons with fibromyalgia, as well as for the corresponding clusters. Nevertheless, there were significant differences in outcome between MPI subgroups in 17 out of 87 pair wise comparisons (last three columns of Table 4). This retrospective MPI subgroup classification (a posteriori) provides information that may help to improve the effects of standard pain management programs. It suggests matching persons with the treatment strategies and therapeutic methods they are most likely to respond to and where they show the greatest need of treatment and/or where they show the largest deficits [17]. The development and implementation (a priori) of classification methods for matching interventions of pain management programs to subgroups of patients may improve clinical outcomes. Several recent studies in the field of (sub-) acute "nonspecific" low back pain and acute neck pain have provided preliminary evidence that using specific inclusion criteria to identify more homogenous subgroups of subjects, and attempting to match treatment to the subgroup, has the potential to enhance treatment effects [37-42].

\section{Future research directions}

A focus of research may be the further analysis of the AC subgroup. Although these people score better than the other two subgroups with self-report measures on pain, self-perceived disability, mental health and their ability to cope with chronic pain, the impact of musculoskeletal pain on their consumption of pain medication and therapeutic interventions, physical performance, not returning to work, etc, is comparable with the ID and DYS subgroups. Aspects of overuse behavior have been hypothesized and are subject of further research [43-48]. 


\section{Limitations of the present study}

The sample consisted of selected persons who had suffered from severe and disabling chronic pain disorders for a long time and who fulfilled certain criteria (e.g. motivation and ability to understand German). Therefore, they may differ in important ways from people with fibromyalgia in general, thus limiting the generalizability of the results. Because the design of the study did not include a control group, the changes after the pain program cannot be solely attributed to the interventions. The number of persons in each subgroup was relatively small ( $n=28, n=45$ and $n=43$ ), but larger than a comparable study. Another limitation is the short-term measurement of effects (between entry and discharge from the rehabilitation clinic after four weeks). Future studies should use standardized outcome measurements, not only at the end of the experimental program, but at follow-up times that are long enough for the person with fibromyalgia to modify behavior patterns and master effective strategies [49]. When using a post- or pre-test difference to define improvement after an intervention, the possibility of regression towards the mean cannot be excluded. We aimed to minimize this effect by using only reliable measurement instruments that have been used previously with persons with fibromyalgia [35]. Also, all outcome variables were obtained from self-reported questionnaires; e.g. MPI "general activities" screening for perceived disability and not observing physical performance. Finally, one study was able to demonstrate that, in two samples of persons with fibromyalgia, MPI classifications may not be stable, trait-like characterizations. As such, caution must be applied when treatment is tailored to MPI clusters [50]. However, new evidence from the data of 976 pain patients provides evidence for the stability and replicability of three new clusters based on the MPI system [51].

\section{Acknowledgements}

We gratefully thank all patients for their participation in the study and Joy Buchanan for her English editing. This study was supported by the Zurzach Rehabilitation Foundation SPA, Bad Zurzach, Switzerland.

\section{Conclusion}

The findings of this study underscore the importance of assessing patients' differences in how they adjust to fibromyalgia. 


\section{References}

1. Wolfe F, Smythe HA, Yunus MB, Bennett RM, Bombardier C, Goldenberg DL, Tugwell P, Campbell SM, Abeles M, Clark P et al: The American College of Rheumatology 1990 Criteria for the Classification of Fibromyalgia. Report of the Multicenter Criteria Committee. Arthritis Rheum 1990, 33(2):160-172.

2. McCarthy $\mathrm{CJ}$, Cairns MC: Why is the recent research regarding non-specific pain so non-specific (editorial)? Man Ther 2005, 10:239-241.

3. Bennett RM, Jones J, Turk DC, Russell IJ, Matallana L: An internet survey of 2,596 people with fibromyalgia. BMC Musculoskelet Disord 2007, 8:27.

4. Porter-Moffitt S, Gatchel RJ, Robinson RC, Deschner M, Posamentier M, Polatin P, Lou L: Biopsychosocial profiles of different pain diagnostic groups. J Pain 2006, 7(5):308-318.

5. de Gier M, Peters ML, Vlaeyen JW: Fear of pain, physical performance, and attentional processes in patients with fibromyalgia. Pain 2003, 104(1-2):121-130.

6. Bergstrom G, Bodin L, Jensen IB, Linton SJ, Nygren AL: Long-term, non-specific spinal pain: reliable and valid subgroups of patients. Behav Res Ther 2001, 39(1):75-87.

7. Turk DC, Okifuji A, Sinclair JD, Starz TW: Pain, disability, and physical functioning in subgroups of patients with fibromyalgia. J Rheumatol 1996, 23(7):1255-1262.

8. Kerns RD, Turk DC, Rudy TE: The West Haven-Yale Multidimensional Pain Inventory (WHYMPI). Pain 1985, 23(4):345-356.

9. Turk DC, Rudy TE: Toward an empirically derived taxonomy of chronic pain patients: integration of psychological assessment data. J Consult Clin Psychol 1988, 56(2):233-238.

10. Soderlund A, Denison E: Classification of patients with whiplash associated disorders (WAD): reliable and valid subgroups based on the Multidimensional Pain Inventory (MPI-S). Eur J Pain 2006, 10(2):113119.

11. Turk DC, Rudy TE: The robustness of an empirically derived taxonomy of chronic pain patients. Pain 1990, 43(1):27-35.

12. Vollenbroek-Hutten MM, Hermens HJ, Wever D, Gorter M, Rinket J, ljzerman MJ: Differences in outcome of a multidisciplinary treatment between subgroups of chronic low back pain patients defined using two multiaxial assessment instruments: the multidimensional pain inventory and lumbar dynamometry. Clin Rehabil 2004, 18(5):566-579.

13. Johansson E, Lindberg P: Low back pain in primary care: Subgroups based on the Multidimensional Pain Inventory. Int J Behav Med 2000, 7(4):340-352.

14. Turk DC: The potential of treatment matching for subgroups of patients with chronic pain: lumping versus splitting. Clin J Pain 2005, 21(1):44-55; discussion 69-72.

15. Turk DC, Okifuji A, Sinclair JD, Starz TW: Differential responses by psychosocial subgroups of fibromyalgia syndrome patients to an interdisciplinary treatment. Arthritis Care Res 1998, 11(5):397404.

16. Turk DC, Sist TC, Okifuji A, Miner MF, Florio G, Harrison P, Massey J, Lema ML, Zevon MA: Adaptation to metastatic cancer pain, regional/local cancer pain and non-cancer pain: role of psychological and behavioral factors. Pain 1998, 74(2-3):247-256.

17. Angst F, Brioschi R, Main CJ, Lehmann S, Aeschlimann A: Interdisciplinary rehabilitation in fibromyalgia and chronic back pain: a prospective outcome study. J Pain 2006, 7(11):807-815.

18. Angst F, Aeschlimann A, Steiner W, Stucki G: Responsiveness of the WOMAC osteoarthritis index as compared with the SF-36 in patients with osteoarthritis of the legs undergoing a comprehensive rehabilitation intervention. Ann Rheum Dis 2001, 60(9):834-840.

19. Flor H: Psychobiologie des Schmerzes. Bern, Switzerland: Verlag Hans Huber; 1991.

20. Flor H, Rudy T, Birbaumer N, Streit B, Schugens M: Zur Anwendbarkeit des West Haven - Yale Multidimensional Pain Inventory im deutschen Sprachraum: daten zur Reliabilität und Validität des MPI-D. Der Schmerz 1990, 4:82-87.

21. Ware JE, Jr., Sherbourne CD: The MOS 36-item short-form health survey (SF-36). I. Conceptual framework and item selection. Med Care 1992, 30(6):473-483. 
22. Ware JE, Snow KK, Kosinski M, Gandek B: SF-36 Health survey: Manual and interpretation guide. Lincoln, RI, USA: QualityMetric Incorporated; 2000.

23. Bullinger M, Kirchberger I: SF-36 Fragebogen zum Gesundheitszustand. Handanweisung. (The SF-36 questionnaire to assess health status. A manual). Göttingen, Germany: Hogrefe; 1998.

24. Zigmond AS, Snaith RP: The hospital anxiety and depression scale. Acta Psychiatr Scand 1983, 67(6):361370.

25. Bjelland I, Dahl AA, Haug TT, Neckelmann D: The validity of the Hospital Anxiety and Depression Scale. An updated literature review. J Psychosom Res 2002, 52(2):69-77.

26. Herrmann C, Buss U, Snaith RP: HADS-D: Hospital Anxiety and Depression Scale - Deutsche Version. Ein Fragebogen zur Erfassung von Angst und Depressivität in der somatischen Medizin (A questionnaire to assess anxiety and depression in somatic medicine - German version). Berne, Switzerland: Verlag Hans Huber; 1995.

27. Rosenstiel AK, Keefe FJ: The use of coping strategies in chronic low back pain patients: relationship to patient characteristics and current adjustment. Pain 1983, 17(1):33-44.

28. Snow-Turek AL, Norris MP, Tan G: Active and passive coping strategies in chronic pain patients. Pain 1996, 64(3):455-462.

29. Verra ML, Angst F, Lehmann S, Aeschlimann A: Translation, cross-cultural adaptation, reliability, and validity of the German version of the Coping Strategies Questionnaire (CSQ-D). J Pain 2006, 7(5):327336.

30. Backhaus K, Erichson B, Plinke W, Weiber R: Faktorenanalyse, logistische regression, Clusteranalyse. In: Multivariate Analysemethoden (Multivariate analysis methods). 10 th edn. Edited by Backhaus $\mathrm{K}$, Erichson B, Plinke W, Weiber R. Berlin: Springer; 2003: 259-542.

31. Wittink H, Turk DC, Carr DB, Sukiennik A, Rogers W: Comparison of the redundancy, reliability, and responsiveness to change among SF-36, Oswestry Disability Index, and Multidimensional Pain Inventory. Clin J Pain 2004, 20(3):133-142.

32. Kazis LE, Anderson JJ, Meenan RF: Effect sizes for interpreting changes in health status. Med Care 1989, 27(3 Suppl):S178-189.

33. Angst F, Verra ML, Lehmann S, Aeschlimann A: Responsiveness of five condition-specific and generic outcome assessment instruments for chronic pain. BMC Med Res Methodol 2008, 8:26.

34. van Tulder M, Malmivaara A, Hayden J, Koes B: Statistical significance versus clinical importance. Spine 2007, 32(16):1785-1790.

35. King SJ, Wessel J, Bhambhani Y, Sholter D, Maksymowych W: Predictors of success of intervention programs for persons with fibromyalgia. J Rheumatol 2002, 29(5):1034-1040.

36. King SJ, Wessel J, Bhambhani Y, Sholter D, Maksymowych W: The effects of exercise and education, individually or combined, in women with fibromyalgia. J Rheumatol 2002, 29(12):2620-2627.

37. Long A, Donelson R, Fung T: Does it matter which exercise? A randomized control trial of exercise for low back pain. Spine 2004, 29(23):2593-2602.

38. Childs JD, Fritz JM, Flynn TW, Irrgang JJ, Johnson KK, Majkowski GR, Delitto A: A clinical prediction rule to identify patients with low back pain most likely to benefit from spinal manipulation: a validation study. Ann Intern Med 2004, 141(12):920-928.

39. Fritz JM, Brennan GP: Preliminary examination of a proposed treatment-based classification system for patients receiving physical therapy interventions for neck pain. Phys Ther 2007, 87(5):513-524.

40. Brennan GP, Fritz JM, Hunter SJ, Thackeray A, Delitto A, Erhard RE: Identifying subgroups of patients with acute/subacute "nonspecific" low back pain: results of a randomized clinical trial. Spine 2006, 31(6):623-631.

41. Fritz JM, Delitto A, Erhard RE: Comparison of classification-based physical therapy with therapy based on clinical practice guidelines for patients with acute low back pain: a randomized clinical trial. Spine 2003, 28(13):1363-1371; discussion 1372.

42. Browder DA, Childs JD, Cleland JA, Fritz JM: Effectiveness of an Extension-Oriented Treatment Approach in a Subgroup of Subjects With Low Back Pain: A Randomized Clinical Trial. Phys Ther 2007, 87(12):1608-1618. 
43. Wittink H, Hoskins Michel $T$, Wagner A, Sukiennik A, Rogers W: Deconditioning in patients with chronic low back pain: fact or fiction? Spine 2000, 25(17):2221-2228.

44. Verbunt JA, Westerterp KR, van der Heijden GJ, Seelen HA, Vlaeyen JW, Knottnerus JA: Physical activity in daily life in patients with chronic low back pain. Arch Phys Med Rehabil 2001, 82(6):726-730.

45. van den Berg-Emons RJ, Schasfoort FC, de Vos LA, Bussmann JB, Stam HJ: Impact of chronic pain on everyday physical activity. Eur J Pain 2007, 11(5):587-593.

46. Bousema EJ, Verbunt JA, Seelen HA, Vlaeyen JW, Knottnerus JA: Disuse and physical deconditioning in the first year after the onset of back pain. Pain 2007, 130(3):279-286.

47. Vlaeyen JW, Morley S: Active despite pain: the putative role of stop-rules and current mood. Pain 2004, 110(3):512-516.

48. Hasenbring $\mathrm{MI}$, Plaas $\mathrm{H}$, Fischbein $\mathrm{B}$, Willburger R: The relationship between activity and pain in patients 6 months after lumbar disc surgery: do pain-related coping modes act as moderator variables? Eur $\mathrm{J}$ Pain 2006, 10(8):701-709.

49. Burckhardt CS: Multidisciplinary approaches for management of fibromyalgia. Curr Pharm Des 2006, 12(1):59-66.

50. Broderick JE, Junghaenel DU, Turk DC: Stability of patient adaptation classifications on the multidimensional pain inventory. Pain 2004, 109(1-2):94-102.

51. Sheffer CE, Deisinger JA, Cassisi JE, Lofland K: A revised taxonomy of patients with chronic pain. Pain Med 2007, 8(4):312-325. 


\section{CHAPTER 6}

\section{Differences in pain, function and coping in Multidimensional Pain Inventory subgroups of chronic back pain: A one-group pretest-posttest study}

Verra ML, Angst F, Staal JB, Brioschi R, Lehmann S, Aeschlimann A, de Bie RA.

Differences in pain, function and coping in Multidimensional Pain Inventory subgroups of chronic back pain: a one-group pretest-posttest study.

BMC Musculoskeletal Disorders 2011;12:145. 


\section{Abstract}

Objectives. Patients with non-specific back pain are not a homogeneous group but heterogeneous with regard to their bio-psycho-social impairments. This study examined a sample of 173 highly disabled patients with chronic back pain to find out how the three subgroups based on the Multidimensional Pain Inventory (MPI) differed in their response to an inpatient pain management program.

Methods. Subgroup classification was conducted by cluster analysis using MPI subscale scores at entry into the program. At program entry and at discharge after four weeks, participants completed the MPI, the MOS Short Form-36 (SF-36), the Hospital Anxiety and Depression Scale (HADS), and the Coping Strategies Questionnaire (CSQ). Pairwise analyses of the score changes of the mentioned outcomes of the three MPI subgroups were performed using the Mann-Whitney-U-test for significance.

Results. Cluster analysis identified three MPI subgroups in this highly disabled sample: a dysfunctional, interpersonally distressed and an adaptive copers subgroup. The dysfunctional subgroup ( $29 \%$ of the sample) showed the highest level of depression in SF-36 mental health ( $33.4 \pm 13.9$ ), the interpersonally distressed subgroup ( $35 \%$ of the sample) a modest level of depression (46.8 \pm 20.4 ), and the adaptive copers subgroup ( $32 \%$ of the sample) the lowest level of depression (57.8 \pm 19.1 ). Significant differences in pain reduction and improvement of mental health and coping were observed across the three MPI subgroups, i.e. the effect sizes for MPI pain reduction were: 0.84 (0.44 $1.24)$ for the dysfunctional subgroup, $1.22(0.86$ - 1.58) for the adaptive copers subgroup, and $0.53(0.24-0.81)$ for the interpersonally distressed subgroup $(p=0.006$ for pairwise comparison). Significant score changes between subgroups concerning activities and physical functioning could not be identified.

Conclusions. MPI subgroup classification showed significant differences in score changes for pain, mental health and coping. These findings underscore the importance of assessing individual differences to understand how patients adjust to chronic back pain. 


\section{Introduction}

For more than twenty years, a simple diagnostic triage for back pain has been widely accepted and advocated as part of various clinical guidelines to distinguish between possible serious spinal pathology, nerve root pain or simple nonspecific back pain $[1,2]$. By far the largest proportion of the three categories is the nonspecific back pain category. Patients with nonspecific back pain, according to this diagnostic model, are viewed as a homogeneous group [1]. Various recent randomized controlled trials that have studied the effect of physiotherapy on nonspecific back pain, for example, found only small improvements in pain and disability $[3,4]$.

However, both health care professionals and researchers often state that patients with nonspecific back pain are heterogeneous with regard to their biopsychosocial impairments and responsiveness to interventions. Classification of people with chronic "nonspecific" back pain into homogeneous subgroups might be an important objective in order to tailor interventions and to control for subgroup differences when evaluating treatment outcome. Consequently, to achieve better clinical outcomes, scientifically confirmed criteria for building subgroups that relate to both diagnoses, pain coping strategies and prognosis of chronic pain patients are required. Thus, it would be possible to fit the treatment modalities to the patient, define the main therapeutic focus and optimally allocate human and financial resources [5-7].

Some randomized trials have demonstrated that effect sizes increase when classification and matching are taken into account $[8,9]$. However, there are several problems with a subgrouping approach and it is important that the subgrouping paradigm is closely examined $[10,11]$. Several studies have proposed methods for subgrouping patients with back pain as a means of determining the treatment most likely to benefit patients with particular characteristics, to aid in prognosis or to identify pathology. However, overall consensus has not yet been achieved [12-16]. In their systematic review Billis et al. identified classification systems of low back pain from nine countries [17]. Most studies were classified according to pathoanatomical and/or clinical features, whereas fewer studies utilized a psychosocial and even less, a biopsychosocial approach. According to the International Classification of Functioning, disability and health (ICF) and the Initiative on Methods, Measurement, and Pain Assessment in Clinical Trials (IMMPACT recommendations), chronic nonspecific back pain disorders should be evaluated within a biopsychosocial framework $[18,19]$.

The Multidimensional Pain Inventory - which measures pain, a number of psychosocial and behavioral variables, and activities - has been used to classify patients with chronic back pain into empirically derived subgroups according to their pattern of symptoms [6, 20-22]. In the studies cited above, the Multidimensional Pain Inventory differentiated between three subgroups labelled as adaptive copers, dysfunctional, and interpersonally distressed [20]. The interpersonally distressed cluster is mainly characterized by lower levels of perceived solicitous and distraction responses from the pa- 
tients' partners or spouses and higher levels of punishing responses compared to the adaptive copers and dysfunctional clusters. The adaptive copers cluster, compared with the other two subgroups, is characterized by less pain severity, less interference with everyday life due to pain and less affective distress, more perception of life control and higher activity level. The persons of the dysfunctional cluster report high pain severity, high interference and activity distress, low life control and low activity level.

The main aim of this study was to examine the score changes on outcomes for pain, physical and mental function, and coping across the Multidimensional Pain Inventory subgroups after a standardized four-week interdisciplinary in-patient pain management program. Based on our previous study on patients with fibromyalgia, we hypothesized that the cluster dysfunctional would report, on average, higher improvements than the adaptive copers and the interpersonally distressed in pain, physical function, mental health, and coping [23]. Secondary aims were to investigate whether it was possible to describe the three Multidimensional Pain Inventory cluster solution in line with Turk and Rudy and validate the three-cluster solution by comparing the three clusters with measures of pain, psychosocial function, physical and mental health, and pain coping strategies. The hypothesis was that the symptom patterns on the Multidimensional Pain Inventory of the subgroups were similar to those of the corresponding subscales of the Medical Outcome Study Short Form-36, the Hospital Anxiety and Depression Scale, and the Coping Strategies Questionnaire. For example, the dysfunctional were expected to report more pain, worse physical function, and worse mental health than the other two subgroups in the corresponding Short Form-36 subscales.

\section{Methods}

\section{Setting and participants}

The study was conducted at the rehabilitation clinic "RehaClinic" (locations Bad Zurzach and Braunwald, Switzerland), which is attended by severely disabled patients suffering from persistent musculoskeletal pain. All subjects were consecutively admitted and included in the study and 1) suffered from chronic non-specific back pain (i.e. lumbar, thoracic, or pan vertebral pain syndrome without serious spinal pathology or nerve root pain) and had had pain for at least six months. Further inclusion criteria were 2) ability to complete self-assessment questionnaires, understand the German language, no psycho-intellectual inabilities; and 3) provision of written, signed informed consent. Exclusion criteria were 1) severe somatic illness requiring specific treatment such as cancer, inflammatory rheumatic disease, neurological disease, and pain after a recent operation 2) manifest psychiatric disorder such as dementia, psychosis, suicidality, and 3) failed inclusion criteria. 
The patients with chronic nonspecific back pain were participants in the "Zurzach Interdisciplinary Pain (German: Schmerz) Program" - ZISP. The program is a four-week inhouse, standardized, interdisciplinary pain management program. This program has three main components: 1) medical care including adapted drug therapy, 2) exercise therapy and 3) psychotherapy, mainly cognitive and operant behavioral therapy (in total over $100 \mathrm{~h}$ of therapy). The program is intensive. Over the course of treatment patients received on average six daily sessions of the following treatments: physiotherapy, aerobic endurance training, qigong / tai chi exercises, individual psychotherapy including cognitive behavioral therapy, participation in a pain coping group, relaxation therapy, humor therapy, information and education about the pathophysiology of pain mechanisms and management of chronic disabling pain, nursing care, and regular medical consultations including drug therapy. The involved health care providers are: rheumatologists, clinical psychologists, physiotherapists, occupational therapists, nurses, a movement analyst and a humor therapist. Individual treatment strategies were identified and discussed during the interdisciplinary meetings of the pain management team ( $2 \mathrm{~h}$ per week for six patients). Detailed information on inclusion / exclusion criteria and interdisciplinary treatment goals are published elsewhere [24].

The study protocol was approved by the Local Ethic Commission (Health Department in Aarau, Switzerland, no. EK AG 2008/026). All participants gave written informed consent according to the Declaration of Helsinki.

\section{Outcome measures}

Sociodemographic data were collected using a standardized questionnaire from a previous study [25]. The West Haven-Yale Multidimensional Pain Inventory assesses pain and its consequences in terms of symptoms, disability, activity, behavior, mood, and social relationships [26]. The German version of the Multidimensional Pain Inventory is a self-reported 51-item inventory with eleven subscales: pain severity, interference due to pain, life control, affective distress (synonymously described as negative mood), support, punishing responses, solicitous responses, distracting responses, social and recreational activities, household chores, and activities away from home [27]. The last three subscales can be summarized into one subscale of general activities. The Multidimensional Pain Inventory has been validated in various settings [26-28]. The Multidimensional Pain Inventory has been used to identify subgroups of people with chronic musculoskeletal pain in different settings and with different biomedical diagnoses [28]. Two studies examined the cluster stability of the empirically derived subgroup classification based on the Multidimensional Pain Inventory and found that retest resulted in 65 to $70 \%$ of patients being assigned to the same cluster $[29,30]$.

For external validation and calculation of effect sizes, the scales of the instruments listed below were used. The Medical Outcome Study Short Form-36 is a selfadministered generic instrument that assesses health-related quality of life [31]. Two 
physical scales (physical functioning and bodily pain) and two mental scales (vitality and mental health) were examined. We used the validated German version of the Short Form-36 to enquire about symptoms and functioning during the preceding four weeks [32]. The Short Form-36 is used and has been validated in a large number of studies all over the world. The Hospital Anxiety and Depression Scale is a short self-rating of anxiety and depression (seven items each), these being two of the most important affective health dimensions for people with chronic musculoskeletal pain [33]. It has especially been developed and validated in non-psychiatric settings [33, 34]. We used the validated German version of the Hospital Anxiety and Depression Scale [34]. The Coping Strategies Questionnaire is a self-report instrument designed to assess the active and passive coping strategies of individuals with chronic pain [35]. For this study we used scales that measure cognitive (catastrophizing) and behavioral coping strategies (increasing activity level). We also used the two one-item scales that assess participants' subjective ability to control or decrease their pain. These two scales measure the perceived effectiveness of participants' coping strategies. We used the validated German version of the Coping Strategies Questionnaire which is a translation and cross-cultural adaptation of the original questionnaire [36]. Validation studies were performed in chronic musculoskeletal pain, including low back pain, and osteoarthritis [35, 36].

\section{Statistical analysis}

The outcome measures were assessed on entry to the clinic (pre-treatment baseline) and at discharge after four weeks (post-treatment). The baseline scores of the scales of the Multidimensional Pain Inventory were used for subgroup classification. Differences between the baseline scores of the Short Form-36-/ Hospital Anxiety and Depression Scale-/ Coping Strategies Questionnaire-subscales of the three Multidimensional Pain Inventory subgroups - as a clue for construct validity - were tested.

The scores of the subscales of the Short Form-36, the Hospital Anxiety and Depression Scale, the Coping Strategies Questionnaire, the Multidimensional Pain Inventory life control/ support/ solicitous responses/ general activities were scaled from $0=$ maximal pain/ maximal disability/ maximal symptoms/ worst coping to $100=$ no pain/ full function/ no symptoms/ best coping, based on a procedure originally described in the Medical Outcomes Study Short Form-36 manual. This scaling was done to facilitate comparison of the clusters on these external validation measures. According to the subgroup classification of Turk and colleagues, the Multidimensional Pain Inventory pain severity/ interference with pain/ affective distress/ punishing responses were scaled from 0 = best to $100=$ worst [20].

According to Turk et al., the empirically derived subgroups were defined by confirmatory cluster analysis using a predefined three cluster solution [20]. The Multidimensional Pain Inventory score patterns were depicted as graphs of the mean Multidimensional Pain Inventory baseline scores and compared to the patterns described by 
Turk and colleagues using the rank orders of the three subgroups within one Multidimensional Pain Inventory subscale. To assess whether a three-cluster solution was appropriate according to mathematical criteria, hierarchical cluster analysis according to the Ward method was performed [37]. Thus, the proposed "best feasible", that is, clinically characterized, empirically determined solution according to the three Multidimensional Pain Inventory subgroups originally defined by Turk and colleagues was chosen.

Effect sizes of the subscales of all four questionnaires were determined by the score difference between entry (baseline) and discharge from the pain management program after four weeks divided by the group standard deviation at entry [38]. Positive effect sizes indicate improvement of the pain condition, while negative effect sizes indicate worsening. An effect size $\geq 0.80$ is considered as large, 0.50-0.79 as moderate, $0.20-0.49$ as small, and $0.00-0.19$ as very small.

Pairwise analyses of the outcomes (entry to discharge) of the three Multidimensional Pain Inventory subgroups were tested using the Mann-Whitney-U-test for significance. In multiple pairwise testing of nonindependent subscale scores (e.g. within the patient rating of pain), the significance level must be reduced by the number of tested subscale scores (k), that is, $p=0.050 /(k ![k-2] ! \times 2 !)$, which is well known as the Bonferroni correction [39]. Thus, the significance level for the Type 1 error was $p=0.050 / 6=$ 0.008 for the comparisons of the $k=4$ scores, $p=0.050 / 3=0.017$ for the comparisons of the $k=3$, and $p=0.050$ for those of two subscale scores.

All analyses were performed using the statistical software package SPSS 17.0 for Windows ${ }^{\circledR}$ (SPSS Inc., Chicago, IL, USA).

\section{Results}

\section{Participants at baseline}

Table 1 describes the demographic and medical data of the total sample of patients with chronic back pain on entry into the pain management program $(n=173)$. The subjects were characterized by a relatively young age, high prevalence and high level of depression, high level of unemployment, and a long history of pain. 
Table 1. Demographic and medical data for the total sample at entry to the pain management program $(n=173)$

\begin{tabular}{|c|c|}
\hline \multicolumn{2}{|l|}{ Age (years) } \\
\hline Mean $\pm s$ & $46.9 \pm 12.8$ \\
\hline Range & 21.3-79.6 \\
\hline \multicolumn{2}{|l|}{ Sex (\%) } \\
\hline Female & 77.8 \\
\hline \multicolumn{2}{|l|}{ Marital status (\%) } \\
\hline Single & 20.1 \\
\hline Married & 72.0 \\
\hline Other & 7.9 \\
\hline \multicolumn{2}{|l|}{ Education (\%) } \\
\hline Grade 10 -12 & 30.9 \\
\hline High school graduate & 50.9 \\
\hline College graduate & 14.5 \\
\hline University graduate & 3.7 \\
\hline \multicolumn{2}{|l|}{ Employment status } \\
\hline Full time & 9.6 \\
\hline Part time & 40.1 \\
\hline Unemployed & 41.9 \\
\hline Retired & 3.6 \\
\hline \multicolumn{2}{|l|}{ Mental health (\%) } \\
\hline Depression* & 54.5 \\
\hline \multicolumn{2}{|l|}{ Pain duration (\%) } \\
\hline 7-12 months & 6.2 \\
\hline 13 - 24 months & 12.7 \\
\hline $25-36$ months & 14.8 \\
\hline $37-48$ months & 4.9 \\
\hline $49-60$ months & 22.8 \\
\hline$>5$ years & 38.6 \\
\hline
\end{tabular}

Abbreviation: s, standard deviation

NOTE. *HADS depression cut-off score: $\leq 9$ out of 21 points.

\section{Classification of persons with chronic back pain into the Multidimensional Pain Inventory subgroups}

Table 2 shows the mean baseline scores of the Multidimensional Pain Inventory. One hundred and sixty-seven out of one hundred and seventy-three patients with chronic back pain could be allocated to one of the three chronic pain subgroups. Thirty-five percent $(n=61)$ were classified as "Interpersonally Distressed", 32\% ( $n=56)$ were classified as "Adaptive Copers", and 29\% ( $n=50)$ were classified as "Dysfunctional". The six remaining persons with chronic back pain (4\%) were classified as "Anomalous" (did not fit into any of the three profiles). The Multidimensional Pain Inventory baseline scores differed between the three clusters: the patients in the dysfunctional cluster showed highest scores for pain severity, interference due to pain, and affective distress and lowest scores for life control and general activities. The cluster interpersonally distressed showed lowest scores for solicitous and distracting responses by their partner 
or spouses, and the highest score for negative or punishing responses by their partner or spouses. Compared to the other two subgroups, the adaptive copers showed best scores for life control, affective distress, and general activities.

Table 2. Multidimensional Pain Inventory subscale baseline scores $(\mathrm{m} \pm \mathrm{s})$

\begin{tabular}{lccc}
\hline MPI subscales & $\begin{array}{c}\text { Interpersonally } \\
\text { distressed } \\
\mathrm{n}=61\end{array}$ & Adaptive copers & Dysfunctional \\
\hline Pain severity (6=worst, most) & $4.2 \pm 1.0$ & $4.6 \pm 0.8$ & $\mathrm{n}=50$ \\
Interference with pain (6=worst, most) & $3.9 \pm 0.9$ & $4.0 \pm 0.9$ & $5.1 \pm 0.7$ \\
Life control (6=best, most) & $2.9 \pm 1.1$ & $3.8 \pm 0.8$ & $1.9 \pm 1.0$ \\
Affective distress (6=worst, most) & $3.3 \pm 1.3$ & $2.4 \pm 1.1$ & $4.6 \pm 1.0$ \\
Support (6=best, most) & $2.5 \pm 1.5$ & $5.4 \pm 0.7$ & $5.2 \pm 0.9$ \\
Punishing responses (6=worst, most) & $1.8 \pm 1.6$ & $0.9 \pm 1.0$ & $1.4 \pm 1.5$ \\
Solicitous responses (6=best, most) & $2.0 \pm 1.0$ & $4.7 \pm 1.0$ & $4.4 \pm 1.1$ \\
Distracting Responses (6=best, most) & $2.3 \pm 1.7$ & $4.1 \pm 1.2$ & $4.2 \pm 1.4$ \\
General activities (6=best, most) & $2.5 \pm 0.8$ & $2.5 \pm 0.8$ & $1.9 \pm 0.9$ \\
\hline
\end{tabular}

Abbreviations: MPI, Multidimensional Pain Inventory; m, mean subscale score; s, standard deviation.

\section{Validation of the subgroup classification}

Comparing the results of Table 2 and Table 3, the scores of the subgroups of the Short Form-36, Hospital Anxiety and Depression Scale, and Coping Strategies Questionnaire showed almost the same pattern as the Multidimensional Pain Inventory. On the Multidimensional Pain Inventory pain severity, the rank order of the three cluster subgroups in terms of reported pain was dysfunctional (most pain), adaptive copers, and interpersonally distressed (least pain). This same order was found on the Short Form-36 bodily pain: the cluster dysfunctional showed most pain, $14.0 \pm 12.8$. The Multidimensional Pain Inventory general activities scale was compared to Short Form-36 physical functioning: the dysfunctional patients showed the lowest activity level (Short Form-36 physical functioning: $34.7 \pm 19.6)$. The mean baseline score of Multidimensional Pain Inventory life control was compared to the score of Coping Strategies Questionnaire ability to control pain: the adaptive copers had best control, 48.5 \pm 22.1 . Multidimensional Pain Inventory affective distress was compared to Short Form-36 mental health, Hospital Anxiety and Depression Scale depression and anxiety, and Coping Strategies Questionnaire catastrophizing: the cluster dysfunctional showed most and the adaptive copers least affective symptoms on all scales (significant differences in all subgroup comparisons). It was not possible to replicate the specific Multidimensional Pain Inventory characteristics of the interpersonally distressed subgroup (punishing responses and lack of support and distraction of pain by partner or spouse) because the scores of the subscales of the Short Form-36, Hospital Anxiety and Depression Scale and Coping Strategies Questionnaire do not assess social support. 
Table 3 Baseline scores for the three Multidimensional Pain Inventory cluster groups $(m \pm s)$

\begin{tabular}{llll}
\hline Subscales & $\begin{array}{l}\text { Interpersonally distressed } \\
\mathbf{n = 6 1}\end{array}$ & $\begin{array}{l}\text { Adaptive copers } \\
\mathbf{n = 5 6}\end{array}$ & $\begin{array}{l}\text { Dysfunctional } \\
\mathbf{n = 5 0}\end{array}$ \\
\hline $\begin{array}{l}\text { SF-36 (100 = best) } \\
\quad \text { Physical functioning }\end{array}$ & & & \\
$\quad$ Bodily pain & $46.0 \pm 20.7$ & $43.1 \pm 22.2$ & $34.7 \pm 19.6$ \\
$\quad$ Vitality & $23.5 \pm 12.7$ & $19.5 \pm 11.1$ & $14.0 \pm 12.8$ \\
Mental health & $28.2 \pm 16.6$ & $35.7 \pm 14.6$ & $18.2 \pm 15.3$ \\
HADS (100 = no anxiety or depression) & $46.8 \pm 20.4$ & $57.8 \pm 19.1$ & $33.4 \pm 13.9$ \\
Anxiety & $52.5 \pm 22.1$ & & \\
Depression & $57.5 \pm 20.1$ & $60.5 \pm 18.5$ & $37.5 \pm 15.4$ \\
CSQ (100 = best) & & $65.1 \pm 18.4$ & $39.9 \pm 18.3$ \\
$\quad$ Catastrophizing & $50.2 \pm 17.9$ & & \\
Increasing activity level & $55.6 \pm 15.0$ & $51.2 \pm 15.4$ & $35.1 \pm 17.2$ \\
Ability to control pain & $48.0 \pm 24.4$ & $63.8 \pm 13.4$ & $51.5 \pm 16.9$ \\
Ability to decrease pain & $38.7 \pm 20.4$ & $48.5 \pm 22.1$ & $33.3 \pm 22.8$ \\
\hline
\end{tabular}

Abbreviations: m, mean subscale score; s, standard deviation; SF-36, Medical Outcome Study Short-Form 36; HADS, Hospital Anxiety and Depression Scale; CSQ, Coping Strategies Questionnaire.

Differential score changes within the Multidimensional Pain Inventory subgroups Table 4 shows entry-to-discharge scores of the three Multidimensional Pain Inventory subgroups. According our main hypothesis, significant differences in pairwise comparison of score changes were found. Comparing the dysfunctional and adaptive copers subgroups, the dysfunctional subgroup showed significantly higher score changes on Multidimensional Pain Inventory life control, Multidimensional Pain Inventory affective distress, and Short Form-36 mental health. The adaptive copers subgroup showed most and significantly higher improvements in Multidimensional Pain Inventory pain severity, Short Form-36 bodily pain, and Coping Strategies Questionnaire ability to decrease pain when compared to the other two subgroups. After Bonferroni correction, the score change of the adaptive copers remained statistically significantly higher than that of the interpersonally distressed in the domain of the four coping dimensions $(p=0.003<$ 0.008). In the domain of the four mental (affective) health scales, the score change of the dysfunctional cluster remained statistically significantly higher than those of the interpersonally distressed and the adaptive copers $(p=0.001<0.008)$.

In all three Multidimensional Pain Inventory subgroups the pain management program led to small improvements in physical function and general activities but did not reach significance between subgroups. 


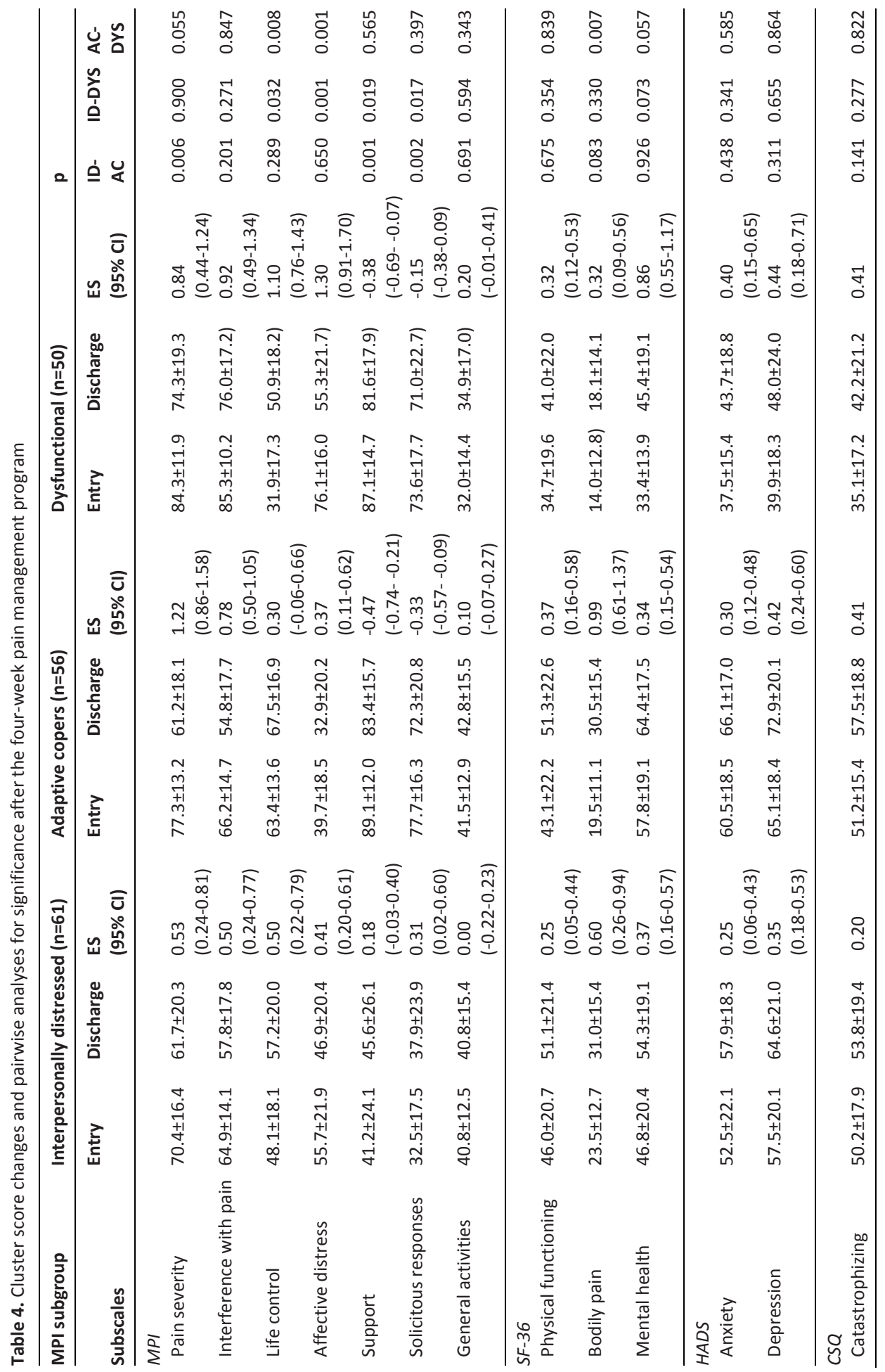




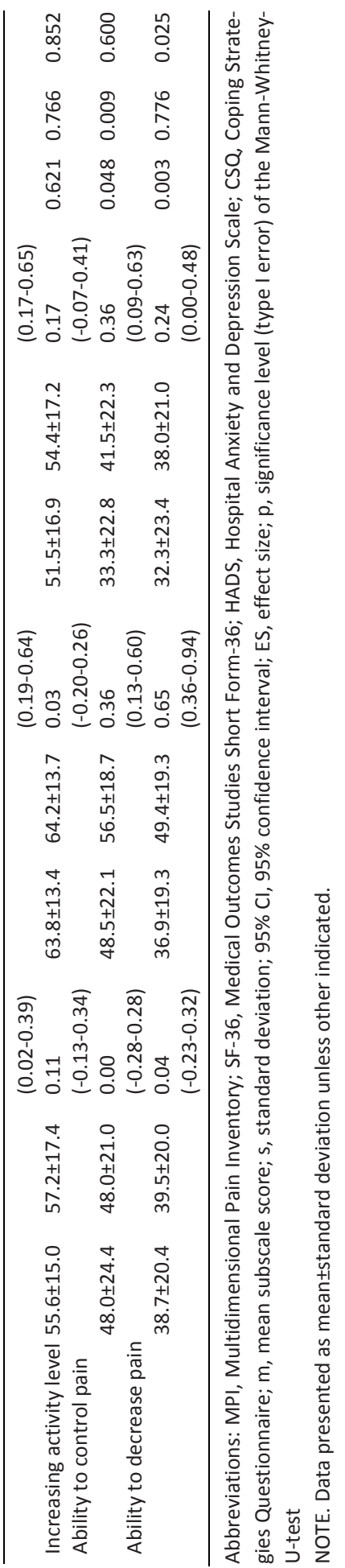




\section{Discussion}

According to the main aim of the study, our hypothesis was that the three Multidimensional Pain Inventory subgroups showed significant differences in the change of pain, physical and mental function and coping after the pain management program. This was partly confirmed by our results: The hypothesis was true for the two scales measuring pain reduction - Multidimensional Pain Inventory pain severity and Short Form-36 bodily pain showed highest effects in the adaptive copers subgroup - , three mental health dimensions - Multidimensional Pain Inventory life control, Multidimensional Pain Inventory affective distress, and Short Form-36 mental health showed highest effects in the dysfunctional subgroup -, and the two pain coping dimensions - Coping Strategies Questionnaire ability to control pain and Coping Strategies Questionnaire ability to decrease pain scored in favor of the adaptive coper and dysfunctional subgroups. In our previous study with one hundred and eighteen persons with fibromyalgia, significant differences in treatment outcome across the three Multidimensional Pain Inventory subgroups were mainly observed in favour of the dysfunctional subgroup [23]. Significant subgroup differences in score changes concerning physical functioning and general activities could not be identified.

Talo et al. first showed that different Multidimensional Pain Inventory subgroups might have different treatment outcomes [40]. Patients with poor functional profiles (the subgroups of dysfunctional and interpersonally distressed) may gain a lot from rehabilitation. Three other studies with chronic back pain patients treated in rehabilitation programs did not find inter-group differences [6, 7, 41]. It was hypothesised that the treatments may not have been relevant to the dysfunctional patients and may not have been sufficiently potent for the interpersonally distressed and adaptive copers patients [28]. In their Multidimensional Pain Inventory subgroup analysis, VollenbroekHutten et al. were able to demonstrate more improvement in the dysfunctional and interpersonally distressed patients, and no differences in the adaptive copers patients [42]. They postulated that the adaptive copers patient group was probably "too good" for an extensive, multidisciplinary, physically oriented rehabilitation program or usual care outside the rehabilitation centre. However, the Multidimensional Pain Inventory subgroups were too small to perform a statistical analysis (dysfunctional, $n=9$; interpersonally distressed, $n=9$; adaptive copers, $n=11$ ). In contrast, the results of the present study showed significant improvements in the different domains of pain reduction, improvement of mental health and pain coping for all three Multidimensional Pain Inventory subgroups, including the adaptive copers patients.

In support of the other hypothesis (secondary aims), the score differences at entry between the subgroups as described by the Multidimensional Pain Inventory were consistent with comparable constructs measured on the Short Form-36, Hospital Anxie- 
ty and Depression Scale, and Coping Strategies Questionnaire. The persons in the adaptive copers subgroup showed better general and mental health, less anxiety and depression, less catastrophizing, and better self-efficacy (ability to control and decrease their pain) than persons in the dysfunctional subgroup. The persons in the dysfunctional cluster reported higher levels of pain, anxiety, depression, and use of maladaptive coping strategies, and lowest levels of physical function, social function, and mental health as compared to the adaptive copers subgroup. The interpersonally distressed pattern of the Multidimensional Pain Inventory could not be replicated by the other instruments due to lack of scales with comparable constructs. Overall, the differences of scores between the three clusters implied support for moderate convergent validity.

This retrospective Multidimensional Pain Inventory subgroup classification (a posteriori) provides information that may help to improve the effects of standard pain management programs. It suggests matching persons with the treatment strategies and therapeutic methods they are most likely to respond to and where they show the greatest need of treatment and/or where they show the largest deficits (i.e. tailored pain management). Several recent studies in the field of (sub-) acute nonspecific low back pain and acute neck pain have provided preliminary evidence that using specific inclusion criteria to identify more homogenous subgroups of subjects and attempting to match treatment to the subgroup has the potential to enhance treatment effects [8, 12-16]. The development and a priori implementation of classification methods for matching interventions of pain management programs to subgroups of patients may improve clinical outcomes. This is being examined in our ongoing randomized controlled trial "Effectiveness of tailored pain management in patients with chronic back pain" (http://www.controlled-trials.com/ ISRCTN25592008/).

In this study, the sample consisted of selected persons who had suffered from a severe and disabling chronic back pain disorder for a long time and who fulfilled certain criteria (e.g. motivation, ability to understand German) and, therefore, possibly differ in important ways from people with chronic back pain in general thus limiting the generalizability of the results. As the design of the study did not include a control group, the changes after the pain program cannot be solely attributed to the interventions. In this singe arm trial it is unclear if the different outcomes for the three subgroups represent different prognosis, response to generic aspects of care, or other factors. Another limitation is the short-term measurement of score changes (between entry and discharge from the rehabilitation clinic after four weeks). Our future study uses standardized outcome measurements not only at the end of the experimental program but at followup times that are long enough for the person with chronic back pain to modify behavior patterns and master effective strategies. When using a post- / pre-test difference to define improvement after an intervention, the possibility of regression towards the mean cannot be excluded. We aimed to minimize this effect by using only reliable measurement instruments that have been used previously with persons with chronic back pain. Regression to the mean was not the case in Multidimensional Pain Inventory 
pain severity, Short Form-36 bodily pain, and Coping Strategies Questionnaire ability to decrease pain. In these three subscales the baseline scores of the dysfunctional subgroups were, compared to the adaptive copers and interpersonally distressed patients, the lowest. However, largest effect sizes in these three subscales were not measured in the dysfunctional subgroup but in the adaptive copers. Finally, all outcome variables were obtained from self-reported questionnaires, e.g. Multidimensional Pain Inventory general activities screening for perceived disability and not from observing physical performance.

\section{Authors' contributions}

$M L V, F A, J B S, A A$ and $R A B$ were responsible for the design of the study. AA procured funding. SL, RB and MLV collected the data. Statistical analysis was performed by FA and MLV. MLV and FA interpreted the data and made a first draft of the manuscript. All authors have read and approved the final manuscript.

\section{Acknowledgements}

We gratefully thank all patients for their participation in the study and Joy Buchanan for her English editing. This study was supported by the Zurzach Rehabilitation Foundation SPA, Bad Zurzach, Switzerland.

\section{Conclusions}

The findings of this study showed that the Multidimensional Pain Inventory subgroups previously identified in less disabled samples of chronic back pain patients are also evident in a highly disabled chronic back pain sample. The three subgroups identified (dysfunctional, interpersonally distressed, and adaptive copers) showed significant differences in score changes in pain, mental health, and coping outcomes following a four-week, standard, inpatient, interdisciplinary, pain management program. However, the pain management program led to small but not significant improvements in physical function and general activities. 


\section{References}

1. Waddell G: Diagnostic triage. In: The back pain revolution. 1 edn. Edinburgh: Churchill Livingstone; 1998: 9-25.

2. Airaksinen O, Brox JI, Cedraschi C, Hildebrandt J, Klaber-Moffett J, Kovacs F, Mannion AF, Reis S, Staal JB, Ursin $\mathrm{H}$ et al: Chapter 4. European guidelines for the management of chronic nonspecific low back pain. European spine journal : official publication of the European Spine Society, the European Spinal Deformity Society, and the European Section of the Cervical Spine Research Society 2006, 15 Suppl 2:S192-300.

3. Team UBT: United Kingdom back pain exercise and manipulation (UK BEAM) randomized trial: effectiveness of physical treatments for back pain in primary care. British medical journal 2004, 329:708-711.

4. Frost H, Lamb SE, Doll HA, Carver PT, Stewart-Brown S: Randomized controlled trial of physiotherapy compared with advice for low back pain. Bmj 2004, 329(7468):708.

5. Scascighini L, Sprott H: Chronic nonmalignant pain: a challenge for patients and clinicians. Nature clinical practice Rheumatology 2008, 4(2):74-81.

6. Bergstrom G, Bodin L, Jensen IB, Linton SJ, Nygren AL: Long-term, non-specific spinal pain: reliable and valid subgroups of patients. Behavior research and therapy 2001, 39(1):75-87.

7. Bergstrom G, Bergstrom C, Hagberg J, Bodin L, Jensen I: A 7-year follow-up of multidisciplinary rehabilitation among chronic neck and back pain patients. Is sick leave outcome dependent on psychologically derived patient groups? European journal of pain 2010, 14(4):426-433.

8. Long A, Donelson R, Fung T: Does it matter which exercise? A randomized control trial of exercise for low back pain. Spine 2004, 29(23):2593-2602.

9. Childs JD, Fritz JM, Flynn TW, Irrgang JJ, Johnson KK, Majkowski GR, Delitto A: A clinical prediction rule to identify patients with low back pain most likely to benefit from spinal manipulation: a validation study. Annals of internal medicine 2004, 141(12):920-928.

10. Brookes ST, Whitely E, Egger M, Smith GD, Mulheran PA, Peters TJ: Subgroup analyses in randomized trials: risks of subgroup-specific analyses; power and sample size for the interaction test. Journal of clinical epidemiology 2004, 57(3):229-236.

11. Wand BM, O'Connell NE: Chronic non-specific low back pain - sub-groups or a single mechanism? $B M C$ musculoskeletal disorders 2008, 9:11.

12. Fritz JM, Delitto A, Erhard RE: Comparison of classification-based physical therapy with therapy based on clinical practice guidelines for patients with acute low back pain: a randomized clinical trial. Spine 2003, 28(13):1363-1371; discussion 1372.

13. Fritz JM, Brennan GP, Clifford SN, Hunter SJ, Thackeray A: An examination of the reliability of a classification algorithm for subgrouping patients with low back pain. Spine 2006, 31(1):77-82.

14. Browder DA, Childs JD, Cleland JA, Fritz JM: Effectiveness of an extension-oriented treatment approach in a subgroup of subjects with low back pain: a randomized clinical trial. Physical therapy 2007, 87(12):1608-1618; discussion 1577-1609.

15. Brennan GP, Fritz JM, Hunter SJ, Thackeray A, Delitto A, Erhard RE: Identifying subgroups of patients with acute/subacute "nonspecific" low back pain: results of a randomized clinical trial. Spine 2006, 31(6):623-631.

16. O'Sullivan P: Diagnosis and classification of chronic low back pain disorders: maladaptive movement and motor control impairments as underlying mechanism. Manual therapy 2005, 10(4):242-255.

17. Billis EV, McCarthy CJ, Oldham JA: Subclassification of low back pain: a cross-country comparison. European spine journal : official publication of the European Spine Society, the European Spinal Deformity Society, and the European Section of the Cervical Spine Research Society 2007, 16(7):865-879.

18. (WHO) WHO: International Classification of Functioning, disability and Health: ICF. Geneva: Library Cataloguing-in-Publication Data; 2001.

19. Dworkin RH, Turk DC, Farrar JT, Haythornthwaite JA, Jensen MP, Katz NP, Kerns RD, Stucki G, Allen RR, Bellamy $\mathrm{N}$ et al: Core outcome measures for chronic pain clinical trials: IMMPACT recommendations. Pain 2005, 113(1-2):9-19. 
20. Turk DC, Rudy TE: Toward an empirically derived taxonomy of chronic pain patients: integration of psychological assessment data. Journal of consulting and clinical psychology 1988, 56(2):233-238.

21. Turk DC, Rudy TE: The robustness of an empirically derived taxonomy of chronic pain patients. Pain 1990, 43(1):27-35.

22. Johansson $E$, Lindberg $P$ : Low back pain patients in primary care: subgroups based on the Multidimensional Pain Inventory. Int J Behavioral Med 2000, 7(4):340-352.

23. Verra ML, Angst F, Brioschi R, Lehmann S, Keefe FJ, Staal JB, de Bie RA, Aeschlimann A: Does classification of persons with fibromyalgia into Multidimensional Pain Inventory subgroups detect differences in outcome after a standard chronic pain management program? Pain research \& management : the journal of the Canadian Pain Society = journal de la societe canadienne pour le traitement de la douleur 2009, 14(6):445-453.

24. Angst F, Brioschi R, Main CJ, Lehmann S, Aeschlimann A: Interdisciplinary rehabilitation in fibromyalgia and chronic back pain: a prospective outcome study. The journal of pain : official journal of the American Pain Society 2006, 7(11):807-815.

25. Angst F, Aeschlimann A, Steiner W, Stucki G: Responsiveness of the WOMAC osteoarthritis index as compared with the SF-36 in patients with osteoarthritis of the legs undergoing a comprehensive rehabilitation intervention. Annals of the rheumatic diseases 2001, 60(9):834-840.

26. Kerns RD, Turk DC, Rudy TE: The West Haven-Yale Multidimensional Pain Inventory (WHYMPI). Pain 1985, 23(4):345-356.

27. Flor H, Rudy TE, Birbaumer N, Streit B, Schugens MM: [The applicability of the West Haven-Yale multidimensional pain inventory in German-speaking countries. Data on the reliability and validity of the MPI-D.]. Schmerz 1990, 4(2):82-87.

28. Turk DC: The potential of treatment matching for subgroups of patients with chronic pain: lumping versus splitting. The Clinical journal of pain 2005, 21(1):44-55; discussion 69-72.

29. Broderick JE, Junghaenel DU, Turk DC: Stability of patient adaptation classifications on the multidimensional pain inventory. Pain 2004, 109(1-2):94-102.

30. Verra ML, Angst F, Staal JB, Brioschi R, Lehmann S, Aeschlimenn A, de Bie RA: Reliability of Multidimensional Pain Inventory (MPI) subgroup classification in chronic pain patients. In: 13th World Congres on Pain. vol. PT 020. Montreal, Canada; 2010: 37.

31. Ware JE, Kosinski M, Gandek B: SF-36 health survey: manual and interpretation guide, vol. 5, 3 edn. Lincoln, RI: QualityMetric Incorporated; 2004.

32. Bullinger M, Kirchberger I: SF-36 Fragebogen zum Gesundheitszustand - Handanweisung, 1998 edn. Göttingen: Hogrefe; 1998.

33. Zigmond AS, Snaith RP: The hospital anxiety and depression scale. Acta psychiatrica Scandinavica 1983, 67(6):361-370.

34. Herrmann C, Buss U, Snaith RP: HADS-D: Hospital Anxiety and Depression Scale-Deutsche Version. Ein Fragebogenzur Erfassung von Angst und Depressivität in der somatischen Medizin. Berne, Switzerland: Verlag Hans Huber; 1995.

35. Rosenstiel AK, Keefe FJ: The use of coping strategies in chronic low back pain patients: relationship to patient characteristics and current adjustment. Pain 1983, 17(1):33-44.

36. Verra ML, Angst F, Lehmann S, Aeschlimann A: Translation, cross-cultural adaptation, reliability, and validity of the German version of the Coping Strategies Questionnaire (CSQ-D). The journal of pain : official journal of the American Pain Society 2006, 7(5):327-336.

37. Backhaus K: Faktorenanalyse, logistische Regression, Clusteranalyse. In: Multivariate Analysemethoden. 10 edn. Edited by Backhaus K, Erichson B, Plinke W. Berlin: Springer; 2003: 259-542.

38. Kazis LE, Anderson JJ, Meenan RF: Effect sizes for interpreting changes in health status. Medical care 1989, 27(3 Suppl):S178-189.

39. Rosner B: Multiple comparisons: Bonferroni approach. In: Fundamentals of biostatistics. 5 edn. Edited by Rosner B. Boston: PWS-Kent; 2000: 527-530.

40. Talo S, Rytokoski U, Puukka P: Patient classification, a key to evaluate pain treatment: a psychological study in chronic low back pain patients. Spine 1992, 17(9):998-1011. 
41. Gatchel RJ, Noe CE, Pulliam C, Robbins H, Deschner M, Gajraj NM, Vakharia AS: A preliminary study of multidimensional pain inventory profile differences in predicting treatment outcome in a heterogeneous cohort of patients with chronic pain. The Clinical journal of pain 2002, 18(3):139-143.

42. Vollenbroek-Hutten MM, Hermens HJ, Wever D, Gorter M, Rinket J, ljzerman MJ: Differences in outcome of a multidisciplinary treatment between subgroups of chronic low back pain patients defined using two multiaxial assessment instruments: the multidimensional pain inventory and lumbar dynamometry. Clinical rehabilitation 2004, 18(5):566-579. 


\section{CHAPTER 7}

\section{Effectiveness of a subgroup-specific pain}

management program based on the MPI

Classification System: A pragmatic randomized controlled trial in patients with chronic back pain

Verra ML, Staal JB, Angst F, Brioschi R, Lehmann S, Benz T, Aeschlimann A, de Bie RA. Effectiveness of a subgroup-specific pain management program based on the MPI Classification System:

A pragmatic randomized controlled trial in patients with chronic back pain.

Shortened version has been submitted. 
CHAPTER 7 


\section{Abstract}

Objectives. Effects of conservative treatments in patients with nonspecific chronic back pain are modest. Prospective classification of these patients into homogeneous subgroups might be an important objective in order to tailor interventions and improve treatment outcomes. This study aimed to investigate the effects in improving pain and disability of a subgroup-specific, 4-week, inpatient interdisciplinary pain management program, compared to a standard pain management program in patients with chronic back pain in a rehabilitation setting.

Methods. A tailored pain management program based on the Multidimensional Pain Inventory (MPI) Classification System was compared to standard pain management in a randomized controlled trial. The primary outcomes were self-reported pain and disability, measured at 4 and 12 weeks after randomization. Secondary outcomes were observed functional disability, anxiety and depression, pain catastrophizing, selfefficacy and psychosocial aspects of pain.

Results. A total of 146 patients were included in this study. With the exception of reduction of minimum pain intensity after 4 weeks with a standard mean difference $(S M D)=0.43,95 \%$ confidence interval $(C I), 0.02$ to $0.84 ; p=0.034$, no significant differences between intervention and control group were found. The secondary analysis, i.e. pairwise comparisons between the individual MPI subgroups and the control group, specified this difference in effect in favor of the control group compared to the MPI subgroup adaptive coper: $\mathrm{SMD}=0.55,95 \% \mathrm{Cl}, 0.02$ to $1.08 ; \mathrm{p}=0.035$ at the 12 -week follow-up. None of the other comparisons for any of the outcomes and follow-up times was statistically significant.

Conclusions. The subgroup-specific pain management program based on the MPI Classification System for patients with chronic back pain was not more effective in improving pain and disability than a standard pain management program. 


\section{Introduction}

Chronic pain of moderate to severe intensity occurs in $19 \%$ of adult Europeans, seriously affecting the quality of their social and working lives [1]. As in the rest of Europe and most developed countries worldwide, low back pain is also the most prevalent health problem in Switzerland. The total economic burden of back pain to Swiss society varied in 2005 between 1.6 and $2.3 \%$ of the gross domestic product (4.8 to 6.6 billion Euros) [2]. Moreover, musculoskeletal pain disorders like back pain do not solely affect quality of life, but are also associated with a long-term increased risk of cancer and cardiovascular-related mortality of 20 to $30 \%$ [3].

In trials with patients with chronic, nonspecific back pain, comparing exercise therapy, behavioral therapy or multidisciplinary treatment with no-treatment, modest effects were found $[4,5]$. In trials comparing two interventions, often no differences were identified [4]. Relative to a host of widely used conventional medical treatments, comprehensive interdisciplinary pain management programs offer the most efficacious and cost-effective, evidence-based treatment for patients with chronic back pain $[6,7]$. However, back pain is nonspecific in about $90 \%$ of cases, which means that no relevant physical cause of the pain can be identified, and its origin remains unclear $[7,8]$.

The search for homogeneous subgroups of patients with nonspecific low back pain who respond best to subgroup-specific pain management interventions - for so many, the Holy Grail of low back pain research - has been on the international research agenda for over 18 years [7, 9-12]. Lack of prospective specification, inadequate sample size, inability to maintain statistical power, and the cumulative effect of sampling errors in trials designed to detect overall treatment effects complicate the interpretation of a posteriori subgroup analyses $[13,14]$. Among other recommendations, studies investigating treatment effect modifiers should limit their analyses to a small number of plausible variables or subgroups that are nominated prior to the conduct of the trial [15, 16]. Several, mainly physiotherapy exercise-based classification systems to subgroup low back pain patients with the intent to guide treatment, have been developed (for overview: reference [17]) and tested in several settings [18-20]. These trials showed large variations in methods for subgrouping, therapeutic interventions and outcome.

The Multidimensional Pain Inventory (MPI) Classification System, which reliably classifies back pain patients into three predominantly psychosocial subgroups, has been used by several research groups to show a posteriori significant effects for pain, mental health and coping [21-23]. So far, no randomized controlled trial has been conducted to evaluate the effects of tailored pain interventions to a priori classified MPI subgroups of patients with chronic back pain in a rehabilitation setting.

The aim of the present study was to examine the effectiveness of tailored pain management on pain and disability in patients with chronic nonspecific back pain classified according the Multidimensional Pain Inventory (MPI) Classification System, com- 
pared to general pain management. The secondary objective focussed on the exploration of differences in effects between individual MPI subgroups and the control group.

\section{Methods}

\section{Trial design}

This single blinded parallel group randomized controlled trial was designed to evaluate the effectiveness of a subgroup-specific pain program, compared to a standard pain program. The Local Research Ethics Committee of the Health Department in Aarau gave ethics approval on the 6th February 2009 (ref: 2008/033). The Ethics Committee of the Health Department in Zurich gave approval on the 12th March 2009 (ref: 15/09). All participants gave written informed consent according to the Declaration of Helsinki. Trial Registration was done at Current Controlled Trials Ltd c/o BioMed Central Ltd (http://www.controlled-trials.com/ ISRCTN25592008/). The acronym of this study is RCTcBPsub.

\section{Setting and participants}

The study was conducted at the rehabilitation clinic RehaClinic (locations Bad Zurzach and Braunwald, Switzerland), which is attended by severely disabled patients suffering from persistent musculoskeletal pain. The patients were participants in the Zurzach Interdisciplinary Pain Program. The program is a four-week, in-house, standardized, interdisciplinary pain management program. Detailed information on its concept and treatment goals have been published elsewhere [24]. All study participants were consecutively admitted and included in the study and 1) suffered from chronic nonspecific back pain (i.e. lumbar, thoracic, or pan vertebral pain syndrome without serious spinal pathology or nerve root pain) and had had pain for at least six months. Further inclusion criteria were 2) ability to complete self-assessment questionnaires, understand the German language, no psycho-intellectual inabilities; and 3) provision of written, signed informed consent. Exclusion criteria were 1) severe somatic illness requiring specific treatment such as cancer, inflammatory rheumatic disease, neurological disease, and pain after a recent operation, and 2) manifest psychiatric disorder such as dementia, psychosis, suicidality.

\section{Randomization and allocation concealment}

Two computer-generated random number lists, one for the patients in RehaClinic Braunwald and one for RehaClinic Zurzach, generated by a researcher who was not involved in the conduct of the study (JBS), were used to allocate patients. To secure 
highest possible equal distribution between the three MPI subgroups in the intervention group and the control group, patients were randomly assigned by central block randomization (blocks of eight, that is two control patients and six intervention patients per block). After inclusion in the study, the study nurse (SL) received the group allocation by telephone by an independent secretary and assigned patients to the interventions. The study nurse and the principal investigator were not involved in the assessment, inclusion or treatment of the patients.

\section{Classification system}

The Multidimensional Pain Inventory Classification System classifies patients with chronic back pain into empirically derived subgroups according to their pattern of symptoms [21, 25-27]. Compared to other diagnostic groups and other examiner-based subgroup classification systems, it is substantially stable in classifying chronic back pain patients [28]. The Multidimensional Pain Inventory differentiates between three subgroups labelled as, dysfunctional, interpersonally distressed and adaptive copers [25]. The subgroup dysfunctional is characterized by severe pain, comprised life activities and enjoyment, reduced sense of control and high levels of emotional distress. The second subgroup, also marked with relatively high degrees of pain and affective distress but further characterized by low levels of perceived support from their significant others, is labelled interpersonally distressed. The third subgroup (adaptive copers) consists of a set of patients with chronic pain who appear to be coping relatively well despite their long-standing pain. Compared to the two other subgroups, lower levels of pain, functional limitations and emotional distress characterize this profile [29]. The three subgroups have been replicated and validated in numerous studies (e.g. [21, 27, 30]). In this study, subgroups were defined by confirmatory cluster analysis using the predefined three cluster solution according to the MPI Classification System [21, 25, 31]. The Multidimensional Pain Inventory (MPI) score patterns were depicted as graphs of the nine mean MPI baseline subscale scores and compared to the patterns described by Turk and colleagues using the rank orders of the three subgroups within one MPI subscale. The therapists were allowed to overrule the MPI subgroup classification if they thought that the decision to overrule was appropriate.

\section{Interventions}

Over the course of treatment patients in both the intervention and control group received on average four daily sessions of the following group therapies: cardiovascular training, relaxation therapy, participation in a pain coping group, humor therapy, information and education about the pathophysiology of pain mechanisms and management of chronic disabling pain, movement analysis, occupational therapy and qigong / tai chi exercises. Individual treatment strategies were identified and discussed during 
the interdisciplinary meetings of the pain management team (two hours per week for six patients). For both groups, subsequent ambulatory care was organized for the time after discharge from the clinic. The different components of the intervention and control group are described in the following two paragraphs (detailed intervention protocols can be obtained upon request from the corresponding author).

\section{Tailored pain management group}

In addition to the group therapies mentioned above, patients in the intervention group received specific interventions, which were tailored to their subgroup classification.

Subgroup dysfunctional: The pacing problem of these patients was mainly underactivity. Patients learned that it is safe to move, while restoring function by receiving feedback and positive reinforcement, treatment of depressive mood and additional stress management.

Subgroup adaptive copers: The coping problem of the patients in this subgroup mainly existed of denying or minimizing their problems and thus often presented a false positive picture [21, 31, 32]. Their pacing problem was mainly overactivity. Therapy focussed on activity pacing to moderate overactivity, use of stop-rules, body awareness, and mental and physical relaxation techniques in stressful situations [33, 34].

Subgroup interpersonally distressed: This subgroup of patients mainly expressed anxiety about how their pain affected other family members, regretted losing full working capacity and worried about financial consequences [35]. Systemic therapy (with pain patient and, if possible and desired, partner or spouse) focussed on encouragement of well behaviors and reduction of negative responses, as well as higher levels of solicitous responses to pain behaviors of both the patient and their partner or spouse [36-39]. Exercise therapy focussed on identification and training of meaningful activities, which the patient could perform in future together with his partner or spouse.

The subgroup-specific intervention consisted of a combination of individual physiotherapy, i.e. four-half hour sessions per week of graded exercise therapy, also called, graded activity [40-43] and individual psychotherapy, i.e. two-one-and-a-half hour sessions per week of cognitive behavioral therapy or systemic therapy [44, 45]). Graded activity exercise developed by Lindstrom et al. consisted of two parts: baseline repeated measurements of functional performance and individual, sub-maximal, gradually increased exercise program with an operant-conditioning behavioral approach. The clinical psychologists applied counselling and exercise of the individual patient based on cognitive-behavioral principles or systemic therapy with the aim of modifying pain behavior of the patients and - for the patients classified in the subgroup interpersonally distressed - their partner or spouse. After initial assessment, the patients went through four further phases: collaborative reconceptualization of the patient's view of pain; skills acquisition and skills consolidation, including cognitive and behavioral rehearsal; generalization, maintenance and relapse prevention; booster sessions and follow up. 


\section{General pain management group}

The patients in the control group absolved progressive resistance training and stretching exercises according to the recommendations of Hayden et al. [46, 47]. In individual physiotherapy sessions medical training therapy with or without training devices focussed on improvement of muscle strength, endurance and stretching of selected muscle groups $[48,49]$. The success of training was assured through systematic progression with exact quantification of the dose $[50,51]$. This sports medicine approach introduces exercise based on the theoretical framework of exercise physiology. Progressive resistance training was shown to improve the ability to generate force, which may carry over into an improved ability to perform daily activities. Central pain modulation during exercise therapy has been explained by activation of endogenous analgesia [52]. Individual psychotherapy sessions were optional and, if selected, not primarily focussed on the management of their musculoskeletal pain syndrome as in the patients in the tailored pain management group.

\section{Contrast between interventions}

The contrast between interventions was an important issue in this trial because both tailored and general pain management interventions were performed by physiotherapists and clinical psychologists and also contained a large basic module of group interventions for both groups. However, there were some important features that were responsible for the contrast. The systematic review of Hayden et al. [46] described general strategies for using exercise therapy to improve outcomes in chronic low back pain, while the graded activity training protocol prescribed the frequency, intensity and duration of the exercise therapy and graded activity in detail. The review by Hayden et al. generally recommended supervised exercise therapy encouraging activity/exercise. However, no further guidance was provided regarding the content of the exercise program (type, intensity, frequency and duration of exercises) or regarding integrating behavioral principles. The physiotherapist was free in his decision to apply a paincontingent or time-contingent approach. In the tailored pain management training protocol the contents of the exercise therapy and operant conditioning were thoroughly described and the physiotherapists were trained to apply these skills in practice. The physiotherapist strictly followed a time-contingent approach. In order to avoid combining the different treatment elements, physiotherapists were trained only to deliver the one treatment element of their personal preference. For feasibility reasons, this subdivision within the comparably small group of clinical psychologists was not made.

\section{Blinding}

In exercise therapy trials, neither health professionals nor patients can be blinded to the treatment. Therefore, this study does not meet the criterion of blinding of care provider and blinding of patients. However, before randomization the patients were 
told that all treatments are effective, but that the exact effectiveness is not yet clear. The treatment providers (physiotherapists and clinical psychologists) were aware of which treatment they provided to the different subgroups of patients in the intervention group and the patients in the control group. Other efforts to achieve a certain level of blinding within therapists and data researchers were a) interventions and measurements were done by different therapists (the physical outcome measures 5-Minute Walk Distance test and Back Performance Scale were blindly assessed by a physiotherapist who was not involved in the treatment of the patients and we asked the patients not to reveal information about their treatment to this physiotherapist); and b) an independent data manager $(\mathrm{SL})$ collected and entered the data, recoded the patients to unique codes before handing the database to the analyzing researchers (MLV, FA). Intention-to-treat analysis was carried out independently and blinded for treatment allocation.

\section{Outcome measures}

Socio-demographic data and utilization of medical and therapeutic resources were recorded in a standardized way [53]. Medical records of the physicians in charge of our clinic (reports of the inpatient rehabilitation sent to the admitting physicians) were reviewed for data on further medical history. Comorbidities were examined with the Self-Administered Comorbidity Questionnaire [54].

\section{Primary outcome variables pain severity and pain disability}

Pain severity was measured by the numeric rating scale (NRS) [55]. This self-report pain scale ranges from 0 (no pain) to 10 (worst conceivable pain). The patients indicated their current pain (pain at the moment of measurement), and their maximum and minimum pain during the last week. Pain disability was measured by the self-report Oswestry Disability Index (ODI) [56]. The ODI is a condition-specific questionnaire and consists of ten items to assess the extent of the patient's back pain and difficulty in carrying out nine different activities of daily life: personal care, lifting, walking, sitting, standing, sleeping, sex life, social life and travelling. Each item is scored from 0 to 5 , with higher values representing greater disability. The total score is multiplied by 2 and discussed in terms of points ( 0 to 100). We used the validated German version of the ODI, a translation and cross-cultural adaptation of the ODI version 2.1, which was tested as a sensitive instrument for detecting clinical change $[57,58]$.

\section{Secondary outcome variables}

Observed functional disability was measured with two physical performance tests. The Back Performance Scale (BPS) is a specific performance measure of observed mobilityrelated activities, extensively validated for people with chronic back pain [59]. The BPS consists of five physical performance tests: The Sock Test, the Pick-up Test, the Roll-up 
Test, the Fingertip-to-Floor Test, and the Lift Test. The 16-point BPS sum score ranges from 0 (= no activity limitation) to 15 (= major activity limitation) [60]. The 5-Minute Walk Distance test (5-MWD) is a performance based test, derived from the 12-Minute Walk Test by Butland and colleagues [61] and explicitly validated for patients with back pain [62]. Distance walked in 5 minutes is measured and reported in meters. A greater distance indicates a better performance. The Hospital Anxiety and Depression Scale (HADS) is a short self-rating of anxiety and depression (seven items each), these being two of the most important affective health dimensions for people with chronic musculoskeletal pain [63]. It has been specifically developed and validated in non-psychiatric settings. We used the validated German version of the HADS [64]. Pain catastrophizing, a significant determinant of self-rated pain and disability, was measured with the German version of the Pain Catastophizing Scale (PCS) $[65,66]$. The PCS consists of 13 items to assess the extent of the patient's catastophizing thoughts and behaviors. Each item is scored on a five-point scale, with higher values representing greater catastrophizing. The total score is computed by summation of all items and ranges from 0 to 52 points. The Coping Strategies Questionnaire (CSQ) is a self-report instrument designed to assess the active and passive coping strategies of individuals with chronic pain [67]. For this study we used the two one-item scales that assess participants' subjective ability to control or decrease their pain. These two scales measure the perceived effectiveness of participants' coping strategies and, as such, are a measure of self-efficacy. Using a 7-point Likert scale, patients rate from 0 to 6 , with 0 signifying "no control/no ability to decrease pain" and 6 signifying "complete control/complete ability to decrease pain". We used the validated German version of the CSQ which is a translation and cross-cultural adaptation of the original questionnaire [68]. To be able to evaluate the effect of the interventions in relation to the patient's partner or spouse and because of lack of a different instrument measuring this social dimension, we used the three Multidimensional Pain Inventory (MPI) scales punishing responses, solicitous responses, and distracting responses $[69,70]$. The psychometric properties of the German version of the MPI are comparable to the original version [28].

\section{Sample size}

Sample size calculations for this study were based on detecting an 18\% (8 to 10 score points) difference on the Oswestry Disability Index at entry to the pain program, which has been identified as the minimum clinically important difference [58, 71]. According to power calculations ( $\alpha=0.05$ and $1-\beta=80 \%$ ), a sample size of 24 patients per treatment group provided $80 \%$ power to detect a clinically important difference of 8 points between the intervention group and control group, assuming a common standard deviation of $12.0[58,72]$. We expected a drop-out rate of $20 \%$ at most. This means that to obtain a total of 96 complete data sets at one year follow-up (two treatment arms with 72 and 24 patients) 120 patients had to be included in the study. However, 
during recruitment, this number was revised to 140 study participants to compensate for a larger than anticipated loss at 3-months follow-up.

\section{Data analysis}

The primary analysis of the data was undertaken using the principle of intention-totreat. The patients were analyzed in the treatment group to which they were randomly allocated. Our intention-to-treat analysis included all participants: study completers, those who had missing data and those who were not fully compliant with the protocol. For missing data, imputation techniques carrying the last available score forward were used. In addition, a per-protocol analysis for the primary outcome was performed to estimate the impact on the effect of loss to follow up and treatment protocol deviations. Deviations of the protocol were defined as either withdrawal from therapy within the four week stay at the rehabilitation clinic or not being treated according to the corresponding treatment allocation.

To determine statistically significant planned pairwise comparisons, clinical effectiveness was examined with a Student's t-test (normally distributed continuous data), a Chi-square test (categorized data) or a Wilcoxon test (not normally distributed continuous data). The primary comparison was made between the intervention group as a whole (i.e. the overall effect of all three MPI subgroups) and the control group. The secondary analysis was made between the three MPI subgroups separately and the control group (the trial was prospectively sufficiently powered for these subgroup analyses). Cohen's Standardized Mean Difference $d$ (SMD) for independent groups with $95 \%$ confidence intervals was calculated between baseline and 4 and 12 week follow up measurements. The SMD equals the difference of the score differences (baseline to follow up) of the means between intervention and control divided by the pooled standard deviation [73].

For all tests, a p-value of less than 0.05 (two-tailed) was considered significant. All analyses were performed using version 21.0 of the statistical software package SPSS for Windows (SPSS Inc., Chicago, IL, USA).

\section{Results}

Figure 1 shows the flow of patients through the study. Patient recruitment started in March 2009 and patients were consecutively included until September 2012. A total of 397 patients with chronic musculoskeletal pain were referred to the Zurzach Interdisciplinary Pain Program, of which 225 were eligible for participation. Seventy-nine patients did not meet the inclusion criteria. The most common reason for exclusion was insufficient understanding of the German language $(n=50)$. One hundred and forty-six patients met the inclusion criteria and were included in the study. The mean number of 
treatment sessions (individual and group therapies) was similar in the intervention and control group. Eighteen physiotherapists and seven clinical psychologists participated in the trial. Training of the physiotherapists and clinical psychologists started in 2008 and refresher courses of the therapists were organised twice a year.

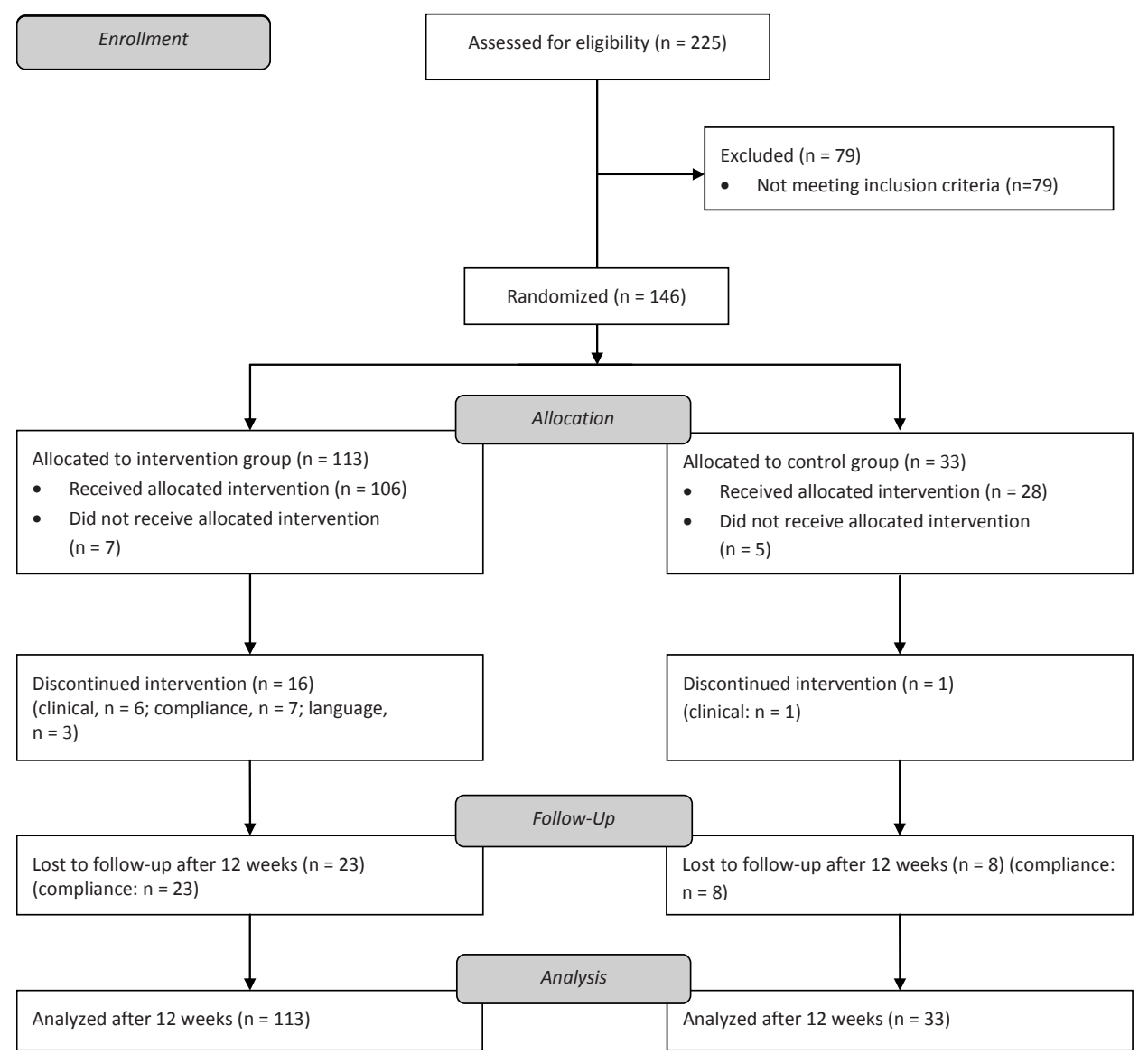

Figure 1. Patient flow through the study

\section{Baseline comparisons and dropouts}

The mean age of study participants was 46 years (range 18-73), and 65\% of 146 patients were women (Table 1). The patients in the intervention and control group were comparable in demographic and clinical characteristics, including their baseline scores for the primary outcomes severity of pain and pain disability. 
Table 1. Patient characteristics of the sample groups at baseline

\begin{tabular}{|c|c|c|}
\hline Characteristic & $\begin{array}{l}\text { Intervention group } \\
(\mathrm{n}=113)\end{array}$ & $\begin{array}{l}\text { Control group } \\
(n=33)\end{array}$ \\
\hline \multicolumn{3}{|l|}{ Demographic characteristic } \\
\hline Female sex (\%) & 62.8 & 69.7 \\
\hline Age (y; m, min-max) & $47.6(18.0-73.4)$ & $45.5(21.8-67.2)$ \\
\hline \multicolumn{3}{|l|}{ School education (\%) } \\
\hline No school education completed & 2.7 & 0.0 \\
\hline Elementary school & 28.3 & 48.5 \\
\hline Secondary school & 62.8 & 51.5 \\
\hline University entrance diploma & 6.2 & 0.0 \\
\hline \multicolumn{3}{|l|}{ Employment status } \\
\hline 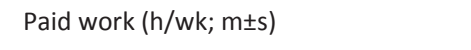 & $16.8 \pm 19.2$ & $20.8 \pm 19.3$ \\
\hline Household chores (h/wk; m, min-max) & $11.3(0.0-56.0)$ & $9.3(0.0-28.0)$ \\
\hline \multicolumn{3}{|l|}{ Sports (h/wk; \%) } \\
\hline None & 42.5 & 45.5 \\
\hline$>2$ & 23.0 & 12.1 \\
\hline \multicolumn{3}{|l|}{ Marital status (\%) } \\
\hline Single & 25.7 & 15.2 \\
\hline Married & 64.6 & 75.8 \\
\hline Other & 9.7 & 9.1 \\
\hline \multicolumn{3}{|l|}{ Clinical characteristics } \\
\hline Duration of symptoms ( $y$; m, min-max) & $10.1(0.5-42.1)$ & $8.6(0.5-39.0)$ \\
\hline \multicolumn{3}{|l|}{ Co morbidities (\%) } \\
\hline None & 20.5 & 28.1 \\
\hline $1-3$ & 59.9 & 43.8 \\
\hline$>3$ & 19.6 & 28.1 \\
\hline Smoking: yes (\%) & 40.7 & 48.5 \\
\hline \multicolumn{3}{|l|}{ Severity of pain (NRS score; $m \pm s$ ) } \\
\hline Current pain & $6.3 \pm 2.1$ & $6.2 \pm 2.0$ \\
\hline Maximum pain in last 7 days & $7.9 \pm 1.7$ & $7.6 \pm 1.6$ \\
\hline Minimum pain in last 7 days & $4.4 \pm 2.3$ & $5.3 \pm 2.4$ \\
\hline \multicolumn{3}{|l|}{ Pain disability $(\mathrm{m} \pm \mathrm{s})$} \\
\hline Self-report (ODI score) & $46.1 \pm 13.0$ & $45.0 \pm 13.3$ \\
\hline Performance test (BPS score) & $6.7 \pm 4.0$ & $7.3 \pm 4.3$ \\
\hline Performance test (5-MWD test; meter) & $320.6 \pm 126.1$ & $307.3 \pm 128.3$ \\
\hline
\end{tabular}




\begin{tabular}{|c|c|c|}
\hline Characteristic & $\begin{array}{l}\text { Intervention group } \\
(n=113)\end{array}$ & $\begin{array}{l}\text { Control group } \\
(n=33)\end{array}$ \\
\hline \multicolumn{3}{|l|}{ Mental health } \\
\hline 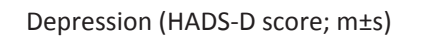 & $11.5 \pm 4.3$ & $11.8 \pm 4.7$ \\
\hline Catastrophizing (PCS score; $\mathrm{m} \pm \mathrm{s}$ ) & $51.0 \pm 22.4$ & $55.0 \pm 26.4$ \\
\hline \multicolumn{3}{|l|}{ 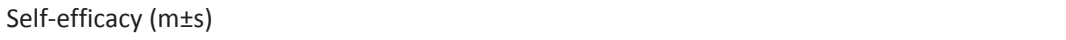 } \\
\hline CSQ item "control over pain" & $2.6 \pm 1.2$ & $2.4 \pm 1.2$ \\
\hline CSQ item "ability to decrease pain" & $2.3 \pm 1.0$ & $2.0 \pm 1.0$ \\
\hline \multicolumn{3}{|l|}{ Treatment expectancy and credibility } \\
\hline 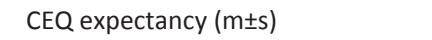 & $61.3 \pm 21.4$ & $59.4 \pm 22.6$ \\
\hline 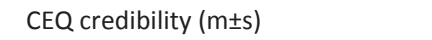 & $53.9 \pm 20.2$ & $52.5 \pm 22.8$ \\
\hline
\end{tabular}

Abbreviations: m, mean; s: standard deviation; NRS, Numeric Rating Scale (range from 0 to 10; 0=no pain, 10=worst conceivable pain); ODI, Oswestry Disability Index (range from 0 to 100; 0=no disability, $100=$ maximum conceivable disability); BPS, Back Performance Scale (range from 0 to 15; 0=best, 15=worst); HADS-D, Depression scale of Hospital Anxiety and Depression Scale (range 0 to 21; $0=$ no depression; 21=maximum conceivable depressive mood; cut-off point of 9 out of 21 points for depression); PCS, Pain Catastrophizing Scale (range 0 to 100; $0=$ no catastrophizing; 100=maximum conceivable catastrophizing); CSQ, Coping Strategies Questionnaire (range 0 to 6; $0=$ least; $6=$ most/ best); CEQ, Credibility and Expectancy Questionnaire (range 0 to $100 ; 0=$ less; $100=$ most).

\section{Classification procedure}

Of the 113 patients randomly allocated to the intervention group, the MPI Classification System classified 27 patients as adaptive copers, 49 patients as interpersonally distressed, and 37 patients were classified as dysfunctional. Based on their clinical examination and observation of the patients, the therapists agreed with the subgroup classifications and did not overrule the MPI Classification System.

\section{Treatment outcome: intention-to-treat analyses}

\section{Primary outcomes}

For the Oswestry Disability Index, the tailored pain management group improved by 1.0 point at 4-week follow up, and 1.7 point at 12-week follow up, respectively (Table 2). The improvements in the general pain management group at 1.3 and 2.3 points, respectively, were comparable small. Between-group differences were at both timepoints non-significant. With the exception of minimum pain intensity after 4 weeks (standard mean difference $(S M D)=0.43,95 \%$ confidence interval $(\mathrm{Cl}), 0.02$ to $0.84 ; \mathrm{p}=$ 0.034 , in favor of the control group), no significant differences in pain between intervention and control group could be measured. The secondary analysis, i.e. pairwise comparisons between the individual MPI subgroups and the control group, attributed this difference in reduction of pain in favor of the control group to the effect of the MPI 
subgroup adaptive coper at 12 weeks follow up: $\mathrm{SMD}=0.55,95 \% \mathrm{Cl}, 0.02$ to $1.08 ; \mathrm{p}=$ 0.035 (Table 3).

Table 2. Effects of primary outcome variables pain severity and pain disability

\begin{tabular}{|c|c|c|c|c|}
\hline $\begin{array}{l}\text { Variable } \\
(\mathrm{m} \pm \mathrm{s})\end{array}$ & $\begin{array}{l}\text { Intervention group } \\
(n=113)\end{array}$ & $\begin{array}{l}\text { Control group } \\
(n=33)\end{array}$ & $\begin{array}{l}\text { Between group difference } \\
\text { (SMD, 95\% CI) }\end{array}$ & $\mathbf{p}$ \\
\hline \multicolumn{5}{|c|}{ NRS current pain } \\
\hline Baseline & $6.3 \pm 2.1$ & $6.2 \pm 2.0$ & & \\
\hline Week 4 & $5.8 \pm 2.7$ & $5.8 \pm 2.3$ & $0.05(-0.35$ to 0.46$)$ & 0.803 \\
\hline Week 12 & $5.7 \pm 2.7$ & $5.7 \pm 2.4$ & $0.05(-0.36$ to 0.46$)$ & 0.804 \\
\hline \multicolumn{5}{|c|}{ NRS maximum pain } \\
\hline Baseline & $8.0 \pm 1.7$ & $7.6 \pm 1.6$ & & \\
\hline Week 4 & $7.6 \pm 2.0$ & $7.5 \pm 2.3$ & $0.11(-0.30$ to 0.51$)$ & 0.607 \\
\hline Week 12 & $7.4 \pm 2.2$ & $7.4 \pm 2.1$ & $-0.19(-0.60$ to 0.22$)$ & 0.352 \\
\hline \multicolumn{5}{|c|}{ NRS minimum pain } \\
\hline Baseline & $4.4 \pm 2.3$ & $5.3 \pm 2.4$ & & \\
\hline Week 4 & $4.0 \pm 2.5$ & $4.2 \pm 2.4$ & $0.43(0.02$ to 0.84$)$ & 0.034 \\
\hline Week 12 & $4.0 \pm 2.5$ & $4.5 \pm 2.3$ & $0.26(-0.15$ to 0.67$)$ & 0.208 \\
\hline \multicolumn{5}{|c|}{ ODI pain disability } \\
\hline Baseline & $46.1 \pm 13.0$ & $45.0 \pm 13.3$ & & \\
\hline Week 4 & $45.1 \pm 14.7$ & $43.7 \pm 16.8$ & $0.04(-0.35$ to 0.42$)$ & 0.859 \\
\hline Week 12 & $44.4 \pm 15.7$ & $42.7 \pm 15.3$ & $0.07(-0.32$ to 0.46$)$ & 0.740 \\
\hline
\end{tabular}

Abbreviations: m, mean; s, standard deviation; SMD, Cohen's standardized mean difference $d ; 95 \% \mathrm{Cl}, 95 \%$ confidence interval; $p$, significance level between groups with t-test; NRS, Numeric Rating Scale $(0=$ best; 10=worst); ODI, Oswestry Disability Index (0=best; 100=worst).

\section{Secondary outcomes}

Within both groups small to medium effects were measured for the dimensions depression, anxiety, catastrophizing, self-efficacy, observed functional performance, and responses of partner or spouse to patient pain behavior (Table 4). Most improvement occurred in reduction of catastrophizing: a mean of 5.6 points in the general pain management group, and 9.1 point in the standard pain management group. For all secondary outcome measures, no significant differences of effects between intervention and control at 4 and 12 week follow up were obtained. 


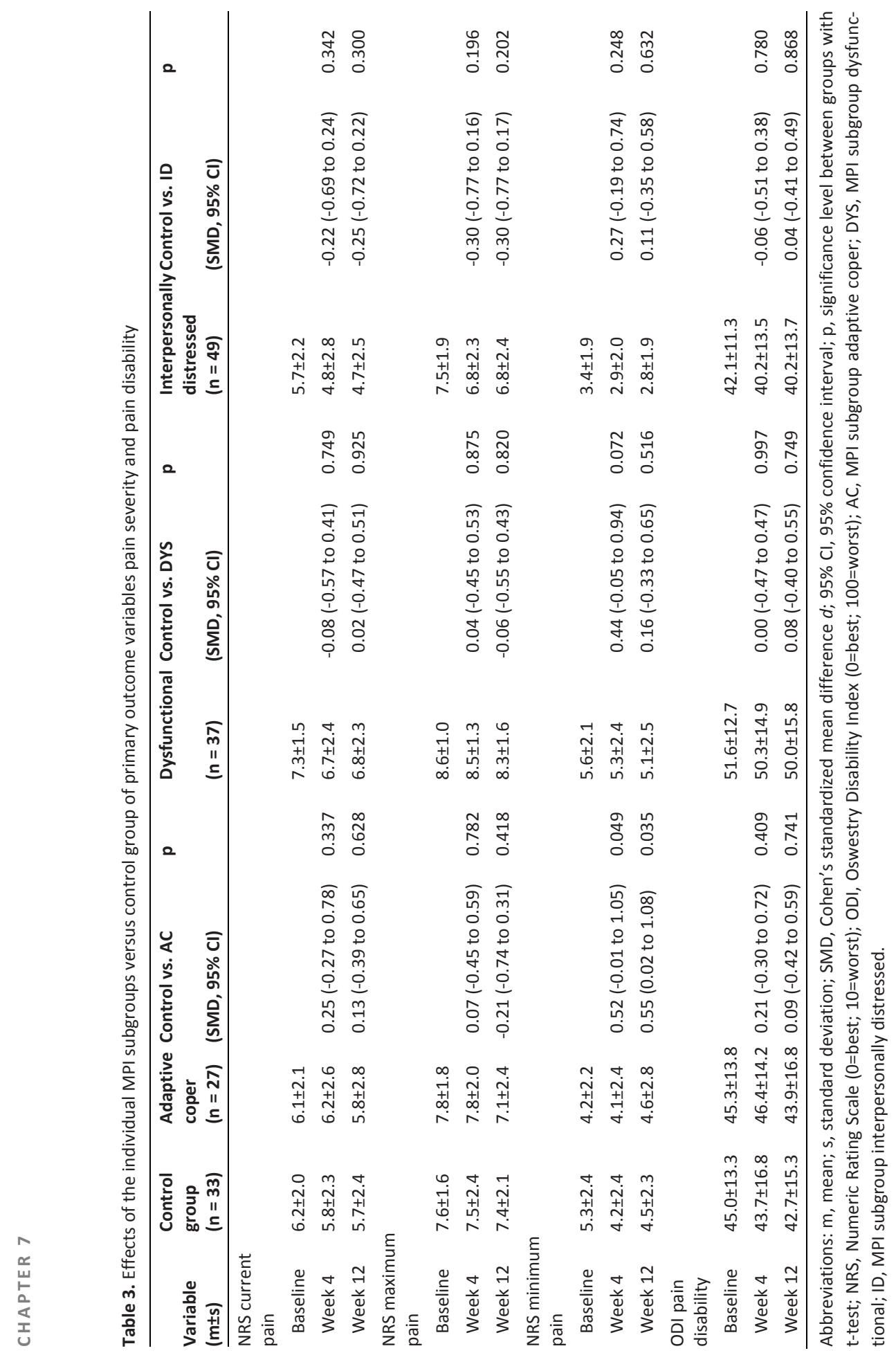


Table 4. Effects found for secondary outcome variables

\begin{tabular}{|c|c|c|c|c|}
\hline $\begin{array}{l}\text { Variable } \\
(\mathrm{m} \pm \mathrm{s})\end{array}$ & $\begin{array}{l}\text { Intervention } \\
\text { group } \\
(\mathrm{n}=113)\end{array}$ & $\begin{array}{l}\text { Control } \\
\text { group } \\
(n=33)\end{array}$ & $\begin{array}{l}\text { Between } \\
\text { group difference } \\
\text { (SMD, 95\% CI) }\end{array}$ & $p$ \\
\hline \multicolumn{5}{|c|}{ HADS depression } \\
\hline Baseline & $54.8 \pm 20.7$ & $56.4 \pm 22.2$ & & \\
\hline Week 4 & $58.6 \pm 23.6$ & $59.2 \pm 24.0$ & $0.08(-0.31$ to 0.48$)$ & 0.688 \\
\hline Week 12 & $56.2 \pm 26.4$ & $59.2 \pm 25.3$ & $-0.09(-0.49$ to 0.31$)$ & 0.660 \\
\hline \multicolumn{5}{|c|}{ HADS anxiety } \\
\hline Baseline & $52.0 \pm 21.2$ & $50.0 \pm 24.0$ & & \\
\hline Week 4 & $56.4 \pm 24.6$ & $53.3 \pm 22.3$ & $0.08(-0.31$ to 0.48$)$ & 0.688 \\
\hline Week 12 & $56.3 \pm 23.3$ & $53.4 \pm 23.3$ & $0.06(-0.34$ to 0.45$)$ & 0.777 \\
\hline \multicolumn{5}{|c|}{ PCS total score } \\
\hline Baseline & $51.0 \pm 22.4$ & $55.0 \pm 26.4$ & & \\
\hline Week 4 & $46.6 \pm 25.2$ & $46.8 \pm 25.6$ & $0.28(-0.13$ to 0.69$)$ & 0.172 \\
\hline Week 12 & $45.4 \pm 26.6$ & $45.9 \pm 25.6$ & $0.23(-0.18$ to 0.64$)$ & 0.267 \\
\hline \multicolumn{5}{|c|}{ CSQ control pain } \\
\hline Baseline & $2.6 \pm 1.2$ & $2.4 \pm 1.2$ & & \\
\hline Week 4 & $2.8 \pm 1.1$ & $2.5 \pm 1.0$ & $0.17(-0.23$ to 0.56$)$ & 0.407 \\
\hline Week 12 & $2.9 \pm 1.3$ & $2.8 \pm 1.1$ & $-0.01(-0.41$ to 0.39$)$ & 0.956 \\
\hline \multicolumn{5}{|c|}{ CSQ decrease pain } \\
\hline Baseline & $2.3 \pm 1.0$ & $2.0 \pm 1.1$ & & \\
\hline Week 4 & $2.6 \pm 1.0$ & $2.3 \pm 1.2$ & $0.01(-0.38$ to 0.41$)$ & 0.956 \\
\hline Week 12 & $2.5 \pm 1.3$ & $2.5 \pm 1.0$ & $-0.19(-0.59$ to 0.21$)$ & 0.341 \\
\hline \multicolumn{5}{|c|}{ Back Performance Scale } \\
\hline Baseline & $6.7 \pm 4.0$ & $7.3 \pm 4.3$ & & \\
\hline Week 4 & $5.2 \pm 4.0$ & $6.2 \pm 4.8$ & $-0.18(-0.62$ to 0.25$)$ & 0.401 \\
\hline \multicolumn{5}{|c|}{5 Minute Walk Distance test } \\
\hline Baseline & $320 \pm 126$ & $307 \pm 128$ & & \\
\hline Week 4 & $358 \pm 129$ & $333 \pm 155$ & $0.17(-0.25$ to 0.59$)$ & 0.438 \\
\hline \multicolumn{5}{|c|}{ MPI negative responses } \\
\hline Baseline & $78.9 \pm 22.8$ & $76.1 \pm 25.1$ & & \\
\hline Week 4 & $78.4 \pm 22.7$ & $79.0 \pm 22.7$ & $-0.19(-0.58$ to 0.19$)$ & 0.665 \\
\hline \multicolumn{5}{|c|}{ MPI solicitous responses } \\
\hline Baseline & $57.3 \pm 27.9$ & $59.3 \pm 21.8$ & & \\
\hline Week 4 & $58.9 \pm 26.7$ & $60.7 \pm 25.6$ & $0.02(-0.37$ to 0.40$)$ & 0.728 \\
\hline \multicolumn{5}{|c|}{ MPI distracting responses } \\
\hline Baseline & $50.6 \pm 26.7$ & $59.3 \pm 23.9$ & & \\
\hline Week 4 & $53.3 \pm 26.2$ & $57.7 \pm 22.3$ & $0.29(-0.10$ to 0.68$)$ & 0.216 \\
\hline
\end{tabular}

Abbreviations: m, mean; s, standard deviation; SMD, Cohen's standardized mean difference $d ; 95 \% \mathrm{Cl}, 95 \%$ confidence interval; $p$, significance level between groups with t-test; HADS, Hospital Anxiety and Depression Scale (range 0 to 100; $0=$ no depression/anxiety; 100=maximum conceivable depression/anxiety; PCS, Pain Catastrophizing Scale (range 0 to 100; $0=$ no catastrophizing; 100=maximum conceivable catastrophizing); $\mathrm{CSQ}$, Coping Strategies Questionnaire (range 0 to 6; 0=least; 6=most/best); MPI, Multidimensional Pain Inventory (range 0 to 100; $0=$ worst; $100=$ best). 


\section{Treatment outcome: per-protocol analysis}

Seventeen patients (that is, $11.6 \%$ ) did not complete treatment during their 4-week stay at the rehabilitation clinic (Figure 1). Compared to one of the 33 patients $(3.0 \%)$ in the standard pain management group, the greatest proportion of non-completers was recorded in the tailored pain management group, 16 of 113 (14.2\%). Reasons for discontinued intervention were clinical $(n=6)$, language $(n=3)$, and compliance $(n=7)$. Loss to follow up after 12 weeks (tailored pain management group, 20.4\%; general pain management group, 24.3\%) was almost equally distributed. Percentages of discontinued intervention or loss to follow up at 12 weeks were 33\% for the adaptive copers, $31 \%$ for the interpersonally distressed, and $41 \%$ for the subgroups dysfunctional (data not shown in detail). Baseline scores of the study completers compared to noncompleters (that is, patients with missing data at any time point) showed less duration of symptoms (completers, $10.6 \mathrm{y}$; non-completers, $7.9 \mathrm{y}$ ) and a lower percentage of women in the group of the study completers (62\% versus $69 \%$ ). All other characteristics did not substantially differ (Table 5). A total of 76 patients were evaluated in the perprotocol analysis of the primary outcome pain severity and pain disability. No significant differences of effects between intervention and control at 4 and 12 week follow up were obtained (Table 6).

Table 5. Baseline scores of study completers compared to patients with missing data at any time point

\begin{tabular}{|c|c|c|c|}
\hline Characteristic & $\begin{array}{l}\text { Completers } \\
(n=97)\end{array}$ & $\begin{array}{l}\text { Non-completers } \\
(\mathrm{n}=49)\end{array}$ & p \\
\hline Gender, female (\%) & 62 & 69 & 0.369 \\
\hline Age (y; m, min-max) & $47.3(18.1-73.4)$ & $46.0(21.0-78.6)$ & 0.419 \\
\hline School education (\%) & & & 0.599 \\
\hline No school education completed & 2 & 2 & \\
\hline Elementary school & 32 & 35 & \\
\hline Secondary school & 60 & 61 & \\
\hline $\begin{array}{l}\text { University entrance } \\
\text { diploma }\end{array}$ & 6 & 2 & \\
\hline Co morbidities (\%) & & & 0.647 \\
\hline None & 23 & 21 & \\
\hline $1-3$ & 53 & 64 & \\
\hline$>3$ & 24 & 15 & \\
\hline Duration of symptoms ( $y$; $m$, min-max) & $10.6(0.5-42.1)$ & $7.9(0.5-39.0)$ & 0.264 \\
\hline 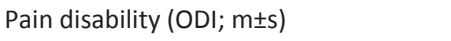 & $45.8 \pm 13.0$ & $45.9 \pm 13.0$ & 0.924 \\
\hline Pain severity (NRS current pain; $m \pm s$ ) & $6.3 \pm 2.2$ & $6.4 \pm 1.8$ & 0.930 \\
\hline
\end{tabular}

Abbreviations: m, mean; s, standard deviation; ODI, Oswestry Disability Index (0=best; 100=worst); NRS, Numeric Rating Scale ( $0=$ best; $10=$ worst); $p$, significance level between groups. 
Table 6. Per-protocol-analysis: Effects of primary outcome variables pain severity and pain disability

\begin{tabular}{|c|c|c|c|c|}
\hline $\begin{array}{l}\text { Variable } \\
(\mathrm{m} \pm \mathrm{s})\end{array}$ & $\begin{array}{l}\text { Intervention } \\
\text { group } \\
(n=68)\end{array}$ & $\begin{array}{l}\text { Control group } \\
(n=8)\end{array}$ & $\begin{array}{l}\text { Between group difference } \\
\text { (SMD, } 95 \% \mathrm{Cl} \text { ) }\end{array}$ & p \\
\hline \multicolumn{5}{|c|}{ NRS current pain } \\
\hline Baseline & $6.5 \pm 2.0$ & $6.8 \pm 2.1$ & & \\
\hline Week 4 & $6.0 \pm 2.8$ & $6.9 \pm 2.3$ & $-0.29(-1.02$ to 0.44$)$ & 0.437 \\
\hline Week 12 & $5.8 \pm 2.7$ & $6.5 \pm 2.5$ & $-0.21(-0.95$ to 0.52$)$ & 0.570 \\
\hline \multicolumn{5}{|c|}{ NRS maximum pain } \\
\hline Baseline & $8.0 \pm 1.5$ & $7.6 \pm 1.6$ & & \\
\hline Week 4 & $7.7 \pm 1.9$ & $7.1 \pm 3.0$ & $0.12(-0.62$ to 0.85$)$ & 0.756 \\
\hline Week 12 & $7.3 \pm 2.1$ & $7.9 \pm 2.8$ & $-0.22(-0.96$ to 0.51$)$ & 0.551 \\
\hline \multicolumn{5}{|c|}{ NRS minimum pain } \\
\hline Baseline & $4.5 \pm 2.3$ & $5.8 \pm 2.0$ & & \\
\hline Week 4 & $4.3 \pm 2.5$ & $5.3 \pm 2.3$ & $0.16(-0.57$ to 0.89$)$ & 0.665 \\
\hline Week 12 & $4.3 \pm 2.6$ & $5.1 \pm 2.5$ & $0.19(-0.54$ to 0.93$)$ & 0.605 \\
\hline \multicolumn{5}{|c|}{ ODI pain disability } \\
\hline Baseline & $46.6 \pm 12.6$ & $46.4 \pm 19.3$ & & \\
\hline Week 4 & $45.5 \pm 14.7$ & $46.4 \pm 21.7$ & $-0.11(-0.84$ to 0.62$)$ & 0.765 \\
\hline Week 12 & $44.6 \pm 16.2$ & $42.0 \pm 21.8$ & $0.20(-0.53$ to 0.94$)$ & 0.588 \\
\hline
\end{tabular}

Abbreviations: m, mean; s, standard deviation; SMD, Cohen's standardized mean difference $d ; 95 \% \mathrm{Cl}, 95 \%$ confidence interval; $p$, significance level between groups with t-test; NRS, Numeric Rating Scale ( $0=$ =best; 10=worst); ODI, Oswestry Disability Index (0=best; 100=worst)

\section{Discussion}

The primary aim of the present study was to examine the effectiveness of a tailored pain management program on pain and disability in patients with chronic nonspecific back pain classified according to the Multidimensional Pain Inventory (MPI) Classification System, compared to general pain management. This study failed to demonstrate that in a rehabilitation setting a subgroup-specific pain management program based on the MPI Classification System for patients with chronic back pain is more effective in improving pain and disability than a standard pain management program.

Interestingly, patients in both groups, in spite of intensive therapies based on best scientific knowledge and best clinical practice (over $110 \mathrm{~h}$ in total), made only small to moderate improvements in reduction of pain, disability, and the secondary outcomes. The effects were, at a group level, not clinically meaningful, although individual patients, in both groups, may have achieved significant improvement.

Another finding of interest was the problem of compliance. As in both groups no serious adverse events occurred, the discontinued interventions for clinical reasons and the three patients with difficulties in understanding the German language have to be attributed to exclusion criteria that were discovered too late. The six patients that were 
non-compliant in the tailored pain management group may be explained by the fact that the main principle of graded activity exercise, progression of physical training on a time-contingent basis instead of a pain-contingent basis, was for some patients hard to tolerate.

To the knowledge of the authors, this is the first RCT evaluating the effects of subgroup-specific interventions in pre-treatment classified chronic back pain patients according the MPI Classification System. Therefore, the present study can only be compared with RCTs evaluating the effects of tailored pain interventions based on other classification systems. The Treatment Based Classification system classifies patients in four treatment groups; a) direction-specific exercises, b) spinal joint manipulation or mobilization, c) trunk strengthening and stabilization exercises, and d) traction [74]. Fritz et al. compared this classification-based treatment approach with minimal physiotherapy interventions according the clinical practice guidelines for acute work-related low back pain in 78 patients with acute low back pain (mean duration of symptoms of three days) [75]. Clinically meaningful and statistically significant improvements in pain disability (measured with Oswestry Disability Index) were obtained at 4- and 52-week follow-up ( $p=0.023$, resp. 0.044). In a similar setting with 123 patients with acute/subacute low back pain (mean pain duration of 15 days), Brennan et al. compared matched to unmatched treatment interventions according to the same Treatment Based Classification system. This study also showed significantly improved Oswestry Disability Index-scores at 4- and 52-week follow up ( $p=0.030$, and 0.006 respectively). Apeldoorn et al. did a cross-validation of these two US-studies with 156 subacute and chronic low back pain patients in the Netherlands (on average 5 months duration of current episode of low back pain) [19]. The positive results of the prior studies could not be replicated: the primary outcomes global perceived effect, pain disability (ODI), and pain severity (NRS) - as all secondary outcomes - were in both the intention-to-treat analysis, as well as in the per-protocol analysis non-significant. As in the present study, it might be more difficult to get increased effects in chronic back pain populations, compared to acute/subacute patients with back pain. Finally, based on the O'Sullivan Classification System [76], Vibe Fersum et al. compared the classification-based cognitive functional therapy with traditional manual therapy and exercise [18]. This study showed significant improved Oswestry Disability Index-scores and NRS pain-scores at 12- and 52-week follow up $(p<0.001)$. However, these positive results may be biased by the fact that only 94 of 121 randomized patients were included in the final analysis. In the present study, even the per-protocol analysis did not show results in favor of the classification-based group.

Psychosocial coping style of the subgroup adaptive copers is controversially discussed in the literature. The question is whether these patients minimize their pain problems or truly better adjust to pain. The focus of the tailored interventions in the present study for this subgroup was on activity pacing to moderate overactivity, use of stop-rules, body awareness, and mental and physical relaxation techniques in stressful 
situations. We elected this approach because of the low baseline disability scores (as compared to population norms). Compared to the baseline scores of the other two subgroups dysfunctional and interpersonally distressed, the adaptive copers perform better, but compared to healthy individuals they are also severely disabled. However, this treatment approach is in conflict with the observations made by Junghaenel et al. [77].

In the present study it was not possible to use the MPI computer program developed by Rudy [78]. The reason for this was that it is based on a version of the MPI different from the one that has been translated and validated in German [69, 70, 79]. The MPI software classifies patients not just in the MPI subgroups dysfunctional, adaptive copers, and interpersonally distressed, but also refers to patients who cannot be classified into one of these three clusters as "anomalous" or "hybrid". In the classification method used in the present study, subgroups were defined by confirmatory cluster analysis using the predefined three cluster solution according to the MPI Classification System. Without exception, all patients were assigned to one of the three subgroups with the clinical profile most likely to fit. Cluster analysis is a reproducible function in SPSS. When the total amount of clusters is defined, cluster analysis classifies all cases, and so, no unclassified cases exist.

The classification-based interventions in this study were not superior to standard pain management. Therefore, if the results of this study are to be replicated in other studies by different research groups in a comparable setting, the additional value of classification of patients with chronic back pain based on the MPI Classification System and the subsequent process of tailoring pain management interventions can be challenged. On the other hand, informed decision making is not solely based on best scientific evidence, but also on clinical expertise of the health care professional and patient's preferences and expectations [80]. Since the classification-based interventions were as equally effective as the interventions in the standard pain management group and credibility and expectancy of both patient and health care provider play an important role in the process of treatment $[81,82]$, subgroup classification and tailoring interventions might be an alternative.

Pragmatic randomized controlled trials, like the present study, compare two or more (sets of) interventions which are believed to be clinically meaningful, and as they are delivered in clinical practice. In this trial both groups had a comprehensive range and number of group therapies. Most group therapies were performed based on a cognitive behavioral approach, and the pain coping group was led by a clinical psychologist. This meant that the patients in the standard pain management group (individual medical training therapy on the principles of exercise physiology by the physiotherapist and optional individual psychotherapy, not focussing on pain coping strategies) also received quite a lot of information on how to cope with different aspects of chronic back pain through these group therapies. This might have minimized contrast between interventions. 
In this study, the sample consisted of selected persons who had suffered from a severe and disabling chronic back pain disorder for a long time and who fulfilled certain criteria (e.g. motivation, ability to understand German) and, therefore, possibly differ in important ways from people with chronic back pain in general thus limiting the generalizability of the results. Another limitation is the short-term measurement of effects (between entry and discharge from the rehabilitation clinic after four weeks and the 3month follow-up). Future analyses should use standardized outcome measurements at follow-up times of up to one year or longer that are long enough for the person with chronic back pain to modify behavior patterns and master effective strategies.

Subgrouping of patients with back pain may be less successful among patients with chronic symptoms and perhaps more meaningful in less disabled patients or patients with acute/subacute low back pain $[18,75,83]$. Classification of chronic back pain on the basis of psychosocial factors and pain coping patterns, as performed in this study, may be less effective. Future trials with chronic and highly disabled back pain patients might focus on classification systems based on mechanical loading strategies or modified movement strategies of the spine (for overview: [17]) or other biopsychosocial features as captured by the MPI Classification System.

\section{Authors' contributions}

$M L V, F A, R A B$, and JBS were responsible for the design of the study. AA procured funding. SL, RB and TB collected the data. Statistical analysis was performed by FA and MLV. MLV and FA interpreted the data and made a first draft of the manuscript. All authors have read and approved the final manuscript.

\section{Funding}

This study was supported by the Zurzach Rehabilitation Foundation SPA, Bad Zurzach, Switzerland. The funding body was not involved in the preparation of the study protocol, management of the trial, analysis of the data, or preparation of the manuscript. The principal investigator (MLV) had full access to all the data in the study and had final responsibility for the decision to submit for publication.

\section{Acknowledgements}

We gratefully thank all patients for their participation in the study and Joy Buchanan for her English editing. 


\section{Conclusions}

The subgroup-specific pain management program based on the Multidimensional Pain Inventory Classification System for patients with chronic back pain in this study was not more effective in improving outcomes for severity of pain and pain disability than a standard pain management program. 


\section{References}

1. Breivik H, Collett B, Ventafridda V, Cohen R, Gallacher D: Survey of chronic pain in Europe: prevalence, impact on daily life, and treatment. European journal of pain 2006, 10(4):287-333.

2. Wieser S, Horisberger B, Schmidhauser S, Eisenring C, Brugger U, Ruckstuhl A, Dietrich J, Mannion AF, Elfering A, Tamcan $O$ et al: Cost of low back pain in Switzerland in 2005. The European journal of health economics : HEPAC : health economics in prevention and care 2011, 12(5):455-467.

3. McBeth J, Symmons DP, Silman AJ, Allison T, Webb R, Brammah T, Macfarlane GJ: Musculoskeletal pain is associated with a long-term increased risk of cancer and cardiovascular-related mortality. Rheumatology 2009, 48(1):74-77.

4. Keller A, Hayden J, Bombardier C, van Tulder M: Effect sizes of non-surgical treatments of non-specific low-back pain. European spine journal : official publication of the European Spine Society, the European Spinal Deformity Society, and the European Section of the Cervical Spine Research Society 2007, 16(11):1776-1788.

5. van Middelkoop M, Rubinstein SM, Kuijpers T, Verhagen AP, Ostelo R, Koes BW, van Tulder MW: A systematic review on the effectiveness of physical and rehabilitation interventions for chronic nonspecific low back pain. European spine journal : official publication of the European Spine Society, the European Spinal Deformity Society, and the European Section of the Cervical Spine Research Society 2011, 20(1):19-39.

6. Gatchel RJ, Okifuji A: Evidence-based scientific data documenting the treatment and cost-effectiveness of comprehensive pain programs for chronic nonmalignant pain. The journal of pain : official journal of the American Pain Society 2006, 7(11):779-793.

7. Koes BW, van Tulder MW, Thomas S: Diagnosis and treatment of low back pain. Bmj 2006, 332(7555):1430-1434.

8. Waddell G: Diagnostic triage. In: The back pain revolution. 1 edn. Edinburgh: Churchill Livingstone; 1998: 9-25.

9. Borkan JM, Cherkin DC: An agenda for primary care research on low back pain. Spine 1996, 21(24):28802884.

10. Airaksinen O, Brox JI, Cedraschi C, Hildebrandt J, Klaber-Moffett J, Kovacs F, Mannion AF, Reis S, Staal JB, Ursin $\mathrm{H}$ et al: Chapter 4. European guidelines for the management of chronic nonspecific low back pain. European spine journal : official publication of the European Spine Society, the European Spinal Deformity Society, and the European Section of the Cervical Spine Research Society 2006, 15 Suppl 2:S192-300.

11. Henschke N, Maher CG, Refshauge KM, Das A, McAuley JH: Low back pain research priorities: a survey of primary care practitioners. BMC family practice 2007, 8:40.

12. Costa Lda C, Koes BW, Pransky G, Borkan J, Maher CG, Smeets RJ: Primary care research priorities in low back pain: an update. Spine 2013, 38(2):148-156.

13. Brookes ST, Whitely E, Egger M, Smith GD, Mulheran PA, Peters TJ: Subgroup analyses in randomized trials: risks of subgroup-specific analyses; power and sample size for the interaction test. Journal of clinical epidemiology 2004, 57(3):229-236.

14. Moye LA, Deswal A: Trials within trials: confirmatory subgroup analyses in controlled clinical experiments. Controlled clinical trials 2001, 22(6):605-619.

15. Kamper SJ, Maher CG, Hancock MJ, Koes BW, Croft PR, Hay E: Treatment-based subgroups of low back pain: a guide to appraisal of research studies and a summary of current evidence. Best practice \& research Clinical rheumatology 2010, 24(2):181-191.

16. Hancock M, Herbert RD, Maher CG: A guide to interpretation of studies investigating subgroups of responders to physical therapy interventions. Physical therapy 2009, 89(7):698-704.

17. Karayannis NV, Jull GA, Hodges PW: Physiotherapy movement based classification approaches to low back pain: comparison of subgroups through review and developer/expert survey. $B M C$ musculoskeletal disorders 2012, 13:24. 
18. Vibe Fersum K, O'Sullivan P, Skouen JS, Smith A, Kvale A: Efficacy of classification-based cognitive functional therapy in patients with non-specific chronic low back pain: A randomized controlled trial. European journal of pain 2012.

19. Apeldoorn AT, Ostelo RW, van Helvoirt H, Fritz JM, Knol DL, van Tulder MW, de Vet HC: A randomized controlled trial on the effectiveness of a classification-based system for subacute and chronic low back pain. Spine 2012, 37(16):1347-1356.

20. Hill JC, Whitehurst DG, Lewis M, Bryan S, Dunn KM, Foster NE, Konstantinou K, Main CJ, Mason E, Somerville $S$ et al: Comparison of stratified primary care management for low back pain with current best practice (STarT Back): a randomised controlled trial. Lancet 2011, 378(9802):1560-1571.

21. Verra ML, Angst F, Staal JB, Brioschi R, Lehmann S, Aeschlimann A, de Bie RA: Differences in pain, function and coping in Multidimensional Pain Inventory subgroups of chronic back pain: a one-group pretest-posttest study. BMC musculoskeletal disorders 2011, 12:145.

22. Bergstrom G, Bergstrom C, Hagberg J, Bodin L, Jensen I: A 7-year follow-up of multidisciplinary rehabilitation among chronic neck and back pain patients. Is sick leave outcome dependent on psychologically derived patient groups? European journal of pain 2010, 14(4):426-433.

23. Vollenbroek-Hutten MM, Hermens HJ, Wever D, Gorter M, Rinket J, ljzerman MJ: Differences in outcome of a multidisciplinary treatment between subgroups of chronic low back pain patients defined using two multiaxial assessment instruments: the multidimensional pain inventory and lumbar dynamometry. Clinical rehabilitation 2004, 18(5):566-579.

24. Angst F, Brioschi R, Main CJ, Lehmann S, Aeschlimann A: Interdisciplinary rehabilitation in fibromyalgia and chronic back pain: a prospective outcome study. The journal of pain : official journal of the American Pain Society 2006, 7(11):807-815.

25. Turk DC, Rudy TE: Toward an empirically derived taxonomy of chronic pain patients: integration of psychological assessment data. Journal of consulting and clinical psychology 1988, 56(2):233-238.

26. Turk DC, Rudy TE: The robustness of an empirically derived taxonomy of chronic pain patients. Pain 1990, 43(1):27-35.

27. Bergstrom G, Bodin L, Jensen IB, Linton SJ, Nygren AL: Long-term, non-specific spinal pain: reliable and valid subgroups of patients. Behaviour research and therapy 2001, 39(1):75-87.

28. Verra ML, Angst F, Staal JB, Brioschi R, Lehmann S, Aeschlimann A, de Bie RA: Reliability of the Multidimensional Pain Inventory and stability of the MPI classification system in chronic back pain. BMC musculoskeletal disorders 2012, 13(1):155.

29. Turk DC: Understanding pain sufferers: the role of cognitive processes. The spine journal : official journal of the North American Spine Society 2004, 4(1):1-7.

30. Johansson E, Lindberg $P$ : Low back pain patients in primary care: subgroups based on the Multidimensional Pain Inventory. Int J Behavioural Med 2000, 7(4):340-352.

31. Verra ML, Angst F, Brioschi R, Lehmann S, Keefe FJ, Staal JB, de Bie RA, Aeschlimann A: Does classification of persons with fibromyalgia into Multidimensional Pain Inventory subgroups detect differences in outcome after a standard chronic pain management program? Pain research \& management : the journal of the Canadian Pain Society = journal de la societe canadienne pour le traitement de la douleur 2009, 14(6):445-453.

32. Angst F, Verra ML, Lehmann S, Aeschlimann A, Angst J: Refined insights into the pain-depression association in chronic pain patients. The Clinical journal of pain 2008, 24(9):808-816.

33. Vlaeyen JW, Morley S: Active despite pain: the putative role of stop-rules and current mood. Pain 2004, 110(3):512-516.

34. Vlaeyen WS, Nielson WR, van Houdenhove B: Overuse as a risk factor for pain disability: cognitive behavioral models and interventions. In: Proceedings of the 11th World Congress on Pain. edn. Edited by Flor H, Kalso E, Dostrovsky JO. Seattle: IASP Press; 2006: 585-596.

35. De Souza L, Frank AO: Patients' experiences of the impact of chronic back pain on family life and work. Disability and rehabilitation 2011, 33(4):310-318.

36. Raichle KA, Romano JM, Jensen MP: Partner responses to patient pain and well behaviors and their relationship to patient pain behavior, functioning, and depression. Pain 2011, 152(1):82-88. 
37. Merkle W, Gaus E: Paartherapie bei patienten mit chronischen Schmerzsyndromen. In: Der Schmerzkranke: grundlagen, Pathogenese, Klinik und Therapie chronischer Schmerzsyndrome aus biopsycho-sozialer Sicht. first edn. Edited by Egle UT, Hoffmann SO. Stuttgart: Schattauer; 1993: 403-413.

38. Leonard MT, Cano A, Johansen AB: Chronic pain in a couples context: a review and integration of theoretical models and empirical evidence. The journal of pain : official journal of the American Pain Society 2006, 7(6):377-390.

39. Cano A, Barterian JA, Heller JB: Empathic and nonempathic interaction in chronic pain couples. The Clinical journal of pain 2008, 24(8):678-684.

40. Lindstrom I, Ohlund C, Eek C, Wallin L, Peterson LE, Fordyce WE, Nachemson AL: The effect of graded activity on patients with subacute low back pain: a randomized prospective clinical study with an operant-conditioning behavioral approach. Physical therapy 1992, 72(4):279-290; discussion 291-273.

41. Köke A, van Wilgen P, Engers A, Geilen M: Graded activity: een gedragsmatige behandelmethode voor paramedici. Houten: Bohn Stafleu van Loghum; 2007.

42. Nielson WR, Jensen MP, Karsdorp PA, Vlaeyen JW: Activity pacing in chronic pain: concepts, evidence, and future directions. The Clinical journal of pain 2013, 29(5):461-468.

43. van der Giessen RN, Speksnijder CM, Helders PJ: The effectiveness of graded activity in patients with non-specific low-back pain: a systematic review. Disability and rehabilitation 2012, 34(13):1070-1076.

44. Turk DC, Okifuji A: A cognitive-behavioral approach to pain management. In: Textbook of pain. fourth edn. Edited by Melzack R. Edinburgh: Churchill Livingstone; 1999: 1431-1443.

45. van den Hout JH, Vlaeyen JW: Problem-solving therapy and behavioral graded activity in the prevention of chronic pain disability. In: Pain research and clinical management. Volume 12, first edn. Edited by Linton SJ. Amsterdam: Elsevier Science BV; 2002: 293-303.

46. Hayden JA, van Tulder MW, Tomlinson G: Systematic review: strategies for using exercise therapy to improve outcomes in chronic low back pain. Annals of internal medicine 2005, 142(9):776-785.

47. Hayden JA, van Tulder MW, Malmivaara A, Koes BW: Exercise therapy for treatment of non-specific low back pain. Cochrane database of systematic reviews 2005(3):CD000335.

48. Scharrer M, Ebenbichler G, Pieber K, Crevenna R, Gruther W, Zorn C, Grimm-Stieger M, Herceg M, Keilani $\mathrm{M}$, Ammer K: A systematic review on the effectiveness of medical training therapy for subacute and chronic low back pain. European journal of physical and rehabilitation medicine 2012, 48(3):361-370.

49. Taylor NF, Dodd KJ, Damiano DL: Progressive resistance exercise in physical therapy: a summary of systematic reviews. Physical therapy 2005, 85(11):1208-1223.

50. Medicine ACoS: Position Stand: progression models in resistence training for healthy adults. Med Sci Sports Exerc 2009, 41(3):687-708.

51. Pollock ML, Franklin BA, Balady GJ, Chaitman BL, Fleg JL, Fletcher B, Limacher M, Pina IL, Stein RA, Williams $M$ et al: AHA Science Advisory. Resistance exercise in individuals with and without cardiovascular disease: benefits, rationale, safety, and prescription: An advisory from the Committee on Exercise, Rehabilitation, and Prevention, Council on Clinical Cardiology, American Heart Association; Position paper endorsed by the American College of Sports Medicine. Circulation 2000, 101(7):828-833.

52. Nijs J, Kosek E, Van Oosterwijck J, Meeus M: Dysfunctional endogenous analgesia during exercise in patients with chronic pain: to exercise or not to exercise? Pain physician 2012, 15(3 Suppl):ES205-213.

53. Angst F, Aeschlimann A, Steiner W, Stucki G: Responsiveness of the WOMAC osteoarthritis index as compared with the SF-36 in patients with osteoarthritis of the legs undergoing a comprehensive rehabilitation intervention. Annals of the rheumatic diseases 2001, 60(9):834-840.

54. Sangha O, Stucki G, Liang MH, Fossel AH, Katz JN: The Self-Administered Comorbidity Questionnaire: a new method to assess comorbidity for clinical and health services research. Arthritis and rheumatism 2003, 49(2):156-163.

55. Von Korff M, Ormel J, Keefe FJ, Dworkin SF: Grading the severity of chronic pain. Pain 1992, 50(2):133149.

56. Fairbank JC, Couper J, Davies JB, O'Brien JP: The Oswestry low back pain disability questionnaire. Physiotherapy 1980, 66(8):271-273. 
57. Mannion AF, Junge A, Fairbank JC, Dvorak J, Grob D: Development of a German version of the Oswestry Disability Index. Part 1: cross-cultural adaptation, reliability, and validity. European spine journal : official publication of the European Spine Society, the European Spinal Deformity Society, and the European Section of the Cervical Spine Research Society 2006, 15(1):55-65.

58. Mannion AF, Junge A, Grob D, Dvorak J, Fairbank JC: Development of a German version of the Oswestry Disability Index. Part 2: sensitivity to change after spinal surgery. European spine journal : official publication of the European Spine Society, the European Spinal Deformity Society, and the European Section of the Cervical Spine Research Society 2006, 15(1):66-73.

59. Strand LI, Moe-Nilssen R, Ljunggren AE: Back Performance Scale for the assessment of mobility-related activities in people with back pain. Physical therapy 2002, 82(12):1213-1223.

60. Magnussen L, Strand LI, Lygren H: Reliability and validity of the back performance scale: observing activity limitation in patients with back pain. Spine 2004, 29(8):903-907.

61. Butland RJ, Pang J, Gross ER, Woodcock AA, Geddes DM: Two-, six-, and 12-minute walking tests in respiratory disease. British medical journal 1982, 284(6329):1607-1608.

62. Simmonds MJ, Olson SL, Jones S, Hussein T, Lee CE, Novy D, Radwan H: Psychometric characteristics and clinical usefulness of physical performance tests in patients with low back pain. Spine 1998, 23(22):2412-2421.

63. Zigmond AS, Snaith RP: The hospital anxiety and depression scale. Acta psychiatrica Scandinavica 1983, 67(6):361-370.

64. Herrmann C, Buss U, Snaith RP: HADS-D: Hospital Anxiety and Depression Scale-Deutsche Version. Ein Fragebogenzur Erfassung von Angst und Depressivität in der somatischen Medizin. Berne, Switzerland: Verlag Hans Huber; 1995.

65. Sullivan MJ, Bishop SR, Pivik J: The Pain Catastropizing Scale: development and validation. Psychol Assess 1995, 7:524-532.

66. Meyer K, Sprott H, Mannion AF: Cross-cultural adaptation, reliability, and validity of the German version of the Pain Catastrophizing Scale. Journal of psychosomatic research 2008, 64(5):469-478.

67. Rosenstiel AK, Keefe FJ: The use of coping strategies in chronic low back pain patients: relationship to patient characteristics and current adjustment. Pain 1983, 17(1):33-44.

68. Verra ML, Angst F, Lehmann S, Aeschlimann A: Translation, cross-cultural adaptation, reliability, and validity of the German version of the Coping Strategies Questionnaire (CSQ-D). The journal of pain : official journal of the American Pain Society 2006, 7(5):327-336.

69. Flor H: Fragebögen: West Haven-Yale Multidimensionaler Schmerzfragebogen (MPI-D). In: Psychobiologie des Schmerzes. first edn. Bern, Göttingen, Toronto: Verlag Hans Huber; 1991: 267-273.

70. Flor H, Rudy TE, Birbaumer N, Streit B, Schugens MM: [The applicability of the West Haven-Yale multidimensional pain inventory in German-speaking countries. Data on the reliability and validity of the MPI-D.]. Schmerz 1990, 4(2):82-87.

71. Ostelo RW, de Vet HC: Clinically important outcomes in low back pain. Best practice \& research Clinical rheumatology 2005, 19(4):593-607.

72. Browder DA, Childs JD, Cleland JA, Fritz JM: Effectiveness of an extension-oriented treatment approach in a subgroup of subjects with low back pain: a randomized clinical trial. Physical therapy 2007, 87(12):1608-1618; discussion 1577-1609.

73. Borenstein M: Effect sizes for continuous data. In: The handbook of research synthesis and metaanalysis. second edn. Edited by Cooper H, Hedges LV, Valentine JC. New York: Russell Sage Foundation; 2009: 221-235.

74. Delitto A, Erhard RE, Bowling RW: A treatment-based classification approach to low back syndrome: identifying and staging patients for conservative treatment. Physical therapy 1995, 75(6):470-485; discussion 485-479.

75. Fritz JM, Delitto A, Erhard RE: Comparison of classification-based physical therapy with therapy based on clinical practice guidelines for patients with acute low back pain: a randomized clinical trial. Spine 2003, 28(13):1363-1371; discussion 1372. 
76. O'Sullivan P: Diagnosis and classification of chronic low back pain disorders: maladaptive movement and motor control impairments as underlying mechanism. Manual therapy 2005, 10(4):242-255.

77. Junghaenel DU, Keefe FJ, Broderick JE: Multi-modal examination of psychological and interpersonal distinctions among MPI coping clusters: a preliminary study. The journal of pain : official journal of the American Pain Society 2010, 11(1):87-96.

78. Rudy TE: Multidimensional Pain Inventory software user's guide. In., 3.0 edn. Pittsburgh: University of Pittsburgh; 2005.

79. Angst F, Verra ML, Lehmann S, Aeschlimann A: Responsiveness of five condition-specific and generic outcome assessment instruments for chronic pain. BMC medical research methodology 2008, 8:26.

80. Sackett DL, Straus S, Richardson S, Rosenberg W, Haynes RB: Evidence-based-medicine: how to practice and teach EBM, second edn. London: Churchill Livingstone; 2000.

81. Smeets RJ, Beelen S, Goossens ME, Schouten EG, Knottnerus JA, Vlaeyen JW: Treatment expectancy and credibility are associated with the outcome of both physical and cognitive-behavioral treatment in chronic low back pain. The Clinical journal of pain 2008, 24(4):305-315.

82. Linton SJ, Vlaeyen J, Ostelo R: The back pain beliefs of health care providers: are we fear-avoidant? Journal of occupational rehabilitation 2002, 12(4):223-232.

83. Brennan GP, Fritz JM, Hunter SJ, Thackeray A, Delitto A, Erhard RE: Identifying subgroups of patients with acute/subacute "nonspecific" low back pain: results of a randomized clinical trial. Spine 2006, 31(6):623-631. 
CHAPTER 8

General discussion 
CHAPTER 8 
This final chapter discusses the main results of the thesis, methodological reflections and the possible impact of this research on physiotherapy and the interdisciplinary pain management of patients with chronic musculoskeletal pain disorders in Switzerland. Finally, I will discuss directions for future research.

\section{Main findings and limitations of this thesis}

\section{Part I: Clinimetric studies}

Training and evaluation of pain coping strategies is a major goal of the Zurzach Interdisciplinary Pain Program as well as of many other pain management programs. Tremendous progress has been made in the last four decades in our understanding of how patients cope with the pain they experience (for overview: [1]). However, the concept of coping and its evaluation is still difficult and partly unknown [2]. One of the three objectives of this thesis was to test the clinimetric features of the self-reported measurement tools Coping Strategies Questionnaire (CSQ) and the Multidimensional Pain Inventory (MPI) for outcome assessment and subgroup classification based on three different pain coping strategies. In Chapter $\mathbf{2}$ we demonstrated that the translation process, cross-cultural adaptation and testing of reliability of the CSQ proceeded without major difficulties. However, its concurrent criterion-related validity and construct validity were low. Factor analysis in our and other studies revealed that only moderate percentages of the observed variance could be explained. Although modifications of the CSQ have been suggested [3-5], the original CSQ is still the most widely used pain coping questionnaire. So far, there is no gold standard assessment for pain coping. However, use of the widely applied outcome measures CSQ and MPI in chronic pain trials would permit pooling of data from different studies and provide a basis for meaningful comparisons of treatments in terms of the clinical importance of their outcomes, particularly through systematic reviews [6]. Therefore, in spite of their deficits, we decided to apply the CSQ and the MPI. In Chapter $\mathbf{3}$ we examined the test-retest reliability of the individual scales of the German MPI and - of high relevance for this thesis - the test-retest stability of the MPI subgroup classification in mainly chronic back pain patients. We demonstrated that test-retest reliability was moderate to good and comparable to other language versions. MPI subgroup classification was substantially stable when compared to other diagnostic groups like fibromyalgia and other examiner-based subgroup classification systems like the Treatment Based Classification by Delitto and the O'Sullivan Classification System. We need to consider that in the studies of this thesis it was not possible to use the MPI computer program developed by Rudy for classification of patients [7]. The reason for this is that it is based on a different version of the MPI compared to the one that has been translated and validated in German [810]. The MPI software classifies patients not just into the MPI subgroups dysfunctional, 
adaptive copers, and interpersonally distressed, but also refers to patients who cannot be classified into one of these three clusters as "anomalous" or "hybrid". Unfortunately, it is not documented in the manual how the classification of these non-classifiable patients is performed. In the classification method used in the present studies, subgroups were defined by confirmatory cluster analysis using the predefined three cluster solution according to the MPI Classification System. Cluster analysis is an exploratory method by which multiple sources of information are analyzed simultaneously to group individuals into clusters. Individuals within a cluster are similar to each other on the variables included in the statistical analysis and differ significantly from those in the other cluster groups. The MPI score patterns were depicted as graphs of the nine mean MPI subscale baseline scores and compared to the patterns described by Turk et al. using the rank orders of the three subgroups within one MPI scale [11, 12]. To assess whether a three-cluster solution was appropriate according to mathematical criteria, hierarchical cluster analysis according to the Ward method was performed [13]. The resulting diagram with the number of clusters and the course of the sum of residual squares did not favor a three-cluster solution. However, factor analysis revealed that a factor solution fitted best with three factors explaining up to $67 \%$ of the variance. Thus, the proposed "best feasible" (i.e. clinically characterized) empirically determined solution according to the subgroups defined by Turk et al. was chosen. Without exception, all patients were assigned to one of the three subgroups into which the clinical profile was most likely to fit. This means that an unknown number of patients without a doubtfree pattern of symptoms and coping styles were assigned to and treated as an MPI subgroup that might have been entirely obvious. This may have biased the outcomes. A recent study reported that patients with unclear classifications were different from those with clear classifications [14]. Within this classification system the unclear patients were on average older, had a longer duration of back pain and less back pain related disability. Consequently, the research group suggested that future studies should investigate the decision process for patients who do not clearly fit into a subgroup. In Chapter 4 we assessed the correlations between depression - the most common co-morbidity in patients with chronic musculoskeletal pain - and pain. It was remarkable that the MPI pain severity scale and the HADS depression scale showed maximum overall correlation of 0.27 to 0.29 , but analysis of the three MPI subgroups led to quite different pain-depression correlations. It was moderate in the subgroup interpersonally distressed (up to 0.57), weak in the subgroup dysfunctional (up to 0.26), and absent in the subgroup adaptive copers (down to -0.09). The strengths of the paindepression associations were too weak to state that a causal relationship between depression and pain would be true. However, in the MPI subgroup interpersonally distressed, the moderate association might be of importance for clinical care: chronic musculoskeletal pain could be treated by treating depression and vice versa. We implemented this finding in the design of the interventions of the randomized controlled trial, see chapter 7. 


\section{Part II: Evaluation studies}

The second objective of this thesis encompassed the validation of the MPI subgroups by other assessment tools and exploration of differences in effects between a posteriori classified individual Multidimensional Pain Inventory subgroups after a standard pain management program. We examined this in Chapter $\mathbf{5}$ in patients with fibromyalgia and in Chapter 6 in patients with chronic back pain. The German version of the MPI obtained identically reliable and valid subgroups of fibromyalgia and back pain patients as derived with the original US version [12] and the Swedish version of the MPI $[15,16]$. Furthermore, previous studies with chronic low back pain patients [17-19] and patients with fibromyalgia $([20,21]$ showed overall disappointing effects of standard multidisciplinary treatments ("one size fits all"-approach), but subgroup analyses showed differences in outcome between MPI subgroups. In the low back pain studies mentioned before, most improvement on several scales was reported in the dysfunctional patients. Because the dysfunctional patients have at baseline the worst scores, this difference in treatment effect has to be at least partly explained by regression to the mean. In contrast, in our explorative studies we observed significant differences in pain reduction and improvement of mental health and coping across all three MPI subgroups. This led to the conclusion that differences in effects could not be completely explained by regression to the mean. However, we did not identify significant score changes between subgroups concerning disability, activities and physical functioning. This made us decide to use the back pain-specific Oswestry Disability Index in the randomized controlled trial (chapter 7), instead of the generic physical activity scales of the Medical Outcome Studies Short Form 36. Limitations in both retrospective MPI-subgroup classification studies were the short-term measurement of effects (between entry and discharge from the rehabilitation clinic after four weeks), multiple pairwise testing of subscale scores of the MPI subgroups (partly compensated by the Bonferroni correction), and the lack of a control group. This made us decide to do a next study designed as a randomized controlled trial with longer follow-up intervals and predefined outcomes.

The primary objective of this thesis was to examine the effectiveness of tailored pain management in patients with chronic musculoskeletal pain, a priori classified according the Multidimensional Pain Inventory Classification System, in order to improve patient care. The randomized controlled trial (Chapter 7) failed to demonstrate that in rehabilitation setting a subgroup-specific pain management program for patients with chronic back pain is more effective in improving pain and disability than a standard pain management program. Interestingly, patients in both groups, despite intensive therapies and a magnitude of over 110 treatment hours in total, based on best scientific knowledge and best clinical practice, made only small to moderate improvements in pain, disability, self-efficacy, catastrophizing, psychosocial responses to pain, anxiety and depression. The effect sizes are comparable with other pain programs [22, 23], but the hypothesized additional value of the tailored interventions could not be determined. The effects were, at a group level, neither statistically significant nor clinically 
meaningful, although individual patients, in both groups, may have made significant improvements.

To the knowledge of the authors, the trial described in this thesis is the first randomized controlled trial evaluating the effects of subgroup-specific interventions in pre-treatment classified chronic back pain patients according to the MPI Classification System. Therefore, the present study can only be compared with randomized controlled trials evaluating the effects of tailored pain interventions based on classification systems other than the MPI (Table 1a and Table 1b). The Treatment Based Classification system classifies patients in four treatment groups; a) direction-specific exercises, b) spinal joint manipulation or mobilization, c) trunk strengthening and stabilization exercises, and d) traction [24]. Fritz et al. compared this classification-based treatment approach with minimal physiotherapy interventions according to the clinical practice guidelines for acute work-related low back pain in 78 patients with acute low back pain (mean duration of symptoms of 3 days) [25]. Clinically meaningful and statistically significant improvements in pain disability (measured with Oswestry Disability Index) were obtained at 4- and 52-week follow ups. In a similar setting with 123 patients with acute/subacute low back pain (mean pain duration of 15 days), Brennan et al. compared matched to unmatched treatment interventions according to the same Treatment Based Classification system. This study also showed significantly improved intergroup Oswestry Disability Index-scores at 4- and 52-week follow up. Compared to the studies by Fritz et al. and Brennan et al, the patients in our study were on average 9 to 12 years older and had a much longer duration of symptoms (ten years versus 3 and 15 days). On the other hand, baseline NRS pain intensity scores and ODI pain disability scores were comparable (6.5 and 5.2 versus 6.3 , and 42.9 and 44.9 versus 46.1 , respectively). Apeldoorn et al. did a cross-validation of these two US-studies with 156 subacute and chronic low back pain patients in the Netherlands (on average 5 months duration of current episode of low back pain) [26]. The positive results of the prior studies could not be replicated: the primary outcomes global perceived effect, pain disability (ODI), and pain severity (NRS) - as all secondary outcomes - were in both the intention-to-treat analysis, as well as in the per-protocol analysis not significant. Patients' age and baseline pain intensity were almost identical to the patients in our study. In contrast, the participants in the study of Apeldoorn et al. were far less disabled (baseline mean ODI pain disability scores of 18.1 versus 46.1 ). It might be more difficult to obtain increased effects in chronic back pain populations such as in our study compared to acute/subacute patients with back pain. However, acute/subacute low back pain takes a positive natural course in the majority of cases, which might complicate the analysis of the additional value of therapeutic interventions. Finally, based on the O'Sullivan Classification System [27], Vibe Fersum et al. compared classification-based cognitive functional therapy with traditional manual therapy and exercise [28]. The objective of the O'Sullivan Classification System is the identification of maladaptive (pain provocative) spinal postures, movement patterns, and motor control 
behaviors associated with low back pain and aims to implement behavioral interventions that focus on cognitive and behavioral change. Compared to our study, the patients in this study were younger at baseline (41.0 versus 47.6 years), had less pain (NRS pain intensity of 4.9 versus 6.3), and, most of all, were less disabled (ODI pain disability score of 21.3 versus 46.1 ). The study by Vibe Fersum et al. showed significantly improved Oswestry Disability Index scores and NRS pain-scores at 12- and 52-week follow up in the classification-based group compared to the group with traditional manual therapy and exercises. However, these positive results may be biased by the fact that only 94 of 121 randomized patients were included in the final analysis. Because 27 randomized patients either did not start treatment or did not complete treatment, the authors decided that an intention-to-treat analysis was not indicated.

Table 1a. Review of classification-based randomized controlled trials in back pain

\begin{tabular}{|c|c|c|c|c|c|c|c|c|}
\hline \multirow[b]{2}{*}{$\begin{array}{l}\text { Name of first } \\
\text { author, } \\
\text { publication date }\end{array}$} & \multirow[b]{2}{*}{$\begin{array}{l}\text { Classification } \\
\text { system }\end{array}$} & \multirow[b]{2}{*}{ Setting } & \multirow[b]{2}{*}{$\begin{array}{l}\text { Sample } \\
\text { size }\end{array}$} & \multirow[b]{2}{*}{$\begin{array}{l}\text { Type of } \\
\text { back pain }\end{array}$} & \multicolumn{4}{|c|}{$\begin{array}{l}\text { Baseline characteristics } \\
\text { of classification-based group }\end{array}$} \\
\hline & & & & & $\begin{array}{l}\text { Duration } \\
\text { of } \\
\text { symptoms }\end{array}$ & $\begin{array}{l}\text { Age } \\
(y ; m \pm s)\end{array}$ & $\begin{array}{l}\text { NRS pain } \\
\text { intensity } \\
(\mathrm{m} \pm s)\end{array}$ & 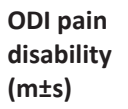 \\
\hline $\begin{array}{l}\text { Fritz JM } \\
\text { et al. } 2003\end{array}$ & TBC & $\begin{array}{l}5 \text { outpatient clinics at } \\
\text { University of Pittsburgh, } \\
\text { Medical Center (USA) }\end{array}$ & 78 & $\begin{array}{l}\text { acute } \\
(<3 w)\end{array}$ & $3 d$ & $35.9 \pm 10.3$ & $6.5 \pm 1.7$ & $42.9 \pm 15.7$ \\
\hline $\begin{array}{l}\text { Brennan GP } \\
\text { et al. } 2006\end{array}$ & TBC & $\begin{array}{l}3 \text { outpatient clinics in } \\
\text { Utah (USA) }\end{array}$ & 123 & $\begin{array}{l}\text { aute/subacute } \\
(<90 \mathrm{~d})\end{array}$ & $15 d$ & $38.4 \pm 10.0$ & $5.2 \pm 2.1$ & $44.9 \pm 11.2$ \\
\hline $\begin{array}{l}\text { Apeldoorn AT } \\
\text { et al. } 2012\end{array}$ & $\begin{array}{l}\text { TBC } \\
\text { (modified) }\end{array}$ & $\begin{array}{l}21 \text { physiotherapy clinics } \\
\text { in Amsterdam (NL) }\end{array}$ & 156 & $\begin{array}{l}\text { subacute/ } \\
\text { chronic }\end{array}$ & $5 \mathrm{~m}$ & $43.2 \pm 11.7$ & $6.0 \pm 1.7$ & $18.1 \pm 11.5$ \\
\hline $\begin{array}{l}\text { Vibe Fersum K } \\
\text { et al. } 2012\end{array}$ & OCS & $\begin{array}{l}\text { private physiotherapy } \\
\text { practices, outpatient } \\
\text { spine clinic in Bergen }(N)\end{array}$ & 121 & chronic & $61 \%>5 y$ & $41.0 \pm 10.3$ & $4.9 \pm 2.0$ & $21.3 \pm 7.5$ \\
\hline $\begin{array}{l}\text { Verra ML } \\
\text { et al. }\end{array}$ & MPI & $\begin{array}{l}\text { rehabilitation clinic, } \\
\text { inpatients }(\mathrm{CH})\end{array}$ & 146 & chronic & $10 y$ & $47.6 \pm 11.9$ & $6.3 \pm 2.1$ & $46.1 \pm 13.0$ \\
\hline
\end{tabular}

Abbreviations: m, mean; s, standard deviation; y, years; m, months; w, weeks; d, days; TBC, Treatment-Based Classification System by Delitto; OCS, O'Sullivan Classification System; MPI, Multidimensional Pain Inventory Classification System; NRS, Numeric Rating Scale ( $0=$ best; $10=$ worst); ODI, Oswestry Disability Index (0=best; $100=$ worst). 


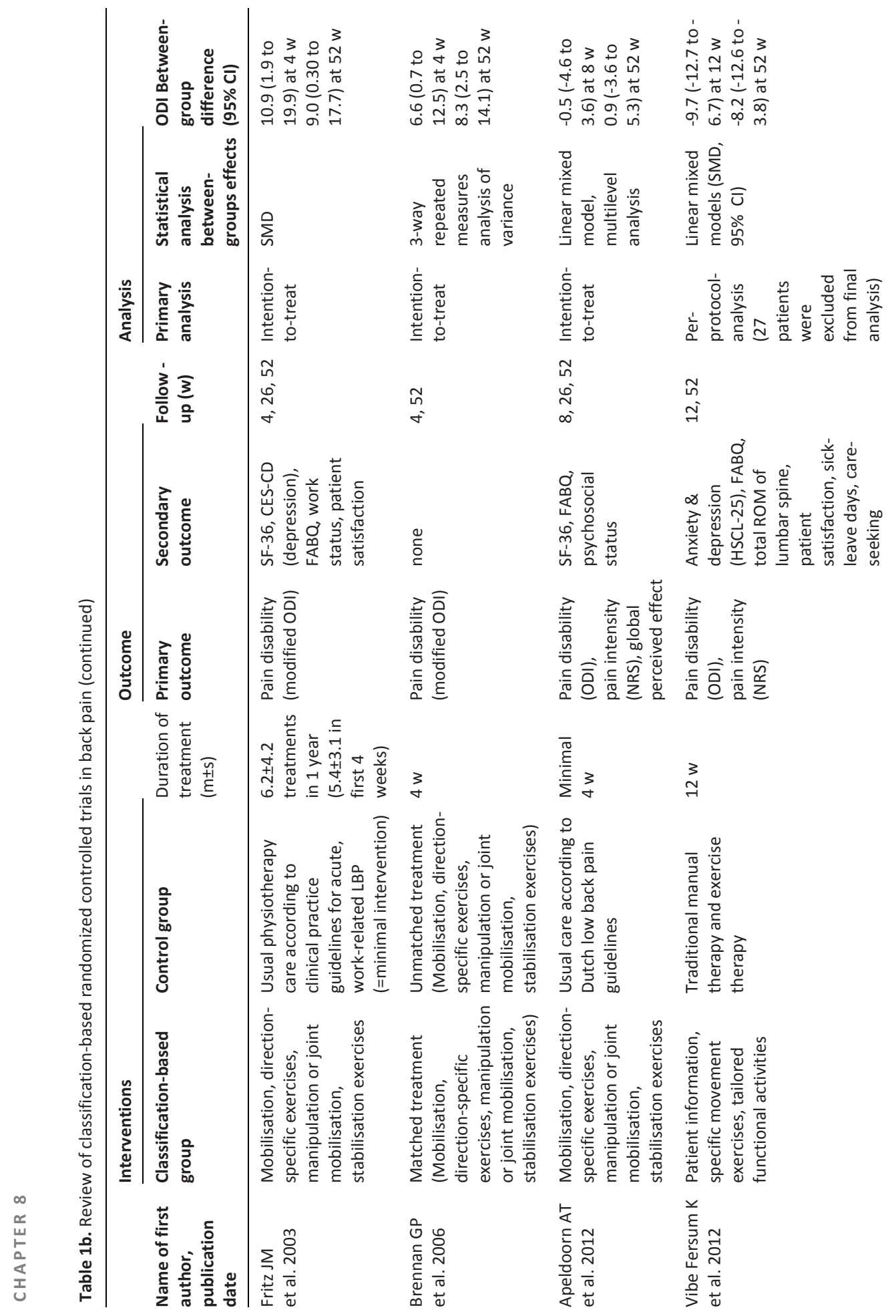




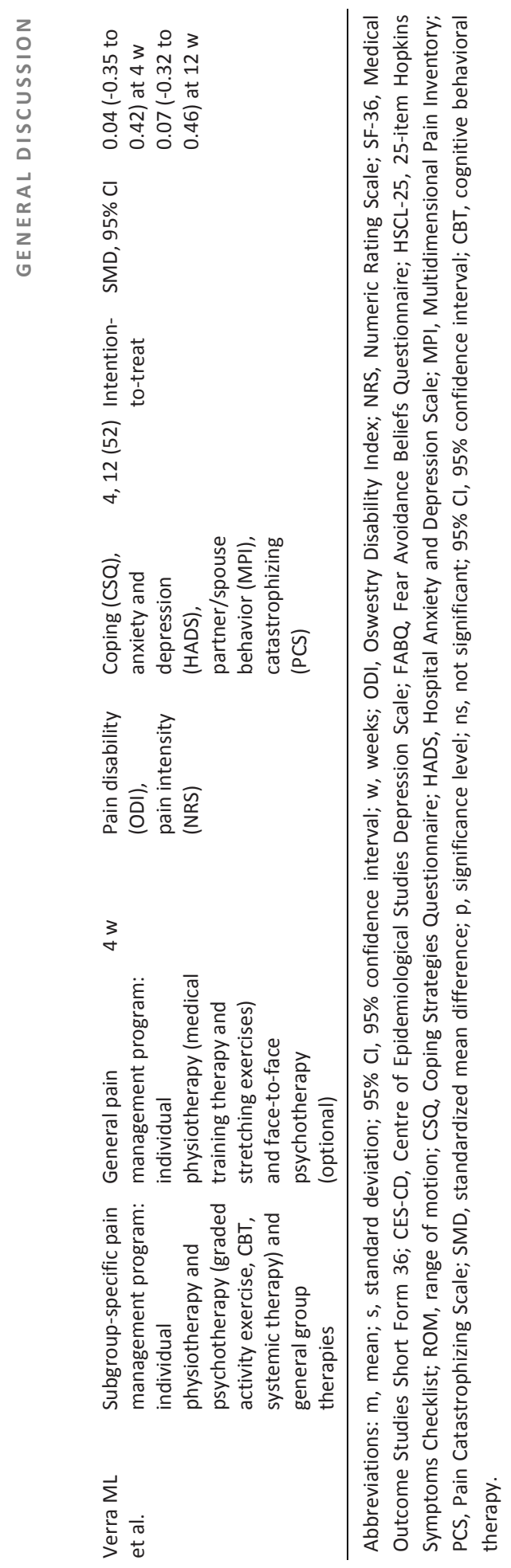


The model of classification-based interventions is based on the identification of relatively homogeneous subgroups of patients [29], with respect to psychosocial and behavioral baseline characteristics. This should lead to less variability in outcome after tailored interventions and larger effect sizes. By definition, effect sizes are determined by the score differences between two time points divided by the group standard deviation at baseline. In other words, the smaller the standard deviation, the larger the effect size. Applying this to the randomized controlled trial in this thesis, we would expect to find smaller standard deviations and confidence intervals and subsequently larger within-subgroup and between-group effects after the tailored interventions. However, this was not the case. With a few exceptions, standard deviations and confidence intervals of the MPI subgroups were as large as those in the non-subclassified control group. Obviously, the MPI Classification System was not able to classify the heterogeneous sample of patients with nonspecific back pain into three more homogeneous subgroups. New studies, published after the start of our trial, proposed a revised taxonomy and made suggestions on how to improve scoring and usefulness of the MPI [30-32]. These adaptations might improve the ability of the MPI Classification to increase homogeneity within subgroups.

Pragmatic randomized controlled trials, like the present study, compare two or more (sets of) interventions which are believed to be clinically meaningful when delivered in clinical practice. In the trial in this thesis both groups had a comprehensive range and number of group therapies. Most group therapies were performed with a cognitive behavioral approach, and the pain coping group was led by a clinical psychologist. This meant that via these group therapies the patients in the general pain management group (i.e. individual medical training therapy on the principles of exercise physiology by the physiotherapist and optional individual psychotherapy, not focused on pain coping strategies) received quite a lot of information on how to cope with different aspects of chronic back pain. For practical and ethical reasons we had to do the trial in this way. However, this might have minimized contrast between interventions.

Another finding of interest was the problem of adherence to treatment during the 4-week stay at the rehabilitation clinic. As in both groups no serious adverse events occurred, the discontinued interventions for clinical reasons and the three patients with difficulties in understanding the German language might be attributed to exclusion criteria that were discovered too late. Six non-compliant patients in the tailored pain management group may have been due to the fact that the main principle of graded activity exercise, progression of physical training on a time-contingent basis instead of a pain-contingent basis, was for some patients hard to tolerate. 


\section{Implications for clinical practice}

Kamper et al. stated in 2010 that research up till then had failed to demonstrate the utility of any classification system with sufficient certainty to recommend implementation into clinical practice [33]. As shown, the classification-based interventions in the randomized controlled trial in this thesis were not superior to standard pain management. Therefore, if the results of this study are to be replicated in other studies by different research groups in a comparable setting, the additional value of classification of patients with chronic back pain based on the MPI Classification System and the subsequent process of tailoring pain management interventions might be challenged. On the other hand, informed decision-making is not solely based on best scientific evidence, but also on clinical expertise of the health care professionals and patient's preferences and expectations [34]. Thus, because the classification-based interventions were equally as effective as the standard pain management group, and credibility and expectancy of both patient and health care provider play an important role in the process of treatment $[35,36]$, subgroup classification and subsequent tailoring of interventions might be an equivalent alternative. With complex treatments such as systemic therapy and graded activity exercise, the expertise of the pain therapist should also be borne in mind [33]. In the trial in this thesis the tailored interventions were performed by specially trained physiotherapists and clinical psychologists.

The psychosocial coping style of the subgroup adaptive copers has caused discussion in the literature. The question is whether these patients minimize their pain problems or truly adjust better to pain. The focus of the tailored interventions in the randomized controlled trial in the present thesis for this subgroup was on activity pacing to moderate overactivity, use of stop-rules, body awareness, and mental and physical relaxation techniques in stressful situations. We elected this approach because of the high baseline disability scores as compared to population norms as described in a previous study [37] and long-term clinical observations made by the pain therapists of the Zurzach Interdisciplinary Pain Program. Although, compared to the baseline scores of the other two subgroups dysfunctional and interpersonally distressed, the adaptive copers performed better, compared to healthy individuals the adaptive copers were also severely disabled and affected by their chronic pain syndrome. Aspects of endurance behavior (synonym: overuse behavior), [38, 39] have been observed by the members of the pain management team. However, our treatment approach for the subgroup adaptive copers is in conflict with the observations made by Junghaenel et al. [40]. In observing patients' pain behavior, they found strong support for the validity of the adaptive copers cluster in that patients' positive adaptation was reliably corroborated by informants. They state that patients in the adaptive copers subgroup indeed fare better than dysfunctional and interpersonally distressed patients and that their positive adaptation cannot be merely attributed to a favorable self-report bias. After termination of the trial in this thesis, semi-structured interviews with the clinical psy- 
chologists who participated in the trial of the Zurzach Interdisciplinary Pain Program revealed that the pain therapists are still unanimously convinced that the adaptive copers largely deny their problems and wish to present a falsely positive picture of them. Consequently, it might seem that more research in this field is needed.

So far, there is no such thing as "magic healing" in chronic musculoskeletal pain. In line with the results of other trials investigating the effects of multimodal pain management programs, the interventions in the trials in this thesis led to small to moderate effects. We have to consider that the average age of patients participating in the pain management program was 46 years (with an average history of pain of 10 years) and variance of age in our studies was large (18-73 years). After completing the pain management program and at follow-up patients were not pain free and were still disabled by pain. This might imply that a currently unknown number of patients will have to deal with musculoskeletal pain for many more years or perhaps till the end of their lives. This indicates that in the near future, health care professionals in clinical care need to be informed about the specific needs of young adolescent pain patients (who will be diagnosed earlier), adults (as now) and also elderly pain patients (who still suffer from chronic disabling pain). The focus may have to shift from cure to (cost-)effective care.

\section{Recommendations for further research}

As discussed before at the beginning of this chapter and shown in Table 1a and Table $1 b$, preliminary conclusions from the (non-systematic) review of RCTs analyzed in Table $1 \mathrm{a}$ and Table $1 \mathrm{~b}$ could be that subgrouping of patients with back pain may be less successful in highly disabled patients with chronic symptoms and perhaps more meaningful in less disabled patients or patients with acute/subacute low back pain [25, 28, 41]. Classification of chronic back pain on the basis of psychosocial factors and pain coping patterns, as performed in the studies in this thesis of real-world clinical care, may be more complex. Future trials with chronic and highly disabled back pain patients might focus on other bio-psycho-social features captured by the MPI Classification System, e.g. classification by pain mechanism [42,43], or focus on classification systems based on, for example, mechanical loading strategies or modified movement strategies of the spine (for overview: [44]). The appropriate study designs for the different research questions relating to the treatment-based subgroups have to be carefully chosen [45], and interpretation of subgroup effects has to be done according to the latest recommendations. These recommendations made by Hancock et al. are that subgroups should be identified using high-quality randomized controlled trials, the investigation should be limited to a relatively small number of potential subgroups for which there is a plausible rationale, subgroup effects should be investigated by formally analyzing statistical interactions, and findings of subgroups should be subject to external validation $[46,47]$. Pair-wise comparisons in a case-control study design might reduce heter- 
ogeneity and demonstrate higher effects. Stratification of pain management according to the patient's prognosis is another model. At this moment it has been successfully tested in one study in a heterogeneous sample of low back pain patients in primary care $[48,49]$. Prognostic screening (low, medium, or high risk) with matched pathways (low risk patients were shown an educational video and given a back book; medium-risk and high-risk patients were referred for further physiotherapy-led treatment sessions) was associated with a small but significant reduction of disability at the four and twelve month follow-ups ( $E S=0.32$, and 0.19 , respectively). Moreover, these stratified interventions were, compared with non-stratified current best practice in the United Kingdom, cost-effective (cost savings at twelve months of $£ 240$ versus $f 274$ compared with the control group). Considering the immense economic costs of back pain to Swiss society of 1.6 to $2.3 \%$ of gross domestic product ( $€ 4.8$ to $€ 6.6$ billion) [50], even small effects in these patients justify further research on this topic.

Another consideration might be the exploration of the most appropriate treatment settings for patients with chronic musculoskeletal pain disorders. In this thesis all studies were conducted in an inpatient rehabilitation setting. In contrast to Switzerland, most Western health insurance companies are not willing to pay the difference in costs between outpatient rehabilitation or primary care, and inpatient rehabilitation. In the near future, Swiss rehabilitation clinics have to clearly show what the additional value is of treating chronic musculoskeletal pain patients in an inpatient rehabilitation setting with a high intensity of treatment modalities, instead of in a less intensive outpatient setting. The solution for treatment of chronic musculoskeletal pain cannot be solely dependent on inpatient programs in rehabilitation clinics: the problem is simply too big. Health professionals in primary care (general practitioners and physiotherapists) are also important stakeholders. Future classification systems should focus on early identification, early diagnosis, and early subgroup-specific treatment of (sub-) acute patients at risk of developing a chronic pain condition. Kamper et al. suggested that a small number of variables (effect modifiers) to define meaningful subgroups have to be identified. Accordingly, treatment effects observed in sufficiently powered, well conducted trials might provide further evidence that certain subgroups of patients may respond better to tailored interventions. Finally, before broad implementation in clinical care, the results of single randomized controlled trials have to be replicated and also tested for the extent to which they will hold good outside the conditions of the original randomized controlled trial $[33,47]$.

Besides pain intensity, pain disability was the primary outcome of the randomized trial in chapter 7. We used the well-validated and responsive Oswestry Disability Index ODI). With this self-report questionnaire patients indicate what they think they are able to do. From a behavioral point of view we think this is decisive. After completion of the pain management program patients have to perform meaningful activities (work, training, household chores, outdoor activities, etc) by themselves. Their self-efficacy, motivation and level of anxiety are crucial in their decision to perform activities or not. 
Compared to the baseline scores, the ODI scores at the 4-week follow-up showed only small improvements: $+2 \%$ in the classification-based group and $+3 \%$ in the general pain management group. However, the 5-Minute Walk Test (a test in which the assessor rates the actual performance of the patient) revealed at the same 4-week follow-up $+12 \%$ in the classification-based group, and $+8 \%$ in the general pain management group. In other words, thinking what a patient is able to do is not always the same as what he or she actually can do [51-53]. Future trials should bear more witness of this clinical entity.

As a final point of interest, I would like to mention the difficulties of conducting the traditional intervention-control-group design of a randomized controlled trial in the context of musculoskeletal pain in a clinical setting. Besides the clear advantages of an RCT-design, limitations of the RCT study design have also been the subject of debate (e.g. [54]. For instance, prospective cohort studies with intra-individual control of effects in patients with chronic (i.e. stable) musculoskeletal pain disorders might be feasible and meaningful alternatives. In a study at the RehaClinic with patients with hip and knee osteoarthritis we used the design of a naturalistic cohort study without control group [55]. The effects observed during the intervention were corrected by those observed during the waiting time prior to the intervention. Baseline scores were compared to the normative data of healthy people, corrected for sex and age). Compared to an RCT, duration and costs of this study design were markedly shorter and lower. However, there is a lack of normative data for several assessments like the widely used questionnaires Multidimensional Pain Inventory and the Coping Strategies Questionnaire [56] and future research projects should focus on the search for these important data.

\section{Conclusions}

The German version of the Coping Strategies Questionnaire is a feasible and reliable outcome measure to be used in (large multicenter multinational) trials with Germanspeaking patients to assess pain coping strategies in patients with chronic musculoskeletal pain. Also, the Multidimensional Pain Inventory (MPI) Classification System is substantially stable and can be recommended for specification of subgroups in interventional studies in patients with chronic back pain. The cross-sectional study investigating the pain-depression relationship revealed that in the MPI subgroup interpersonally distressed, the moderate pain-depression association may have an impact on pain management, that is, pain could be treated by treatment of depression and vice versa. Moreover, the MPI subgroups previously described by other studies with less disabled samples of fibromyalgia and chronic nonspecific back pain patients are also evident in highly disabled samples. A posteriori cluster analysis revealed that the three MPI subgroups identified showed significant differences in pain severity, mental health and 
coping outcomes following a standard inpatient pain management program. However, the tailored pain management program with subgroup-specific physiotherapy and psychotherapy interventions based on the MPI Classification System for patients with chronic back pain was not more effective in improving pain and disability than a standard pain management program with non-matched interventions in a rehabilitation setting at 4- and 12-week follow-up.

With the results of the present thesis and the hitherto existing other publications on this topic it is at this moment probably too early to reject or accept the concept of sub classification of patients with chronic musculoskeletal pain. In accordance with the widely used Swiss proverb "Eine Studie ist keine Studie", further research is necessary to confirm these results before definite recommendations can be made. Replication of the present randomized controlled trial by other research groups, in different settings, and with longer follow-up, and meta-analysis of existing trials is necessary. On the other hand, classification of chronic, highly disabled patients into psychosocial subgroups might turn out to be less promising than expected. Together with health professionals in diverse clinical settings, the research community might start looking for an alternative Holy Grail [57-59] in back pain research. As a current example of shifting emphasis back towards the biological part of chronic low back pain, Albert et al. demonstrated that an antibiotic protocol was significantly more effective than placebo in improving disability, reduction of lumbar pain, and a host of secondary outcomes [60]. 


\section{References}

1. Keefe FJ, Somers TJ, Kothadia SM: Coping with pain. In: Pain clinical updates. vol. 5. Seattle: International Association for the Study of Pain; 2009: 1-5.

2. Jensen MP, Turner JA, Romano JM, Karoly P: Coping with chronic pain: a critical review of the literature. Pain 1991, 47(3):249-283.

3. Riley JL, 3rd, Robinson ME, Geisser ME: Empirical subgroups of the Coping Strategies QuestionnaireRevised: a multisample study. The Clinical journal of pain 1999, 15(2):111-116.

4. Riley JL, 3rd, Robinson ME: CSQ: five factors or fiction? The Clinical journal of pain 1997, 13(2):156-162.

5. Swartzman LC, Gwadry FG, Shapiro AP, Teasell RW: The factor structure of the Coping Strategies Questionnaire. Pain 1994, 57(3):311-316.

6. Dworkin RH, Turk DC, Farrar JT, Haythornthwaite JA, Jensen MP, Katz NP, Kerns RD, Stucki G, Allen RR, Bellamy $\mathrm{N}$ et al: Core outcome measures for chronic pain clinical trials: IMMPACT recommendations. Pain 2005, 113(1-2):9-19.

7. Rudy TE: Multidimensional Pain Inventory software user's guide. In., 3.0 edn. Pittsburgh: University of Pittsburgh; 2005.

8. Flor H: Fragebögen: West Haven-Yale Multidimensionaler Schmerzfragebogen (MPI-D). In: Psychobiologie des Schmerzes. first edn. Bern, Göttingen, Toronto: Verlag Hans Huber; 1991: 267-273.

9. Flor H, Rudy TE, Birbaumer N, Streit B, Schugens MM: [The applicability of the West Haven-Yale multidimensional pain inventory in German-speaking countries. Data on the reliability and validity of the MPI-D.]. Schmerz 1990, 4(2):82-87.

10. Angst F, Verra ML, Lehmann S, Aeschlimann A: Responsiveness of five condition-specific and generic outcome assessment instruments for chronic pain. BMC medical research methodology 2008, 8:26.

11. Turk DC, Rudy TE: Toward an empirically derived taxonomy of chronic pain patients: integration of psychological assessment data. Journal of consulting and clinical psychology 1988, 56(2):233-238.

12. Turk DC, Rudy TE: The robustness of an empirically derived taxonomy of chronic pain patients. Pain 1990, 43(1):27-35.

13. Backhaus K, Erichson B, Plinke W, Weiber R: Faktorenanalyse, logistische regression, Clusteranalyse. In: Multivariate Analysemethoden (Multivariate analysis methods). 10 th edn. Edited by Backhaus $\mathrm{K}$, Erichson B, Plinke W, Weiber R. Berlin: Springer; 2003: 259-542.

14. Stanton TR, Hancock MJ, Apeldoorn AT, Wand BM, Fritz JM: What characterizes people who have an unclear classification using a treatment-based classification algorithm for low back pain? A crosssectional study. Physical therapy 2013, 93(3):345-355.

15. Bergstrom G, Bodin L, Jensen IB, Linton SJ, Nygren AL: Long-term, non-specific spinal pain: reliable and valid subgroups of patients. Behaviour research and therapy 2001, 39(1):75-87.

16. Johansson $E$, Lindberg $P$ : Low back pain patients in primary care: subgroups based on the Multidimensional Pain Inventory. Int J Behavioural Med 2000, 7(4):340-352.

17. Riipinen M, Niemisto L, Lindgren KA, Hurri H: Psychosocial differences as predictors for recovery from chronic low back pain following manipulation, stabilizing exercises and physician consultation or physician consultation alone. Journal of rehabilitation medicine : official journal of the UEMS European Board of Physical and Rehabilitation Medicine 2005, 37(3):152-158.

18. Vollenbroek-Hutten MM, Hermens HJ, Wever D, Gorter M, Rinket J, ljzerman MJ: Differences in outcome of a multidisciplinary treatment between subgroups of chronic low back pain patients defined using two multiaxial assessment instruments: the multidimensional pain inventory and lumbar dynamometry. Clinical rehabilitation 2004, 18(5):566-579.

19. Strategier LD, Chwalisz K, Altmaier EM, Russell DW, Lehmann TR: Multidimensional assessment of chronic low back pain: predicting treatment outcomes. Journal of Clinical Psychology in Medical Settings 1997, 4(1):91-110. 
20. Turk DC, Okifuji A, Sinclair JD, Starz TW: Pain, disability, and physical functioning in subgroups of patients with fibromyalgia. The Journal of rheumatology 1996, 23(7):1255-1262.

21. Turk DC, Okifuji A, Sinclair JD, Starz TW: Differential responses by psychosocial subgroups of fibromyalgia syndrome patients to an interdisciplinary treatment. Arthritis care and research : the official journal of the Arthritis Health Professions Association 1998, 11(5):397-404.

22. Keller A, Hayden J, Bombardier C, van Tulder M: Effect sizes of non-surgical treatments of non-specific low-back pain. European spine journal : official publication of the European Spine Society, the European Spinal Deformity Society, and the European Section of the Cervical Spine Research Society 2007, 16(11):1776-1788.

23. van Middelkoop M, Rubinstein SM, Kuijpers T, Verhagen AP, Ostelo R, Koes BW, van Tulder MW: A systematic review on the effectiveness of physical and rehabilitation interventions for chronic nonspecific low back pain. European spine journal : official publication of the European Spine Society, the European Spinal Deformity Society, and the European Section of the Cervical Spine Research Society 2011, 20(1):19-39.

24. Delitto A, Erhard RE, Bowling RW: A treatment-based classification approach to low back syndrome: identifying and staging patients for conservative treatment. Physical therapy 1995, 75(6):470-485; discussion 485-479.

25. Fritz JM, Delitto A, Erhard RE: Comparison of classification-based physical therapy with therapy based on clinical practice guidelines for patients with acute low back pain: a randomized clinical trial. Spine 2003, 28(13):1363-1371; discussion 1372.

26. Apeldoorn AT, Ostelo RW, van Helvoirt H, Fritz JM, Knol DL, van Tulder MW, de Vet HC: A randomized controlled trial on the effectiveness of a classification-based system for subacute and chronic low back pain. Spine 2012, 37(16):1347-1356.

27. O'Sullivan P: Diagnosis and classification of chronic low back pain disorders: maladaptive movement and motor control impairments as underlying mechanism. Manual therapy 2005, 10(4):242-255.

28. Vibe Fersum K, O'Sullivan P, Skouen JS, Smith A, Kvale A: Efficacy of classification-based cognitive functional therapy in patients with non-specific chronic low back pain: A randomized controlled trial. European journal of pain 2012.

29. Turk DC: The potential of treatment matching for subgroups of patients with chronic pain: lumping versus splitting. The Clinical journal of pain 2005, 21(1):44-55; discussion 69-72.

30. McKillop JM, Nielson WR: Improving the usefulness of the Multidimensional Pain Inventory. Pain research \& management : the journal of the Canadian Pain Society = journal de la societe canadienne pour le traitement de la douleur 2011, 16(4):239-244.

31. Sheffer CE, Deisinger JA, Cassisi JE, Lofland K: A revised taxonomy of patients with chronic pain. Pain medicine 2007, 8(4):312-325.

32. Hopwood CJ, Creech SK, Clark TS, Meagher MW, Morey LC: Optimal scoring of the Multidimensional Pain Inventory in a chronic pain sample. J Clin Psychol Med Settings 2008, 15(4):301-307.

33. Kamper SJ, Maher CG, Hancock MJ, Koes BW, Croft PR, Hay E: Treatment-based subgroups of low back pain: a guide to appraisal of research studies and a summary of current evidence. Best practice \& research Clinical rheumatology 2010, 24(2):181-191.

34. Sackett DL, Straus S, Richardson S, Rosenberg W, Haynes RB: Evidence-based-medicine: how to practice and teach EBM, second edn. London: Churchill Livingstone; 2000.

35. Smeets RJ, Beelen S, Goossens ME, Schouten EG, Knottnerus JA, Vlaeyen JW: Treatment expectancy and credibility are associated with the outcome of both physical and cognitive-behavioral treatment in chronic low back pain. The Clinical journal of pain 2008, 24(4):305-315.

36. Linton SJ, Vlaeyen J, Ostelo R: The back pain beliefs of health care providers: are we fear-avoidant? Journal of occupational rehabilitation 2002, 12(4):223-232.

37. Angst F, Brioschi R, Main CJ, Lehmann S, Aeschlimann A: Interdisciplinary rehabilitation in fibromyalgia and chronic back pain: a prospective outcome study. The journal of pain : official journal of the American Pain Society 2006, 7(11):807-815. 
38. Hasenbring $\mathrm{MI}$, Plaas $\mathrm{H}$, Fischbein $\mathrm{B}$, Willburger $\mathrm{R}$ : The relationship between activity and pain in patients 6 months after lumbar disc surgery: do pain-related coping modes act as moderator variables? European journal of pain 2006, 10(8):701-709.

39. Vlaeyen WS, Nielson WR, van Houdenhove B: Overuse as a risk factor for pain disability: cognitive behavioral models and interventions. In: Proceedings of the 11th World Congress on Pain. edn. Edited by Flor H, Kalso E, Dostrovsky JO. Seattle: IASP Press; 2006: 585-596.

40. Junghaenel DU, Keefe FJ, Broderick JE: Multi-modal examination of psychological and interpersonal distinctions among MPI coping clusters: a preliminary study. The journal of pain : official journal of the American Pain Society 2010, 11(1):87-96.

41. Brennan GP, Fritz JM, Hunter SJ, Thackeray A, Delitto A, Erhard RE: Identifying subgroups of patients with acute/subacute "nonspecific" low back pain: results of a randomized clinical trial. Spine 2006, 31(6):623-631.

42. Wand BM, O'Connell NE: Chronic non-specific low back pain - sub-groups or a single mechanism? BMC musculoskeletal disorders 2008, 9:11.

43. Nijs J, Kosek E, Van Oosterwijck J, Meeus M: Dysfunctional endogenous analgesia during exercise in patients with chronic pain: to exercise or not to exercise? Pain physician 2012, 15(3 Suppl):ES205-213.

44. Karayannis NV, Jull GA, Hodges PW: Physiotherapy movement based classification approaches to low back pain: comparison of subgroups through review and developer/expert survey. $B M C$ musculoskeletal disorders 2012, 13:24.

45. Kent $\mathrm{P}$, Hancock M, Petersen $\mathrm{DH}$, Mjosund HL: Clinimetrics corner: choosing appropriate study designs for particular questions about treatment subgroups. The Journal of manual \& manipulative therapy 2010, 18(3):147-152.

46. Hancock MJ, Kjaer P, Korsholm L, Kent P: Interpretation of Subgroup Effects in Published Trials. Physical therapy 2013.

47. Hancock M, Herbert RD, Maher CG: A guide to interpretation of studies investigating subgroups of responders to physical therapy interventions. Physical therapy 2009, 89(7):698-704.

48. Hill JC, Whitehurst DG, Lewis M, Bryan S, Dunn KM, Foster NE, Konstantinou K, Main CJ, Mason E, Somerville $S$ et al: Comparison of stratified primary care management for low back pain with current best practice (STarT Back): a randomised controlled trial. Lancet 2011, 378(9802):1560-1571.

49. Hill JC, Dunn KM, Lewis M, Mullis R, Main CJ, Foster NE, Hay EM: A primary care back pain screening tool: identifying patient subgroups for initial treatment. Arthritis and rheumatism 2008, 59(5):632-641.

50. Wieser S, Horisberger B, Schmidhauser S, Eisenring C, Brugger U, Ruckstuhl A, Dietrich J, Mannion AF, Elfering A, Tamcan O et al: Cost of low back pain in Switzerland in 2005. The European journal of health economics : HEPAC : health economics in prevention and care 2011, 12(5):455-467.

51. Bousema EJ, Verbunt JA, Seelen HA, Vlaeyen JW, Knottnerus JA: Disuse and physical deconditioning in the first year after the onset of back pain. Pain 2007, 130(3):279-286.

52. Verbunt JA, Westerterp KR, van der Heijden GJ, Seelen HA, Vlaeyen JW, Knottnerus JA: Physical activity in daily life in patients with chronic low back pain. Archives of physical medicine and rehabilitation 2001, 82(6):726-730.

53. Wittink H, Hoskins Michel T, Wagner A, Sukiennik A, Rogers W: Deconditioning in patients with chronic low back pain: fact or fiction? Spine 2000, 25(17):2221-2228.

54. Grossman J, Mackenzie FJ: The randomized controlled trial: gold standard, or merely standard? Perspectives in biology and medicine 2005, 48(4):516-534.

55. Angst F, Verra ML, Lehmann S, Benz T, Aeschlimann A: Effects of inpatient rehabilitation in hip and knee osteoarthritis. A naturalistic prospective cohort study with intra-individual control of effects. Archives of physical medicine and rehabilitation 2013.

56. Nicholas MK, Asghari A, Blyth FM: What do the numbers mean? Normative data in chronic pain measures. Pain 2008, 134(1-2):158-173.

57. Waddell G: Diagnostic triage. In: The back pain revolution. 1 edn. Edinburgh: Churchill Livingstone; 1998: 9-25. 
58. Borkan JM, Cherkin DC: An agenda for primary care research on low back pain. Spine 1996, 21(24):28802884.

59. Costa Lda C, Koes BW, Pransky G, Borkan J, Maher CG, Smeets RJ: Primary care research priorities in low back pain: an update. Spine 2013, 38(2):148-156.

60. Albert HB, Sorensen JS, Christensen BS, Manniche C: Antibiotic treatment in patients with chronic low back pain and vertebral bone edema (Modic type 1 changes): a double-blind randomized clinical controlled trial of efficacy. European spine journal : official publication of the European Spine Society, the European Spinal Deformity Society, and the European Section of the Cervical Spine Research Society 2013, 22(4):697-707. 



\section{English summary}

The focus of this thesis is the validation and effectiveness of a classification-based pain management program in patients with chronic musculoskeletal pain in an inpatient rehabilitation setting in Switzerland. Chronic pain of moderate to severe intensity occurs in $19 \%$ of adult Europeans. Chronic pain represents a substantial burden to individuals and their family and friends, employers, health care systems and society in general. Although treatment effects are small to moderate, comprehensive interdisciplinary pain management programs offer the most efficacious and cost-effective, evidence-based treatment for patients with chronic back pain. In Switzerland, inpatient rehabilitation of chronic musculoskeletal pain is a commonly used treatment option. However, back pain is nonspecific in about $90 \%$ of cases, which means that no relevant physical cause of the pain can be identified. The search for classification systems identifying homogeneous subgroups of patients with nonspecific low back pain who respond best to subgroup-specific pain management has been on the research agenda for over eighteen years. So far, the effects of a few classification-based interventions have been tested in different settings. These trials showed large variations in categorization method, therapeutic interventions and outcome. In this research project we tested the Multidimensional Pain Inventory (MPI) Classification System, which classifies back pain patients into three predominantly psychosocial subgroups based on patients' pain coping behavior. All studies in this thesis were performed with patients participating in the Zurzach Interdisciplinary Pain Program (ZISP). The primary objective of this thesis is to examine the effectiveness of tailored pain management in patients with chronic musculoskeletal pain classified according to the MPI Classification System, in order to improve patient care. The secondary objective encompasses the exploration of differences in effects between individual Multidimensional Pain Inventory subgroups. Finally, the third objective, as a prerequisite to achieve the first two objectives, is testing clinimetric features of the measurement tools Coping Strategies Questionnaire and the Multidimensional Pain Inventory Classification System.

The aim of the study described in Chapter $\mathbf{2}$ was to translate and cross-culturally adapt the American version of the Coping Strategies Questionnaire (CSQ) and to test the reliability and validity of the German version (CSQ-D). The training and evaluation of active, adaptive pain coping strategies is a major goal in pain management. Therefore, the CSQ was translated and cross-culturally adapted following international guidelines. Reliability and validity were tested in 62 individuals with chronic musculoskeletal pain syndromes. For the concurrent criterion-related validity, the CSQ-D scales were 
compared with the German Pain Coping Questionnaire (FESV-BW) and for the construct validity with the German Short Form 36 (SF-36). The translation process proceeded without major difficulties. In testing for reliability, the CSQ-D as a whole had a Cronbach's alpha of 0.94 and an intraclass correlation coefficient of 0.89 ( $95 \% \mathrm{Cl}$ : $0.86-$ 0.98). The total CSQ-D score was correlated to the FESV-BW scales with scores of $r=$ 0.32-0.55 and with the SF-36 Mental Component Summary with scores of $r=0.32-0.53$. In conclusion, the CSQ-D is a precisely translated and highly reliable instrument in the assessment of chronic pain coping strategies. Its concurrent criterion-related validity and construct validity are low. The main reason for the low level of agreement between the CSQ-D and the FESV-BW was revealed by factor analysis. The CSQ-D is recommended to be used in trials with German-speaking patients or large multicenter multinational trials to assess pain coping strategies in patients with chronic musculoskeletal pain.

Reliability of the German Multidimensional Pain Inventory (MPI) was only examined once in the past in a small sample. Previous international studies mainly involving fibromyalgia patients showed that retest resulted in 33-38\% of patients being assigned to a different MPI subgroup classification. Chapter 3 presents the results of the cross validation study examining the reliability of the MPI and the stability of the MPI Classification System of the empirically derived subgroup classification obtained by cluster analysis in chronic musculoskeletal pain. Participants were 204 persons with chronic musculoskeletal pain (82\% chronic non-specific back pain). Subgroup classification was conducted by cluster analysis at 4 weeks before entry (= test) and at entry into the pain management program (= retest) using MPI scale scores. No therapeutic interventions in this period were conducted. Reliability was quantified by intraclass correlation coefficients (ICC) and stability by kappa coefficients ( $\mathrm{k}$ ). Reliability of the MPI scales was least with ICC $=0.57$ for the scale life control and further ranged from ICC $=0.72$ (negative mood) to 0.87 (solicitous responses) in the other scales. At retest, $82 \%$ of the patients in the MPI cluster interpersonally distressed $(\mathrm{k}=0.69), 80 \%$ of the adaptive copers $(\mathrm{k}=$ $0.58)$, and $75 \%$ of the dysfunctional patients $(k=0.70)$ did not change classification. In total, $22 \%$ of the patients changed MPI cluster group, mainly into the adaptive copers subgroup. In conclusion, test-retest reliability of the German MPI was moderate to good and comparable to other language versions. MPI subgroup classification is substantially stable in chronic back pain patients when compared to other diagnostic groups and other examiner-based subgroup classification systems. Therefore, the MPI Classification System can be recommended for reliable and stable specification of subgroups in observational and interventional studies in patients with chronic musculoskeletal pain.

The relationship between depression, a co morbidity with the highest prevalence in patients with chronic musculoskeletal pain, and chronic pain is controversial and the data on association show strong variation. Chapter 4 evaluates the consistency of chronic disabling pain and depression and aims to provide refined correlation and regression data on the basis of categorical and continuous measures. Cross-sectional 
assessment was based on standardized instruments that measure on a quasicontinuous scale, the Short Form-36 (SF-36), the Hospital Anxiety and Depression Scale (HADS) and the MPI. Correlations between depression and pain were determined by the instruments' scales, with and without correction for confounders, and within chronic pain subgroups using multivariate regression analysis. In 273 chronic pain patients participating in the Zurzach Interdisciplinary Pain Program, the MPI pain severity scale and the HADS depression scale showed maximum overall correlations of 0.27 to 0.29 (bivariate) and 0.30 (partial). The odds ratios for depression varied between 1.72 and 2.10 for different pain levels. Distinguishing three subtypes of pain patients, the paindepression correlation was moderate in the MPI "interpersonally distressed" subgroup (up to 0.57) (characterized by relatively low support, high punishing, low solicitous, and low distracting responses), weak in the MPI "dysfunctional" subgroup (up to 0.26), and absent in the MPI "adaptive copers" subgroup (up to -0.09). Altogether, the strengths of the pain-depression association and the "dose-response" relationship were both weak - weaker than to be expected if the hypothesis of a causal relationship were true. In the MPI subgroup interpersonally distressed, the moderate association may have an impact on pain management, that is, pain could be treated by treatment of depression and vice versa.

Patients with non-specific musculoskeletal pain are not a homogeneous group but heterogeneous with regard to their bio-psycho-social impairments. As mentioned before, evaluation of effectiveness of classification-based pain management is the major objective of this thesis. The study presented in Chapter 5 aimed to replicate and validate the empirically derived subgroup classification based on the MPI in a sample of highly disabled fibromyalgia patients. Second, it examined how the retrospectively identified subgroups differed in their response to a standard, interdisciplinary inpatient pain management program. Participants were 118 patients with fibromyalgia who experienced persistent pain and were highly disabled. Subgroup classification was conducted by cluster analysis using MPI subscale scores at entry to the program. At program entry and discharge, participants completed the MPI, SF-36, HADS, and the CSQ. Cluster analysis identified three subgroups in this highly disabled sample that were similar to those described by other studies using less disabled samples of fibromyalgia. The dysfunctional subgroup (DYS; $36 \%$ of the sample) showed the highest level of depression, the interpersonally distressed subgroup (ID; 24\%) showed a modest level of depression and the adaptive copers subgroup (AC; 38\%) showed the lowest depression scores in the MPI (negative mood), SF-36 (mental health), HADS (depression), and CSQ (catastrophizing). Significant differences in treatment outcome were observed among the three subgroups in terms of reduction of pain severity (as assessed using the MPI). The effect sizes were 1.42 for DYS, 1.32 for AC, and 0.62 for ID ( $p=0.004$ for pair wise comparison of ID-AC and $p=0.018$ for ID-DYS). These findings underscore the importance of assessing patients' differences in how they adjust to fibromyalgia. 
In a comparable design, the study described in Chapter 6 examined a sample of 173 highly disabled patients with chronic back pain to find out how the three subgroups based on the MPI differed in their response to the standard inpatient Zurzach Interdisciplinary Pain Program. Again, subgroup classification was conducted by cluster analysis using MPI subscale scores at entry into the program. At program entry and at discharge after four weeks, participants completed the MPI, the SF-36, the HADS, and the CSQ. Pairwise analyses of the score changes of the mentioned outcomes of the three MPI subgroups were performed using the Mann-Whitney-U-test for significance. Cluster analysis identified three MPI subgroups in this highly disabled sample: a dysfunctional, interpersonally distressed and an adaptive copers subgroup. The dysfunctional subgroup (29\% of the sample) showed the highest level of depression in SF-36 mental health $(33.4 \pm 13.9)$, the interpersonally distressed subgroup ( $35 \%$ of the sample) a modest level of depression $(46.8 \pm 20.4)$, and the adaptive copers subgroup ( $32 \%$ of the sample) the lowest level of depression $(57.8 \pm 19.1)$. Significant differences in pain reduction and improvement of mental health and coping were observed across the three MPI subgroups, i.e. the effect sizes for MPI pain reduction were: 0.84 (0.44 - 1.24) for the dysfunctional subgroup, $1.22(0.86-1.58)$ for the adaptive copers subgroup, and $0.53(0.24-0.81)$ for the interpersonally distressed subgroup $(p=0.006$ for pairwise comparison). Significant score changes between subgroups concerning activities and physical functioning could not be identified. In conclusion, MPI subgroup classification showed significant differences in score changes for pain, mental health and coping. These findings underscore the importance of assessing individual differences to understand how patients adjust to chronic back pain.

In Chapter 7 we report on a randomized controlled trial examining the effectiveness of tailored interventions in a priori classified patients with nonspecific chronic back pain.

The study aimed to investigate the effects in terms of improving pain and disability of a subgroup-specific, 4-week, inpatient interdisciplinary pain management program, compared to a standard pain management program in patients with chronic back pain in a rehabilitation setting. Before starting treatment and in order to match them to a subgroup-specific therapy based on physiotherapy and psychotherapeutic interventions, the patients in the intervention group were classified according to the MPI Classification System. The primary outcomes were self-reported pain and disability, measured at 4 and 12 weeks after randomization; secondary outcomes were observed functional disability, anxiety and depression, pain catastrophizing, self-efficacy and psychosocial aspects of pain. Blinded intention-to-treat analysis was performed at 4 and 12 weeks after start of treatment. A total of 146 patients were included in this study. With the exception of minimum pain intensity after 4 weeks (standard mean difference $(S M D)=0.43,95 \%$ confidence interval $(C l), 0.02$ to $0.84 ; p=0.034)$, no significant differences between intervention and control group could be measured. The secondary analysis, i.e. pairwise comparisons between the individual MPI subgroups and the con- 
trol group, explained this difference in effect in favor of the control group to the MPI subgroup adaptive coper: $\mathrm{SMD}=0.55,95 \% \mathrm{Cl}, 0.02$ to $1.08 ; \mathrm{p}=0.035$ at 12 weeks follow up. For all other comparisons for any of the outcomes at any of the follow ups there were no significant differences. The results of this study justify the conclusion that, in this study, a subgroup-specific pain management program based on the MPI Classification System for patients with chronic back pain was not more effective in improving pain and disability than a standard pain management program.

Chapter $\mathbf{8}$ discusses the main results and methodological reflections of this thesis. Implications of the studies in this thesis for clinical care are discussed and recommendations for future research projects are provided. Comparison with other randomized controlled trials evaluating effects of classification-based interventions in patients with back pain reveals mixed outcomes. In our randomized trial as well as in the studies that have been published so far, classification-based interventions do not automatically yield bigger effects. However, subgroup classification and tailored interventions might be at least an equivalent alternative to general pain management. Future research should search for more homogeneous subgroups and the behavioral pattern of the subgroup adaptive copers. 



\section{Deutsche Zusammenfassung}

Das Hauptziel dieser Dissertation ist die Untersuchung der Gültigkeit (Validität) und Wirksamkeit eines klassifikations-basierten Schmerzprogrammes bei Patienten mit chronischen, muskuloskelettalen Schmerzen in der stationären Rehabilitation in der Schweiz. Chronische Schmerzen mittlerer bis höherer Intensität kommen bei $19 \%$ der erwachsenen Europäer vor. Chronische Schmerzen sind eine erhebliche Belastung für den Betroffenen, seine Familie und Freunde, für die Arbeitgeber, die Gesundheitssysteme und die Gesellschaft im Allgemeinen. Obwohl die Behandlungseffekte klein bis mässig sind, bieten umfassende, interdisziplinäre Schmerzprogramme die wirksamste und kostengünstigste, evidenz-basierte Behandlung für Patienten mit chronischen Rückenschmerzen. In der Schweiz ist die stationäre Rehabilitation für Patienten mit chronischen, muskuloskelettalen Schmerzen eine geläufige Behandlungsmöglichkeit. Rückenschmerzen sind jedoch in ungefähr $90 \%$ der Fälle unspezifisch, was bedeutet, dass keine einschlägige, körperliche Ursache der Schmerzen gefunden werden kann. Die Suche nach Klassifikationssystemen, die Patienten mit unspezifischen Rückenschmerzen in homogene Untergruppen unterscheiden, damit sie in einer untergruppenspezifischen Schmerzbehandlung besser behandelt werden können, steht seit mehr als 18 Jahren auf der Forschungsagenda. Bis jetzt wurden die Effekte von nur wenigen klassifikations-basierten Interventionen in unterschiedlichen Therapiesituationen untersucht. Diese Studien berichten von grossen Unterschieden in Klassifikationsmethoden, therapeutischen Interventionen und Resultaten. In diesem Forschungsprojekt haben wir das Multidimensional Pain Inventory (MPI) - Klassifikationssystem untersucht. Basierend auf das individuelle Schmerzbewältigungsverhalten, gruppiert das MPI-Klassifikationssystem Patienten mit Rückenschmerzen in drei (hauptsächlich psychosoziale) Untergruppen. Alle Studien in dieser Dissertation wurden mit Teilnehmenden des Zurzacher Interdisziplinären Schmerz-Programms (ZISP) durchgeführt. Das erste, primäre Ziel dieser Dissertation ist, mittels Untersuchung der Wirksamkeit der massgeschneiderten Schmerzbehandlung nachzuweisen, dass diese bei Patienten mit chronischen, unspezifischen, muskuloskelettalen Schmerzen die Patientenversorgung verbessern kann. Das zweite Ziel beinhaltet die Erkundung von Unterschieden bei den Effekten zwischen einzelnen MPI-Untergruppen. Das dritte Ziel, als Bedingung, die ersten beiden Ziele erreichen zu können, ist die Testung der klinimetrischen Eigenschaften der beiden Messinstrumente Coping Strategies Questionnaire und MPIKlassifikationssystem.

In Kapitel $\mathbf{2}$ der Dissertation wurde das Ziel beschrieben, die amerikanische Originalversion des Schmerzbewältigungsfragebogens (Coping Strategies Questionnaire - 
CSQ) zu übersetzen, transkulturell zu adaptieren und die Reliabilität und Validität der deutschen Version (CSQ-D) zu testen. Das Training und die Evaluation von aktiven, adaptierten Schmerzbewältigungsstrategien, ist eine der Hauptziele im Schmerzmanagement. Deswegen wurde der CSQ nach den international geltenden Richtlinien übersetzt und transkulturell adaptiert. Die Reliabilität und Validität wurde bei 62 Patienten mit chronischen, muskuloskelettalen Schmerzsyndromen getestet. Für die Testung der konkurrenten Kriteriumsvalidität wurden die Skalen der CSQ-D mit dem Fragebogen zur Erfassung der Schmerzverarbeitung/Schmerzbewältigung (FESV-BW) und für die Konstruktvalidität mit den Skalen der deutschen Version des Fragebogens zur gesundheitsbezogenen Lebensqualität (SF-36) verglichen. Der Übersetzungsprozess erfolgte ohne Schwierigkeiten. Die Testung der Reliabilität ergab für den gesamten CSQ-D einen Wert für die interne Konsistenz (Cronbach's alpha) von 0.94 und eine Intraklassen-Korrelation (ICC) von 0.89 (95\% Vertrauensintervall: 0.86 bis 0.98). Der CSQ-D Gesamtscore korreliert mit den Skalen des FESV-BW mit Scores von $r=0.32$ bis 0.55 und mit $r=0.32$ bis 0.53 für den SF-36 (psychische Summenskala PCS). Zusammengefasst ist der Fragebogen CSQ-D ein sorgfältig übersetztes und hoch reliables Instrument für die Untersuchung von Bewältigungsstrategien bei chronischen Schmerzen. Die konkurrente Kriterienvalidität und Konstruktvalidität ist mässig. Der Hauptgrund für die tiefe Übereinstimmung zwischen den CSQ-D und den FESV-BW wurde mittels Faktorenanalyse eruiert. Der CSQ-D kann für Studien, die Schmerzbewältigungsstrategien von deutschsprachigen Patienten mit chronischen, muskuloskelettalen Schmerzen untersuchen oder für grosse internationale Multizenterstudien empfohlen werden.

Die Reliabilität der deutschen Version des Multidimensionalen Schmerzfragebogens (Multidimensional Pain Inventory - MPI) wurde in der Vergangenheit erst einmal in einer kleinen Stichprobe untersucht. Frühere internationale Studien, mehrheitlich mit Patienten mit Fibromyalgie, zeigten ausserdem, dass beim Wiederholungsversuch 33 bis 38\% der Patienten einer anderen MPI-Untergruppe zugeteilt wurde. Kapitel 3 präsentiert die Resultate der Vergleichsprüfung, die die Reliabilität der Skalen des MPI und die Stabilität des MPI-Klassifikationssystems bei Patienten mit chronischen, muskuloskelettalen Schmerzen untersucht. Es nahmen 204 Patienten an der Studie teil (82\% hatten chronische, unspezifische Rückenschmerzen). Die Klassifizierung in Untergruppen wurde mittels Gruppenanalyse der Scores der MPI-Skalen, 4 Wochen vor Beginn (=Test) und beim Eintritt (= Wiederholungstest) ins Schmerzprogramm durchgeführt. In diesem Zeitraum wurden keine therapeutischen Behandlungen durchgeführt. Die Reliabilität wurde mittels Intraklassen-Korrelationskoeffizienten und die Stabilität mittels Kappa-Koeffizienten (к) quantifiziert. Die Reliabilität der MPI-Skalen war mit einer Intraklassen-Korrelationskoeffizienten von 0.57 für die Skala Lebenskontrolle am geringsten und variierte in den anderen Skalen von 0.72 (affektive Verstimmung) bis 0.87 (zuwendende Reaktionen der Hauptbezugsperson). Beim Wiederholungstest gab es keine Aenderung der ursprünglichen Untergruppen-Klassifikation bei $82 \%$ der Patienten in der MPI-Untergruppe "Interpersonally Distressed" ( $\mathrm{k}=0.69$ ), 80\% der "Adaptive Co- 
pers" ( $\kappa=0.58)$, und 75\% der "Dysfunctionals" ( $\kappa=0.70)$. Insgesamt wechselten $22 \%$ der Patienten ihre MPI-Untergruppenzuteilung und zwar hauptsächlich zur Untergruppe "Adaptive Copers". Schliesslich kann man festhalten, dass die Test-Retest Reliabilität der deutschen Version des MPI mässig bis gut und vergleichbar mit Versionen in anderen Sprachen ist. Verglichen mit anderen diagnostischen Gruppen und anderen Klassifikationssystemen ist die Klassifikation in MPI-Untergruppen bei Patienten mit chronischen Rückenschmerzen im Wesentlichen stabil. Deshalb kann das MPIKlassifikationssystem für Studien, zur zuverlässigen und stabilen Spezifizierung von Untergruppen bei Patienten mit chronischen, muskuloskelettalen Schmerzen empfohlen werden.

Der Zusammenhang zwischen depressiver Verstimmung (der Komorbidität mit der höchsten Prävalenz bei Patienten mit chronischen, muskuloskelettalen Schmerzen) und chronischen Schmerzen ist umstritten und die Daten betreffend Assoziation zeigen grosse Streuung. In Kapitel 4 wird die Übereinstimmung zwischen chronischen Schmerzen und Depression untersucht. Das Ziel war, auf der Basis von kategorialen und kontinuierlichen Messinstrumenten, verfeinerte Daten betreffend Korrelation und Regression zu generieren. Die Querschnittsuntersuchung basierte auf standardisierten Messinstrumenten, die auf einer quasi-kontinuierlichen Skala messen: der SF-36, der HADS und der MPI. Korrelationen zwischen Depression und Schmerz wurden mittels der Skalen der Messinstrumente bestimmt, mit und ohne Korrektur für konfundierte Merkmale und mittels multivariater Regressionsanalyse innerhalb der Untergruppen von Patienten mit chronischen Schmerzen. Die MPI-Skala "Schmerzstärke" und die HADS-Skala "Depression" wiesen bei 273 chronischen Schmerzpatienten, die am Zurzacher Interdisziplinären Schmerz-Programm teilnahmen, maximale Gesamtkorrelationen von 0.27 bis 0.29 (bivariat) und 0.30 (partial). Die Odds-Ratios für unterschiedliche Schmerzintensitäten in Depression, variierte zwischen 1.72 und 2.10. Bei der Unterscheidung von Schmerzpatienten in drei MPI-Untergruppen, war die Schmerz-Depression Korrelation in der MPI-Untergruppe „Interpersonally Distressed“ mässig (bis 0.57), in der MPIUntergruppe „Dysfunctional“ schwach (bis 0.26) und in der MPI-Untergruppe „Adaptive Copers" nicht vorhanden (bis -0.09). Alles in allem waren das Ausmass der SchmerzDepression-Assoziation und die Dosis-Wirkungsbeziehung beide schwach, schwächer als man erwarten würde, wenn die Hypothese eines kausalen Zusammenhangs richtig wäre. Die mässige Assoziation in der MPI-Untergruppe „Interpersonally Distressed“ könnte eine Bedeutung für das Schmerzmanagement haben: Schmerzen können beeinflusst werden mittels Behandlung der Depression und umgekehrt.

Patienten mit unspezifischen, muskuloskelettalen Schmerzen sind keine homogene Gruppe, sondern, wegen ihrer biopsychosozialen Beeinträchtigungen, sehr heterogen. Wie bereits vorher erwähnt, ist das Hauptziel dieser Dissertation die Untersuchung der Wirkung von klassifikation-basiertem Schmerzmanagement. Die Studie in Kapitel 5 beabsichtigte, in einer Stichprobe mit schwerstbetroffenen Fibromyalgiepatienten, die empirisch abgeleitete Untergruppenklassifikation, basierend auf der MPI, zu wiederho- 
len und zu validieren. Zweitens wurde untersucht, wie die retrospektiv identifizierten Untergruppen sich in ihren Effekten nach einem standardisierten, interdisziplinären, stationären Schmerzprogramm unterscheiden. 118 Fibromyalgiepatienten mit anhaltenden Schmerzen und schweren Beeinträchtigungen bei der Ausführung ihrer Alltagsaktivitäten nahmen an der Studie teil. Die Klassifikation in Untergruppen wurde mittels Clusteranalyse ausgeführt; dafür wurden die Mittelwerte der Skalen der MPIUntergruppen beim Eintritt ins Schmerzprogramm verwendet. Die Teilnehmenden füllten bei Eintritt und Austritt des Schmerzprogramms die Fragebögen MPI, SF-36, HADS und die CSQ aus. Die Clusteranalyse wies in dieser schwerstbetroffenen Stichprobe drei Untergruppen aus, die identisch mit denjenigen aus anderen Studien mit weniger betroffenen Fibromyalgiepatienten beschrieben waren. Die Untergruppe "Dysfunctional "(DYS; 36\% der Stichprobe) wies das höchste Ausmass an Depression aus, die Untergruppe "Interpersonally Distressed "(ID; 24\%) wies ein mässiges Depressionsniveau aus und die Untergruppe "Adaptive Copers" (AC; 38\%) wies die tiefsten Punktwerte für Depression aus. Beurteilt wurden die Skalen MPI Affektive Verstimmung, SF-36 Psychische Gesundheit, HADS Depression, und CSQ Katastrophisieren. Betreffend Schmerzlinderung (gemessen mit MPI-Skala Schmerzstärke) wurden signifikante Unterschiede im Behandlungsresultat zwischen den drei Untergruppen beobachtet. Die Effektstärken betrugen 1.42 für DYS, 1.32 für AC, und 0.62 für ID ( $p=0.004$ im Paarvergleich ID-AC und $p=0.018$ für ID-DYS). Diese Ergebnisse betonen die Bedeutung der Beurteilung, wie unterschiedlich sich Patienten an Fibromyalgie anpassen.

In einer ähnlich aufgemachten Studie, beschrieben in Kapitel 6, wurde in einer Stichprobe mit 173 schwerstbetroffenen Patienten mit chronischen Rückenschmerzen untersucht, wie die drei MPI-Untergruppen unterschiedlich auf das standardisierte, stationäre Zurzacher Schmerz-Programm ansprachen. Auch hier wurde die Klassifikation in Untergruppen mittels Clusteranalyse ausgeführt; dafür wurden die Mittelwerte der Skalen der MPI-Untergruppen beim Eintritt ins Schmerzprogramm verwendet. Die Teilnehmenden füllten bei Eintritt und Austritt des Schmerzprogramms die Fragebögen MPI, SF-36, HADS und die CSQ aus. Mittels Mann-Whitney-Tests für unabhängige Stichproben, wurden die Signifikanzniveaus im Paarvergleich der Veränderungen der Mittelwerte der vorhererwähnten Fragebögen bestimmt. Die Clusteranalyse ergab in dieser Stichprobe bei der Ausführung ihrer Alltagsaktivitäten drei MPI-Untergruppen: "Dysfunctional", "Interpersonally Distressed", und "Adaptive Copers". Die Untergruppe "Dysfunctional" (DYS; 29\% der Stichprobe) wies das höchste Ausmass an Depression (gemessen mit dem SF-36 Psychische Gesundheit) aus (33.4 \pm 13.9); die Untergruppe "Interpersonally Distressed" (ID; 35\%) wies ein mässiges Depressionsniveau aus (46.8 \pm 20.4) und die Untergruppe "Adaptive Copers" (AC; 32\%) wies die tiefsten Punktwerte für Depression aus (57.8 \pm 19.1$)$. Betreffend Schmerzlinderung, Verbesserung der psychischen Gesundheit und Schmerzbewältigung, wurden signifikante Unterschiede im Behandlungsresultat zwischen den drei Untergruppen beobachtet. Die Effektstärken für MPI-Schmerzlinderung betrugen 0.84 (0.44 - 1.24) für DYS, $1.22(0.86-1.58)$ für AC, 
und 0.53 (0.24 - 0.81) für ID ( $p=0.006$ im Paarvergleich). Betreffend Aktivitätsniveau und körperlicher Funktion konnten keine signifikanten Unterschiede im Behandlungsresultat zwischen den drei Untergruppen beobachtet werden. Zum Schluss kann man festhalten, dass die retrospektive Klassifizierung in MPI-Untergruppen signifikante Unterschiede der Effekte für Schmerz, psychische Gesundheit und Schmerzbewältigung aufdeckte. Diese Resultate betonen die Bedeutung der Untersuchung, wie unterschiedlich sich Patienten an chronische Rückenschmerzen adaptieren.

In Kapitel 7 werden die Resultate einer randomisiert kontrollierten Studie, die die Wirkung von massgeschneiderten Behandlungen bei a priori-klassifizierten Patienten mit chronischen, unspezifischen Rückenschmerzen untersucht, beschrieben. Das Ziel der Studie war die Untersuchung der Unterschiede in den Effekten betreffend Schmerzreduktion und Reduktion der funktionellen Behinderung bei Alltagsaktivitäten bei Patienten mit chronischen Rückenschmerzen, die an einem Untergruppen-spezifischen, 4wöchigen, stationären, interdisziplinären Schmerzprogramm teilnehmen, im Vergleich mit einem Standard-Schmerzprogramm. Die Patienten in der Experimentalgruppe wurden vor Behandlungsbeginn mittels des MPI-Klassifikationssystems in Untergruppen eingeteilt: so konnten die Patienten einer Untergruppen-spezifischen Therapie, basierend auf Physiotherapie und Psychotherapie, zugeteilt werden. Die primären Outcomes waren Schmerz und funktionelle Behinderung, gemessen mittels Fragebögen 4 und 12 Wochen nach Randomisierung; sekundäre Outcomes waren beobachtete, funktionelle Behinderung, Angst und Depression, Schmerz Katastrophisieren, Selbstwirksamkeit und psychosoziale Aspekte von Schmerz. 4 und 12 Wochen nach Behandlungsbeginn wurde eine verblindete intention-to-treat-Analyse durchgeführt. Insgesamt wurden 146 Patienten in diese Studie eingeschlossen. Mit Ausnahme von minimaler Schmerzintensität nach 4 Wochen (Standard Mean Difference $(\mathrm{SMD})=0.43,95 \%$ Vertrauensintervall $(\mathrm{CI})$, 0.02 bis $0.84 ; p=0.034$ ) wurden keine signifikanten Unterschiede zwischen der Experimentalgruppe und der Kontrollgruppe gemessen. Die sekundäre Analyse, das heisst, Paarvergleiche zwischen den individuellen MPI-Untergruppen und der Kontrollgruppe, erklärte diesen Unterschied im Effekt bei der Nachkontrolle nach 12 Wochen zu Gunsten der Kontrollgruppe im Vergleich mit der MPI-Untergruppe "Adaptive Copers": SMD $=0.55,95 \% \mathrm{Cl}, 0.02$ bis 1.08; $\mathrm{p}=0.035$. Alle anderen Vergleiche für alle Outcomes und alle Nachkontrollen ergaben keine signifikanten Unterschiede. Die Resultate dieser Studie rechtfertigen die Schlussfolgerung, dass ein Untergruppen-spezifisches Schmerzprogramm, basierend auf dem MPI-Klassifikationssystem, für Patienten mit chronischen Rückenschmerzen in dieser Studie nicht effektiver betreffend Schmerzreduktion und Reduktion der funktionellen Behinderung war als ein StandardSchmerzprogramm.

In Kapitel 8 werden die Hauptresultate und methodologischen Überlegungen dieser Thesis besprochen. Die Konsequenzen der Studien dieser Thesis für das klinische Patientenmanagement werden diskutiert und es werden Empfehlungen für zukünftige Forschungsprojekte gemacht. Vergleiche mit anderen randomisierten, kontrollierten 
Studien, die die Effekte von klassifikations-basierten Interventionen untersucht haben, zeigen unterschiedliche Resultate. Sowohl in unserer randomisierten Studie als auch in den anderen bis dato publizierten Studien, führen klassifikations-basierte Interventionen nicht automatisch zu grösseren Effekten. Untergruppen-spezifische Interventionen könnten jedoch wenigstens eine ebenbürtige Alternative zum allgemeinen Schmerzmanagement sein. In weiteren Forschungsprojekten sollten homogenere Untergruppen und das Verhaltensmuster der Untergruppe „Adaptive Copers“ untersucht werden. 


\section{Nederlandse samenvatting}

De focus van dit proefschrift is de validering en het testen van de effectiviteit van een op een classificatiesysteem gebaseerd revalidatieprogramma bij patiënten met chronische pijn aan het bewegingsapparaat in een derdelijns setting (revalidatie kliniek) in Zwitserland. Chronisch pijn met matige tot sterke intensiteit komt bij $19 \%$ van de volwassenen in Europa voor. Chronisch pijn vormt niet alleen een grote belasting voor het individu en zijn sociale omgeving, maar ook voor de gezondheidszorg, werkgevers en de maatschappij in het algemeen. Hoewel de behandeleffecten klein tot bescheiden zijn, zijn uitvoerige interdisciplinaire pijnprogramma's waarschijnlijk het meest kosteneffectief voor patiënten met chronische rugklachten. In Zwitserland is therapie in een revalidatie instelling bij patiënten met chronische pijnklachten aan het bewegingsapparaat een gangbare behandeloptie. Rugklachten zijn echter in ongeveer $90 \%$ van de gevallen niet-specifiek, hetgeen betekent dat er geen lichamelijke oorzaak voor de pijn gevonden worden kan. De zoektocht naar classificatie systemen, die in staat zijn om homogene subgroepen van patiënten met niet-specifieke rugklachten te onderscheiden die het beste reageren op een subgroep-specifieke pijnbehandeling, staat al meer dan 18 jaar op de internationale onderzoeks agenda. Tot nu toe zijn de effecten van slechts aan paar op classificatie-gebaseerde interventies in verschillende settings onderzocht. Deze interventies brachten een grote variatie in indelingen, therapeutische interventies en resultaten aan het licht. In dit project hebben we het Multidimensional Pain Inventory (MPI) classificatie systeem onderzocht, dat rugpatiënten - op basis van hun omgang met de pijnklachten indeelt in drie voornamelijk psychosociale subgroepen. Alle onderzoeken in dit proefschrift werden met patiënten uitgevoerd die deelnamen aan het Zurzach Interdisciplinaire Pijnprogramma (ZISP) uit. De voornaamste doelstelling van dit proefschrift bestond uit het onderzoeken van de effectiviteit van de subgroepspecifieke behandeling van patiënten met chronische pijnklachten aan het bewegingsapparaat die geclassificeerd worden met het MPI classificatie systeem. Zo zou de toekomstige behandeling van patiënten eventueel geoptimaliseerd kunnen worden. De tweede doelstelling betrof het onderzoeken van verschillen in effecten tussen de individuele MPI-subgroepen. Tenslotte bestond het derde doel - als voorwaarde om de eerste twee doelstellingen te bereiken - uit het testen van de klinimetrische eigenschappen van de Coping Strategies Questionnaire (CSQ) en de MPI.

Het trainen en evalueren van actieve, geadapteerde strategieën in de omgang met pijn (coping) is een van de prioriteiten in de behandeling van pijnklachten. Het doel van het onderzoek dat in hoofdstuk $\mathbf{2}$ beschreven wordt was het vertalen en transcultureel aanpassen van de Amerikaanse versie van de CSQ en het testen van de betrouwbaar- 
heid en de validiteit van de Duitse versie (CSQ-D). De CSQ werd volgens de internationale richtlijnen vertaald en transcultureel aangepast. De betrouwbaarheid en validiteit werden bij 62 individuen met chronische pijnklachten aan het bewegingsapparaat onderzocht. Om de concurrente criterium validiteit te testen werden de schalen van de CSQ met die van de German Pain Coping Questionnaire (FESV-BW) vergeleken en voor de constructvaliditeit met de schalenschalen van de German Short Form-36 (SF-36). Het vertaalproces verliep zonder noemenswaardige moeilijkheden. Voor de betrouwbaarheid had de CSQ-D als geheel een Cronbach's alpha van 0.94 en een intraclass correlatie coëfficiënt van 0.89 (95\% betrouwbaarheidsinterval: 0.86 tot 0.98 ). De totaalscore van de CSQ-D correleerde met de schalen van de FESV-BW met scores van $r=0.32$ tot 0.55 en met de SF-36 Mental Component Summary met scores van $r=0.32$ tot 0.53 . Concluderend, de CSQ-D is een goed vertaald en betrouwbaar meetinstrument voor het onderzoeken van de omgang met pijn. Deconcurrente criterium validiteit en constructvaliditeit waren laag. De voornaamste reden voor het lage niveau van overeenstemming tussen de CSQ-D en de FESV-BW kon met behulp van factoranalyse aangetoond worden. De CSQ-D kan aanbevolen worden voor onderzoek met Duitstalige patiënten of grote internationaal multicenter onderzoek, waarin de omgang van patiënten met pijn wordt geëvalueerd.

De betrouwbaarheid van de Duitse versie van de MPI (MPI-D) is in het verleden slechts eenmaal in een kleine steekproef onderzocht. Eerdere internationale onderzoeken voornamelijk met patiënten met fibromyalgie, toonden aan dat 33-38\% van de patiënten bij de hertest aan een andere MPI-subgroep waren toegewezen. Hoofdstuk 3 presenteert de resultaten van een crossvalideringsstudie die de betrouwbaarheid van de MPI en de stabiliteit van het MPI-classificatiesysteem bij patiënten met chronische pijnklachten aan het bewegingsapparaat onderzocht. De deelnemers aan het onderzoek waren 204 personen met chronische pijn (82\% had chronische niet-specifieke rugklachten). Met behulp van de scores van de MPI-schalen 4 weken voor deelname aan het pijnprogramma (= test) en bij het begin van het pijnprogramma (= hertest) werd via cluster analyse de classificatie in subgroepen uitgevoerd. In deze periode werden geen therapeutische interventies uitgevoerd. De betrouwbaarheid werd met behulp van intraclass correlation coefficients (ICC) en de stabiliteit met behulp van kappa coefficients $(\kappa)$ gekwantificeerd. De betrouwbaarheid van de MPI-schalen was voor de schaalschaal life control het laagst met een ICC van 0.57 en varieerde in de andere schalen tussen ICC $=0.72$ ('negative mood') en 0.87 ('solicitous responses'). Bij de hertest veranderden in het MPI-cluster Interpersonally Distressed $82 \%$ van de patiënten ( $\mathrm{k}$ $=0.69), 80 \%$ van de Adaptive Copers $(\mathrm{k}=0.58$ ), en $75 \%$ van de Dysfunctionals $(\mathrm{k}=0.70$ ) hun oorspronkelijke classificatie niet. Bijeengeteld wisselden $22 \%$ van de patiënten bij hertest van MPI cluster groep, voornamelijk in richting van de subgroep Adaptive Copers. Concluderend, de test-hertest betrouwbaarheid van de Duitse versie van de MPI was matig tot goed en vergelijkbaar met versies in anderen talen. Vergeleken met andere diagnosegroepen en andere classificatiesystemen is de classificatie van patiënten 
met chronische rugklachten in MPI-subgroepen vrij stabiel. Daarom kan het MPI classificatiesysteem worden aanbevolen om op betrouwbare wijze onderscheid te maken in subgroepen ten behoeve van observationeel en interventieonderzoek bij patiënten met chronische pijnklachten van het bewegingsapparaat.

De relatie tussen depressie, een comorbiditeit met de hoogste prevalentie bij patienten met pijnklachten van het bewegingsapparaat, en chronisch pijn is omstreden en de cijfers betreffende deze associatie laten veel variatie zien. In hoofdstuk 4 wordt de samenhang tussen chronisch pijn en depressie onderzocht. Het doel was om met behulp van categoriale en continue meetinstrumenten verfijnde data te genereren om correlatie en regressieanalyses te kunnen uitvoeren. Een cross-sectioneel onderzoek werd uitgevoerd met gebruikmaking van gestandaardiseerde instrumenten, die op een quasi-continue schaal meten: te weten de SF-36, de Hospital Anxiety and Depression Scale (HADS) en de MPI. Correlaties tussen depressie en pijn in de MPI-subgroepen werden met behulp van de subschalen van deze meetinstrumenten bepaald, met en zonder correctie voor confounders, en met behulp van multivariate regressie analyse. Correlaties tussen de MPI-schaal 'pain severity' en de HADS-schaal depressie resulteerden bij 273 pijn patiënten die aan het Zurzach interdisciplinaire pijnprogramma deelnamen in correlaties van 0.27 tot 0.29 (bivariaat) en 0.30 (partieel). De odds ratios voor depressie varieerden voor de verschillende pijnniveaus tussen 1.72 en 2.10. De pijndepressie correlatie was matig in de MPI-subgroep Interpersonally Distressed (tot 0.57), laag in de subgroep Dysfunctional (tot 0.26) en afwezig in de MPI-subgroep Adaptive Copers (tot -0.09). Alles wel beschouwd waren de pijn-depressie associatie en de dosisresponse relatie laag, lager als men zou kunnen verwachten als de hypothese van een causale samenhang waar zou zijn. Voor de MPI-subgroep Interpersonally Distressed zou de matige associatie gevolgen kunnen hebben voor de behandeling van pijn: pijn zou via de behandeling van depressie beïnvloed kunnen worden en omgekeerd.

Patiënten met niet-specifieke pijnklachten van het bewegingsapparaat zijn geen homogene groep, maar zeer heterogeen wat betreft hun biopsychosociale problemen. Zoals reeds eerder vermeld was de evaluatie van de effectiviteit van een op classificatie gebaseerd pijnprogramma de hoofddoelstelling van dit proefschrift. Het onderzoek dat in hoofdstuk 5 beschreven wordt had tot doel de empirisch ontwikkelde MPI-classificatie in een steekproef met fibromyalgiepatiënten met veel beperkingen te herhalen en te valideren. Ten tweede werd onderzocht in hoeverre de retrospectief geïdentificeerde subgroepen na behandeling in een standaard pijnprogramma verschilden voor wat betreft hun effecten. De deelnemers aan dit onderzoek waren 118 patiënten met fibromyalgie die aanhoudende pijnklachten en substantiële beperkingen in de uitvoering van hun activiteiten van het dagelijks leven ervoeren. De classificatie in subgroepen werd met behulp van cluster analyse uitgevoerd, waarbij de scores van de MPI schalen werden gebruikt. Bij begin en aan het einde van het pijnprogramma vulden de deelnemers aan het onderzoek de vragenlijsten MPI, SF-36, HADS en CSQ in. Met behulp van clusteranalyse werden in deze steekproef drie subgroepen onderscheiden, die identiek 
waren met subgroepen die in steekproeven met fibromyalgie patiënten met minder beperkingen beschreven werden. De subgroep Dysfunctional (DYS; 36\% van de steekproef) had het hoogste niveau van depressie, de subgroep Interpersonally Distressed (ID; 24\%) had een matig niveau van depressie en de subgroep Adaptive Copers (AC; $38 \%$ ) had de laagste depressie-scores in de MPI (schaal negative mood), SF-36 (mental health), HADS (depressie), en CSQ (catastroferen). Tussen de drie subgroepen werden voor wat betreft reductie van de MPI-pijnintensiteit significante verschillen in behandelingsresultaat gemeten. De effect sizes waren1.42 voor de MPI-subgroep DYS, 1.32 voor $A C$, en 0.62 voor ID ( $p=0.004$ in de paarvergelijking ID-AC en $p=0.018$ voor ID-DYS). Deze resultaten onderstrepen de betekenis van het onderzoeken van de verschillen tussen patiënten in aanpassing aan het ziektebeeld fibromyalgie.

In een vergelijkbaar onderzoek dat in hoofdstuk 6 beschreven staat werden 173 patiënten geïncludeerd met veel beperkingen ten gevolge van chronische rugpijn. Het doel hier was om uit te vinden in hoeverre de drie MPI-subgroepen verschillende effecten lieten zien op het standaard pijnrevalidatieprogramma in Zurzach. Ook hier werd de classificatie in subgroepen met behulp van cluster analyse uitgevoerd, waarbij de scores van de MPI schalen gebruikt werden. Bij begin en einde van het pijnprogramma na vier weken vulden de deelnemers aan het onderzoek de vragenlijsten MPI, SF-36, HADS en CSQ in. Met behulp van de Mann-Whitney-U-test werden paarsgewijze tussen de veranderingen in scores van de hiervoor genoemde meetinstrumenten in de MPI-subgroepen uitgevoerd. De clusteranalyse identificeerde in deze steekproef drie subgroepen: een Dysfunctional, een Interpersonally Distressed en een Adaptive Copers subgroep. De subgroep Dysfunctional (DYS; $29 \%$ van de steekproef) had het hoogste niveau van depressie in de SF-36 psychische gezondheid (33.4 \pm 13.9 ), de subgroep Interpersonally Distressed (ID; $35 \%)$ had een matig niveau van depressie $(46.8 \pm 20.4)$ en de subgroep Adaptive Copers (AC; 32\%) had de laagste depressie-scores $(57.8 \pm 19.1)$. Tussen de drie subgroepen werden significante verschillen in pijnreductie, verbetering van de psychische gezondheid en omgang met de pijnklachten geobserveerd. De effect sterktes (effect sizes) voor MPI pijnreductie bedroegen 0.84 (0.44 - 1.24) voor de subgroep Dysfunctional, $1.22(0.86-1.58)$ voor de subgroep Adaptive Copers en 0.53 (0.24 - 0.81) voor de subgroep Interpersonally Distressed ( $p=0.006$ voor de paarvergelijking). Wat betreft activiteiten en lichamelijke functie konden tussen de subgroepen geen significante verschillen aangetoond worden. Concluderend, de classificatie in MPI-subgroepen liet significante verschillen in effecten wat betreft pijn, psychische gezondheid en omgang met pijn zien. Deze resultaten onderstrepen het belang van het evalueren van de verschillen in hoe patiënten zich aanpassen aan chronische rugklachten.

In hoofdstuk 7 rapporteren we over een gerandomiseerd gecontroleerde studie die de effecten van subgroep-specifieke interventies bij a priori geclassificeerde patiënten met niet-specifieke rugklachten onderzocht. De doelstelling van dit onderzoek was het meten bij patiënten met chronische rugklachten van de verschillen in pijnreductie en het verbeteren van de uitvoering van activiteiten in het dagelijks leven na een sub- 
groep-specifiek, 4-weeks, interdisciplinair pijnrevalidatieprogramma, vergeleken met een standaard-pijnrevalidatieprogramma. Voor begin van de behandeling werden de patiënten in de experimentele groep geclassificeerd volgens het MPI-classificatiesysteem, met het doel ze subgroep-specifieke fysiotherapie en psychotherapie aan te bieden. De primaire uitkomstmaten waren pijn en functionele beperkingen bij de uitvoering van activiteiten in het dagelijks leven (disability) - gemeten middels vragenlijsten - en werden 4 en 12 weken na de randomisatie gemeten; secundaire uitkomstmaten waren geobserveerde functionele beperkingen, angst en depressie, pijn catastroferen, zelfwerkzaamheid, en psychosociale aspecten van pijn. 4 en 12 weken na randomisatie werd een geblindeerde intention-to-treat analyse gedaan. In totaal werden 146 patiënten gerekruteerd. Met uitzondering van de daling van de minimale pijnintensiteit na 4 weken (standard mean difference $(S M D)=043,95 \%$ betrouwbaarheidsinterval $(\mathrm{Cl}), 0.02$ tot $0.84 ; \mathrm{p}=0.034$ ) konden er geen significante verschillen tussen de experimentele groep en de controle groep vastgesteld worden. De secundaire analyse - een paarsgewijze vergelijking tussen de individuele MPI-subgroepen en de controle groepverklaarde dit verschil in effect 12 weken na randomisatie ten gunste van de controle groep in vergelijking met de MPI-subgroep Adaptive Copers (SMD = 0.55, 95\% Cl, 0.02 tot 1.08; $p=0.035$ ). Voor alle andere vergelijkingen met alle andere meetinstrumenten waren er geen significante verschillen. De resultaten van dit onderzoek rechtvaardigen de conclusie, dat subgroep-specifieke pijnbehandeling gebaseerd op het MPI classificatiesysteem bij patiënten met chronische rugklachten niet effectiever is in pijnreductie en verbetering van het functioneren, dan een standaard-pijnrevalidatieprogramma.

In hoofdstuk 8 worden de voornaamste resultaten en methodologische overwegingen besproken. De implicaties van de onderzoeken beschreven in dit proefschrift voor de klinische patiëntenzorg worden bediscussieerd en er worden aanbevelingen voor toekomstig onderzoek gedaan. Een vergelijking met andere gerandomiseerde gecontroleerde studies die de effecten van op classificatie-gebaseerde interventies onderzochten gaf een gemengd beeld. Zowel in ons onderzoek als ook in andere studies die tot dusver gepubliceerd werden, leiden op classificatie-gebaseerde interventies niet automatisch tot grotere effecten. Niettemin kunnen subgroep classificatie en subgroepspecifieke interventies op zijn minst een gelijkwaardig alternatief bieden voor algemene pijnbehandeling zijn. Toekomstige onderzoeken zouden homogenere subgroepen moeten zoeken en tevens het gedragspatroon van de patiënten in de MPI-subgroep Adaptive Copers moeten nagaan. 



\section{Acknowledgments}

Ultimately now, writing these acknowledgments, I realize very deeply that doing research in general and completing this PhD thesis in particular would not have been possible without the goodwill and support from my family, friends, and colleagues.

First of all, I would like to thank my supervisor, Prof. Dr. Rob de Bie, PhD, PT. Rob and I met in 2007 at the World Congress Physiotherapy (WCPT), Vancouver, Canada. During a coffee break on the first day of the congress he asked me what I had been doing so far and what next steps I had in mind. Having carefully listened to my explanations, he concluded that this would be an exciting PhD project and he would be happy to introduce me tomorrow to my future co-promoter Bart Staal. This all happened during a half a cup of coffee and I confess, that night I did not sleep that much. I learned from Rob that "Luck is where the crossroads of opportunity and preparation meet". He guided me professionally and with a delighting sense of humour through the process of the thesis. Supervision sessions in Winterthur or contact by email or telephone, you always helped me to take the next step. Rob, also many thanks for organizing my eight week stay at your Department at Maastricht University to do the final writing of this thesis.

I want to express my deepest thanks to my co-promoter Dr. Bart Staal, PhD, PT. When we first met, Bart just published the European guidelines for the management of chronic non-specific low back pain. His profound scientific and clinical knowledge of back pain has been an important source of wisdom for me. Bart, you gave me important inputs, answered my many questions and coached me through my PhD trajectory (even at the research station Jungfraujoch, 3450 meters above sea level).

Sehr grossen Dank schulde ich den Herren Felix Angst, MD, MPH und Roberto Brioschi, MSc. Felix, Du bist mein wissenschaftlicher Mentor seit Beginn meiner akademischen Karriere als Master of Science-Student im 2002. Deine methodologischen und statistischen Kenntnisse einerseits und Deine Vorbildfunktionen als Triathlet („zum Publizieren braucht es Ausdauer..."), Hobby-Winzer und Naturliebhaber anderseits, machen Dich zu einem Kollegen und Freund, der jeder sich nur wünschen kann. Roberto, ich habe sehr viel von Deinem Umgang mit Schmerzpatienten und Schmerztherapeuten und Deinen einmaligen, didaktischen Fähigkeiten gelernt. Zusammen haben wir an vielen nationalen und internationalen Kongressen unsere gemeinsamen Forschungsresultate präsentiert. Dabei ist eine sehr wertvolle Freundschaft entstanden. Felix und Roberto, es ist für mich eine Ehre, dass Ihr beide an der Promotion meine Paranymphen seid. 
Ich möchte mich bei Herrn Prof. Andre Aeschlimann, MD, bedanken. André, Du hast mich immer motiviert, meinen Weg als klinisch-tätigen Physiotherapeut, als Forscher und als Manager im Gesundheitswesen zu gehen, sowohl in der RehaClinic als auch im Inselspital Bern. Weiter möchte ich mich bei meinen RehaClinic-ForschungskollegInnen Frau Susanne Lehmann, Studienkoordinatorin und Herrn Thomas Benz, MSc, PT, bedanken. Ohne Eure tatkräftige und professionelle Unterstützung hätte ich dieses Projekt niemals durchführen und erfolgreich beenden können.

Diese Dissertation wäre ohne die Unterstützung und Teilnahme aller KollegInnen des Schmerzteams des Zurzacher Interdisziplinäres Schmerzprogramms ZISP nicht möglich gewesen. Mein spezieller Dank geht an die PhysiotherapeutInnen und klinischen Psychologinnen, die die subgruppen-spezifischen Interventionen der RCT durchgeführt haben: Herr Thomas Benz, Frau Isabelle Gloor, Herr Jens-Peter Hamann, Herr Markus Meyer, Frau Michele Frei, Herr Marco Hillenbrand, Herr Ralf Pfister, Frau Sigrid Schindler, Frau Caroline Haase, Herr Thomas Bürgi, Herr Valentin Deiss, Frau Viola Gross, Herr David Schmidt, Frau Anne Kowal, Herr Steffen Blunk, Frau Eva Conrad, Frau Christiane Geier, Frau Karin Winterberger-Smits, Frau Sabina Nyffeler, Frau Gaby Scholz, Frau Cornelia Zink, Frau Lydia Angelozzi und Frau Rukiye Isik. Danke Leute, Ihr seid phantastisch!

Vervolgens wil ik graag Dr. Carolien Bastiaenen, PhD, PT, en Dr. Judith Sieben, PhD, bedanken. Zij vormden samen met Rob de Bie het "Unimaas-Powerteam": ze deden supervisie bij mij en mijn Zwitserse collegas die hetzelfde PhD-traject volgen. Ze ondersteunden me ook met raad en daad gedurende mijn 8-weeks verblijf aan de Universiteit Maastricht. Judith en Carolien, bedankt voor de belangrijke adviezen en de warme gastvrijheid.

Ich bedanke mich bei meinem direkten Vorgesetzten, Herr Prof. Andreas Tobler, MD, ärztlicher Direktor, für das in mich gesetzte Vertrauen. Andreas, Du und der Verwaltungsrat hattet mich per 1. Januar 2009 als ersten Direktor des neuen Instituts für Physiotherapie im Inselspital angestellt, obwohl ich das Anforderungsprofil der Stelle (unter anderem einen PhD-Abschluss) damals noch nicht ganz erfüllte. Du hast mir Kraft und Zuversicht gegeben, das Projekt erfolgreich abzuschliessen.

Mein spezieller Dank geht an meine Mitglieder der Institutsleitung Physiotherapie am Inselspital: Frau Irène Thaler, Frau Sandra Frauchiger, Frau Isabelle Fankhauser, Herr Joachim Schmidt, Herr Balz Winteler und Herr Nikola Donev. Unsere Zusammenarbeit ist aus meiner Sicht in vieler Hinsicht einmalig. Ihr habt mir in kritischen Momenten während meines PhD-Projekts den Rücken freigehalten. Irène, Du hast mich während meinem scientific sabbatical an der Universität Maastricht im Frühling 2013 phantastisch vertreten.

Prof. Dr. Franc Keefe, $\mathrm{PhD}$ is an international leader in the field concerning pain management and training of coping strategies. Dear Franc, thank you for your participation as a co-author and for all your true interest, our intensive discussions and your warm support. 
An dieser Stelle möchte ich mich auch bei Frau Omega Huber, MAS, PT, und Frau Prof. Dr. Karin Niedermann, PhD, PT, ganz herzlich bedanken. Als Pionierinnen der Akademisierung der schweizerischen Physiotherapie habt Ihr es vor über 10 Jahren mir und vielen anderen KollegInnen ermöglicht, eine Masterausbildung in der Schweiz zu absolvieren. Karin und Omega, ich bin Euch dankbar, dass Ihr mir so den Zugang zur scientific community ermöglicht habt.

Ik wil de leden van de beoordelingscommissie en de corona Prof. Dr. Lodewijk van Rhijn, Dr. Adrie Apeldoorn, Prof. Dr. Paul Helders, Prof. Dr. Martin Prins, Prof. Dr. Rob Smeets en Prof. dr. Jeanine Verbunt bedanken voor het lezen en positief beoordelen van mijn proefschrift. Rob, jammer dat je niet aan de corona kunt deelnemen, maar bedankt voor je vele goede methodologische en klinische adviezen gedurende onze gezamelijke fietstochten door het prachtige Limburgse landschap.

Dan als laatste - zo hoort dat nu eenmaal in een proefschrift - mijn eigen gezin. Tom, Max en Rob: jullie zijn drie fantastische jongens, gaan jullie eigen weg in opleiding, beroep en relaties, en dat is goed zo. Ik ben trots op jullie. Lieve Bregit, een PhD op 45-jarige leeftijd beginnen was niet alleen een zoektocht naar mijn wetenschappelijke zelf, maar tot op zekere hoogte ook een narcistische egotrip. Ik had deze vele onderzoeken, cursussen en congressen zonder jou niet kunnen doen. Jij hield het huishouden, het gezin en nog veel meer draaiende en zorgde er voor dat ik met beide voeten op de grond bleef. De promotie is op onze $23^{\text {ste }}$ trouwdag: ik ben dankbaar voor je enorme hulp, steun en liefde.

So many people have been involved in this PhD project or showed their sympathy. I might have forgotten to acknowledge somebody here. In this case, thank you very much. 



\section{About the author}

\section{Curriculum Vitae}

Martinus Lodewijk (Martin) Verra was born on September 8, 1964 in Dieren, The Netherlands. He completed his secondary school (type VWO) in 1982 at the Rijksscholengemeenschap in Schagen, and studied physiotherapy at the Akademie Jan van Essen in Amsterdam. After graduation in 1986 he started working as a clinical physiotherapist in a nursing home in Arnhem, The Netherlands. In 1988 he and his wife decided to move to Switzerland and Martin worked consecutively at a general hospital, a private hospital, a private praxis, the rehabilitation clinic RehaClinic in Bad Zurzach and at a university hospital. During this time he undertook many continuing education courses, among others resulting in an international Diploma in Orthopedic Manipulative Physical Thera-

py $\left(\mathrm{OMT}^{\mathrm{SVOMP}}\right)$. His main focus was on the rehabilitation of patients with chronic back pain, fibromyalgia, whiplash-associated disorders, and osteoarthritis. He became increasingly interested in the interdisciplinary management of patients with chronic musculoskeletal pain conditions. Since 2009, he has been director of the Department of Physiotherapy at Inselspital, Bern University Hospital, Switzerland. Additionally, he is a research fellow at RehaClinic, Bad Zurzach, Switzerland. This has resulted in several research articles, including the publications covered in this thesis.

As an external student, he gained a Master degree in Physiotherapy Science in 2005 at the Department of Epidemiology, Faculty of Health Sciences at the University of Maastricht, The Netherlands. Since then, the author is co-founder and organizer of the annual Swiss Clinical Research Forum. Martin is also a guest lecturer at Bern University of Applied Sciences (BFH) and at the Zurich University of Applied Sciences (ZHAW): he is involved in teaching health care professionals at a Bachelor and Master level about assessment and management of chronic musculoskeletal pain and evidence-based physiotherapy. In 2009 Martin was elected as vice president of the Swiss Physiotherapy Sciences Foundation. In 2012 he became a member of the physiotherapy group at the French Cochrane Center in Paris, France. The paper "Horticultural therapy for patients with chronic musculoskeletal pain: Results of a prospective controlled pilot study" (Verra et al.) wan in 2013 the American Charles A Lewis Excellence in Research Award. After finishing his PhD, his work focus will be on a combination of hospital management, clinical research, teaching and patient care.

Martin lives with his wife and their three sons close to Bern, Switzerland. 


\section{Memberships}

physioswiss Schweizer Physiotherapie Verband

KNGF Koninklijk Nederlands Genootschap voor Fysiotherapie

IASP International Association for the Study of Pain

PMM IASP special interest group Pain, Mind and Movement

SGSS Schweizerische Gesellschaft zum Studium des Schmerzes

SB SGSS special interest group Schmerz und Bewegung

SAR Schweizerische Arbeitsgemeinschaft fuer Rehabilitation

IGPTR-B Interessengemeinschaft Physiotherapie Rehabilitation Bewegungsapparat

SVOMP Schweizer Verband für Orthopädische Manipulative Physiotherapie 


\section{Publications}

\section{International peer reviewed publications}

Angst F, Verra ML, Lehmann S, Benz T, Aeschlimann A. Effects of inpatient rehabilitation in hip and knee osteoarthritis: A naturalistic prospective cohort study with intra-individual control of effects. Arch Phys Med Rehabil 2013, Apr 12. doi:pii: S0003-9993(13)00287-6. 10.1016/j.apmr.2013.03.026.

Verra ML, Angst F, Staal JB, Brioschi R, Lehmann S, Aeschlimann A, de Bie RA. Reliability of the Multidimensional Pain Inventory and stability of the MPI classification system in chronic back pain. BMC Musculoskeletal Disorders 2012;13:155.

Verra ML, Angst F, Beck T, Lehmann S, Brioschi R, Schneiter R, Aeschlimann A. Horticultural therapy for patients with chronic musculoskeletal pain: Results of a prospective controlled pilot study. Altern Ther Health Med 2012;18(2):44-50.

Angst F, Verra ML, Lehmann S, Gysi F, Benz T, Aeschlimann A. Responsiveness of the North American Spine Society questionnaire (NASS) and the Short Form 36 (SF-36) in chronic whiplash. Clin Rehabil 2012;26(2):142-151.

Verra ML, Angst F, Staal JB, Brioschi R, Lehmann S, Aeschlimann A, de Bie RA. Differences in pain, function and coping in Multidimensional Pain Inventory subgroups of chronic back pain: a one-group pretest-posttest study. BMC Musculoskeletal Disorders 2011;12:145.

Angst F, Gysi F, Verra ML, Lehmann S, Jenni W. Aeschlimann A. Interdisciplinary rehabilitation after whiplash injury: an observational prospective outcome study. J Rehabil Med 2010;42:350-356.

Verra ML, Angst F, Brioschi R, Lehmann S, Keefe FJ, Staal JB, de Bie RA, Aeschlimann A. Does classification of persons with fibromyalgia into Multidimensional Pain Inventory (MPI) subgroups detect differences in outcome from a standard chronic pain program? Pain Res Manage 2009;14(6):445-453.

Angst F, Verra ML, Lehmann S, Brioschi R, Aeschlimann A. Clinical effectiveness of an interdisciplinary pain program as compared with standard inpatient rehabilitation in chronic pain: A naturalistic, prospective controlled cohort study. J Rehabil Med 2009;41:569-575.

Angst F, Verra ML, Lehmann S, Aeschlimann A, Angst J. Refined insights into the paindepression association in chronic pain patients. Clin J Pain 2008;24(9):808-816. 
Angst F, Verra ML, Lehmann S, Aeschlimann A. Responsiveness of four conditionspecific and generic outcome assessment instruments for chronic pain. BMC Med Res Methodol 2008;8(1):26.

Verra ML, Angst F, Lehmann S, Aeschlimann A. Translation, Cross-Cultural Adaptation, Reliability, and Validity of the German Version of the Coping Strategies Questionnaire (CSQ-D). J Pain 2006;7(5):327-336.

\section{National scientific publications}

Verra ML. Update: Physiotherapeutische Evidenz auf den Punkt gebracht. Ars Medici Med \& Move, 2013;3:1-2.

Verra ML, Winteler B. Stellenwert der Physiotherapie bei chronischen Schmerzen. Rheuma Schweiz 2013;5:12-14.

Bengough T, Verra ML, von Elm E. Sind manuelle Therapien wirksam bei akutem lumbalem Rückenschmerz? Mini-Review Cochrane für die Praxis. PRAXIS, Schweizerische Rundschau für Medizin 2013;102(17):1072-1073.

Scascighini L, Verra ML. Inaktivität und Dekonditionierung - ein Update. physioactive 2012;6:23-27.

Verra ML. Evidenz - Physiotherapie nach einer Bandscheibenoperation: Wer trainiert, gewinnt. physiofacts 2012;2.

Verra ML. Evidenz - Präoperative Physiotherapie: gut vorbereitet in die Operation, schneller und selbständiger wieder nach Hause. physiofacts 2012;1.

Verra ML. Kapitel 7: Physiotherapie. In: Curatolo M (Ed.). Behandlung chronischer Schmerzen. Ther Umschau 2011;68(9):517-521.

Verra ML. Subgruppen bei Patienten mit chronischen unspezifischen Rückenschmerzen. In: Vier Dissertationen zu Rückenschmerzen. physioactive 2011;4:25-33.

Verra ML. Ein Vibrationsalarm in Unterarm-Gehstützen reduziert Überbelastung. physioactive 2011;4:51-52.

Verra ML. Die Rolle der Physiotherapie bei Patienten mit chronifizierten Schmerzen. Physio Magazin 2011;4.

Verra ML. Forschung \& Praxis: Intensives Widerstandstraining des gesunden Beins nach Gelenkersatz. Physioactive 2010;3:43-44.

Verra ML. Assessment Back-Performance-Scale: Beurteilung der Beweglichkeit der Wirbelsäule bei Alltagsaktivitäten. Physiopraxis 2009;11/12:50-51.

Verra ML. Die Schmerzbewältigung messen: Coping-Strategies-Questionnaire. Physiopraxis 2007;7/8:40-41.

Verra ML, Angst F. Wissenschaft verstehen Folge 34: Selbstbeurteilungsfragebogen zur Ergebnismessung in der Physiotherapie - Chancen und Probleme übersetzter Instrumente. Zeitschrift für Physiotherapeuten 2006;58:370-376. 


\section{Book chapters}

Oesch P, Hilfiger, Keller S, Kool J, Luomajoki H, Schädler S, Tal-Akabi A, Verra M, Widmer Leu C. Assessments in der muskuloskelettalen Rehabilitation. Band 2: Bewegungsapparat. 2. vollständig überarbeitete und erweiterte Auflage. ISBN 9783456848938. Bern, Switzerland: Verlag Hans Huber; 2011.

Schneiter-Ulmann R, Hoffmann R, Föhn M, Beck T, Karn S, Verra M, Höchli K, Vef-Georg G. Lehrbuch Gartentherapie. ISBN 9783456847849. Bern, Switzerland: Verlag Hans Huber; 2010.

Oesch P, Hilfiger, Keller S, Kool J, Schädler S, Tal-Akabi A, Verra M, Widmer Leu C. Assessments in der muskuloskelettalen Rehabilitation. ISBN 9783456844527. Bern, Switzerland: Verlag Hans Huber; 2007.

Fiechter Lienert B, Sonderegger A, Rau B, Verra M, Neuhaus C, Roeseler J, Reychler G, Contal O, Michotte J, Kool J, Lütolf-Keller B, Bürge E, Wanner-Gaille F. Evidence Based Physiotherapy. Verlag Fisio, Physioswiss; 2006.

\section{International conference papers}

Verra ML, Angst F, Brioschi R, Lehmann S, Benz T, Aeschlimann A, de Bie RA, Staal JB. Effectiveness of a subgroup-specific pain management program based on the MPI Classification System: A pragmatic RCT in chronic back pain. European Federation of IASP Chapters (EFIC) Congres, Florence, Italy, 2013.

Verra ML, Angst F, Beck T, Lehmann S, Brioschi R, Schneiter R, Aeschlimann A. Horticultural therapy for patients with chronic musculoskeletal pain: Results of a controlled study (invited speaker). Annual congress of the American Horticultural Therapy Association (AHTA), Minneapolis, USA, 2013.

Verra ML, Angst F, Benz T, Staal JB, Brioschi R, Lehmann S, Aeschlimann A, de Bie RA. Similarities and differences between Multidimensional Pain Inventory subgroups in fibromyalgia and chronic non-specific back pain. World Congress on Pain (IASP), Milano, Italy, 2012.

Verra ML, Angst F, Staal JB, Aeschlimann A, de Bie RA. Differences in pain, function and depression between subgroups of patients with chronic musculoskeletal pain classified by the Multidimensional Pain Inventory. Abstract in: Physiotherapy 2011;97:Supp S1:1309-1310. World Congress Physiotherapy (WCPT), Amsterdam, The Netherlands, 2011.

Angst F, Verra ML, Benz T, Lehmann S, Aeschlimann A. Consistency of effect differences between MPI cluster subgroups in chronic pain. Abstract in: Eur J Pain;2011;5(S1):182-183. European Federation of IASP Chapters (EFIC) Congres, Hamburg, Germany, 2011. 
Verra ML, Angst F, Staal JB, Brioschi R, Lehmann S, Aeschlimann A, de Bie RA. Stability of Multidimensional Pain Inventory subgroup classification in chronic pain patients. World Congress on Pain (IASP), Montreal, Canada, 2010.

Verra ML, Angst F, Beck T, Lehmann S, Brioschi R, Schneiter R, Aeschlimann A. Horticultural therapy for chronic pain patients - a longitudinal pretest-posttest control group study. European Federation of IASP Chapters (EFIC) Congres, Lisbon, Portugal, 2009.

Verra ML, Angst F, Staal JB, Brioschi R, Lehmann S, Benz T, Aeschlimann A, de Bie RA. Does classification of persons with chronic non-specific back pain into Multidimensional Pain Inventory Pain subgroups detect differences in outcome from a standard chronic pain program? World Congress on Pain (IASP), Glasgow, Scotland, 2008.

Verra ML, Angst F, Staal JB, Brioschi R, Lehmann S, Benz T, Aeschlimann A, de Bie RA. Effectiveness of tailored pain management in MPI-subgroups in patients with chronic back pain: Study design of a randomized controlled trial. IASP Satellite Symposium, Liverpool, England, 2008.

Verra ML. Classification of fibromyalgia into subgroups based on the Multidimensional Pain Inventory: does it help to individualize pain management in standard chronic pain programs? World Congress Physiotherapy (WCPT), Vancouver, Canada, 2007.

Verra ML, Angst F, Lehmann S, Aeschlimann A. IASP Kongress Swiss precision in clinimetrics - Translation, cross-cultural adaptation, reliability, and validity of the German version of the Coping Strategies Questionnaire. World Congress on Pain (IASP), Sydney, Australia, 2005.

\section{National conference papers}

Verra ML, Angst F, Staal JB, Brioschi R, Lehmann S, Benz T, Aeschlimann A, de Bie RA. Stabilität der Subgruppenklassifikation basierend auf dem Multidimensionalen Schmerzfragenbogen (MPI) bei Patienten mit chronischen muskuloskelettalen Schmerzen. Kongress der Physiotherapie. physioswiss, Geneva, Switzerland, 2012.

Verra ML, Aeschlimann A. Physical Physiotherapy (key lecture, invited speaker). Gemeinsame Jahrestagung Schweizerische Gesellschaft für Neurochirurgie (SGN)/ Schweizerische Kopfwehgesellschaft (SKG)/ Schweizerische Gesellschaft zum Studium des Schmerzes (SGSS)/ Interessengruppe Neurochirurgisches Operationspersonal Schweiz (IG-NOPPS). Interlaken, Switzerland, 2011.

Verra ML, Angst F, Staal JB, Brioschi R, Lehmann S, Benz T, Aeschlimann A, de Bie RA. Reliability of Multidimensional Pain Inventory subgroup classification in chronic pain patients. Gemeinsamer Kongress Schweizerische Gesellschaft zum Studium des Schmerzes (SGSS) / Swiss Insurance Medicine (SIM)/ Schweizerische Gesellschaft fuer Sportmedizin (SGSM)/ Schweizerische Arbeitsgemeinschaft fuer Rehabi- 
litation (SAR)/ Schweizerische Gesellschaft für Physikalische Medizin und Rehabilitation (SGPMR). Basel, Switzerland, 2010.

Verra ML, Angst F, Staal JB, Brioschi R, Lehmann S, Benz T, Aeschlimann A, de Bie RA. Differences in pain and depression between subgroups classified by the Multidimensional Pain Inventory (MPI). Gemeinsamer Kongress Schweizerische Gesellschaft zum Studium des Schmerzes (SGSS) / Swiss Insurance Medicine (SIM)/ Schweizerische Gesellschaft fuer Sportmedizin (SGSM)/ Schweizerische Arbeitsgemeinschaft fuer Rehabilitation (SAR)/ Schweizerische Gesellschaft für Physikalische Medizin und Rehabilitation (SGPMR). Basel, Switzerland, 2010.

Verra ML, Luomajoki H, Kool J, Hengeveld E. Wissenschaft versus Praxis: Physiotherapie bei Rückenschmerzen (debate, invited speaker). Kongress der Physiotherapie. physioswiss, Basel, Switzerland, 2010.

Verra ML. Graded Exercise Therapy bei chronischen Schmerzpatienten (invited speaker). Symposium "Low back pain - Evidenz, Möglichkeiten und Grenzen", Winterthur, Switzerland, 2009.

Angst F, Verra ML, Benz T, Lehmann S, Aeschlimann A. Gain and loss in therapy improvements of interdisciplinary versus standard pain management - a naturalistic, prospective controlled cohort study. Jahreskongress der Schweizerische Gesellschaft zum Studium des Schmerzes (SGSS) / Schweizerische Kopfwehgesellschaft (SKG). Bern, Switzerland, 2009.

Angst F, Verra ML, Benz T, Lehmann S, Aeschlimann A, Angst J. Refined insights into the pain-depression association in chronic pain patients. Schweizerischer Kongress Schweizerische Gesellschaft für Rheumatologie (SGR) und Schweizerische Gesellschaft für Physikalische Medizin und Rehabilitation (SGPMR). Zürich, Switzerland, 2008.

Verra ML. Wie kann ich als PhysiotherapeutIn meinen Schmerzpatienten/-in motivieren, sich zu bewegen? (invited speaker). Jahreskongress der Schweizerische Gesellschaft zum Studium des Schmerzes (SGSS). Biel, Switzerland, 2008.

Verra ML, Angst F, Staal JB, Brioschi R, Lehmann S, Benz T, Aeschlimann A, de Bie RA. Tailored exercise therapy and psychotherapy for patients with chronic back pain design of a randomized controlled trial. Jahreskongress der Schweizerische Gesellschaft zum Studium des Schmerzes (SGSS). Biel, Switzerland, 2008.

Verra ML, Angst F, Staal JB, Brioschi R, Lehmann S, Benz T, Aeschlimann A, de Bie RA. Klassifikation von chronischen unspezifischen Rückenschmerzen in Subgruppen unspezifisch wird spezifischer! Kongress der Physiotherapie. physioswiss. St. Gallen, Switzerland, 2008.

Verra ML, Angst F, Lehmann S, Aeschlimann A. Übersetzung, transkulturelle Adaptation, Reliabilität und Validität der deutschen Version der Coping Strategies Questionnaire (CSQ-D). Kongress der Physiotherapie. physioswiss. Interlaken, Switzerland, 2005. 